\begin{abstract}
Universidade de São Paulo
Faculdade de Medicina de Ribeirão Preto

Programa de Pós-Graduação em Farmacologia
\end{abstract}

Eduardo Albino Trindade Fortaleza

\title{
FUNÇÃO DA NEUROTRASMISSÃO NORADRENÉRGICA DO NÚCLEO MEDIAL DA AMÍGDALA NA MODULAÇÃO DO SISTEMA CARDIOVASCULAR EM RATOS
}

-Ribeirão Preto- 


\section{Eduardo Albino Trindade Fortaleza}

\section{FUNÇÃO DA NEUROTRASMISSÃO NORADRENÉRGICA DO NÚCLEO MEDIAL DA AMÍGDALA NA MODULAÇÃO DO SISTEMA CARDIOVASCULAR EM RATOS}

Tese apresentada ao curso de Pós-graduação da Faculdade de Medicina de Ribeirão Preto da Universidade de São Paulo, para obtenção do título de Doutor em ciências.

Área de concentração: Farmacologia.

Orientador: Prof. Dr. Fernando Morgan de Aguiar Corrêa

-Ribeirão Preto- 
AUTORIZO A REPRODUÇÃO TOTAL OU PARCIAL DESTE TRABALHO, POR QUALQUER MEIO CONVENCIONAL OU ELETRÔNICO, PARA FINS DE ESTUDO E PESQUISA, DESDE QUE CITADA A FONTE.

\section{FICHA CATALOGRÁFICA}

Preparada pela Biblioteca Central do Campus Administrativo de

Ribeirão Preto/USP

Fortaleza, Eduardo Albino Trindade.

Função da neurotransmissão noradrenérgica do núcleo medial da amígdala na modulação do sistema cardiovascular em ratos. Ribeirão Preto, 2013.

153p. il. $30 \mathrm{~cm}$.

Tese de Doutorado apresentada à Faculdade de Medicina de Ribeirão Preto/USP.

Área de concentração: Farmacologia.

Orientador: Corrêa, Fernando Morgan de Aguiar

1. Estresse por restrição. 2. Pressão Arterial. 3. Freqüência cardíaca. 4. Núcleo medial da Amígdala. 5. Noradrenalina. 
FOLHA DE APROVAÇÃO

FUNÇÃO DA NEUROTRASMISSÃO NORADRENÉRGICA DO NÚCLEO MEDIAL DA AMÍGDALA NA MODULAÇÃO DO SISTEMA CARDIOVASCULAR EM RATOS

Eduardo Albino Trindade Fortaleza

Tese apresentada à Faculdade de Medicina de Ribeirão

Preto da Universidade de São Paulo para obtenção do grau de Doutor, pelo programa de Pós-graduação em Ciências.

Área de concentração: Farmacologia

Aprovado em:

Banca Examinadora:

Prof. Dr. Fernando Morgan de Aguiar Corrêa Instituição: FMRP-USP Assinatura:

Prof. Dr. Benedito Honório Machado Instituição: FMRP-USP Assinatura:

Prof. Dr. Hélio Zangrossi Junior Instituição: FMRP-USP

Assinatura:

Prof. Dra. Marli Cardoso Martins Pinge Instituição: UEL Assinatura:

Prof. Dr. Fabrício de Araújo Moreira Instituição: UFMG Assinatura: 
"A verdadeira felicidade se completa quando sabemos quem somos, pois ela habita em nós. Devemos sempre estar de olhos abertos, pois sempre alguém nos afastará deste objetivo".

Tim Maia. 


\section{Dedico,}

Aos meus pais José Albino Fortaleza e Luzia Trindade Fortaleza, que nunca mediram esforços para minha formação profissional e individual, por me ensinarem a ser um cidadão de caráter, lutador e acima de tudo a ser honesto. Os responsáveis são vocês por eu estar aqui, muito obrigado por tudo, amo muito vocês.

A minha irmã Edneide Trindade Fortaleza, uma pessoa muito especial muito preocupada comigo e com a minha felicidade que cuida e acredita muito em mim, te amo muito, obrigado.

Ao meu super padrinho Osmar, que sempre me apoiou em tudo o que fiz nesta vida, uma pessoa maravilhosa que sempre acreditou em mim, amo muito você obrigado por tudo, você é importantíssimo pra mim.

A minha madrinha Renilda pelo amor e carinho, que sempre teve uma palavra de sabedoria, nas horas difíceis em que passei nessa minha jornada que se completa. Obrigado, por me conforta na ausência de minha família. Você foi fundamental nessa minha fase de vida. 


\section{AGRADECIMENTOS}

Ao Prof. Dr. Fernando Morgan de Aguiar Corrêa, por conceder-me a oportunidade de estudar em seu laboratório. Agradeço por toda a orientação, compreensão e paciência em me ensinar e suprir minhas dificuldades. $E$ além de tudo agradeço pela confiança no meu trabalho e no meu esforço, obrigado.

Aos membros da banca examinadora, por se disporem a participar e pela avaliação e contribuição com sugestões para o engrandecimento deste trabalho.

A Prof. Dra. Ana Maria de Oliveira por me ensinar farmacologia com muita atenção, dedicação, carinho e disponibilidade. É uma pessoa a quem sou muito grato obrigado.

Prof. Dr. Leonardo Resstel, apesar de ser docente considero ele como meu amigo no qual respeito muito e tenho admiração, principalmente por que, sempre esteve pronto a ensinar e ajudar-me. Muito obrigado.

Ao Prof. Dr.Francisco Silveira Guimarães pela contribuição e assessoria na realização deste trabalho.

As minhas técnicas conhecidas agora como tias do Morgan:

A Ivanilda A.C. Sou muito grato por tudo, pela amizade, confiança e carinho e principalmente pelo cuidado com a preparação dos cortes histológicos, você é uma pessoa muito especial pra mim obrigado.

A Idália I.B.Aguiar, Obrigado por tudo, você sempre foi muito atenciosa e dedicada comigo e principalmente por pegar na minha mão e supervisionar todas as minhas cirurgias, pela amizade, carinho e brincadeiras.

A Simone S. Guilhaume, pela atenção, simpatia e amizade e principalmente pelas confecções das cânulas de femoral, que foram de extrema importância para conclusão deste trabalho e por várias vezes nos recepcionarmos tão bem em sua casa.

A Maria Inês, obrigado pela amizade e carinho e por sempre cuidar dos animais com atenção e respeito. 
A Eliana pela alegria, simpatia e elogios a minha pessoa e principalmente por cuidar dos animais com muita atenção, respeito e dedicação.

A Diva, pelo bom humor sempre estampado no rosto, amizade e cuidado com o nosso material.

Aos funcionários José Waldik Ramon, Sônia Andrade e Fátima Petean, por toda competência, disponibilidade e atenção com que atendem a burocracia do departamento.

Aos meus amigos do laboratório:

A América Scopinho uma pessoa maravilhosa que Deus colocou na minha vida, por toda atenção, paciência, dedicação, carinho e gentileza em todas as horas e "momentos" nessa pós-graduação, pelos conflitos de interesses e brincadeiras, você realmente é uma parceira, te agradeço muito por tudo. Obrigado.

Aos meus amigos de laboratório, Cristiane Busnardo, Carlos Crestani, Milena Deolindo, Daniel Reis, Fernando Alves, Silvana Lopes, Aline Fassini, Bruna Muza e Gislaine Pelosi e aos amigos de laboratório do professor Leonardo pela amizade e companheirismo. De alguma forma, todos contribuíram com muita ajuda, atenção e dedicação para minha formação. Obrigado.

Rodrigo F. Tavares, Obrigado, agradeço muito a você "Rodrigão", pela paciência e dedicação em nosso laboratório.

Ao meu amigo e irmão Lucas Gabarra, meu amigão de infância que cada vez mais, vem provando ser meu amigo do peito, por que, sempre torce por mim e esta disposto a me ajudar quando preciso.

Aos meus amigos e irmãos do judô que sempre acreditaram, apoiaram e torcem por mim, por que, realmente a nossa equipe é uma família sei que posso contar com vocês. Obrigado a todos.

A todos que direta ou indiretamente contribuíram para a realização deste trabalho.

A CNpq e a FAEPA, pelo auxílio financeiro durante realização deste trabalho. 


\section{RESUMO}

FORTALEZA, E. A. T. Função da neurotransmissão noradrenérgica do núcleo medial da amígdala na modulação do sistema cardiovascular em ratos. 2013. 153p. Tese (Doutorado) - Faculdade de Medicina de Ribeirão Preto, Universidade de São Paulo, Ribeirão Preto, 2013.

O núcleo medial da amígdala (NMA) está envolvido no controle de uma variedade de processos fisiológicos e comportamentais, dentre eles, a regulação do sistema cardiovascular durante situações aversivas. Além disso, existem evidências indicando a presença de receptores noradrenérgicos no NMA e que os níveis de noradrenalina (NA) no NMA aumentam quando animais são submetidos ao modelo de estresse por restrição (ER). Portanto, o presente estudo foi dividido em duas partes: 1) avaliamos os efeitos da microinjeção local de NA no NMA de ratos, bem como os receptores locais e os mecanismos periféricos envolvidos na sua mediação e 2) investigamos o papel desempenhado pela neurotransmissão noradrenérgica do NMA sobre as respostas cardiovasculares causadas pelo ER. A primeira parte dos nossos resultados indicou que doses crescentes de NA (3, 9, 27 ou 45nmol/100nL) microinjetadas no NMA causavam respostas pressoras e bradicardicas de maneira dose-dependente em ratos não anestesiados. Os efeitos da NA no NMA foram abolidos pelo pré-tratamento local com antagonista de receptores $\alpha_{2}$-adrenérgicos (RX821002, $10 \mathrm{nmol} / 100 \mathrm{~nL}$ ), porém não foram alterados pelo pré-tratamento com antagonista de receptores $\alpha_{1}$ adrenérgicos (WB4101, $10 \mathrm{nmol} / 100 \mathrm{~nL}$ ). A magnitude da resposta pressora à NA no NMA foi aumentada pelo pré-tratamento intravenoso (i.v.) com o bloqueador ganglionar pentolínio $(5 \mathrm{mg} / \mathrm{kg})$ e foi significativamente reduzida pelo pré-tratamento i.v. com antagonista dos receptores vasopressinérgicos do tipo V1 dTyr(CH2)5(Me)AVP $(50 \mu \mathrm{g} / \mathrm{Kg})$ sugerindo que o mecanismo periférico envolvido nestas respostas cardiovasculares é a liberação de vasopressina na circulação sanguínea. Como estruturas finais participando das respostas cardiovasculares desencadeadas pela microinjeção de NA no NMA, foi observado o possível envolvimento dos núcleos paraventricular (NPV) e supra-óptico (NSO) do hipotálamo, que sintetizam vasopressina. O bloqueio de sinapses, tanto no NPV quanto no NSO, com cloreto de cobalto $\left(\mathrm{CoCl}_{2}, 1 \mathrm{mM} / 100 \mathrm{~nL}\right)$, reduziu as respostas cardiovasculares desencadeadas pela microinjeção de NA no NMA, sugerindo que ambos os núcleos são responsáveis pela liberação de vasopressina em resposta à NA no NMA. Na segunda parte deste estudo, os resultados mostraram que a microinjeção bilateral de WB4101, antagonista seletivo dos receptores $\alpha_{1}$ - 
adrenérgicos (10, 15 e 20nmol/100nL) no NMA 10 min antes do ER, reduziu a resposta taquicárdica evocada pelo ER, de maneira dose-dependente. Em contraste, a microinjeção bilateral de RX821002, antagonista seletivo dos receptores $\alpha_{2}$ adrenérgicos (10, 15 e 20nmol/100nL) no NMA $10 \mathrm{~min}$ antes do ER, aumentou a resposta taquicárdica evocada pelo ER de maneira dose-dependente. Ambos os tratamentos não causaram alterações na resposta pressora observada nos animais submetidos ao ER. Estes resultados sugerem que receptores $\alpha_{1}$ - e $\alpha_{2}$-adrenérgicos no NMA desempenham papel facilitatório e inibitório, respectivamente, na resposta taquicárdica durante o ER. Além disso, a microinjeção bilateral de propranolol, antagonista não seletivo dos receptores $\beta$-adrenérgicos (10, 15 e 20nmol/100nL), no MNA 10 min antes do ER, causou aumento na resposta taquicárdica apenas quando os animais foram pré-tratados com a dose de $15 \mathrm{nmol}$, sem efeito significativo sobre a resposta pressora observada durante o ER. Este resultado indica que receptores $\beta$-adrenérgicos no NMA desempenham um papel inibitório sobre a frequência cardíaca durante o ER. Uma vez que foi observada a participação dos receptores $\beta$ adrenérgicos, realizamos o pré-tratamento com os antagonistas seletivos dos receptores $\beta 1$ - e $\beta 2$ - adrenérgicos, CGP 20712 e ICI 118,551, respectivamente. A microinjeção bilateral de ICI 118,551 (10, 15 e 20nmol/100nL) no NMA aumentou as respostas taquicárdicas ao ER após a microinjeção das doses de 15 e 20 nmol. Esse efeito foi semelhante ao observado após o tratamento prévio com propranolol, na dose de $15 \mathrm{nmol}$, sem efeito significativo sobre a resposta da pressora durante o ER. Porém, o pré-tratamento com o CGP 20712 (10, 15 e 20 nmol/100 nL) causou um efeito oposto sobre a resposta taquicárdica evocada pelo ER, ocorrendo uma redução da resposta taquicárdica que foi observada apenas após a dose de $20 \mathrm{nmol}$ no NMA, sem efeito significativo sobre a resposta pressora evocada pelo ER. Esses resultados sugerem que os receptores $\beta 2$-adrenérgicos desempenham influência inibitória sobre a resposta taquicárdica, ao passo que, os receptores $\beta 1$-adrenérgicos desempenham influência facilitatória na resposta taquicárdica evocada pelo ER. 


\section{ABSTRACT}

FORTALEZA, E. A. T. Noradrenergic neurotransmission function of the medial nucleus of the amygdala in the modulation of the cardiovascular system in rats. 2013. 153p. Thesis (Doctoral) - School of Medicine of Ribeirão Preto, University of São Paulo, Ribeirão Preto, 2013.

The medial amygdaloid nucleus (MeA) regulates a variety of physiological and behavioral processes, as well as regulation of the cardiovascular system during aversive situations. Moreover, there is evidence indicating that noradrenergic receptors are present into the MeA and that the levels of noradrenaline (NA) in this nucleus increases when animals are submitted to acute restraint model. Therefore, this study was divided into two parts: 1) we tested the effects of local NA microinjection into the $\mathrm{MeA}$ on cardiovascular responses in unaesthetized rats. Moreover, we describe the type of adrenoceptors activated and the peripheral mechanisms involved in the cardiovascular responses and 2) we investigated the involvement of MeA adrenoceptors in the modulation of cardiovascular responses that are observed during acute restraint. The first part of our results indicated that increasing doses of NA $(3,9,27$ or $45 \mathrm{nmol} / 100 \mathrm{~nL})$ microinjected into the MeA of unanesthetized rats caused dose-related pressor and bradycardiac responses. The cardiovascular effects of NA were abolished by MeA local pretreatment with $10 \mathrm{nmol} /$ $100 \mathrm{~nL}$ of the specific $\alpha_{2}$-adrenoceptor antagonist RX821002, but were not affected by local pretreatment with $10 \mathrm{nmol} / 100 \mathrm{~nL}$ of the specific $\alpha_{1}$-adrenoceptor antagonist WB4101. The magnitude of pressor response evoked by NA microinjected into the $\mathrm{MeA}$ was potentiated by intravenous pretreatment with the ganglion blocker pentolinium ( $5 \mathrm{mg} / \mathrm{kg}$, i.v.) and blocked by intravenous pretreatment with the selective $\mathrm{V}_{1}$ vasopressin antagonist dTyr $(\mathrm{CH} 2) 5(\mathrm{Me}) \mathrm{AVP}(50 \mu \mathrm{g} / \mathrm{Kg}$, i.v. $)$. Our results suggest that microinjection of NA into the MeA of unanesthetized rats activates local $\alpha_{2^{-}}$ adrenoceptors, evoking pressor and bradycardiac responses, which are mediated by vasopressin release in the blood circulation. The vasopressin is synthesized by magnocellular cells of paraventricular (PVN) and supraoptic nucleus (SON) of the hypothalamus. Thus, it was investigated the role of these hypothalamic nucleus on the cardiovascular pathway activated by the microinjection of NA into the MeA. Pressor and bradycardiac responses to NA $(27 \mathrm{nmol} / 100 \mathrm{~nL})$ were blocked when cobalt chloride $\left(\mathrm{CoCl}_{2}, 1 \mathrm{mM} / 100 \mathrm{~nL}\right)$ was microinjected into the PVN or SON, thus indicating that both hypothalamic nucleus are responsible for the mediation of the cardiovascular responses evoked by NA microinjection into the MeA. Our results 
suggest that pressor and bradycardic responses caused by NA microinjection into the MeA are mediated by magnocellular neurons in the PVN and SON. In the second part of this study Male Wistar rats received bilateral microinjections of the selective $\alpha_{1}$-adrenoceptor antagonist WB4101 (10, 15, and $\left.20 \mathrm{nmoL} / 100 \mathrm{~nL}\right)$ or the selective $\alpha_{2}$-adrenoceptor antagonist RX821002 (10, 15, and $\left.20 \mathrm{nmoL} / \mathrm{nL}\right)$ into the MeA, 10 min before the exposure to acute restraint. The injection of WB4101 into the MeA reduced the restraint-evoked tachycardia. In contrast, the injection of RX821002 increased the tachycardia. Both drugs had no effect on the BP increase observed during the acute restraint. Our findings indicate that $\alpha_{1}$ and $\alpha_{2}$-adrenoceptors in the MeA play different roles in the modulation of the HR increase evoked by restraint stress in rats. Results suggest that $\alpha_{1}$-adrenoceptors and $\alpha_{2}$-adrenoceptors respectively mediate the MeA facilitatory and inhibitory influences on restraint-related HR responses. Moreover, we investigated the involvement of $\beta$-adrenoceptors in the $\mathrm{MeA}$ in cardiovascular responses evoked in rats submitted to an acute restraint stress. We first pretreated Wistar rats with the nonselective $\beta$-adrenoceptor antagonist propranolol, microinjected bilaterally into the $\operatorname{MeA}(10,15$, and 20 $\mathrm{nmol} / 100 \mathrm{~nL}$ ) $10 \mathrm{~min}$ before exposure to acute restraint. The pretreatment with propranolol did not affect the BP increase evoked by restraint. However, it increased the tachycardiac response caused by acute restraint when animals were pretreated with a dose of $15 \mathrm{nmol}$, without a significant effect on the BP response. This result indicates that $\beta$-adrenoceptors in the MeA have an inhibitory influence on restraintevoked HR changes. Pretreatment with the selective $\beta_{2}$ - adrenoceptor antagonist ICI $118,551(10,15$, and $20 \mathrm{nmol} / 100 \mathrm{~nL})$ significantly increased the restraint evoked tachycardiac response after the doses of 15 and $20 \mathrm{nmol}$, an effect that was similar to that observed after the pretreatment with propranolol at the dose of $15 \mathrm{nmol}$, without a significant effect on the BP response. Pretreatment of the MeA with the selective $\beta_{1}$-adrenoceptor antagonist $\operatorname{CGP} 20712$ (10, 15, and $\left.20 \mathrm{nmol} / 100 \mathrm{~nL}\right)$ caused an opposite effect on the HR response, and a significant decrease in the restraint-evoked tachycardia was observed only after the dose of $20 \mathrm{nmol}$, without a significant effect on the BP response. Because propranolol is an equipotent antagonist of both $\beta_{1}$ and $\beta_{2}$-adrenoceptors, and opposite effects were observed after the treatment with the higher doses of the selective antagonists ICI 118,551 and CGP 20712, the narrow window in the dose-response to propranolol could be explained by a functional antagonism resulting from the simultaneous inhibition of $\beta_{1}$ and $\beta_{2}$-adrenoceptors by the treatment with propranolol. 


\section{SUMÁRIO}

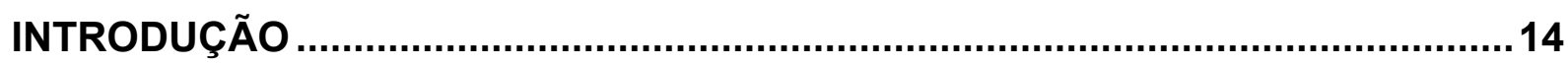

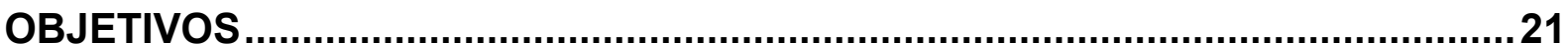

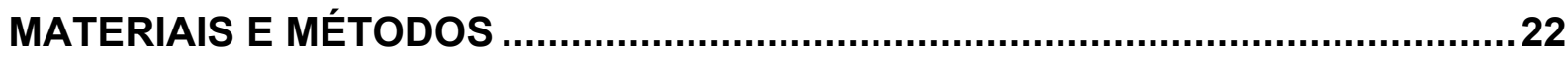

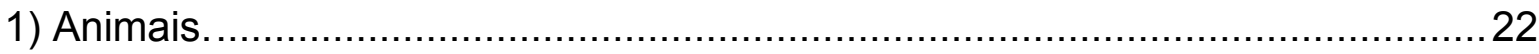

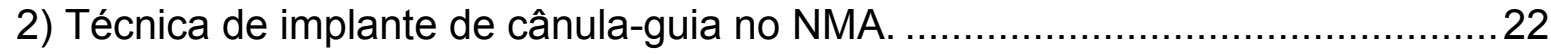

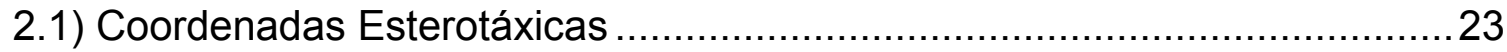

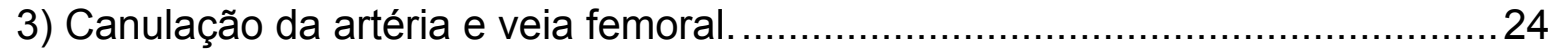

4) Registro da pressão arterial e frequência cardíaca. .......................................2 25

5) Técnica para microinjeção de drogas no cérebro......................................25

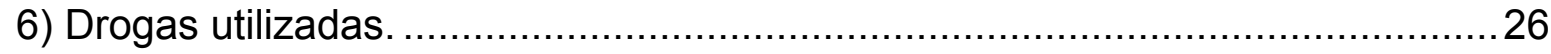

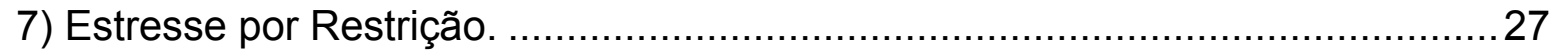

8) Determinação anatômica do sítio de injeção. ............................................28

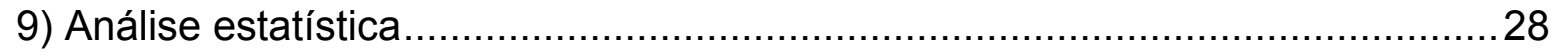

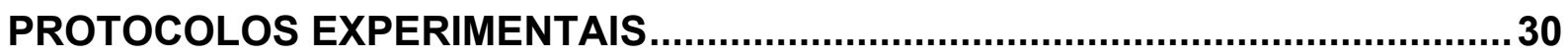

1) Efeito da microinjeção de diferentes doses de NA no NMA sobre a pressão arterial e frequência cardíaca de ratos (curva dose-resposta)............................. 31

2) Efeito da microinjeção de NA em áreas fora do NMA sobre a pressão arterial

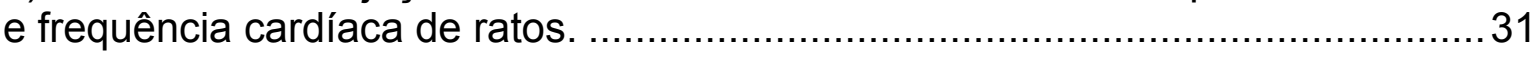

3) Efeito da microinjeção de antagonistas de receptores $\alpha$-adrenérgicos no NMA sobre as respostas cardiovasculares à microinjeção de NA.

4) Efeito do pré-tratamento com antagonistas periféricos sobre as respostas cardiovasculares à microinjeção de NA no NMA de ratos.

5) Efeito da microinjeção de um inibidor de sinapses no NPV sobre as respostas cardiovasculares a microinjeção de NA no NMA de ratos...

6) Efeito da microinjeção de um inibidor de sinapses no NSO sobre as respostas cardiovasculares a microinjeção de NA no NMA de ratos.

7) Efeito da microinjeção de antagonistas dos receptores $\alpha_{1}$-adrenérgico no NMA sobre as respostas cardiovasculares ao ER.

8) Efeito da microinjeção de antagonistas dos receptores $\alpha_{2}$-adrenérgico no NMA sobre as respostas cardiovasculares ao ER.

9) Efeito da microinjeção de antagonistas não seletivo dos receptores $\beta$ adrenérgico no NMA sobre as respostas cardiovasculares ao ER.

10) Efeito da microinjeção de antagonistas dos receptores $\beta_{1}$-adrenérgico no NMA sobre as respostas cardiovasculares ao ER. 
11) Efeito da microinjeção de antagonistas dos receptores $\beta_{2}$-adrenérgico no NMA sobre as respostas cardiovasculares ao ER.

RESULTADOS.

1) Efeito da microinjeção de diferentes doses de NA no NMA sobre a pressão arterial e frequência cardíaca de ratos (curva dose-resposta).

2) Efeito da microinjeção de NA em áreas fora do NMA sobre a pressão arterial e frequência cardíaca de ratos.

3) Efeito da microinjeção local de antagonistas de receptores a-adrenérgicos sobre as respostas cardiovasculares à microinjeção de NA no NMA em ratos. ....42

4) Efeito do pré-tratamento intravenoso com bloqueador ganglionar (pentolínio) sobre as respostas cardiovasculares causadas pela microinjeção de NA no NMA de ratos.

5) Efeito do pré-tratamento intravenoso com antagonista dos receptores V1 (dTyr(CH2)5MeAVP) sobre as respostas cardiovasculares causadas pela microinjeção de NA no NMA de ratos.

6) Efeito do pré-tratamento do NPV com um inibidor sináptico sobre as respostas cardiovasculares causadas pela microinjeção de NA no NMA de ratos.

7) Efeito do pré-tratamento do NSO com um inibidor sináptico sobre as respostas cardiovasculares causadas pela microinjeção de NA no NMA de ratos.

8) Efeito da microinjeção de diferentes doses de antagonista $\alpha_{1}$-adrenérgico no MNA sobre as respostas cardiovasculares ao ER.

9) Efeito da microinjeção de diferentes doses de antagonista dos receptores $\alpha_{2-}$ adrenérgico no MNA sobre as respostas cardiovasculares ao ER.

10) Efeito da microinjeção de diferentes doses de antagonista não seletivo dos receptores $\beta$-adrenérgico propranolol no MNA sobre as respostas cardiovasculares ao ER.

11) Efeito da microinjeção de diferentes doses de antagonista dos receptores $\beta_{1}$-adrenérgico no MNA sobre as respostas cardiovasculares ao ER.

12) Efeito da microinjeção de diferentes doses de antagonista dos receptores

$\beta_{2}$-adrenérgico no MNA sobre as respostas cardiovasculares ao ER. 


\section{INTRODUÇÃO}

O sistema cardiovascular é importante para manutenção da homeostase, provendo fluxo sangüíneo adequado e garantindo a distribuição dos nutrientes necessários para as funções vitais dos órgãos e tecidos. O controle do sistema cardiovascular envolve a participação do sistema nervoso central (SNC), de mecanismos humorais e de mecanismos regulatórios locais presentes no coração, nos rins e nos vasos sangüíneos.

O SNC é o principal regulador do sistema circulatório. As regiões responsáveis por essa regulação situam-se ao longo de todo o eixo neural, envolvendo tanto estruturas bulbares quanto suprabulbares. $O$ bulbo contém estruturas que são responsáveis pelo controle cardiovascular, mantendo a pressão arterial dentro de estreitos limites de variações (GUYENET et al., 1990; DAMPNEY, 1994). O núcleo do trato solitário (NTS) é uma importante região bulbar que atua como centro integrador de aferências sensoriais periféricas, tais como as provenientes dos barorreceptores, às estruturas responsáveis pela geração e controle da atividade autonômica simpática e parassimpática. A área rostroventrolateral do bulbo (RVL) é responsável pela geração da atividade simpática vasomotora e manutenção do tônus vascular simpático. Os neurônios presentes nesta área determinam a frequência de disparos dos neurônios pré-ganglionares simpáticos (GUERTZENSTEIN e SILVER, 1974; REIS, 1984).

Estruturas suprabulbares também participam do controle do sistema cardiovascular (HILTON, 1966), atuando principalmente em situações comportamentais. Dentre estas se destacam estruturas ventrais e dorsais da ponte, incluindo o núcleo braquial, o núcleo de Kolliker-Fuse, o grupo de células A5, o 
hipotálamo, a substância cinzenta periaquedutal (PAG) e o núcleo cuneiforme, bem como estruturas prosencefálicas incluindo regiões específicas do córtex cerebral, a área septal e a amígdala (LOEWY e MCKELLAR, 1980; LOEWY, 1991; DAMPNEY, 1994).

Particularmente, a amígdala é uma estrutura límbica subcortical situada no lobo temporal, na posição medial do cérebro, entre a cápsula externa e o hipotálamo. Ela é dividida em vários subnúcleos com diferenciações funcionais (PITKANEN et al., 1997; SAH et al., 2003). Estes subnúcleos são agrupados em 3 complexos: 1) O grupo profundo ou basolateral, que inclui os núcleos lateral, basal e acessório basal; 2) O grupo superficial ou cortical, que inclui o núcleo cortical e o do trato olfatório lateral; e 3) O grupo centro-medial composto pelos núcleos central e medial. A nomenclatura foi introduzida por Price e colaboradores (1987) e modificada por McDonald (1988).

A amígdala é estrutura chave na regulação de respostas autonômicas associadas à ansiedade e ao medo (DAVIS, 1992; LEDOUX, 1998), estando envolvida na modulação de mecanismos efetores viscerais e comportamentais, dentre eles: aprendizagem e memória, agressividade e defesa, reprodução e ingestão de alimentos (AGGLETON et al., 1992; AGGLETON, 2000). Além disso, disfunções na amígdala estão associadas a várias doenças neurológicas e psiquiátricas (SIMS e WILLIAMS, 1990; PITKANEN e AMARAL, 1991).

A amígdala conecta-se ao hipotálamo e áreas do tronco cerebral conhecidas por desempenharem papel importante na regulação cardiovascular (OHTA et al., 1991; DAMPNEY, 1994). Vários estudos mostraram a ocorrência de alterações cardiovasculares e reação de defesa após a estimulação elétrica da amígdala em diferentes espécies (HILTON e ZBROZYNA, 1963; FAIERS et al., 1975; STOCK et 
al., 1978; GALENO et al., 1982; GELSEMA et al., 1987). Além disso, existem evidências que a amígdala modula a atividade do barorreflexo em ratos (QUAGLIOTTO et al., 2008), sugerindo que a amígdala está envolvida no controle central cardiovascular.

O núcleo medial da amígdala (NMA) recebe inervação substancial de terminais noradrenérgicos que se originam no locus coeruleos (LC) e em outros grupos de neurônios noradrenérgicos localizados na área tegmental lateral e no bulbo (SADIKOT e PARENT, 1990; RODER e CIRIELLO, 1993). Além disso, estudos de expressão de RNAm e ligação a receptores detectaram a presença de receptores noradrenérgicos do subtipo $\alpha$ e $\beta$ no NMA (RAINBOW et al., 1984; JONES et al., 1986; ORDWAY et al., 1988; DOMYANCIC e MORILAK, 1997), sugerindo a existência de um sistema noradrenérgico funcional nesta estrutura.

A noradrenalina (NA) é um neurotransmissor envolvido no controle da pressão arterial e um importante mediador em diversas estruturas do sistema nervoso central. Foram observadas respostas cardiovasculares após a microinjeção de NA em regiões do cérebro envolvidas na modulação do sistema cardiovascular, tais como o núcleo do trato solitário (NTS) (VLAHAKOS et al., 1985), o córtex pré-frontal medial (CPFM) (FERNANDES et al., 2003), a área septal lateral (ASL) (SCOPINHO et al., 2006), o núcleo leito da estria terminal (NLET) (CRESTANI et al., 2007) e a amígdala (OHTA et al., 1991).

Além disso, existem evidências de envolvimento da neurotransmissão noradrenérgica do complexo amigdalóide na modulação das respostas cardiovasculares. A microinjeção de NA neste complexo causa respostas pressoras e bradicárdicas, similares aos efeitos da administração sistêmica de NA (OHTA et al., 1991). Porém, esses autores observaram alterações cardiovasculares 
significativas somente após a microinjeção bilateral, mas não unilateral de NA no complexo amigdalóide. Ainda, esses autores não diferenciaram os núcleos da amígdala nos quais a NA foi microinjetada e quais seriam os mecanismos periféricos e os receptores envolvidos nestas respostas. Assim, permanece a ser explorado o papel da neurotransmissão noradrenérgica do NMA na regulação do sistema cardiovascular.

Estímulos estressantes causam alterações autonômicas, comportamentais e neuroendócrinas (LAM et al., 1995; KAEHLER et al., 2000; KNUEPFER et al., 2001; MULLER et al., 2001; VAN DEN BUUSE et al., 2001; KAPUSTA et al., 2002; KUBO et al., 2002). Em particular, o estresse por restrição (ER) é um modelo experimental que gera um estímulo aversivo inescapável. Este modelo consiste em colocar o animal em um tubo plástico ou metálico que restringe seus movimentos (CONTI et al., 2001; YOSHINO et al., 2005). O ER provoca alterações comportamentais (PADOVAN et al., 2000), alterações hormonais (BUSNARDO et al., 2010) e também respostas cardiovasculares caracterizadas por elevação da pressão arterial e frequência cardíaca (KUBO et al., 2002; TAVARES e CORREA, 2006).

Estudos mostraram que a lesão da amígdala atenuou as respostas cardiovasculares evocadas por choques intermitentes nas patas de ratos (SANDERS et al., 1994), bem como a resposta pressora causada por estímulo sonoro de alta intensidade (GALENO et al., 1984), sugerindo a participação dessa estrutura na modulação de respostas cardiovasculares causadas por estímulos estressantes.

O complexo amigdalóide está envolvido na modulação de diversas respostas comportamentais e fisiológicas ao estresse, incluindo a regulação do eixo hipotálamo-pituitaria-adrenal (HPA). Vários estudos sugerem o núcleo central da 
amígdala (NCA) como o principal local de modulação do eixo HPA. Entretanto, há relatos de que lesões do NCA não causaram aumento da expressão da proteína cfos no núcleo paraventricular do hipotálamo (NPV), após o ER (DAYAS et al., 1999). Da mesma forma, animais submetidos ao ER não apresentaram diferenças na expressão da proteína c-fos quando comparados com os animais não estressados (ARNOLD et al., 1992; MA e MORILAK, 2004). Por outro lado, estimulação do NMA aumenta a secreção de corticosterona e causa indução da expressão de c-fos no NPV em resposta ao ER ou ao nado forçado (CULLINAN et al., 1995). Além disso, a lesão do NMA causa supressão na ativação da proteína c-fos em neurônios da porção parvocelular medial do NPV, contendo hormônio liberador de corticotropina $(\mathrm{CRH})$, bem como reduz a síntese de ocitocina no núcleo supra-óptico (NSO) e NPV, sugerindo que o NMA participa efetivamente na modulação de respostas associadas ao estresse (DAYAS et al., 1999). Dessa forma, dentre todos os subnúcleos da amígdala, dados da literatura sugerem maior participação do NMA (ALONSO et al.) na modulação de respostas desencadeadas por situações estressantes, sendo observada maior expressão de proteína c-fos nessa área após exposição a diversas situações aversivas, tais como o ER (ARNOLD et al., 1992; CHEN e HERBERT, 1995; CULLINAN et al., 1995; BHATNAGAR e DALLMAN, 1998; DAYAS et al., 1999; DAYAS, BULLER, CRANE et al., 2001; DAYAS, BULLER e DAY, 2001; DAYAS e DAY, 2002; KUBO et al., 2004; CRANE et al., 2005; TRNECKOVA et al., 2006); ao estímulo aversivo condicionado (CAMPEAU et al., 1991; PEZZONE et al., 1992; DUNCAN et al., 1996); ao estresse audiogênico (CAMPEAU e WATSON, 1997); ao choque nas patas (LI e SAWCHENKO, 1998); ou ao estresse por imobilização, o qual priva o rato de qualquer movimento (FURUSE et al., 2005). Interessantemente, Kubo e colaboradores (2004) relataram que a inibição do NMA, 
por microinjeção bilateral de muscimol, atenuou a resposta pressora desencadeada pelo $E R$, indicando o envolvimento específico deste subnúcleo da amígadala na mediação das respostas cardiovasculares induzidas por situações aversivas.

Dados da literatura relataram que o NMA está envolvido na ativação de neurônios noradrenérgicos no tronco cerebral, em resposta ao ER (DAYAS e DAY, 2002). Portanto, uma redução na ativação do NMA induzida pelo estresse, poderia ser um mecanismo potencial para avaliar a redução na ativação do sistema noradrenérgico na indução do estresse em ratos. No entanto, o NMA além de fornecer aferências excitatórias descendente é também alvo de inervação ascendente do sistema noradrenérgico do tronco cerebral.

Uma incapacidade para iniciar ou regular adequadamente respostas ao estresse foi proposta como fator crítico na fisiopatologia de várias doenças relacionadas ao estresse (JOHNSON et al., 1992; GOLD e CHROUSOS, 1999). desequilíbrio da neurotransmissão noradrenérgica implica em doenças psiquiátricas relacionadas ao estresse, tais como depressão e ansiedade e correlatos do estresse pós-traumático (SOUTHWICK et al., 1993; SULLIVAN et al., 1999).

Estímulos estressantes aumentam a liberação de NA, a qual desempenha papel importante na modulação de várias funções, facilitando a transmissão sináptica em diversas regiões do cérebro envolvidas na regulação ou mediação de respostas comportamentais e psicológicas evocadas pelo estresse (ASTON-JONES et al., 1999; MORILAK e FRAZER, 2004). Além disso, estudos empregando microdiálise mostraram que em várias regiões prosencéfalicas do sistema límbico tais como: o núcleo leito da estria terminal lateral, a área septal lateral, o córtex préfrontal medial, o núcleo central e em particular no NMA, a liberação de NA está aumentada em animais submetidos ao estresse de imobilização (CECCHI, 
KHOSHBOUEI, JAVORS et al., 2002; CECCHI, KHOSHBOUEI e MORILAK, 2002; PARDON et al., 2002; MA e MORILAK, 2005; MORILAK et al., 2005; BONDI et al., 2007). Esse dados sugerem, o envolvimento da neurotransmissão noradrenérgica do NMA na modulação de respostas a estímulos aversivos.

As respostas cardiovasculares se inserem no componente fisiológico da resposta comportamental a um estímulo estressante. Uma vez que o NMA conectase a outras estruturas cerebrais do sistema límbico envolvidas no controle neurovegetativo, permanece por ser explorado o papel da neurotransmissão noradrenérgica deste núcleo na integração de respostas comportamentais e cardiovasculares.

Portanto, as nossas hipóteses são: 1) A estimulação farmacológica de receptores noradrenérgicos presentes no NMA causa respostas cardiovasculares e 2) A neurotransmissão noradrenérgica do NMA participa de um circuito neuronial central, envolvido na modulação de respostas cardiovasculares causadas pelo ER. 


\section{OBJETIVOS}

Nosso objetivo foi avaliar o papel da neurotransmissão noradrenérgica do NMA na modulação do sistema cardiovascular. Além disso, investigamos o papel da neurotransmissão noradrenérgica desse núcleo na modulação das respostas cardiovasculares causadas pelo ER. Para isso o nosso estudo foi dividido em duas partes:

1) Estudo farmacológico das respostas cardiovasculares causadas pela microinjeção de NA no NMA, onde os objetivos foram:

a) estudar os efeitos da microinjeção de NA no NMA sobre as respostas cardiovasculares em ratos.

b) Caracterizar o tipo de receptor noradrenérgico envolvido na resposta cardiovascular à microinjeção de NA no NMA.

c) Determinar os mecanismos periféricos envolvidos na efetuação da resposta cardiovascular à microinjeção de NA no NMA.

d) Investigar a possível participação dos núcleos hipotalâmicos envolvidos nas respostas cardiovasculares à microinjeção de NA no NMA.

2) Estudo do envolvimento da neurotransmissão noradrenérgica do NMA na modulação das respostas cardiovasculares causadas pelo ER, por meio da microinjeção de WB4101 (antagonista dos receptores $\alpha_{1}$-adrenérgicos), RX821002 (antagonista dos receptores $\alpha_{2}$-adrenérgicos), propranolol (antagonista não seletivo dos receptores $\beta$-adrenérgicos), CGP20712 (antagonista dos receptores $\beta_{1}$ adrenérgicos) ou ICl118,551 (antagonista dos receptores $\beta_{2}$-adrenérgicos) no NMA. 


\section{MATERIAIS E MÉTODOS}

\section{1) Animais}

Nos experimentos foram utilizados ratos Wistar com peso variando entre 230280g. Os animais foram fornecidos pelo biotério central da USP de Ribeirão Preto sendo mantidos em caixas individuais, com alimentação de ração e água. Os animais foram submetidos à alternância de luz (12 h claro/ 12 h escuro). O comitê de ética da Faculdade de Medicina de Ribeirão Preto da Universidade de São Paulo aprovou as condições de manutenção dos animais e os protocolos experimentais (Protocolo N057/2009).

\section{2) Técnica de implante de cânula-guia no NMA}

O anestésico utilizado neste procedimento cirúrgico foi o tribromo-cloro-etanol (Adrich Chemical Co. Inc.) na dose de $250 \mathrm{mg} / \mathrm{Kg}$ por via intraperitoneal. A cabeça do animal foi imobilizada em um estereotáxico (Stoelting, USA) e após tricotomia foi feita assepsia do local com álcool a 70\%. A seguir, foram injetados $0,3 \mathrm{~mL}$ de lidocaína com vasoconstritor subcutaneamente no escalpo, para anestesia local. A calota craniana foi exposta através de incisão na pele de aproximadamente $1,5 \mathrm{~cm}$, afastando-se todo o periósteo. A assepsia local foi feita com salina e água oxigenada a $10 \%$. A interaural foi utilizada como ponto de referência para a coordenada antero-posterior. As coordenadas foram escolhidas tomando-se como referência o atlas do cérebro do rato publicado por Paxinos e Watson (1997). 


\section{1) Coordenadas Esterotáxicas}

\section{Núcleo medial da amígdala (NMA)}

Antero-posterior: + 6,2 mm em relação à linha interaural

Lateral: $+3,4 \mathrm{~mm}$ em relação à sutura sagital

Vertical: - 8,0 mm em relação à estrutura óssea da calota craniana

Incisivo: - 3,2 mm

\section{Núcleo Paraventricular do Hipotálamo (NPV)}

Antero-Posterior: $+7,2 \mathrm{~mm}$ em relação à linha interaural

Lateral: +1,9 mm em relação à sutura média

Vertical: $-6,8 \mathrm{~mm}$ em relação à estrutura óssea da calota craniana

Incisivo: $-3,2 \mathrm{~mm}$

Ângulo: 12 graus de inclinação

\section{Coordenada do NMA para o protocolo de bloqueio do Núcleo Supra-óptico do}

\section{Hipotálamo}

Antero-posterior: + 6,2 mm em relação à linha interaural

Lateral: + 1,9 mm em relação à sutura sagital

Vertical: - 9,5 mm em relação à estrutura óssea da calota craniana

Incisivo: - 3,2 mm

Ângulo: 35 graus de inclinação 


\section{Núcleo Supra-óptico do Hipotálamo (NSO)}

Antero-Posterior: $+6,9 \mathrm{~mm}$ em relação à linha interaural

Lateral: +1,9 mm em relação à sutura média

Vertical: -8,0 mm em relação à estrutura óssea da calota craniana Incisivo: $-3,2 \mathrm{~mm}$

Com o auxílio de uma broca odontológica foi feita a perfuração do crânio e por este orifício foi introduzida a cânula-guia no NMA unilateral, ipsilateral na posição esquerda do cérebro ou bilateralmente de acordo com o protocolo utilizado. A cânula foi constituída por um segmento de agulha hipodérmica com 0,55 $\mathrm{mm}$ de diâmetro externo (24G) e $15 \mathrm{~mm}$ de comprimento. Ela foi fixada ao crânio com resina acrílica autopolimerizável e um pequeno parafuso foi previamente rosqueado na calota craniana. Um mandril de $0,2 \mathrm{~mm}$ de diâmetro externo foi introduzido na cânula com o objetivo de evitar sua obstrução durante o período de recuperação pós-cirurgia. Por prevenção, ao final da cirurgia o animal recebeu $0,2 \mathrm{~mL}$ de Pentabiótico veterinário (White, Brasil) por via intramuscular e $2,5 \mathrm{mg} / \mathrm{Kg}$ do analgésico e antiinflamatório flunixina meglumina (Banamine, Schering-Plough, Brasil) por via subcutânea.

\section{3) Canulação da artéria e veia femoral}

Após 72 horas da cirurgia para implante de cânula-guia no cérebro, os animais foram novamente anestesiados com tribromo-cloro-etanol, e foram implantadas cânulas na artéria femoral para o registro da pressão arterial e frequência cardíaca e, quando necessário, foram implantadas cânulas na veia femoral para administração intravenosa de drogas. A cânula da artéria femoral foi introduzida até 
a aorta abdominal inferior, enquanto a cânula da veia femoral foi introduzida até a veia cava. As cânulas foram constituídas por segmento de polietileno PE-10 $(4-5$ cm) fundido a segmento de polietileno PE-50 $(12-13 \mathrm{~cm})$, sendo preenchidas com uma solução de salina ( $\mathrm{NaCl}$ a $0,9 \%)$ e anticoagulante $(5 \mathrm{U} / \mathrm{mL}$ de heparina) e obstruídas com pino de metal. Os registros da pressão arterial média, pulsátil e frequência cardíaca foram realizados $24 \mathrm{~h}$ após a cirurgia.

\section{4) Registro da pressão arterial e frequência cardíaca}

Os registros dos parâmetros cardiovasculares foram iniciados após um período de 30 min para adaptação dos animais às condições de som e iluminação do laboratório.

Antes do início dos registros, $0,1 \mathrm{ml}$ de solução salina com heparina (15 U/ml) foi injetada nos catéteres, evitando obstruções. O cateter implantado na artéria femoral foi conectado a um transdutor de pressão (Hewlett Packard, Palo Alto, CA, EUA) por um segmento de polietileno PE-50. A pressão arterial pulsátil (PAP) e a frequência cardíaca (FC) foram registradas usando um pré-amplificador de um polígrafo (HP7754-A, Hewlett Packard, Palo Alto, CA, EUA) e uma placa de aquisição de dados (MP100A, Biopac systems Inc. Goleta, CA, EUA) conectado a um computador.

\section{5) Técnica para microinjeção de drogas no cérebro}

A drogas foram dissolvidas em líquido cefalorraquidiano artificial (LCA) $(\mathrm{NaCl}$ 100mM; Na3PO4 2mM; KCl 2,5mM; MgCl2 1,0mM; NaHCO3 27mM; CaCl2 2,5mM; $\mathrm{pH}=7,4)$, e administradas diretamente na área desejada. Quando necessário, após a dissolução, o pH foi ajustado para 7,4. Para as microinjeções foi utilizada uma 
seringa de 1,0 $\mu \mathrm{l}$ modelo $\mathrm{KH}-7001$ (Hamilton, USA) conectada por um tubo de polietileno PE-10 a uma agulha microinjetora de metal (gauge 33). A agulha microinjetora utilizada era $1 \mathrm{~mm}$ mais longa do que a cânula-guia. Todas as microinjeções foram realizadas no volume de $100 \mathrm{~nL}$.

\section{6) Drogas utilizadas}

- Cloreto de noradrenalina (Sigma, USA). As doses utilizadas foram (3, 9, 27 e $45 \mathrm{nmol} / 100 \mathrm{~nL}$ ) para realização de uma curva dose-resposta.

- RX821002 (RBI), antagonista dos receptores $\alpha_{2}$-adrenérgicos. A dose de 10nmol/100nL foi determinada com base em experimentos de inibição realizados em nosso laboratório (FERNANDES et al., 2003). Para os experimentos com ER, as doses utilizadas foram $(10,15,20 \mathrm{nmol} / 100 \mathrm{~nL})$ para realização de uma curva de inibição.

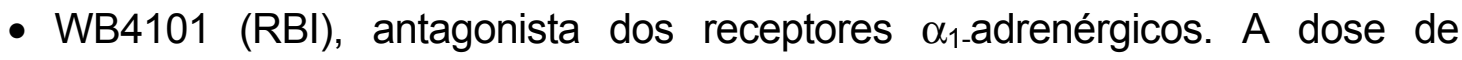
10nmol/100nL foi determinada com base em experimentos de inibição realizados em nosso laboratório (FERNANDES et al., 2003). Para os experimentos com ER as doses utilizadas foram $(10,15,20 \mathrm{nmol} / 100 \mathrm{~nL})$ para realização de uma curva de inibição.

- Propranolol (Sigma, St. Louis, MO, USA), antagonista não seletivo dos receptores $\beta$-adrenérgicos. Para os experimentos com ER as doses utilizadas foram de 10, 15, 20nmol/100nL para realização de uma curva de inibição.

- CGP20712 (1-[2-((3-carbamoyl-4-hydroxy)phenoxy)ethylamino]-3-[4-(1methyl-4-trifluoromethyl-2-imidazolyl)phenoxy]-2-propanol dihydrochloride; Tocris), antagonista dos receptores $\beta_{1}$-adrenérgicos. Para os experimentos com ER, as doses utilizadas foram de $10,15,20 \mathrm{nmol} / 100 \mathrm{~nL}$ para realização de uma curva de inibição. 
- $\quad \mathrm{ICl} 118,551 \quad(( \pm)-1-[(2,3-d i h y d r o-7-m e t h y l-1 H-i n d e n-4-y l) \quad$ oxy] $\quad$-3- [(1methylethyl) amino] -2- butanol hydrochloride; Tocris), antagonista dos receptores $\beta_{2}$-adrenérgicos. Para os experimentos com ER, as doses utilizadas foram de 10,15 , 20nmol/100nL para realização de uma curva de inibição.

- Cloreto de cobalto $\left(\mathrm{CoCl}_{2}\right.$, Merck), bloqueador não seletivo de sinapses (KRETZ, 1984). A dose de $1 \mathrm{mM} / 100 \mathrm{~nL}$ foi escolhida a partir de trabalhos em que a administração desta droga foi eficaz em bloquear a transmissão sináptica (RESSTEL et al., 2004; TAVARES e CORREA, 2006).

- Pentolínio (Sigma, USA), bloqueador ganglionar. A dose de $5 \mathrm{mg} / \mathrm{Kg}$ (i.v.) foi determinada em experimentos realizados em nosso laboratório, a partir de trabalhos descritos na literatura (MORIGUCHI et al., 1998; MATSUMURA et al., 2000).

- dTyr(CH2)5(Me)AVP (Península, USA), antagonista de receptores vasopressinérgicos do tipo V1 (Kruszynski et al., 1980). A dose de $50 \mu \mathrm{g} / \mathrm{Kg}$ (i.v.) foi escolhida tendo-se como referência experimentos descritos na literatura (CORREA et al., 1985; FERNANDES et al., 2003; TAVARES e DE AGUIAR CORREA, 2003).

- Uretana (Sigma, USA)

- Tribromo-cloro-etanol (Aldrich Chemical Co. Inc., USA)

\section{7) Estresse por Restrição}

O tubo de restrição é constituído por um cilindro plástico, medindo $15 \mathrm{~cm}$ de comprimento e $6,5 \mathrm{~cm}$ de diâmetro. O rato foi conectado ao sistema de registro de pressão arterial e frequência cardíaca e permaneceu em sua caixa individual. Em seguida, o animal recebeu a microinjeção bilateral de antagonistas noradrenérgicos e após 10 min foi transferido para o tubo de restrição, sendo que a pressão arterial e 
a frequência cardíaca foram registradas continuamente durante o período de permanência no tubo.

\section{8) Determinação anatômica do sítio de injeção}

Ao final de cada experimento, os animais foram anestesiados com uretana $(1,2 \mathrm{~g} / \mathrm{kg}$ i.p.) e foi injetado o corante azul de Evans a $1 \%$ no local da microinjeção das drogas, para determinação do sítio de injeção. Em seguida, os ratos foram submetidos à perfusão. Para isso, foi feita abertura da caixa torácica para exposição do coração, e em seguida a aorta descendente foi bloqueada com uma pinça hemostática. Uma agulha para perfusão foi introduzida no ventrículo esquerdo, e uma incisão foi feita na aurícula direita para o escoamento do sangue e do perfusado. A perfusão foi realizada inicialmente com $20 \mathrm{~mL}$ de solução fisiológica de $\mathrm{NaCl}$ 0,9\%, seguida por $40 \mathrm{~mL}$ de solução tamponada de formalina a $10 \%$. Posteriormente, os cérebros foram retirados da caixa craniana e foram pós-fixados em solução de perfusão. Os cérebros foram seccionados (em cortes frontais de 40 $\mu \mathrm{m}$ de espessura) com o auxílio de um criostato. Foram feitas várias secções da área do NMA, coradas com cresil violeta a 0,5\% e analisadas utilizando-se o atlas (PAXINOS e WATSON, 1997) como referência.

\section{9) Análise estatística}

Para análise estatística dos dados foi utilizado o programa Prism (GraphPad, USA).

Para os experimentos com microinjeção de noradrenalina no NMA foi realizado o teste de regressão não-linear, para construção da curva dose resposta.

O teste $\mathrm{t}$ de Student pareado foi utilizado para comparar os valores basais da PAM e FC antes e após o tratamento farmacológico ou controle. A análise de 
variância de dois fatores (two-way ANOVA) seguida pelo pós-teste de Bonferroni foi utilizada para analisar como fator variável o tratamento (controle ou droga) e o fator tempo como medida repetida.

Os valores de pressão arterial média (PAM) e frequência cardíaca (FC) foram continuamente registrados por 10 min antes (basal) e 60 min durante o ER. Os dados foram expressos como média \pm erro padrão da média (EPM) das variações de PAM ou das variações da $F C$ da linha basal ( $\triangle \mathrm{PA}$ e $\triangle \mathrm{FC})$, de onde foi coletado com uma amostragem de 0,9 pontos por minuto. Para propósito estatístico, as curvas de 60 pontos foram re-amostradas para seis pontos, correspondentes ao número de animais por grupo: o $1^{\circ}$ ponto foi obtido fazendo-se uma média aritmética de pontos entre 1 a $3 \mathrm{~min}, \mathrm{o} 2^{\circ}$ ponto entre 8 a $10 \mathrm{~min}$, o $3^{\circ}$ ponto foi obtido no minuto $11, \mathrm{o} 4^{\circ}$ ponto entre 29 a $31 \mathrm{~min}$, o $5^{\circ}$ ponto entre 49 a 51 min e o $6^{\circ}$ ponto entre 58 a $60 \mathrm{~min}$. Os dois primeiros correspondem ao período basal que antecede o início da restrição, enquanto os quatros últimos correspondem ao período de restrição. As figuras ilustrativas mostradas nos resultados foram feitas com 20 pontos para melhor visualização da curva temporal. Foram considerados como significativos os resultados que apresentaram $\mathrm{P}<0,05$.

Para os estudos que investigaram a participação NMA e da neurotransmissão noradrenérgica presente no NMA na modulação da atividade cardiovascular durante o estresse por restrição foram utilizadas análises de regressão linear para investigar a correlação do efeito da administração de diferentes doses dos antagonistas $\alpha$ adrenérgicos no NMA sobre as respostas cardiovasculares ao estresse por restrição. Os pontos para a composição da curva foram gerados a partir da média de todos os pontos a partir do início da restrição dos animais. 


\section{PROTOCOLOS EXPERIMENTAIS}

Todos os animais foram submetidos à cirurgia para implantação de cânula guia no NMA, e mantidos em recuperação por 72 h. Após o período de recuperação, foi realizada a canulação da artéria femoral (e veia femoral, quando necessário) e o experimento foi realizado $24 \mathrm{~h}$ após a cirurgia.

Para realizar todos os protocolos, os animais foram levados à sala de experimentação acusticamente isolada do meio ambiente, em suas próprias caixas e os experimentos foram iniciados após 30 min de adaptação dos animais às condições de som e iluminação do ambiente. As microinjeções unilaterais de NA foram realizadas com intervalo de 15-20 min para o retorno dos valores basais de pressão arterial e a frequência cardíaca. 10 min após a administração dos antagonistas no NMA a NA foi novamente microinjetada neste núcleo.

Nos protocolos para o estudo das alterações cardiovasculares ocasionadas pelo ER, cada animal foi conectado ao sistema de registro da pressão arterial e frequência cardíaca em sua respectiva caixa, para registro da pressão arterial e a frequência cardíaca basal por $10 \mathrm{~min}$. Em seguida, ainda conectado ao sistema de registro da pressão arterial, o rato recebeu a microinjeção bilateral de antagonistas noradrenérgicos e após $10 \mathrm{~min}$ foi transferido para o tubo de restrição, onde permaneceu por $1 \mathrm{~h}$. A pressão arterial e a frequência cardíaca foram registradas durante todo o período de restrição. Foi feita a microinjeção, bilateral, intracerebral de droga ou LCA, 10 min antes da restrição. Em todos os protocolos durante os dias de experimentos os animais permaneciam acordados. 
1) Efeito da microinjeção de diferentes doses de NA no NMA sobre a pressão arterial e frequência cardíaca de ratos (curva dose-resposta)

Este protocolo teve por objetivo verificar as alterações cardiovasculares causadas pela microinjeção unilateral de diferentes doses de NA $(3 ; 9 ; 27$; 45nmol/100nL) no NMA. Cada animal recebeu de uma a três doses de NA, mantendo-se o intervalo de 15 min entre cada injeção. A dose de $27 \mathrm{nmol} / 100 \mathrm{~nL}$ de $\mathrm{NA}$, próxima ao $\mathrm{ED}_{50}$, foi utilizada nos protocolos subseqüentes.

2) Efeito da microinjeção de NA em áreas fora do NMA sobre a pressão arterial e frequência cardíaca de ratos

Este protocolo teve por objetivo verificar se a NA microinjetada em áreas fora do NMA causava respostas cardiovasculares semelhantes às da NA no NMA. Para isso, foi microinjetada NA (27 nmol/100nL) no trato óptico ou na cápsula interna.

3) Efeito da microinjeção de antagonistas de receptores $\alpha$-adrenérgicos no NMA sobre as respostas cardiovasculares à microinjeção de NA

Este protocolo teve por objetivo verificar qual subtipo de receptor adrenérgico estaria envolvido na resposta desencadeada pela microinjeção de NA no NMA. Os animais receberam NA antes e após a microinjeção de WB4101 (10nmol/100nL, antagonista dos receptores $\alpha_{1}$-adrenérgico), RX821002 (10nmol/100nL, antagonista dos receptores $\alpha_{2}$-adrenérgico) ou veículo (LCA, 100nL) no NMA. 


\section{4) Efeito do pré-tratamento com antagonistas periféricos sobre as respostas} cardiovasculares à microinjeção de NA no NMA de ratos

Este protocolo teve por objetivo verificar a mediação periférica das respostas cardiovasculares à microinjeção de NA no NMA. Os animais receberam a microinjeção de NA no NMA. Após a PAM e FC retornarem para o basal, os animais receberam a injeção intravenosa de pentolínio $(5 \mathrm{mg} / \mathrm{Kg}$, bloqueador ganglionar), dTyr(CH2)5(Me)AVP (50 $\mathrm{\mu g} / \mathrm{kg}$, antagonista de receptores V1 de vasopressina) ou veículo (LCA) e 15 min depois, eles receberam novamente a microinjeção de NA no NMA.

5) Efeito da microinjeção de um inibidor de sinapses no NPV sobre as respostas cardiovasculares a microinjeção de NA no NMA de ratos

Este protocolo teve por objetivo verificar se o NPV do hipotálamo estaria envolvido na resposta desencadeada pela NA no NMA de ratos. A microinjeção de cloreto de cobalto $\left(\mathrm{CoCl}_{2}\right)$ no NPV foi ipsilateral ao sítio de injeção de NA no NMA. Os animais receberam a microinjeção de NA $(27 \mathrm{nmol} / 100 \mathrm{~nL})$ no NMA, após 20min, foi feita a microinjeção de $\mathrm{CoCl}_{2}(1 \mathrm{mM} / 100 \mathrm{~nL})$ ou veículo no NPV e, seguidos 15 min, a NA foi novamente administrada no NMA.

6) Efeito da microinjeção de um inibidor de sinapses no NSO sobre as respostas cardiovasculares a microinjeção de NA no NMA de ratos

Este protocolo teve por objetivo verificar se o NSO do hipotálamo estaria envolvido na resposta desencadeada pela NA no NMA de ratos. A microinjeção de $\mathrm{CoCl}_{2}$ no NSO foi ipsilateral ao sítio de injeção de NA no NMA. Os animais receberam a microinjeção de NA $(27 \mathrm{nmol} / 100 \mathrm{~nL})$ no NMA, após $20 \mathrm{~min}$, foi feita a 
microinjeção de $\mathrm{CoCl}_{2}(1 \mathrm{mM} / 100 \mathrm{~nL})$ ou veículo no NSO e, seguidos 15 min, a NA foi novamente administrada no NMA.

7) Efeito da microinjeção de antagonistas dos receptores $\alpha_{1}$-adrenérgico no NMA sobre as respostas cardiovasculares ao ER

Este protocolo teve por objetivo determinar se os receptores $\alpha_{1}$-adrenérgico estão envolvidos na modulação das alterações cardiovasculares ao ER. Os animais foram divididos em dois grupos. Em um grupo foi microinjetado bilateralmente 100 $\mathrm{nL}$ de LCA no NMA, enquanto que no outro foi microinjetado diferentes doses de WB4101 (10, 15 e 20nmol/100nL) e 10 min após, os animais foram submetidos ao ER por 1 hora.

8) Efeito da microinjeção de antagonistas dos receptores $\alpha_{2}$-adrenérgico no NMA sobre as respostas cardiovasculares ao ER

Este protocolo teve por objetivo determinar se os receptores $\alpha_{2}$-adrenérgico estão envolvidos na modulação das alterações cardiovasculares ao ER. Os animais foram divididos em dois grupos. Em um grupo foi microinjetado bilateralmente $100 \mathrm{~nL}$ de LCA no NMA, enquanto que no outro foi microinjetado diferentes doses de $\mathrm{RX821002}(10,15$ e 20nmol/100nL) e 10 min após, os animais foram submetidos ao ER por 1 hora.

9) Efeito da microinjeção de antagonistas não seletivo dos receptores $\beta$-adrenérgico no NMA sobre as respostas cardiovasculares ao ER

Este protocolo teve por objetivo determinar se os receptores $\beta$-adrenérgicos estão envolvidos na modulação das alterações cardiovasculares ao ER. Os animais 
foram divididos em dois grupos. Em um grupo foi microinjetado bilateralmente 100 $\mathrm{nL}$ de LCA no NMA, enquanto que no outro foi microinjetado diferentes doses de propranolol (10, 15 e 20nmol/100nL) e 10 min após, os animais foram submetidos ao ER por 1 hora.

10) Efeito da microinjeção de antagonistas dos receptores $\beta_{1}$-adrenérgico no NMA sobre as respostas cardiovasculares ao ER

Este protocolo teve por objetivo determinar se os receptores $\beta_{1}$-adrenérgicos estão envolvidos na modulação das alterações cardiovasculares ao ER. Os animais foram divididos em dois grupos. Em um grupo foi microinjetado bilateralmente 100 $\mathrm{nL}$ de LCA no NMA, enquanto que no outro foi microinjetado diferentes doses de CGP20712 (10, 15 e 20nmol/100nL) e 10 min após, os animais foram submetidos ao ER por 1 hora.

11) Efeito da microinjeção de antagonistas dos receptores $\beta_{2}$-adrenérgico no NMA sobre as respostas cardiovasculares ao ER

Este protocolo teve por objetivo determinar se os receptores $\beta_{2}$-adrenérgicos estão envolvidos na modulação das alterações cardiovasculares ao ER. Os animais foram divididos em dois grupos. Em um grupo foi microinjetado bilateralmente 100 $\mathrm{nL}$ de LCA no NMA, enquanto que no outro foi microinjetado diferentes doses de ICl118,551 (10, 15 e 20nmol/100nL) e 10 min após, os animais foram submetidos ao ER por 1 hora. 


\section{RESULTADOS}

\section{1) Efeito da microinjeção de diferentes doses de NA no NMA sobre a pressão arterial e frequência cardíaca de ratos (curva dose-resposta)}

Diferentes doses de noradrenalina (NA) foram microinjetadas no NMA em ratos. Todos os animais receberam uma microinjeção do veículo (LCA) ou uma microinjeção de NA (3; 9; 27; 45 nmol/100 nL) no NMA. As microinjeções em doses diferentes de NA no NMA em ratos normotensos (valor basal PAM=100 $\pm 2 \mathrm{mmHg}$ e $\mathrm{FC}=353 \pm 8 \mathrm{bpm}, \mathrm{n}=10$ ) causaram respostas pressoras e bradicárdicas de maneira dose-dependente. A microinjeção de LCA no NMA não causou alterações na PAM e FC. A análise de regressão não-linear mostrou uma correlação significante entre a dose de NA e as respostas cardiovasculares (PA: $r^{2}=0.9$, df= 16, $P<0.05 ; \mathrm{FC}: \mathrm{r}^{2}=$ $0.9, \mathrm{df}=16, \mathrm{P}<0.05)$, figura 1.

A dose de $N A$ de $27 \mathrm{nmol} / 100 \mathrm{~nL}$, próxima à $\mathrm{DE}_{50}$, a qual foi utilizada nos experimentos subsequentes, causou resposta pressora $(\Delta \mathrm{PAM}=+26 \pm 1 \mathrm{mmHg}, \mathrm{t}=$ 12.2, $\mathrm{P}<0,01, \mathrm{n}=5$ ) que foram acompanhadas por redução na frequência cardíaca $(\Delta \mathrm{FC}=-32 \pm 2 \mathrm{bpm}, \mathrm{t}=25.3, \mathrm{P}<0,0001, \mathrm{n}=5)$.

A figura 2(A) mostra os diagramas representativos modificados do atlas de Paxinos e Watson (1997) indicando os sítios de microinjeção de NA no NMA. A fotomicrografia de um corte de cérebro de rato mostrando o sítio de microinjeção da NA no NMA está representado na figura 2(B).

A figura 3 mostra um registro representativo de pressão arterial média, pressão arterial pulsátil e da frequência cardíaca de um animal representativo do grupo, que recebeu a microinjeção de NA (27nmol/100nL). 

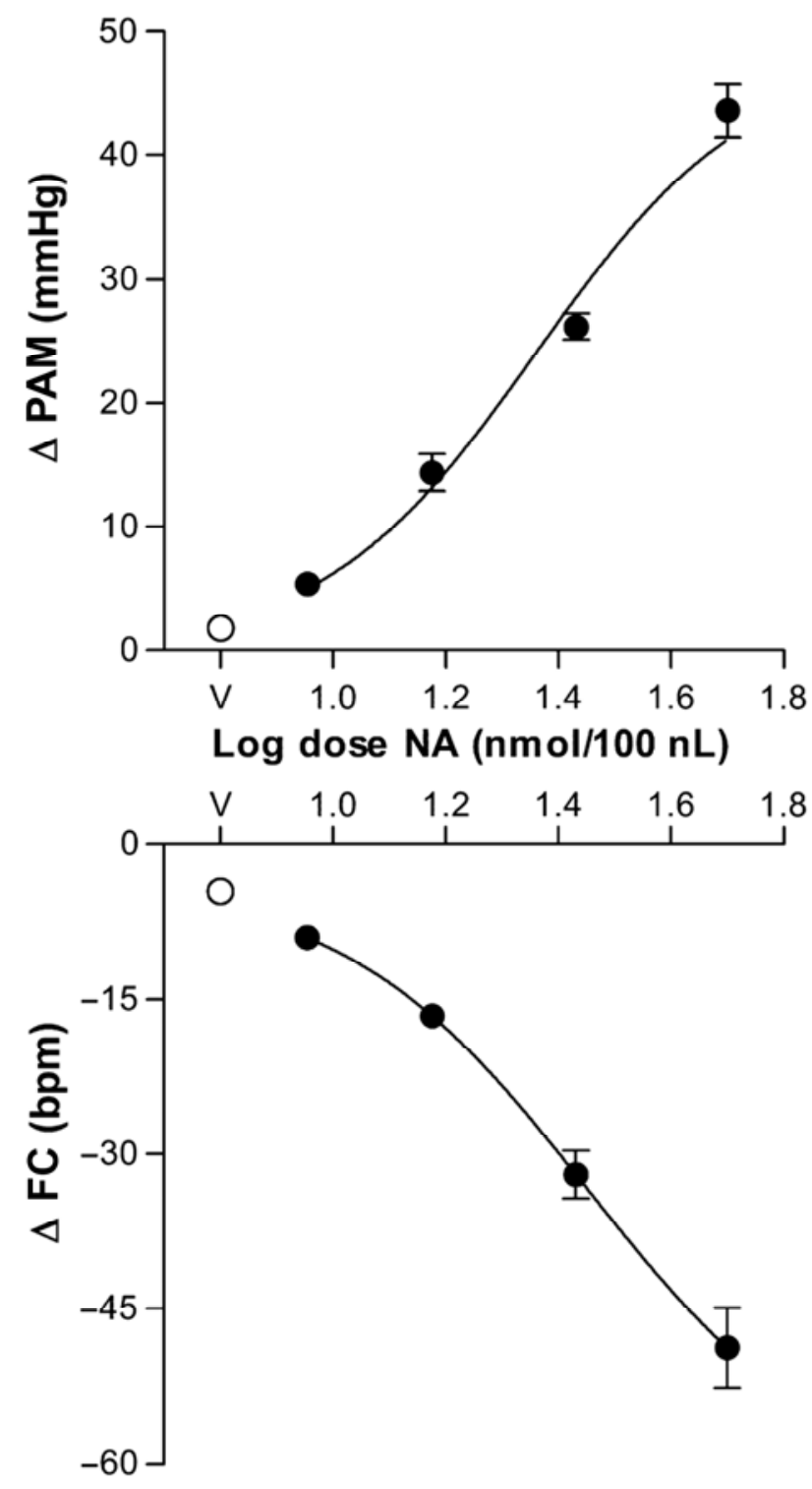

Figura 1. Variações na pressão arterial média $(\triangle P A M, m m H g)$ e frequência cardíaca $(\triangle \mathrm{FC}, \mathrm{bpm}$ ) após a microinjeção de veículo (líquido cefalorraquidiano artificial - LCA/ círculos brancos) ou doses crescentes de noradrenalina (NA; 3; 9; $27 ; 45$ nmol/100 $\mathrm{nL} /$ círculos pretos) no NMA de ratos. 

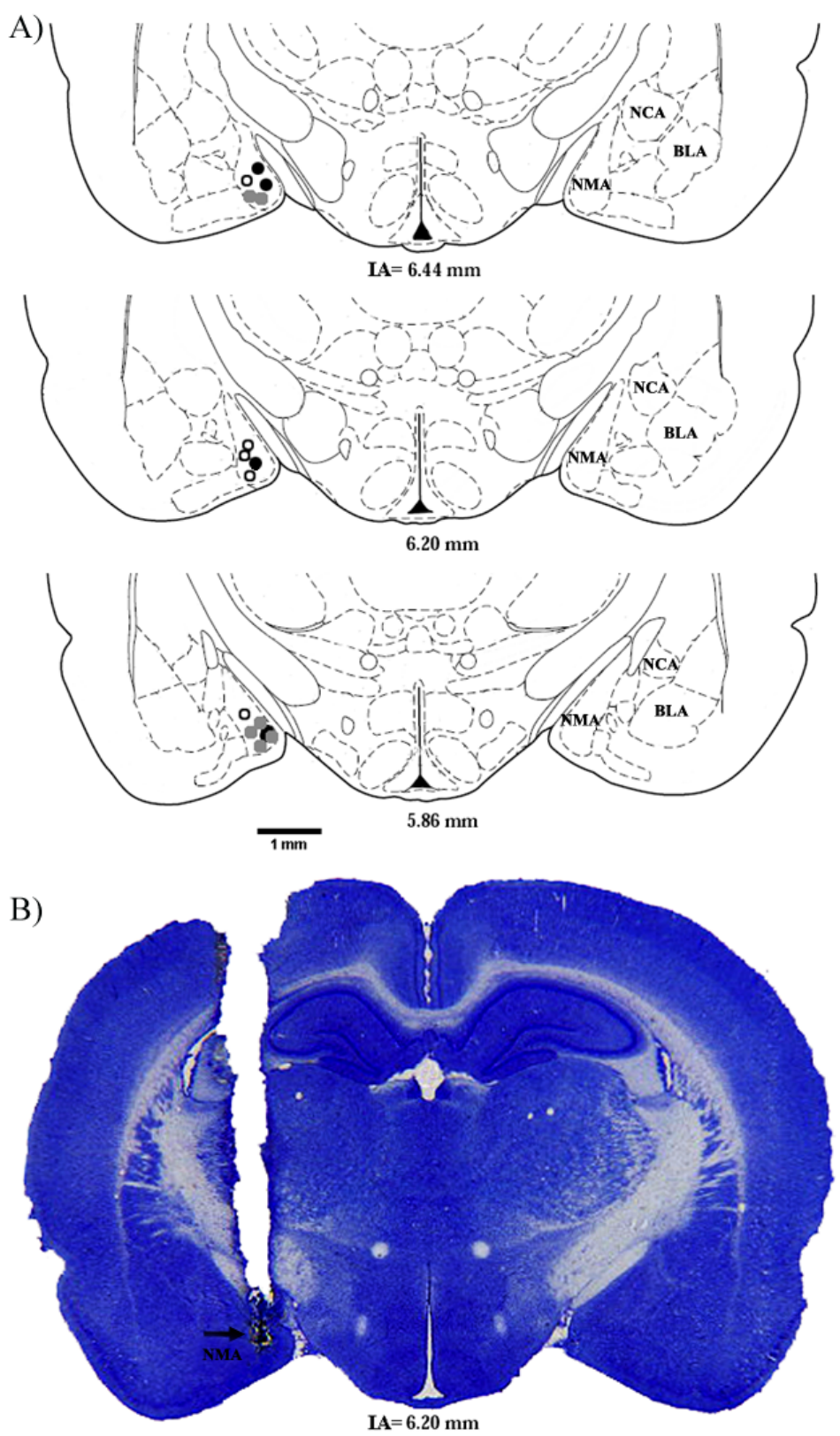

Figura 2. A) Diagrama do cérebro de rato baseado no atlas Paxinos e Watson (1997) mostrando os sítios de microinjeção de drogas. Os círculos pretos indicam locais de microinjeção de WB4101, os círculos cinza indicam locais de microinjeção de RX821002 e os círculos brancos indicam locais de microinjeção de LCA no núcleo medial da amígdala (NMA). B) Fotomicrografia de corte histológico do cérebro de rato mostrando o sítio da microinjeção de (NA) 27nmol/100nL no NMA, indicado pela seta. IA, interaural; NCA, núcleo central da amígdala; BLA, núcleo basolateral da amígdala; NMA, núcleo medial da amígdala. 


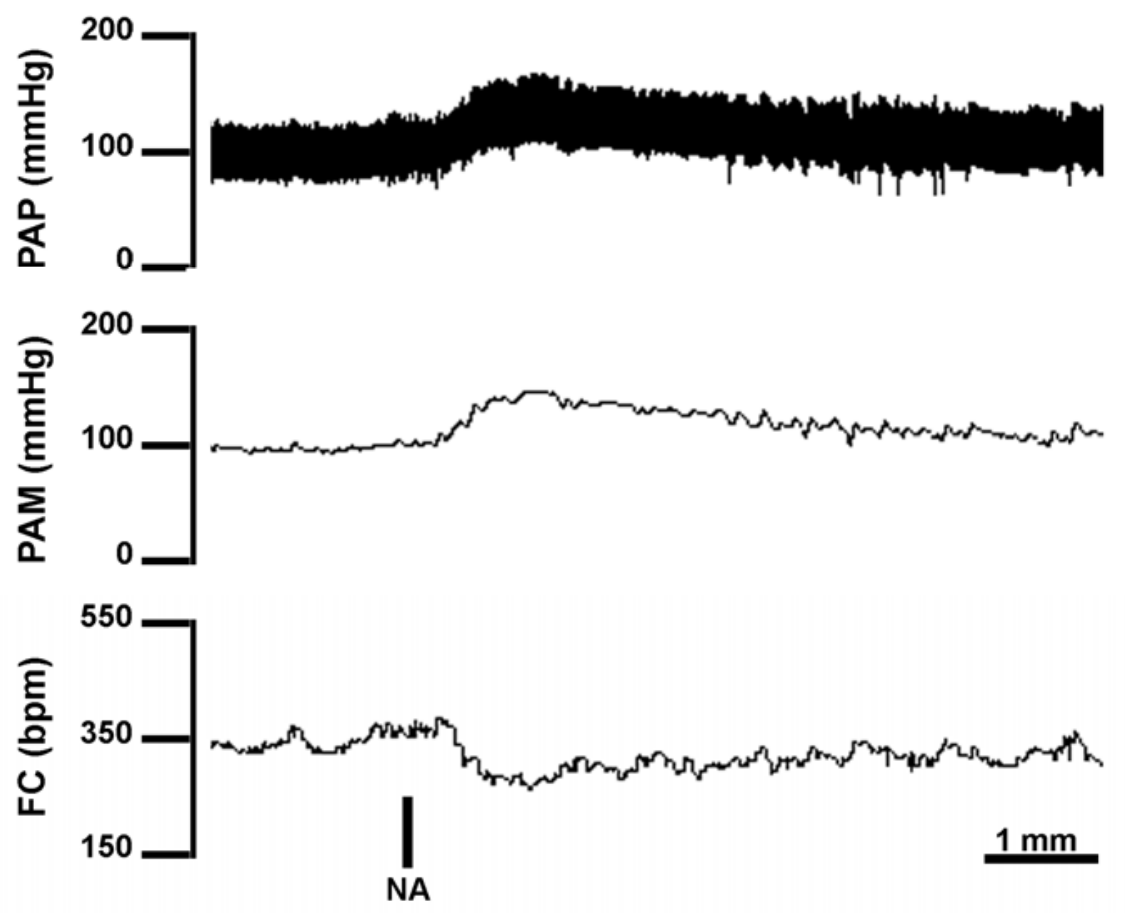

Figura 3. Registros representativos de um rato não anestesiado mostrando as alterações na pressão arterial pulsátil (PAP), pressão arterial média (PAM) e frequência cardíaca (FC) após microinjeção de noradrenalina (NA) $27 \mathrm{nmol} / 100 \mathrm{~nL}$ no NMA. 


\section{2) Efeito da microinjeção de NA em áreas fora do NMA sobre a pressão arterial} e frequência cardíaca de ratos

A microinjeção de $27 \mathrm{nmol} / 100 \mathrm{~nL}$ de NA em áreas fora do NMA, no trato óptico ou na cápsula interna, não causou efeito sobre a PA ou FC. Os valores basais cardiovasculares antes e após a microinjeção de NA no trato óptico foram respectivamente: $\mathrm{PAM}=100 \pm 0.3$ vs $99 \pm 0.3 \mathrm{mmHg}, \mathrm{t}=0.9, \mathrm{P}>0,05$ e $\mathrm{FC}=365 \pm 5$ vs $365 \pm 4 \mathrm{bpm}, \mathrm{t}=0.3, \mathrm{P}>0,05 ; \mathrm{n}=3$. Os valores basais cardiovasculares antes $\mathrm{e}$ após a microinjeção de NA na cápsula interna foram respectivamente: $P A M=99 \pm$ 0.3 vs $99 \pm 0.3 \mathrm{mmHg}, \mathrm{t}=0.3, \mathrm{P}>0,05$ e $\mathrm{FC}=360 \pm 1.5$ vs $359 \pm 2.1 \mathrm{bpm}, \mathrm{t}=0,8, \mathrm{P}>$ $0,05, n=3$. A figura 4 apresenta uma representação diagramática mostrando os sítios de microinjeção no trato óptico ou cápsula interna.

A figura 5 mostra um registro representativo de pressão arterial média, pressão arterial pulsátil e da frequência cardíaca de um animal representativo do grupo, que recebeu a microinjeção de NA $(27 \mathrm{nmol} / 100 \mathrm{~nL})$ no trato óptico. 


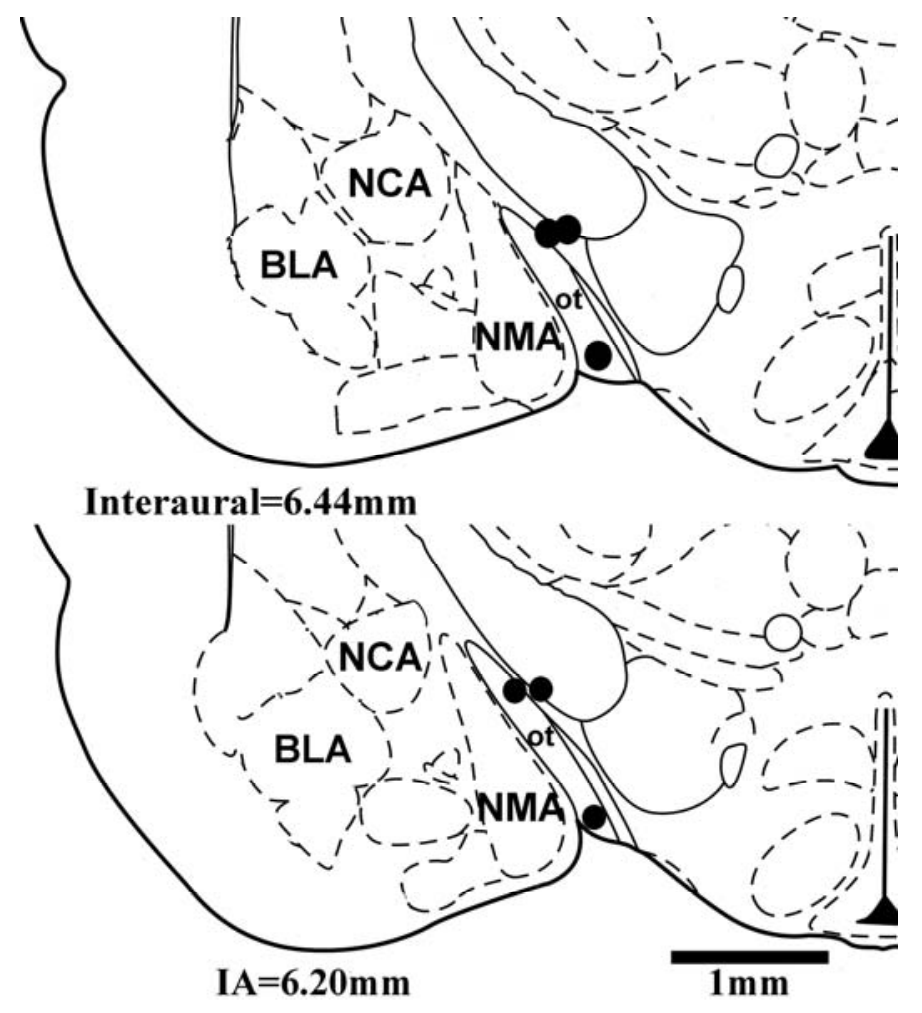

Figura 4. Diagrama do cérebro de rato baseado no atlas Paxinos e Watson (1997) mostrando os sítios de microinjeção de drogas nas áreas fora do NMA. Os círculos pretos indicam locais de microinjeção de $N A 27 \mathrm{nmol} / 100 \mathrm{~nL}$ no trato óptico ou cápsula interna. IA, interaural; ot, trato óptico; NCA, núcleo central da amígdala; BLA, núcleo basolateral da amígdala; NMA, núcleo medial da amígdala. 

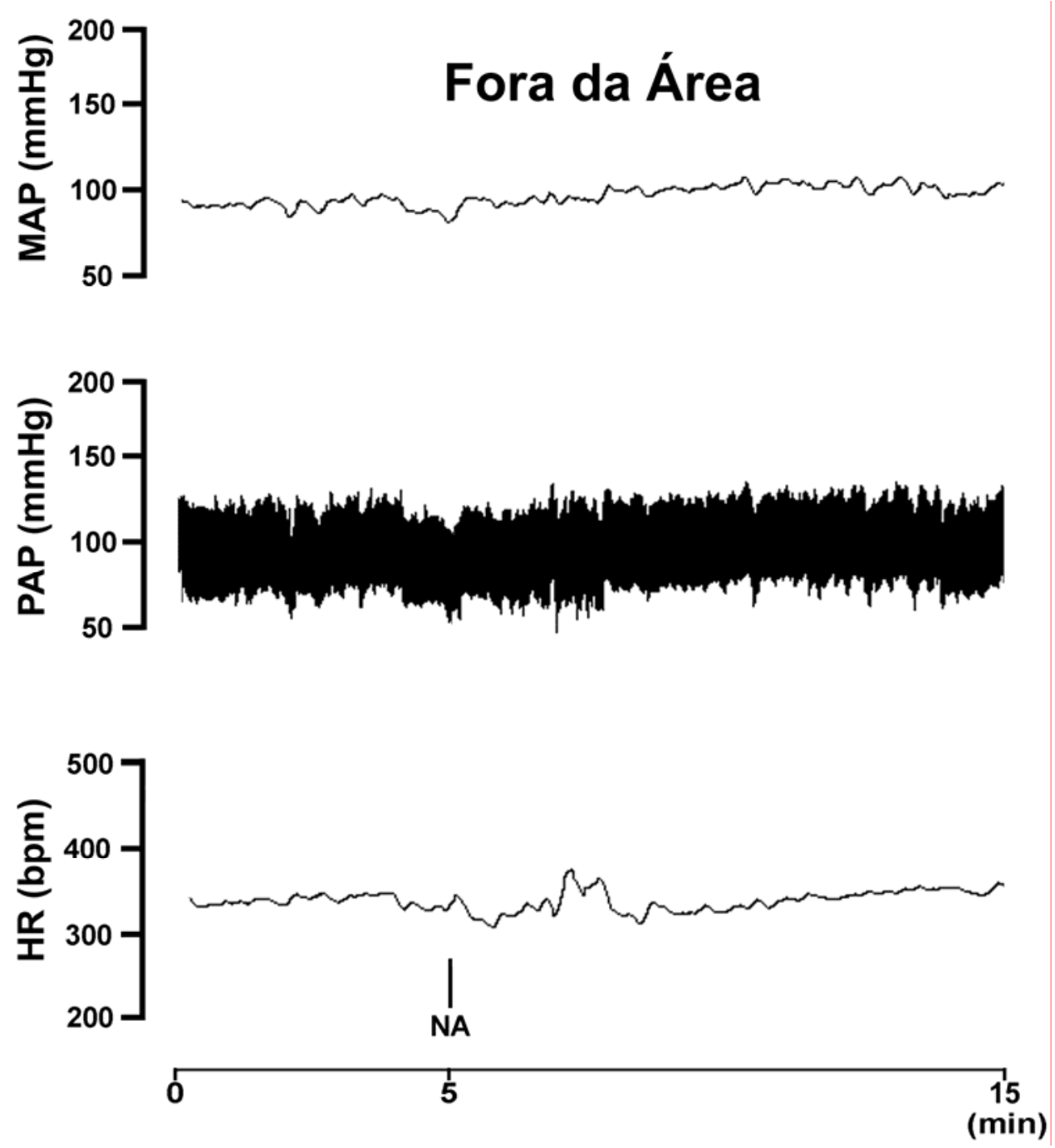

Figura 5. Registros representativos de um rato não anestesiado mostrando as alterações na pressão arterial pulsátil (PAP), pressão arterial média (PAM) e frequência cardíaca (FC) após microinjeção de noradrenalina (NA) $27 \mathrm{nmol} / 100 \mathrm{~nL}$ no trato óptico. 


\section{3) Efeito da microinjeção local de antagonistas de receptores $\alpha$-adrenérgicos} sobre as respostas cardiovasculares à microinjeção de NA no NMA em ratos

Líquido cefalorraquidiano artificial (LCA) - A microinjeção de veículo (LCA, 100 $\mathrm{nL})$ no NMA não causou alterações nos valores basais da PAM $(98.5 \pm 0.6 \mathrm{mmHg}$ vs $100.3 \pm 0.2 \mathrm{mmHg}, \mathrm{t}=2.6, \mathrm{P}>0.05, \mathrm{n}=5)$ ou $\mathrm{FC}(362.8 \pm 4.1 \mathrm{bpm}$ vs $365.3 \pm 3.6$ bpm, $\mathrm{t}=1.1, \mathrm{P}>0.05, \mathrm{n}=5)$. O pré-tratamento com LCA não alterou as respostas cardiovasculares da microinjeção de NA no NMA.

RX821002 (antagonista dos receptores $\alpha_{2}$-adrenérgico) - A microinjeção de RX821002 (10nmol/100 nL) no NMA não causou alterações nos valores basais de PAM (100.6 $\pm 0.5 \mathrm{mmHg}$ vs $100 \pm 0.4 \mathrm{mmHg}, \mathrm{t}=0.0, \mathrm{P}>0.05, \mathrm{n}=6)$ ou $\mathrm{FC}(365.6 \pm$ $3.4 \mathrm{bpm}$ vs $364.6 \pm 2.3 \mathrm{bpm}, \mathrm{t}=0.8, \mathrm{P}>0.05, \mathrm{n}=6)$. A análise de variância de dois fatores indicou efeito significativo do tratamento com RX821002 sobre as respostas cardiovasculares de NA (PAM: $F_{5,60}=17.8, P<0.0001$; e FC: $F_{5,60}=21.8, \mathrm{P}<$ 0.0001); houve efeito significativo sobre o tempo (PAM: $F_{5,60}=3.4, P>0.0001$; e FC: $\left.F_{5,60}=7.1, P<0.0001\right)$ e interação entre o tratamento e tempo $\left(P A M: F_{5,60}=2.7, P>\right.$ 0.01; e FC: $\left.F_{5,60}=2.5, P>0.01\right)$, figura 6 .

WB4101 (antagonista dos receptores $\alpha_{1}$-adrenérgico) - A microinjeção de WB4101 (10 nmol/100 nL) no NMA não causou alterações nos valores basais de PAM $(99.2 \pm 0.6 \mathrm{mmHg}$ vs $99.8 \pm 0.5 \mathrm{mmHg}, \mathrm{t}=1.1, \mathrm{P}>0.05, \mathrm{n}=5)$ ou $\mathrm{FC}(364 \pm 3$ bpm vs $363.6 \pm 2.5 \mathrm{bpm}, \mathrm{t}=0.6, \mathrm{P}>0.05, \mathrm{n}=5)$. A análise de variância de dois fatores não indicou efeito do tratamento com WB4101 sobre as respostas cardiovasculares de NA (PAM: $F_{5,60}=0.01, P>0.1$; e FC: $F_{5,60}=0.2, P>0.1$ ); 
houve efeito significativo sobre o tempo (PAM: $F_{5,60}=25.5, P<0.0001$; e FC: $F_{5,60}=$ 17.6, $P<0.0001)$ e não houve interação entre o tratamento e tempo (MAP: $F_{5,60}=$ $0.5, P>0.1$; e $\left.F C: F_{5,60}=0.3, P>0.1\right)$, figura 7 .

A figura 8 mostra um registro representativo de pressão arterial média, pressão arterial pulsátil e da frequência cardíaca de um animal representativo do grupo, que recebeu a microinjeção de NA no NMA (27nmol/100nL), antes e após o prétratamento local de RX821002. 

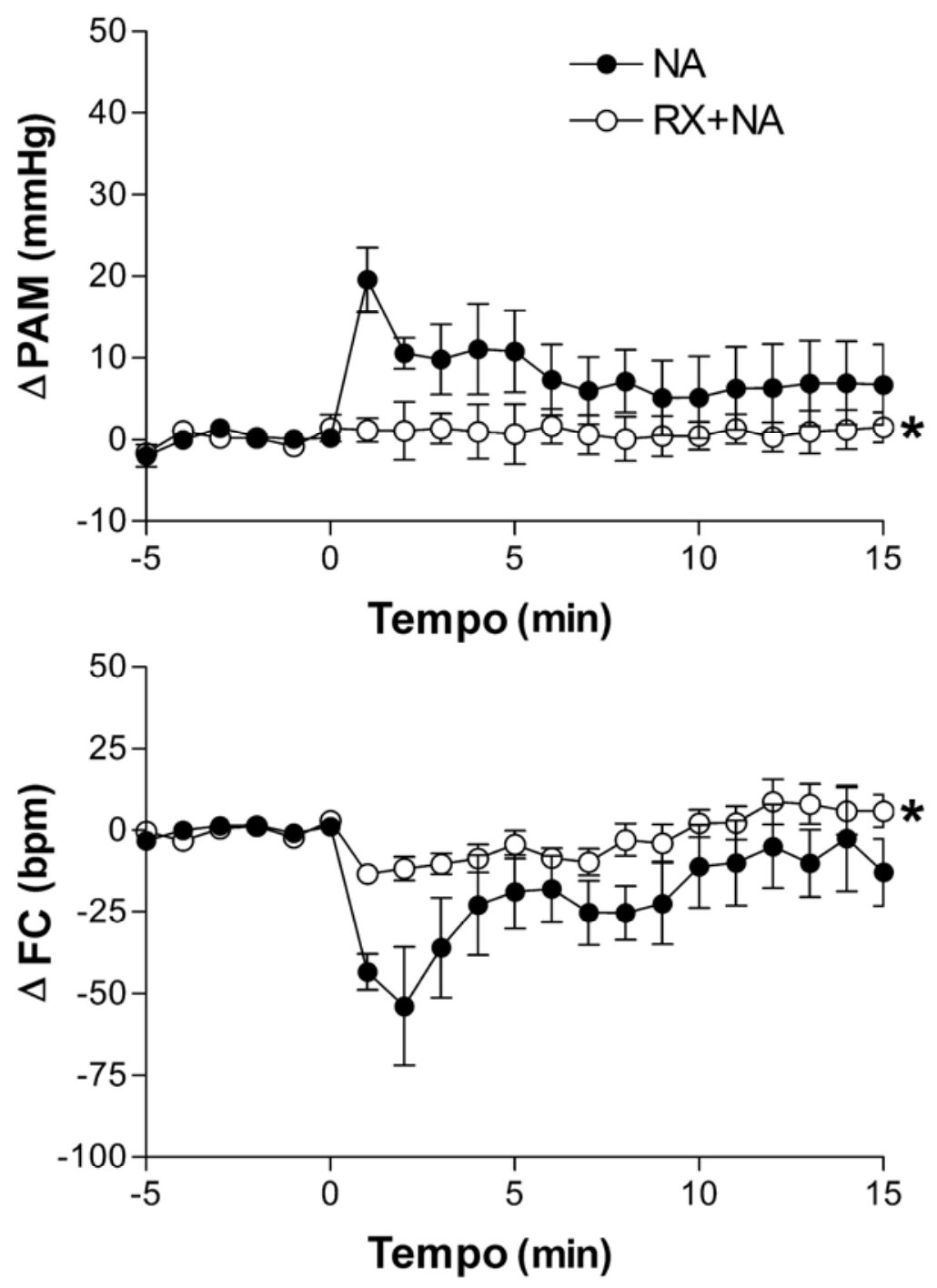

Figura 6. Curvas temporais mostrando as alterações na $\triangle \mathrm{PAM}$ e $\triangle \mathrm{FC}$ observadas pela microinjeção de NA (27nmol/100nL) no NMA antes e após o pré-tratamento local com RX821002 (10nmol/100nL). As microinjeções foram feitas no tempo 0. Pontos representam a média e as barras O E.P.M. Dados foram analisados utilizando o two-way ANOVA (variância de dois fatores) seguida pelo pós-teste de Bonferroni, ${ }^{*} p<0,05$. 

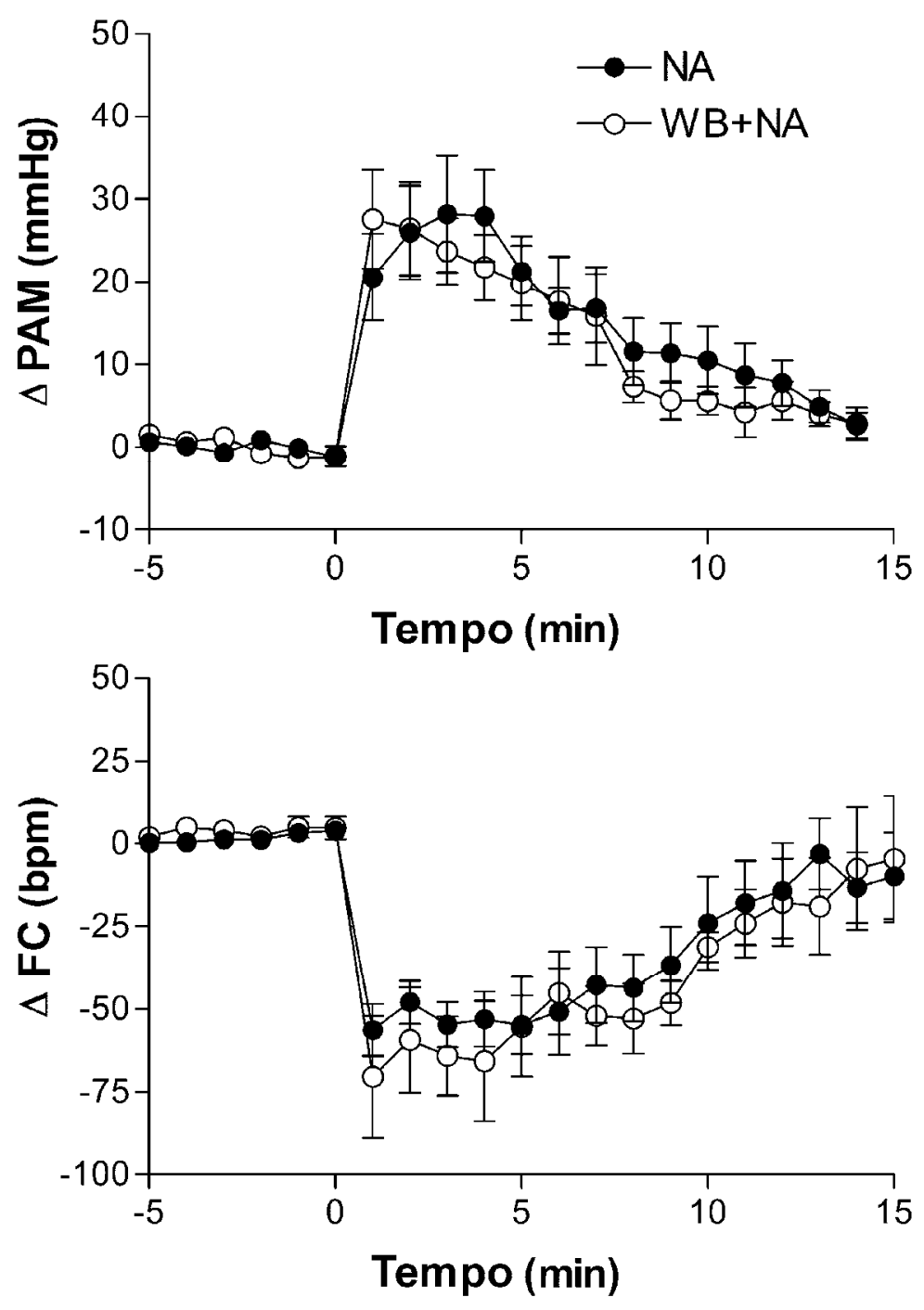

Figura 7. Curvas temporais mostrando as alterações na $\triangle \mathrm{PAM}$ e $\triangle \mathrm{FC}$ observadas pela microinjeção de NA $(27 \mathrm{nmol} / 100 \mathrm{~nL})$ no NMA antes e após o pré-tratamento local com WB4101 (10nmol/100nL). As microinjeções foram feitas no tempo 0. Pontos representam a média e as barras o E.P.M. 

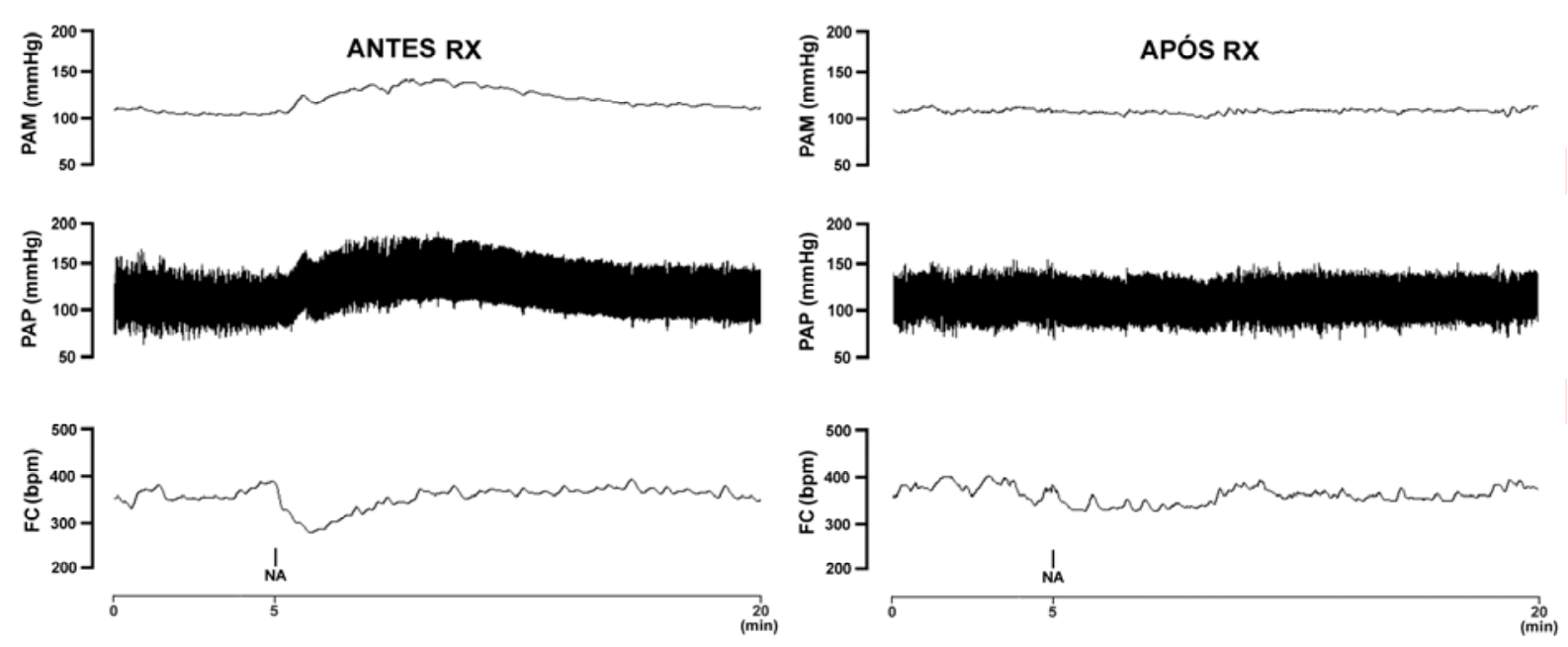

Figura 8. Registro representativo de pressão arterial média (PAM), pressão arterial pulsátil (PAP) e frequência cardíaca $(F C)$ de um animal representativo do grupo, mostrando o efeito da microinjeção de NA $(27 \mathrm{nmol} / 100 \mathrm{~nL})$ no NMA antes e após o pré-tratamento local com RX821002. 
4) Efeito do pré-tratamento intravenoso com bloqueador ganglionar (pentolínio) sobre as respostas cardiovasculares causadas pela microinjeção de NA no NMA de ratos

A pressão arterial basal dos animais foi significantemente reduzida após administração de pentolínio (5 mg/Kg, i.v.) (PAM= $100 \pm 3 \mathrm{mmHg}$ vs $75 \pm 5 \mathrm{mmHg}$, $t=3,6, P<0,01, n=5)$, mas não alterou a frequência cardíaca basal $(F C=375 \pm 16$ bpm vs $376 \pm 17 \mathrm{bpm}, \mathrm{t}=0,07, \mathrm{P}>0,05, \mathrm{n}=5)$. O pré-tratamento com pentolínio potencializou a resposta pressora causada pela administração local de NA no NMA e a bradicardia foi significativamente reduzida $\left(\triangle \mathrm{PAM}: \mathrm{F}_{5,48}=43.7, \mathrm{P}<0.0001\right.$; e $\left.\Delta \mathrm{FC}: \mathrm{F}_{5,48}=35.4, \mathrm{P}<0.0001\right)$; houve efeito significativo sobre o tempo ( $\triangle \mathrm{PAM}: \mathrm{F}_{5,48}$ $=32.6, \mathrm{P}<0.0001$; e $\left.\Delta \mathrm{FC}: \mathrm{F}_{5,48}=9.4, \mathrm{P}<0.0001\right)$ e a interação entre o tratamento e o tempo ( $\triangle \mathrm{PAM}: \mathrm{F}_{5,48}=5.3, \mathrm{P}>0.0001$; e $\left.\Delta \mathrm{FC}: \mathrm{F}_{5,48}=6.1, \mathrm{P}>0.0001\right)$, figura 9.

A figura 10 mostra um registro representativo de pressão arterial média, pressão arterial pulsátil e da frequência cardíaca de um animal representativo do grupo, que recebeu a microinjeção de NA no NMA (27nmol/100nL), antes e após o pré-tratamento sistêmico com pentolínio. 

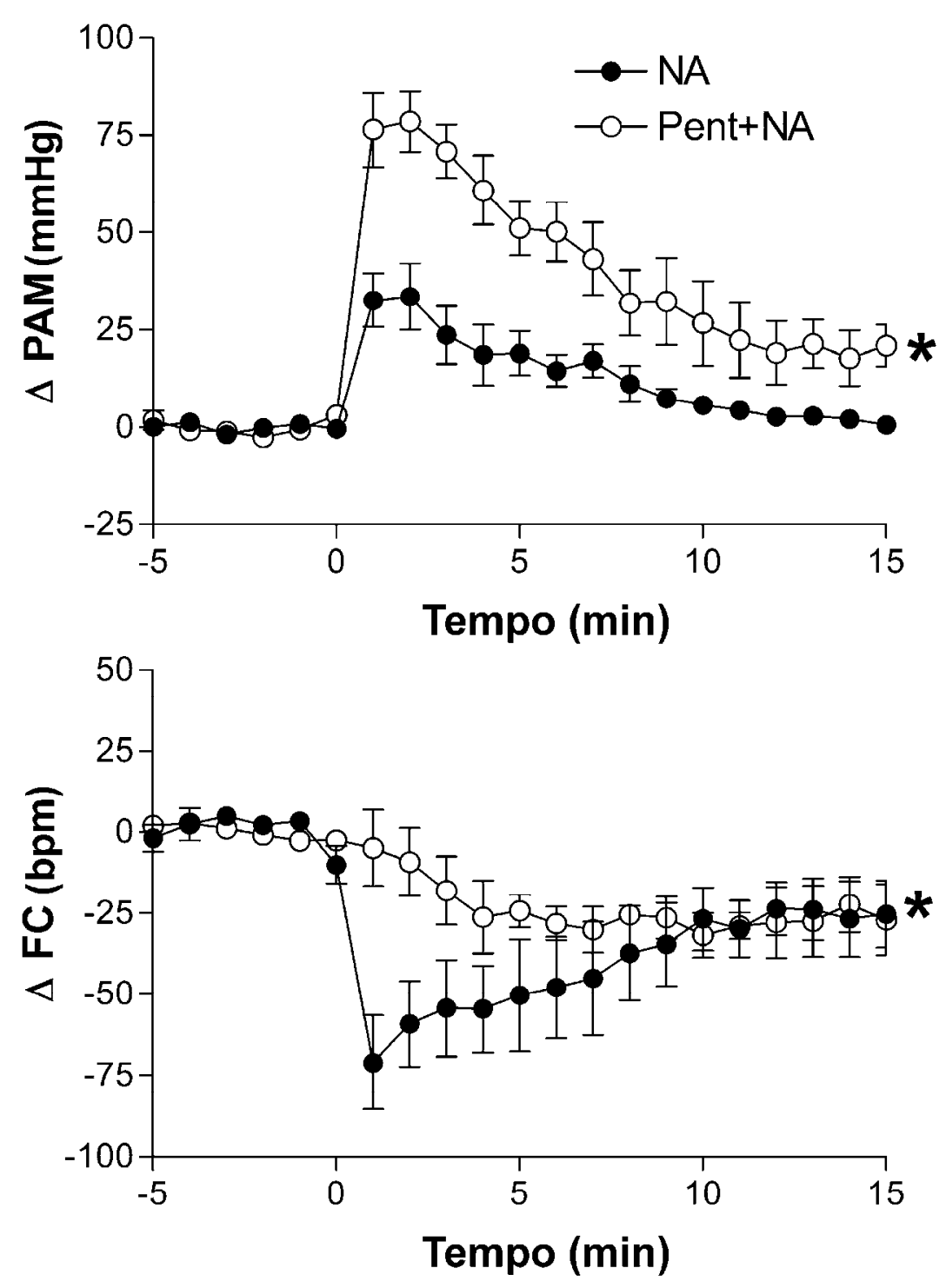

Figura 9. Curvas temporais mostrando as alterações na $\triangle P A M$ e $\triangle F C$ observadas pela microinjeção de NA $(27 \mathrm{nmol} / 100 \mathrm{~nL})$ no NMA antes e após o pré-tratamento intravenoso com pentolínio. As microinjeções foram feitas no tempo 0 . Pontos representam a média e as barras o E.P.M. Dados foram analisados utilizando o twoway ANOVA (variância de dois fatores) seguida pelo pós-teste de Bonferroni, * $p<0,05$. 

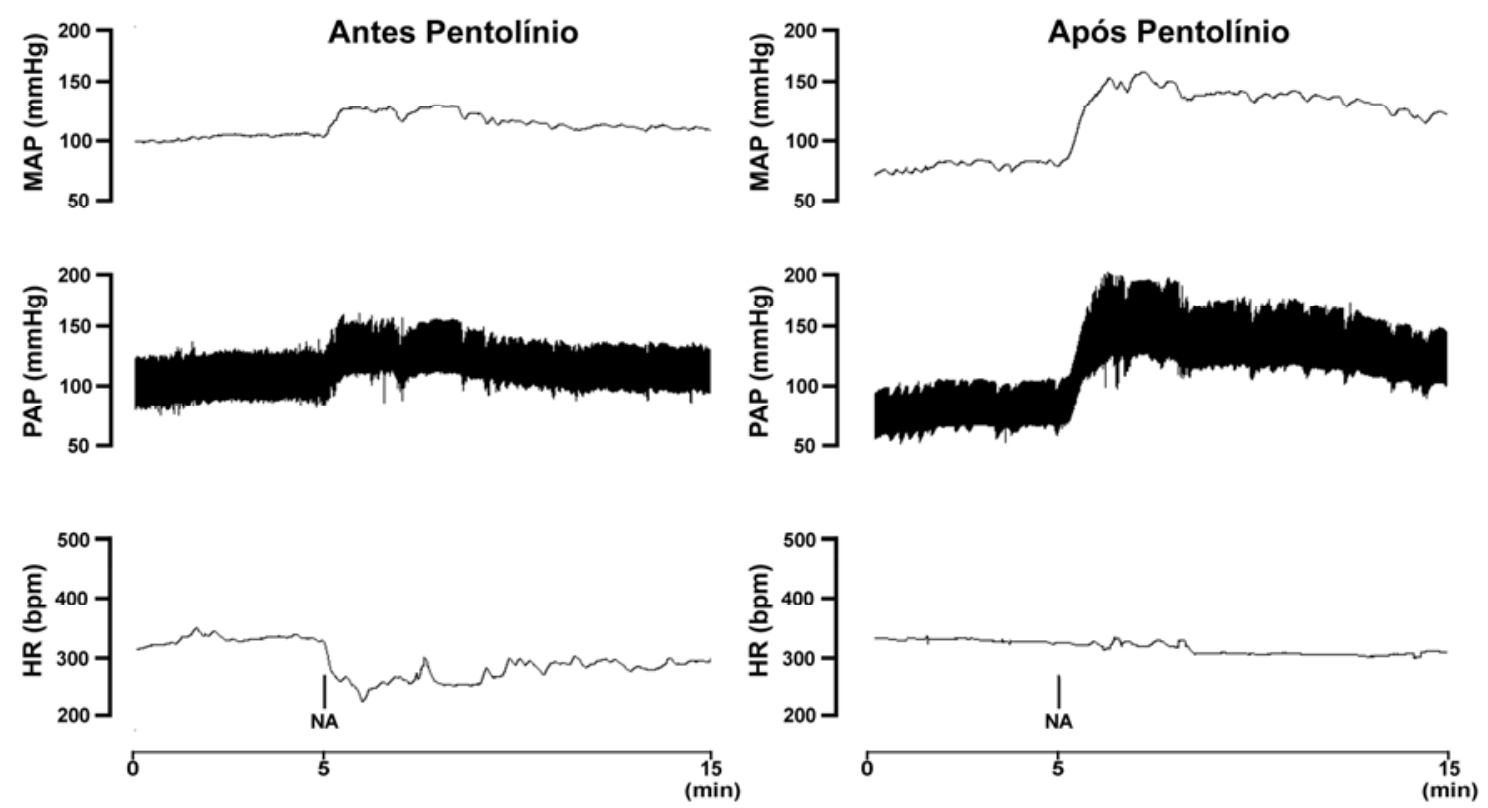

Figura 10. Registro representativo de pressão arterial média (PAM), pressão arterial pulsátil (PAP) e frequência cardíaca ( $F C$ ) de um animal representativo do grupo, mostrando o efeito da microinjeção de NA $(27 \mathrm{nmol} / 100 \mathrm{~nL})$ no NMA antes e após o pré-tratamento sistêmico com pentolínio. 
5) Efeito do pré-tratamento intravenoso com antagonista dos receptores V1 (dTyr(CH2)5MeAVP) sobre as respostas cardiovasculares causadas pela microinjeção de NA no NMA de ratos

O pré-tratamento com dTyr( $\mathrm{CH} 2) 5 \mathrm{MeAVP}$ não alterou a PAM basal $(\mathrm{PAM}=97$ $\pm 4 \mathrm{mmHg}$ vs $96 \pm 4 \mathrm{mmHg}, \mathrm{t}=0,45, \mathrm{P}>0,05, \mathrm{n}=5)$ ou a $\mathrm{FC}$ basal $(\mathrm{FC}=409 \pm 14$ bpm vs $406 \pm 14$ bpm, t= 1,5, P > 0,05, n=5). O pré-tratamento com o antagonista de vasopressina reduziu significativamente as respostas cardiovasculares causadas pela administração local de NA no NMA quando comparadas com aquelas respostas observadas antes do pré-tratamento com antagonista $\left(\triangle \mathrm{PAM}: \mathrm{F}_{5,48}=35.4, \mathrm{P}<\right.$ 0.0001; e $\Delta \mathrm{FC}: \mathrm{F}_{5,48}=17.6, \mathrm{P}=0.0001$ ), houve efeito significativo sobre o tempo $\left(\Delta\right.$ PAM: $F_{5,48}=8.6, P<0.0001 ;$ e $\left.F C: F_{5,48}=5.9, P>0.0001\right)$ e a interação entre o tratamento e o tempo (PAM: $F_{5,48}=5.6, P>0.0001$; e $\Delta F C: F_{5,48}=4.6, P>0.0001$ ), figura 11.

Figura 12 mostra um registro representativo de pressão arterial média, pressão arterial pulsátil e da frequência cardíaca de um animal representativo do grupo, que recebeu a microinjeção de NA no NMA (27nmol/100nL), antes e após o prétratamento sistêmico com dTyr(CH2)5MeAVP. 

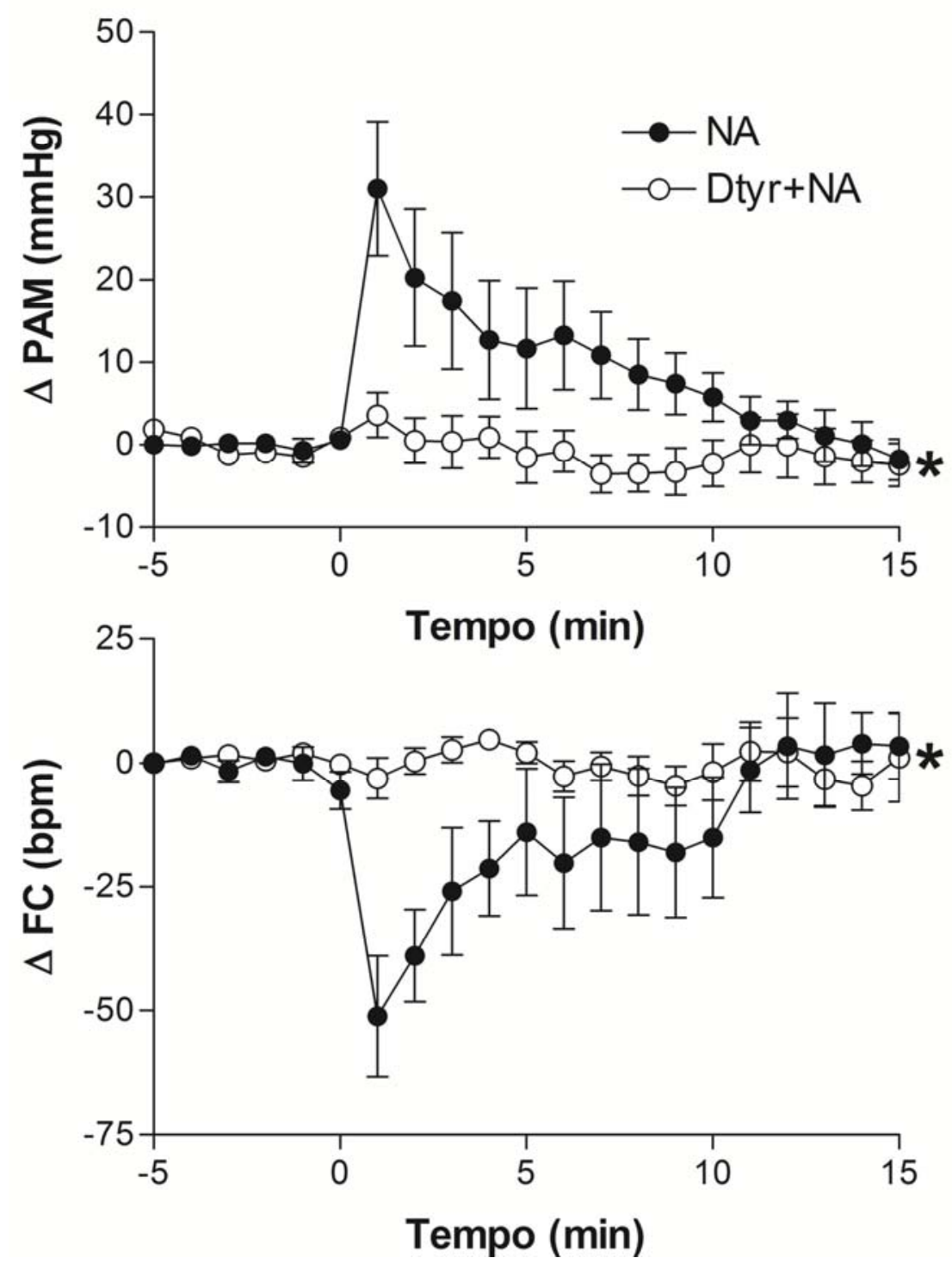

Figura 11. Curvas temporais mostrando as alterações na $\triangle P A M$ e $\triangle F C$ observadas pela microinjeção de NA $(27 \mathrm{nmol} / 100 \mathrm{~nL})$ no NMA antes e após o pré-tratamento intravenoso com dTyr $(\mathrm{CH} 2) 5 \mathrm{MeAVP}$. As microinjeções foram feitas no tempo 0. Pontos representam a média e as barras O E.P.M. Dados foram analisados utilizando o two-way ANOVA (variância de dois fatores) seguida pelo pós-teste de Bonferroni, ${ }^{*} p<0,05$. 

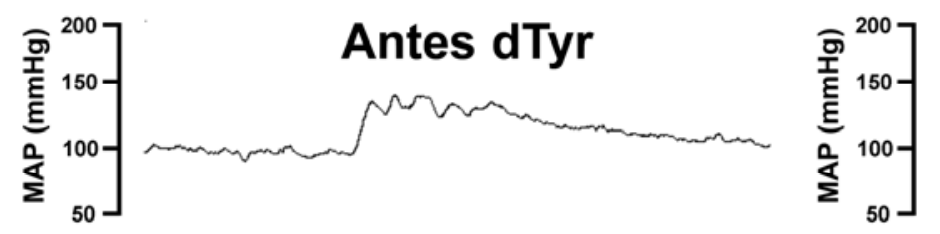

\section{Após dTyr}
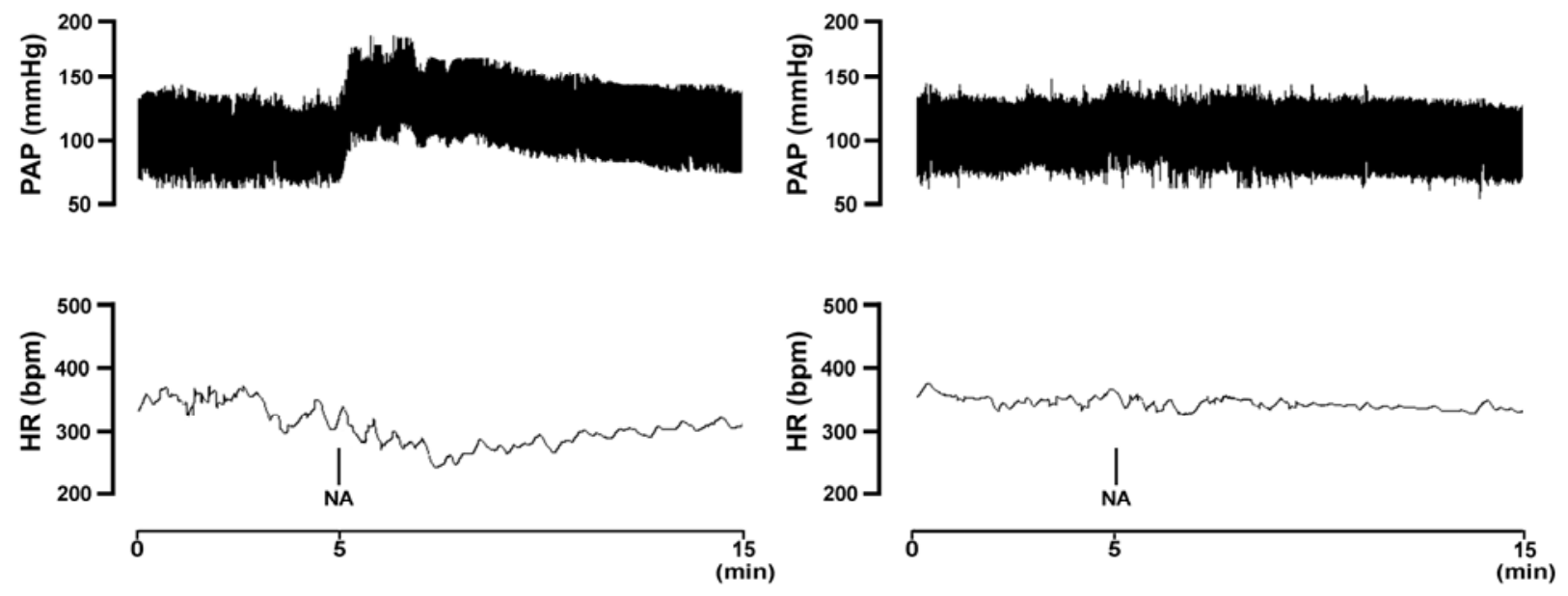

Figura 12. Registro representativo de pressão arterial média (PAM), pressão arterial pulsátil (PAP) e frequência cardíaca ( $F C$ ) de um animal representativo do grupo, mostrando o efeito da microinjeção de NA $(27 \mathrm{nmol} / 100 \mathrm{~nL})$ no NMA antes e após o pré-tratamento sistêmico com dTyr(CH2)5MeAVP. 
6) Efeito do pré-tratamento do NPV com um inibidor sináptico sobre as respostas cardiovasculares causadas pela microinjeção de NA no NMA de ratos

A microinjeção de $100 n L$ de LCA no NPV não causou alteração nos valores basais de $\mathrm{PAM}$ e FC $(\mathrm{PAM}=93 \pm 6$ vs $97 \pm 3 \mathrm{mmHg} ; \mathrm{t}=0.8157, \mathrm{P}>0.05, \mathrm{n}=6$ e $\mathrm{FC}=$ $331 \pm 18$ vs $333 \pm 14 \mathrm{bpm} ; \mathrm{t}=0.07503, \mathrm{P}>0.05, \mathrm{n}=6)$. Ainda, a microinjeção de cloreto de cobalto $\left(\mathrm{CoCl}_{2} 1 \mathrm{mM} / 100 \mathrm{~nL}\right)$ no NPV não causou alteração nos valores basais de PAM e FC $(\mathrm{PAM}=98 \pm 3$ vs $99 \pm 3 \mathrm{mmHg} ; \mathrm{t}=0.1468, \mathrm{P}>0.05, \mathrm{n}=6$ e FC= $370 \pm 12$ vs $358 \pm 16$ bpm; t= 0.5734, $\mathrm{P}>0.05, \mathrm{n}=6)$. Entretanto o pré-tratamento do NPV com $\mathrm{CoCl}_{2}$ reduziu significativamente a resposta pressora ( $\triangle \mathrm{PAM}$ Interação: $\mathrm{F}=$ 7762, $\mathrm{P}<0.0001$; Tratamento: $\mathrm{F}=216.6, \mathrm{P}<0.0001$; Tempo: $\mathrm{F}=13.49, \mathrm{P}<0.0001$ ) e bradicárdica $(\triangle \mathrm{FC}$ Interação: $\mathrm{F}=2763, \mathrm{P}=0.0004$; Tratamento: $\mathrm{F}=78.06, \mathrm{P}<$ 0.0001; Tempo: $F=8019, P<0.0001)$ evocadas pela microinjeção de NA no NMA quando comparados com os animais tratados com veículo (LCA) no NPV, figura 13.

Registros representativos de pressão arterial pulsátil, pressão arterial média e frequência cardíaca estão representados na figura 14, mostrando o efeito da microinjeção de NA no NMA antes e após o pré-tratamento com $\operatorname{LCA}$ ou $\mathrm{CoCl}_{2}$ no NPV. As fotomicrografias dos sítios de microinjeção de NA na NMA e de $\mathrm{CoCl}_{2}$ no NPV estão representadas na figura 15. 

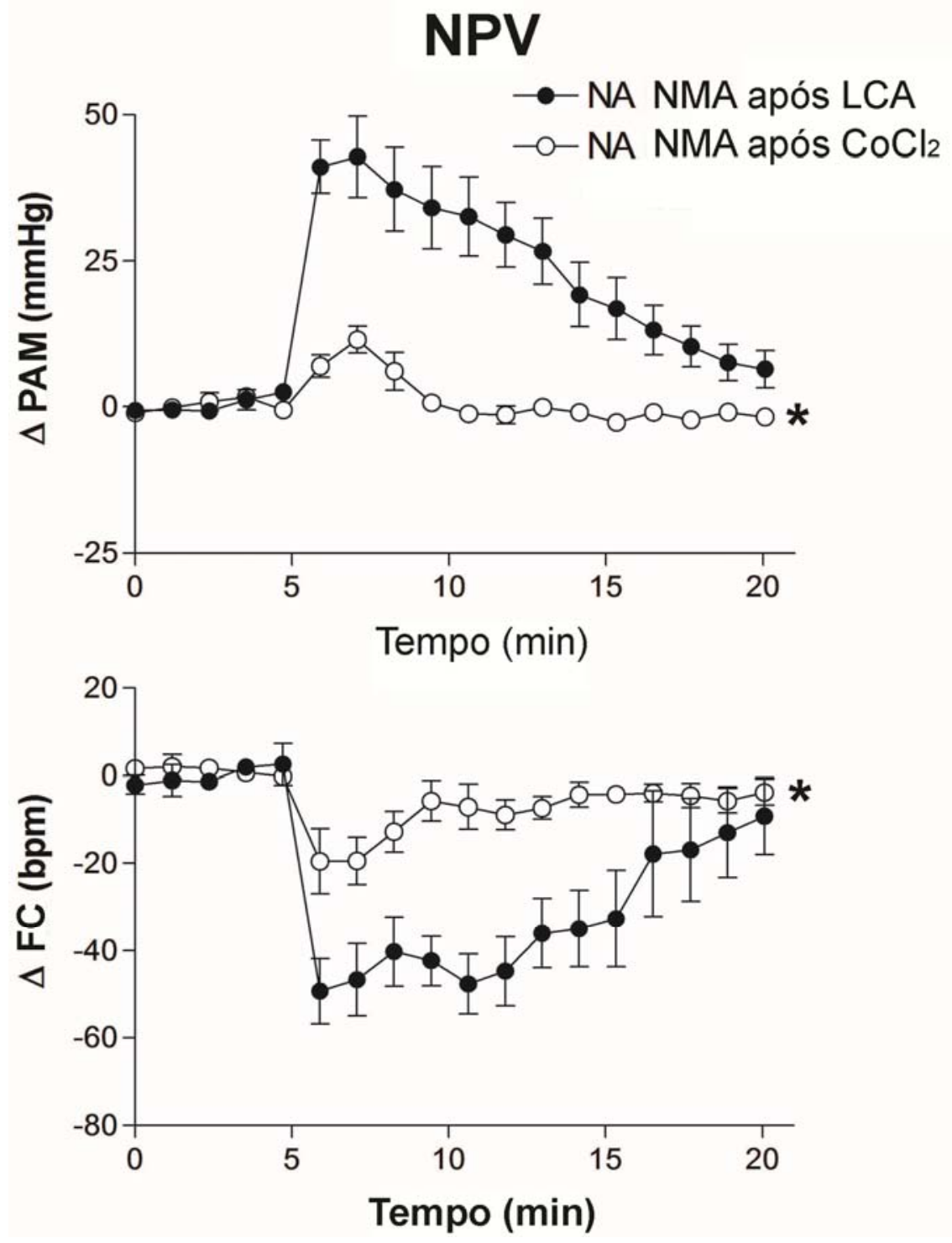

Figura 13. Curvas temporais mostrando as alterações na $\triangle P A M$ e $\triangle F C$ observadas pela microinjeção de NA $(27 \mathrm{nmol} / 100 \mathrm{~nL})$ no NMA após o pré-tratamento com LCA ou $\mathrm{CoCl}_{2} 1 \mathrm{mM} / 100 \mathrm{~nL}$ no NPV de ratos $(n=6)$. Dados foram analisados utilizando o two-way ANOVA (variância de dois fatores) seguida pelo pós-teste de Bonferroni, * $p<0,05$. 


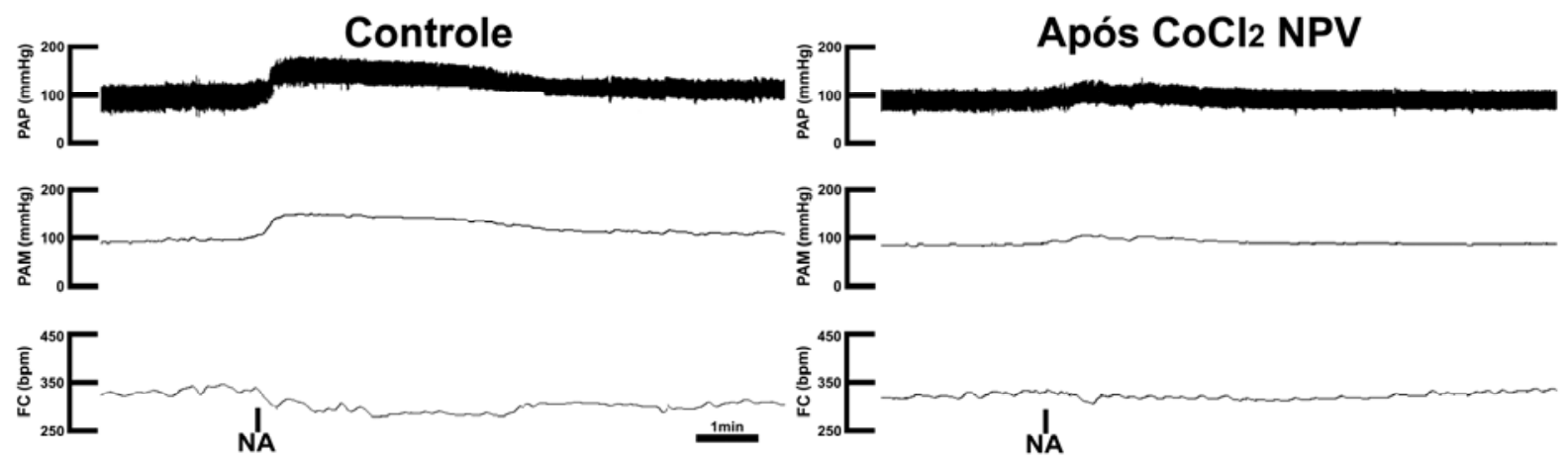

Figura 14. Registros representativos de pressão arterial média (PAM), pressão arterial pulsátil (PAP) e frequência cardíaca (FC) de um animal representativo do grupo, mostrando o efeito da microinjeção de NA (27nmol/100nL) no NMA após o pré-tratamento com LCA (controle) ou $\mathrm{CoCl}_{2}$ no NPV. 


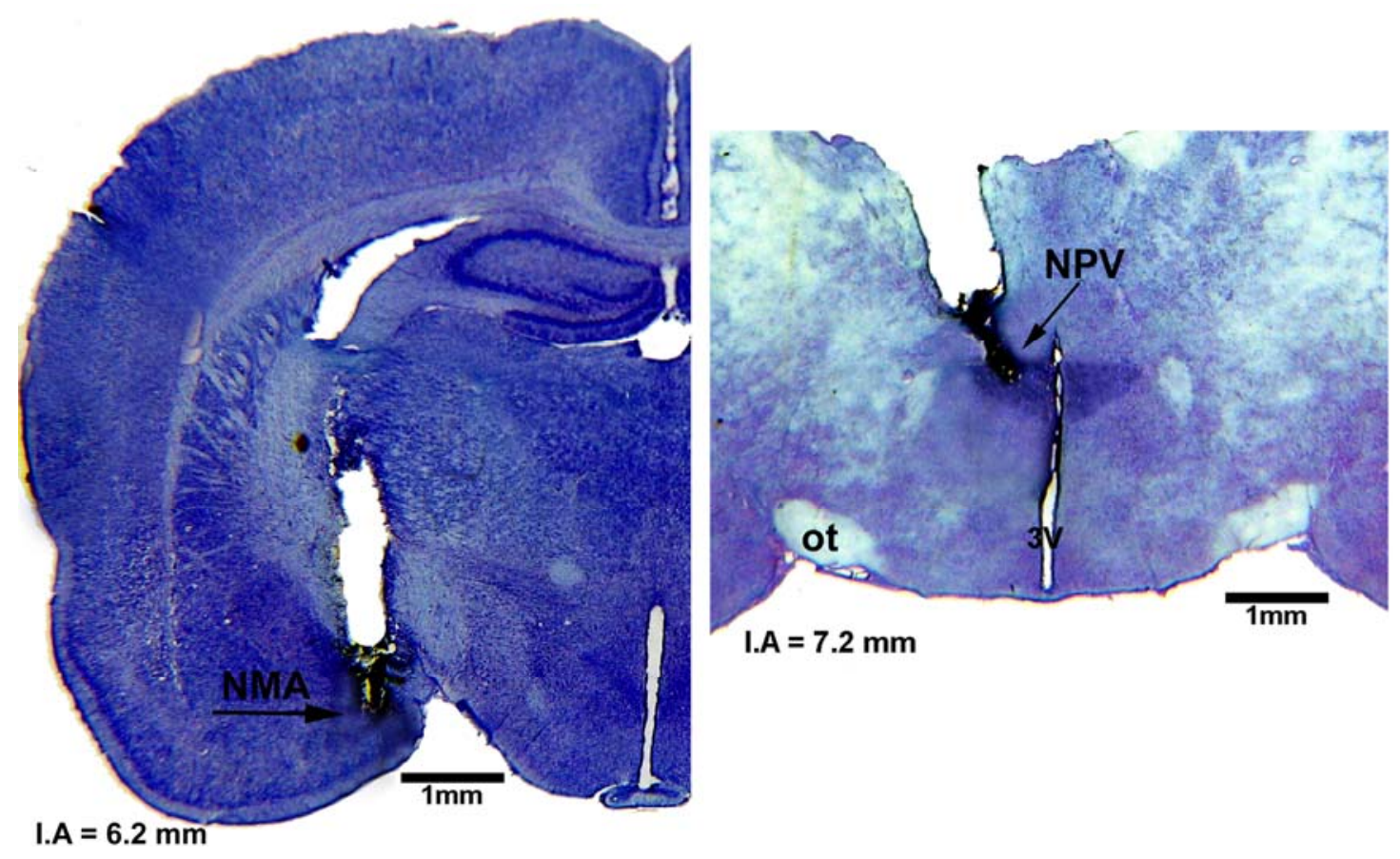

Figura 15. Fotomicrografias de cortes histológicos do cérebro de rato mostrando os locais da microinjeção de NA no NMA e $\mathrm{CoCl}_{2}$ no NPV. IA: interaural, NMA: núcleo medial da amígdala , NPV: núcleo paraventricular, ot: trato óptico. 
7) Efeito do pré-tratamento do NSO com um inibidor sináptico sobre as respostas cardiovasculares causadas pela microinjeção de NA no NMA de ratos

A microinjeção de $100 \mathrm{~nL}$ de veículo (LCA) no NSO não alterou os valores basais de PAM e FC (PAM = $96 \pm 2$ vs $98 \pm 2 \mathrm{mmHg} ; \mathrm{t}=0.5390, \mathrm{P}=0.6017, \mathrm{n}=6$ e a $\mathrm{FC}=358 \pm 8$ vs $366 \pm 6 \mathrm{bpm} ; \mathrm{t}=0.7637, \mathrm{P}=0.4627, \mathrm{n}=6)$. Além disso, $\mathrm{a}$ microinjeção de cloreto de cobalto $\left(\mathrm{CoCl}_{2} 1 \mathrm{nM} / 100 \mathrm{~nL}\right)$ no NSO não causou alteração nos valores basais de PAM e FC $(\mathrm{PAM}=95 \pm 2$ vs $100 \pm 1 \mathrm{mmHg} ; \mathrm{t}=2.000, \mathrm{P}=$ 0.0734, $\mathrm{n}=6$ e $F C=361 \pm 19$ vs $350 \pm 15$ bpm; $t=0.4849, P=0.6382, n=6)$. Entretanto, o pré-tratamento do $\mathrm{NSO}$ com $\mathrm{CoCl}_{2}$ reduziu significativamente a respostas pressora e bradicárdica evocada pela microinjeção de NA no NMA ( $\triangle \mathrm{PAM}$ Interação: $F=2879, P=0.0002 ;$ Tratamento: $F=70.39, P<0.0001$; Tempo: $F=$ 17.51, $\mathrm{P}<0.0001 ; \Delta \mathrm{FC}$ Interação: $\mathrm{F}=2603, \mathrm{P}=0.0009 ;$ Tratamento: $\mathrm{F}=70.67, \mathrm{P}<$ 0.0001; Tempo: $F=5471, P<0.0001)$, figura 16 .

Registros representativos de pressão arterial pulsátil, pressão arterial média e frequência cardíaca estão representados na figura 17, mostrando o efeito da microinjeção de NA no NMA antes e após o pré-tratamento do NSO com LCA ou $\mathrm{CoCl}_{2}$. As fotomicrografias dos sítios de microinjeção de $\mathrm{NA}$ na NMA e de $\mathrm{CoCl}_{2}$ no NSO estão representadas na figura 18. 

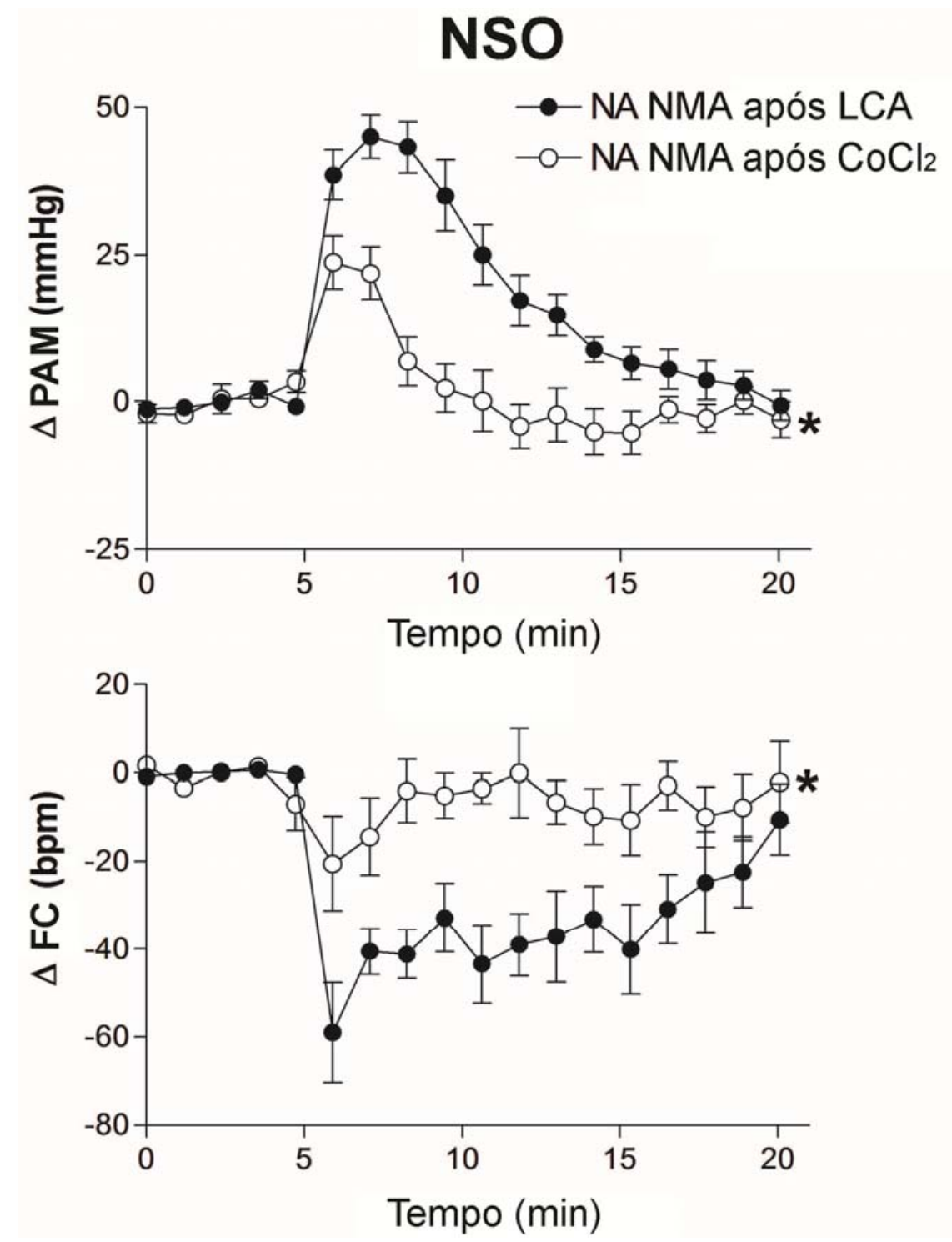

Figura 16. Curvas temporais mostrando as alterações na $\triangle P A M$ e $\triangle F C$ observadas pela microinjeção de NA (27nmol/100nL) no NMA após o pré-tratamento do NSO com LCA ou $\mathrm{CoCl}_{2}(1 \mathrm{mM} / 100 \mathrm{~nL})$ de ratos $(\mathrm{n}=6)$. Dados foram analisados utilizando 0 two-way ANOVA (variância de dois fatores) seguida pelo pós-teste de Bonferroni, * $p<0,05$. 


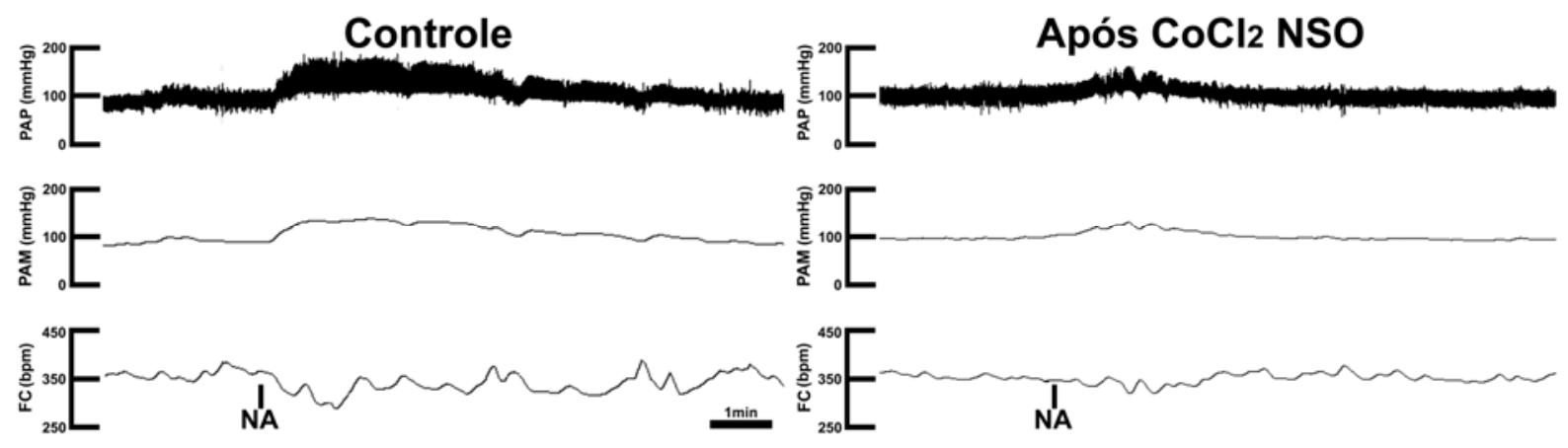

Figura 17. Registro representativo de pressão arterial pulsátil (PAP), pressão arterial média (PAM) e frequência cardíaca (FC) de um animal representativo do grupo, mostrando o efeito da microinjeção de NA $(27 \mathrm{nmol} / 100 \mathrm{~nL})$ no NMA após o prétratamento do NSO com LCA ou $\mathrm{CoCl}_{2}$. 


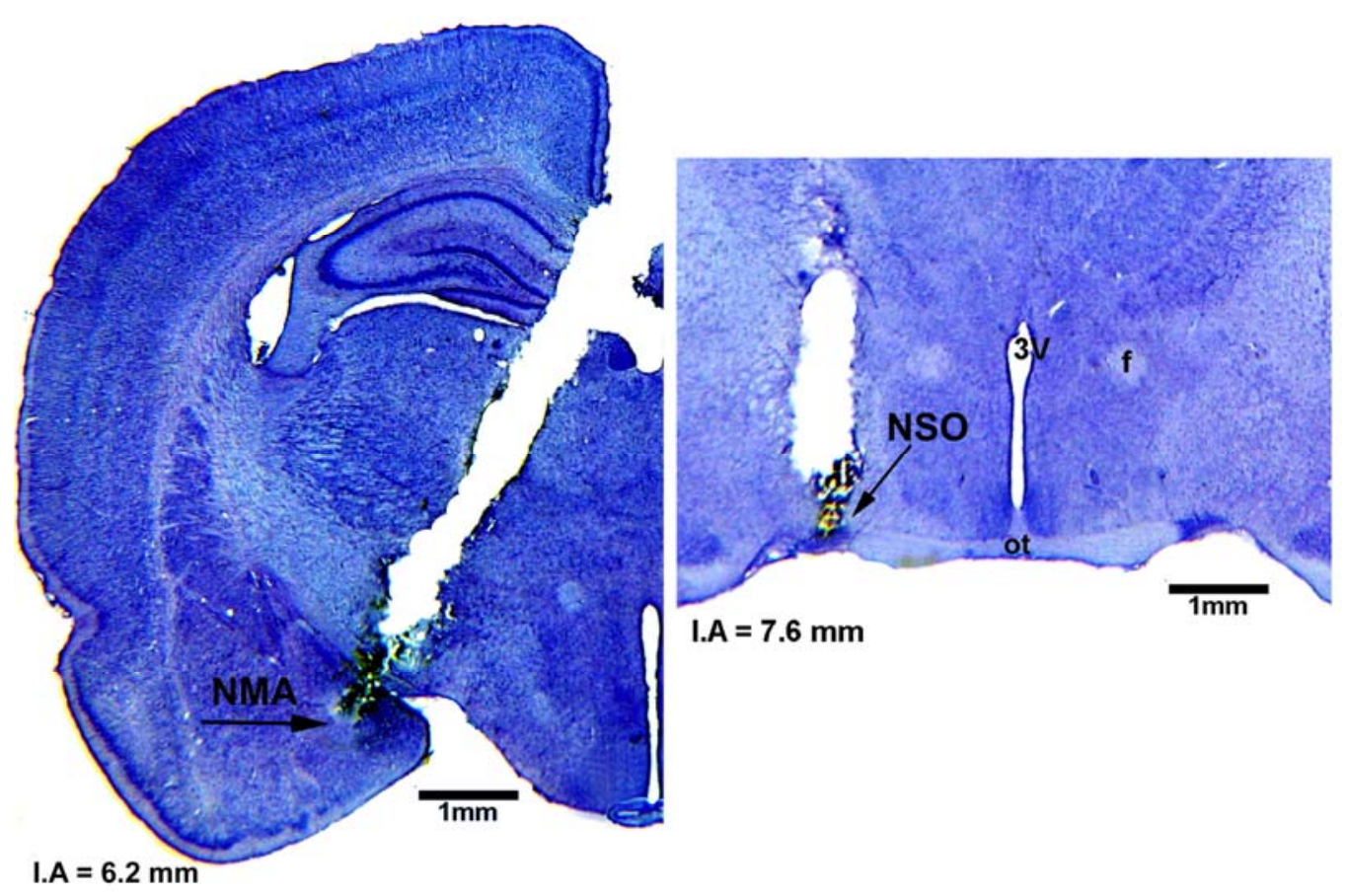

Figura 18. Fotomicrografias de cortes histológicos do cérebro de ratos mostrando os locais da microinjeção de NA no NMA ou LCA (controle) e $\mathrm{CoCl}_{2}$ no NSO. IA: interaural, NMA: núcleo medial da amígdala, NSO: núcleo supraóptico, ot: trato óptico, 3V: terceiro ventrículo, f: fórnix. 


\section{8) Efeito da microinjeção de diferentes doses de antagonista $\alpha_{1}$-adrenérgico no} MNA sobre as respostas cardiovasculares ao ER

A microinjeção bilateral de doses crescentes de WB4101, antagonista seletivo dos receptores $\alpha_{1}$-adrenérgicos $(10,15$, e 20 nmol/100nL) ( $n=5,5$ e 7 , respectivamente, para cada dose utilizada) no NMA, não afetou os valores basais de PAM ou FC, (tabela 1 e 2). Entretanto, o tratamento do NMA com as diferentes doses de WB4101, causou uma redução dose-dependente na resposta taquicárdica $(r 2=0.30, d f=23, P<0.05)$ sem causar alterações na resposta pressora $(r 2=0,003$, $d f=23, P=0,77)$ causada pelo $E R$ (Figura 19). A figura 20 mostra as curvas temporais geradas a partir das respostas cardiovasculares durante o ER, nas diferentes doses do WB4101 microinjetado no NMA.

Diagramas modificados do atlas do cérebro de rato (PAXINOS e WATSON, 1997), indicando a dispersão dos sítios de microinjeção das diferentes doses de WB4101 (10, 15 e 20nmol) e LCA no NMA estão apresentados na figura 21 A. Uma fotomicrografia de uma secção coronal do cérebro de um rato mostrando sítios bilaterais de microinjeção no NMA está apresentada na figura 21 B.

Registros representativos de um rato do grupo tratado com veículo (LCA) e de um rato tratado com a microinjeção bilateral de WB4101 na dose de $15 \mathrm{nmol}$ mostrando os efeitos sobre as alterações cardiovasculares decorrentes ao ER estão apresentados na figura 22. 
Tabela 1 - Valores basais de pressão arterial média (PAM), antes e após a microinjeção de doses crescentes de WB4101, antagonista receptores $\alpha_{1}$ adrenérgicos no NMA de ratos.

\begin{tabular}{|c|c|c|c|c|}
\hline $\begin{array}{c}\text { WB4101 } \\
\text { (nmol/100nL) }\end{array}$ & $\begin{array}{c}\text { Antes } \\
\text { (PAM) }\end{array}$ & $\begin{array}{c}\text { Após } \\
\text { (PAM) } \pm \text { EPM }\end{array}$ & $\mathbf{t}=$ & $\begin{array}{c}\mathbf{n}= \\
\text { (amostra) }\end{array}$ \\
\hline $\mathbf{0}$ & $96 \pm 4 \mathrm{mmHg}$ & $94 \pm 3 \mathrm{mmHg}$ & 0.26 & 8 \\
\hline $\mathbf{1 0}$ & $101 \pm 4 \mathrm{mmHg}$ & $100 \pm 6 \mathrm{mmHg}$ & 0.02 & 5 \\
\hline $\mathbf{1 5}$ & $86 \pm 1 \mathrm{mmHg}$ & $88 \pm 1 \mathrm{mmHg}$ & 0.77 & 5 \\
\hline $\mathbf{2 0}$ & $91 \pm 1 \mathrm{mmHg}$ & $87 \pm 2 \mathrm{mmHg}$ & 1.26 & 7 \\
\hline
\end{tabular}

Tabela 2 - Valores basais de frequência cardíaca (FC), antes e após a microinjeção de doses crescentes de WB4101, antagonista dos receptores $\alpha_{1}$-adrenérgico no NMA de ratos.

\begin{tabular}{|c|c|c|c|c|}
\hline $\begin{array}{c}\text { WB4101 } \\
\text { (nmol/100nL) }\end{array}$ & $\begin{array}{c}\text { Antes } \\
\text { (FC) } \pm E P M\end{array}$ & 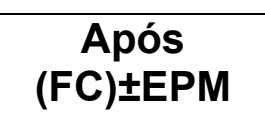 & $t=$ & $\begin{array}{c}n= \\
\text { (amostra) }\end{array}$ \\
\hline 0 & $366 \pm 8 b p m$ & $358 \pm 5 b p m$ & 0.82 & 8 \\
\hline 10 & $330 \pm 16 b p m$ & $334 \pm 8 b p m$ & 0.21 & 5 \\
\hline 15 & $361 \pm 13 \mathrm{bpm}$ & $370 \pm 10 \mathrm{bpm}$ & 0.55 & 5 \\
\hline 20 & $370 \pm 7 \mathrm{bpm}$ & $375 \pm 5 b p m$ & 0.57 & 7 \\
\hline
\end{tabular}



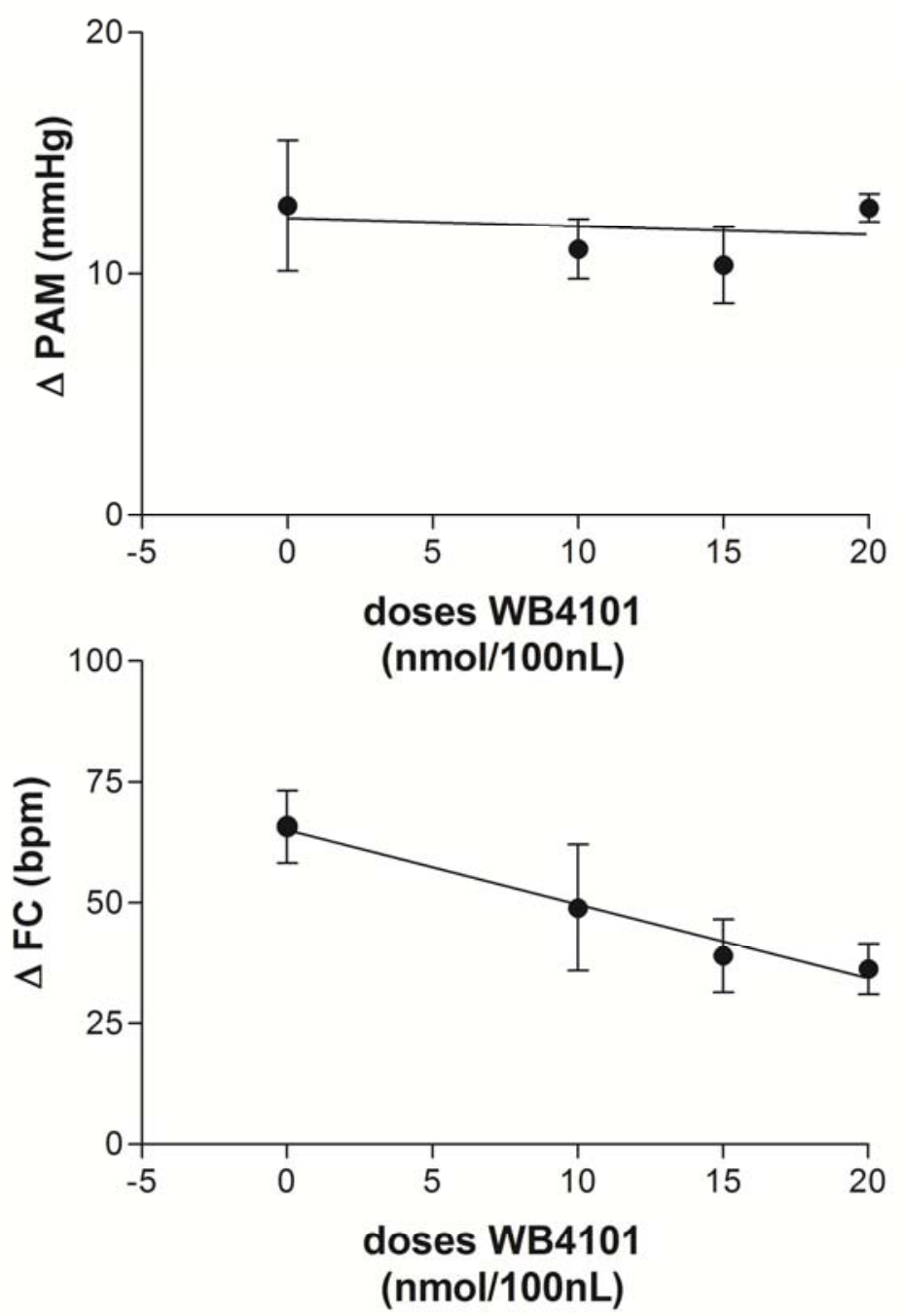

Figura 19. Curvas de regressão linear mostrando a inibição da resposta taquicárdica causada pelo ER decorrente da microinjeção bilateral de diferentes doses de WB4101 (10, 15 e 20nmol/100nL) no NMA de ratos. Círculos representam as média e as barras o E.P.M. 

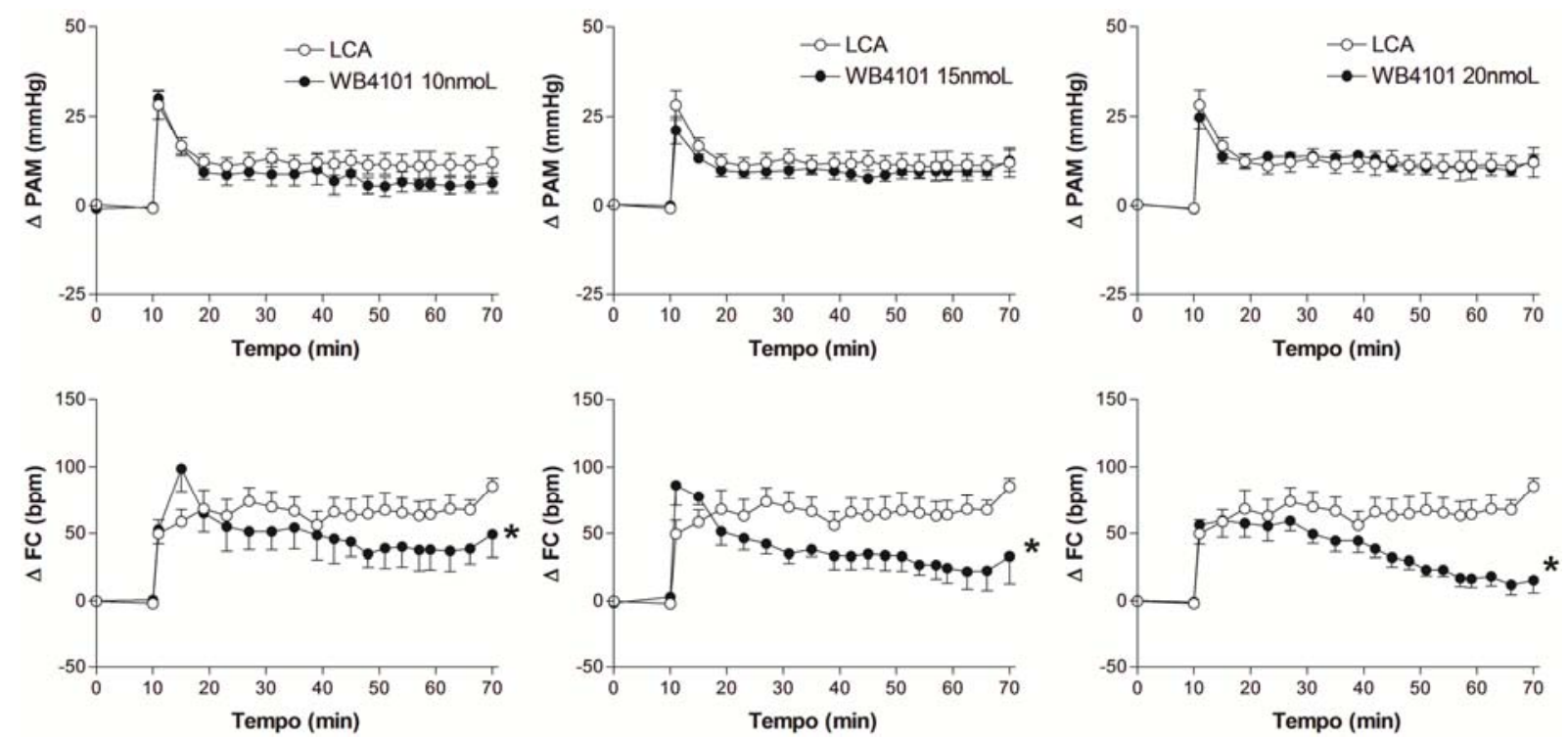

Figura 20. Curvas temporais mostrando as alterações na $\triangle P A M$ e $\triangle F C$ observadas durante o ER em animais tratados bilateralmente com 100nL LCA $(n=8)$ ou WB4101 em diferentes doses (10, 15 e 20nmol; $n=5,5$ e 7 respectivamente). Dados foram analisados utilizando o two-way ANOVA (variância de dois fatores) seguida pelo pós-teste de Bonferroni, * $p<0,05$. 
A)
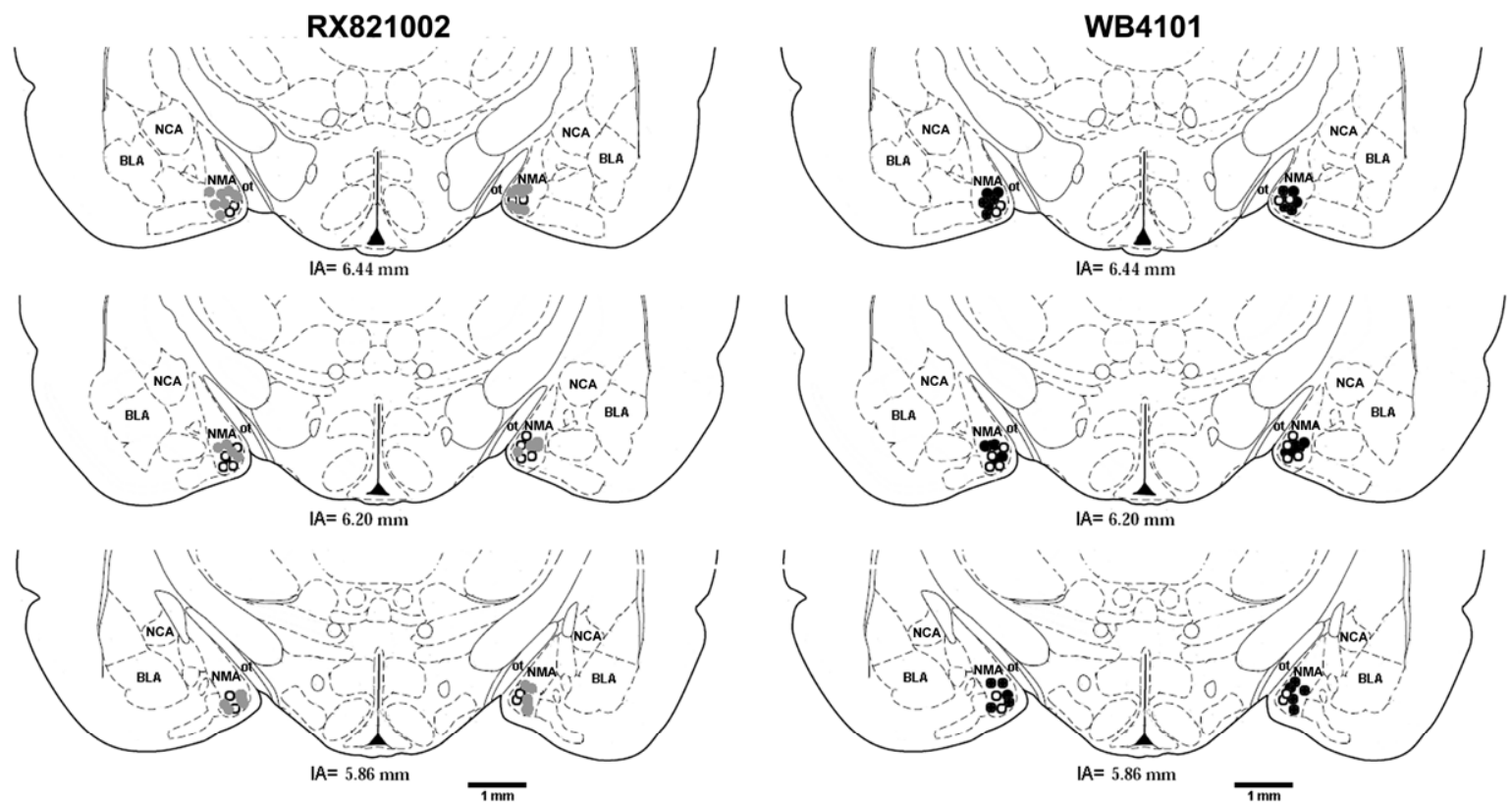

B)

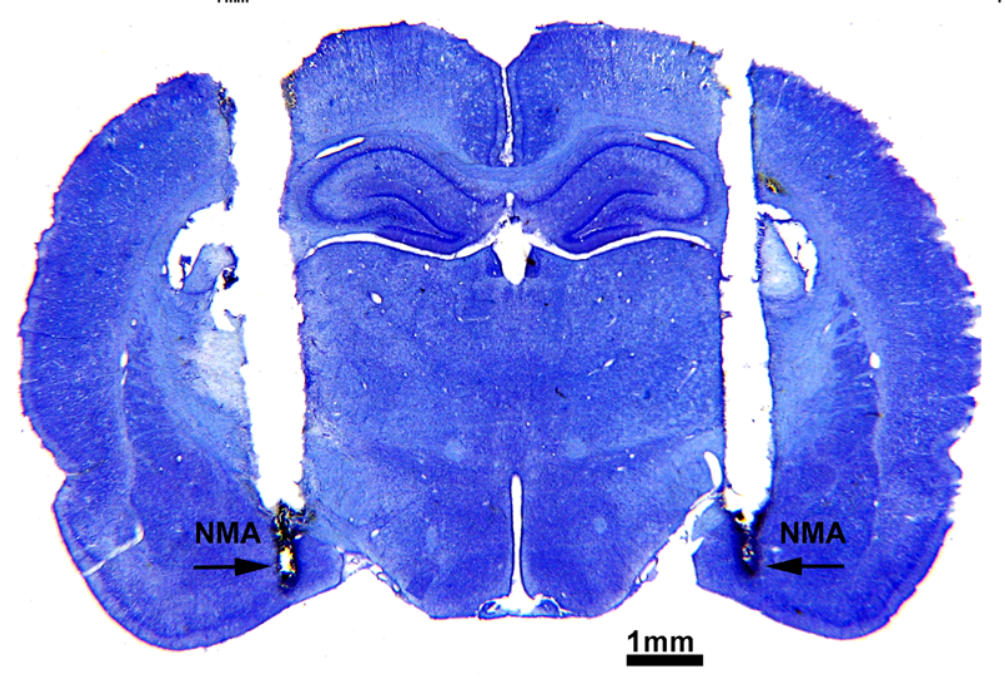

Figura 21. A) Diagramas modificados do atlas do cérebro de rato (PAXINOS e WATSON, 1997), indicando a dispersão dos sítios de microinjeção das diferentes doses de RX821002 (círculos cinzas) e WB4101 (círculos pretos) ambos com LCA (círculos brancos) no núcleo medial da amígdala (NMA), IA - interaural; NCA - núcleo central da amígdala. BLA - núcleo basolateral da amígdala. ot - trato óptico. B) Fotomicrografia de corte histológico do cérebro de rato mostrando o sítio da microinjeção de drogas no NMA, indicado pela seta. 

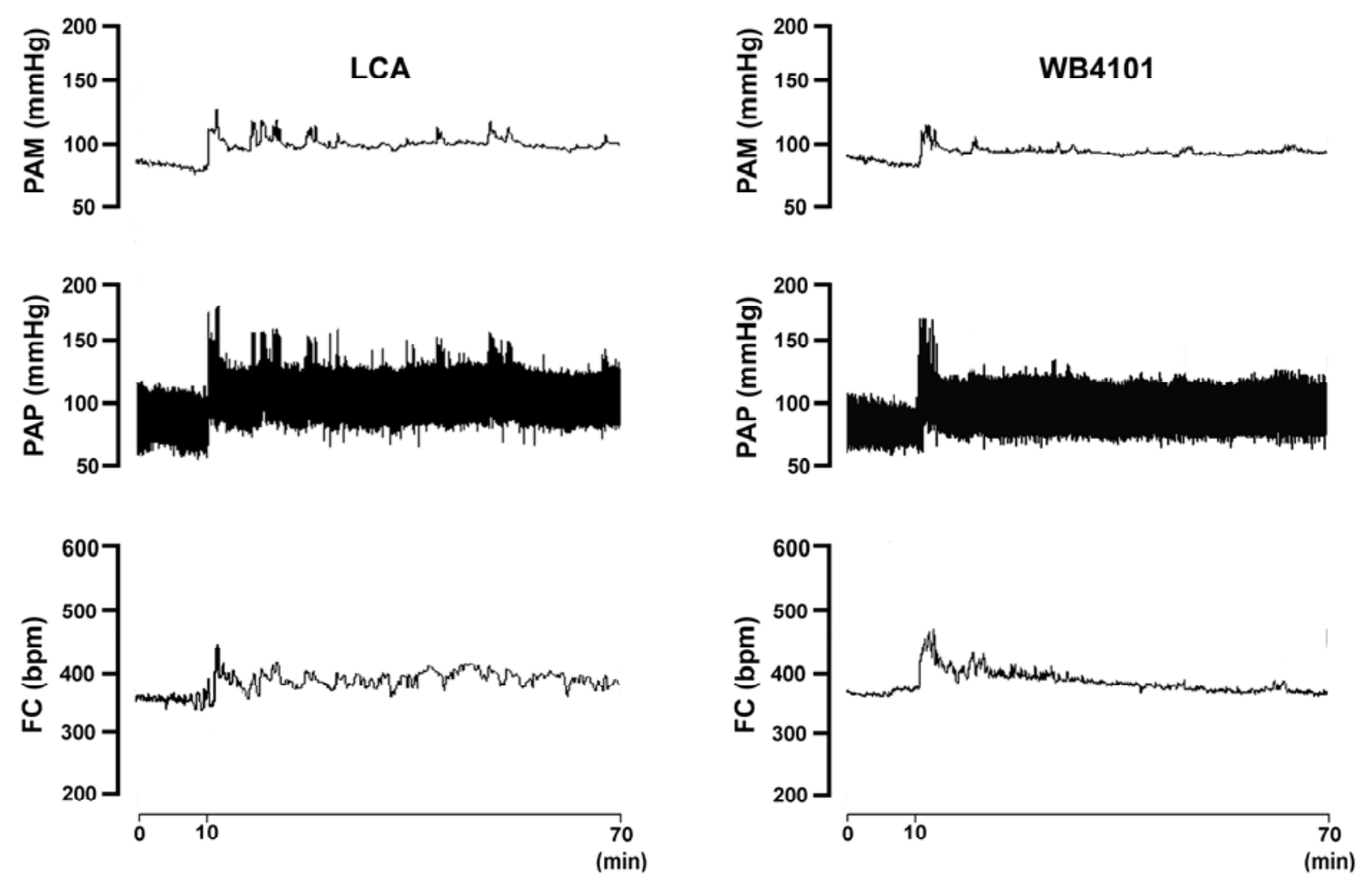

Figura 22. Registros representativos de um rato do grupo tratado com microinjeção bilateral de veículo (LCA) e de um rato tratado com WB4101 (15nmol/100nL) no NMA, e submetidos ao ER, mostrando as alterações na pressão arterial média (PAM), pressão arterial pulsátil (PAP) e frequência cardíaca (FC) observadas durante o período de 60 min de restrição. $O$ inicio da restrição ocorreu em t=10 min. 


\section{9) Efeito da microinjeção de diferentes doses de antagonista dos receptores $\alpha_{2}$-adrenérgico no MNA sobre as respostas cardiovasculares ao ER}

A microinjeção bilateral de doses crescentes de RX821002 (antagonista dos receptores $\alpha_{2}$-adrenérgicos) (10, 15, e $20 \mathrm{nmol} / 100 \mathrm{~nL}, \mathrm{n}=6,5$,6 respectivamente para cada dose utilizada) no NMA, não afetou os valores basais de PAM ou FC, (tabela 3 e 4). Entretanto, o tratamento do NMA com essas diferentes doses de RX821002, causou um aumento dose-dependente na resposta taquicárdica ( $r 2=$ $0,37, d f=23, P<0.05)$ sem causar alterações na resposta pressora $(r 2=0,001, d f=$ $23, P>0.05)$ causada pelo ER, figura 23. A figura 24 mostra as curvas temporais geradas a partir das respostas cardiovasculares durante o ER, nas diferentes doses do RX821002 microinjetadas no NMA.

Diagramas modificados do atlas do cérebro de rato (PAXINOS e WATSON, 1997), indicando a dispersão dos sítios de microinjeção das diferentes doses de RX821002 e veículo (LCA) no NMA estão apresentados na Figura 21 A.

Registros representativos de um rato do grupo tratado com LCA e de um rato tratado com a microinjeção bilateral de RX821002 na dose de 15 nmol mostrando os efeitos sobre as alterações cardiovasculares decorrentes ao ER estão apresentados na figura 25. 
Tabela 3 - Valores basais de pressão arterial média (PAM), antes e após a microinjeção de doses crescentes de RX821002, antagonista seletivo de $\alpha_{2-}$ adrenoceptores no NMA de ratos.

\begin{tabular}{|c|c|c|c|c|}
\hline $\begin{array}{c}\text { RX821002 } \\
\text { (nmol/100nL) }\end{array}$ & $\begin{array}{c}\text { Antes } \\
\text { (PAM) } \pm \text { EPM }\end{array}$ & $\begin{array}{c}\text { Após } \\
\text { (PAM) } \pm \text { EPM }\end{array}$ & $\mathbf{t}=$ & $\begin{array}{c}n= \\
\text { (amostra) }\end{array}$ \\
\hline 0 & $96 \pm 4 \mathrm{mmHg}$ & $94 \pm 3 \mathrm{mmHg}$ & 0.26 & 8 \\
\hline 10 & $104 \pm 3 \mathrm{mmHg}$ & $101 \pm 4 \mathrm{mmHg}$ & 0.48 & 6 \\
\hline 15 & $93 \pm 3 \mathrm{mmHg}$ & $92 \pm 5 \mathrm{mmHg}$ & 0.17 & 5 \\
\hline 20 & $87 \pm 4 \mathrm{mmHg}$ & $90 \pm 5 \mathrm{mmHg}$ & 0.53 & 6 \\
\hline
\end{tabular}

Tabela 4 - Valores basais de frequência cardíaca (FC), antes e após a microinjeção de doses crescentes de RX821002, antagonista seletivo de $\alpha_{2}$-adrenoceptores no NMA de ratos.

\begin{tabular}{|c|c|c|c|c|}
\hline $\begin{array}{c}\text { RX821002 } \\
\text { (nmol/100nL) }\end{array}$ & $\begin{array}{c}\text { Antes } \\
\text { (FC) } \pm E P M\end{array}$ & 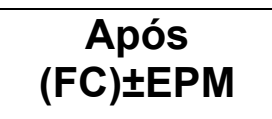 & $\mathbf{t}=$ & $\begin{array}{c}n= \\
\text { (amostra) }\end{array}$ \\
\hline 0 & $366 \pm 8 b p m$ & $358 \pm 5 b p m$ & 0.82 & 8 \\
\hline 10 & $356 \pm 7 \mathrm{bpm}$ & $355 \pm 8 b p m$ & 0.12 & 6 \\
\hline 15 & $351 \pm 8 b p m$ & $363 \pm 11 \mathrm{bpm}$ & 0.81 & 5 \\
\hline 20 & $355 \pm 9 b p m$ & $367 \pm 7 \mathrm{bpm}$ & 0.98 & 6 \\
\hline
\end{tabular}



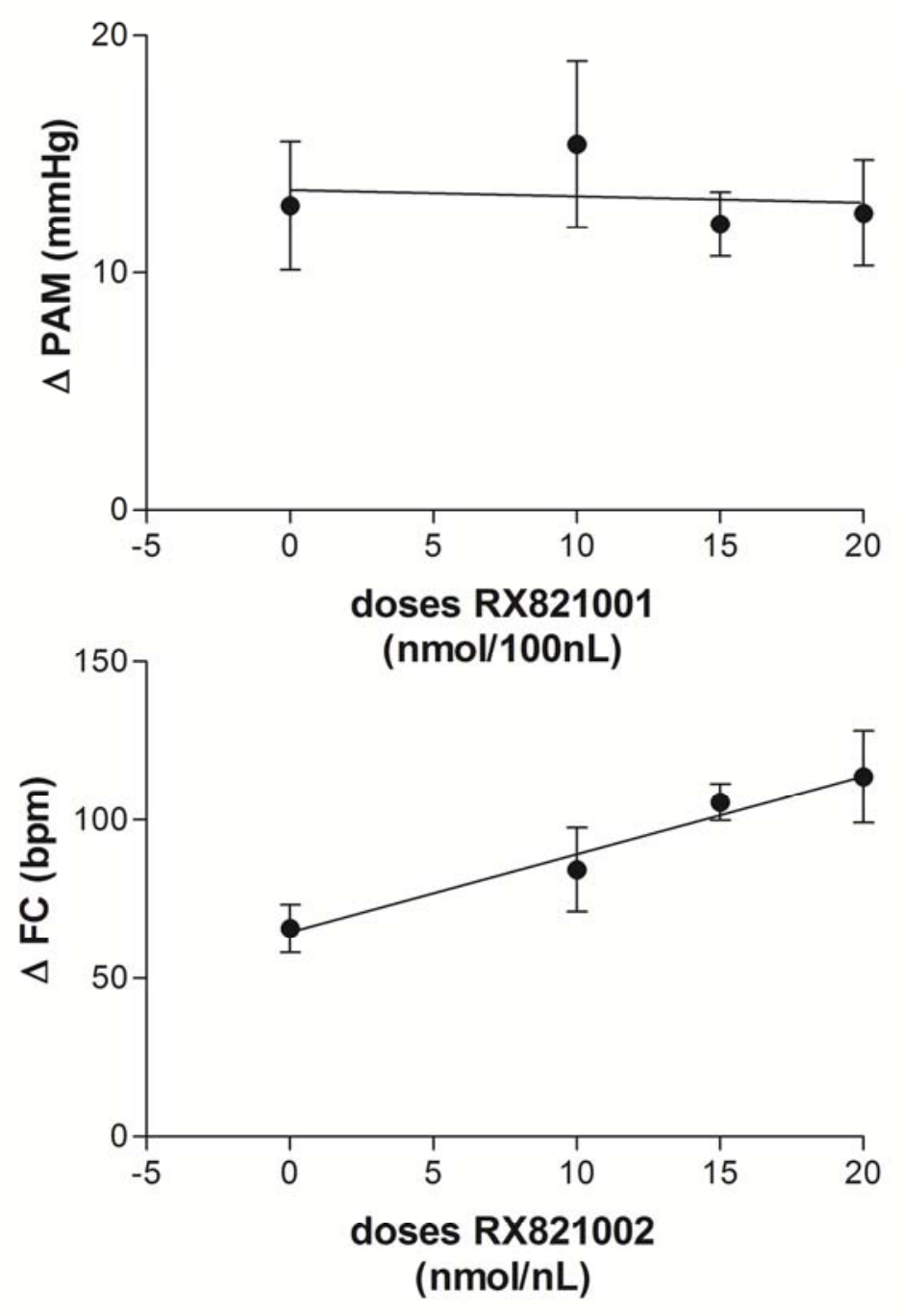

Figura 23. Curvas de regressão linear mostrando 0 aumento da resposta taquicárdica causadas pelo ER após a microinjeção bilateral de diferentes doses de $\mathrm{RX821002}(10,15$ e 20nmol/100nL) no NMA de ratos. Círculos representam à média e as barras o E.P.M. 

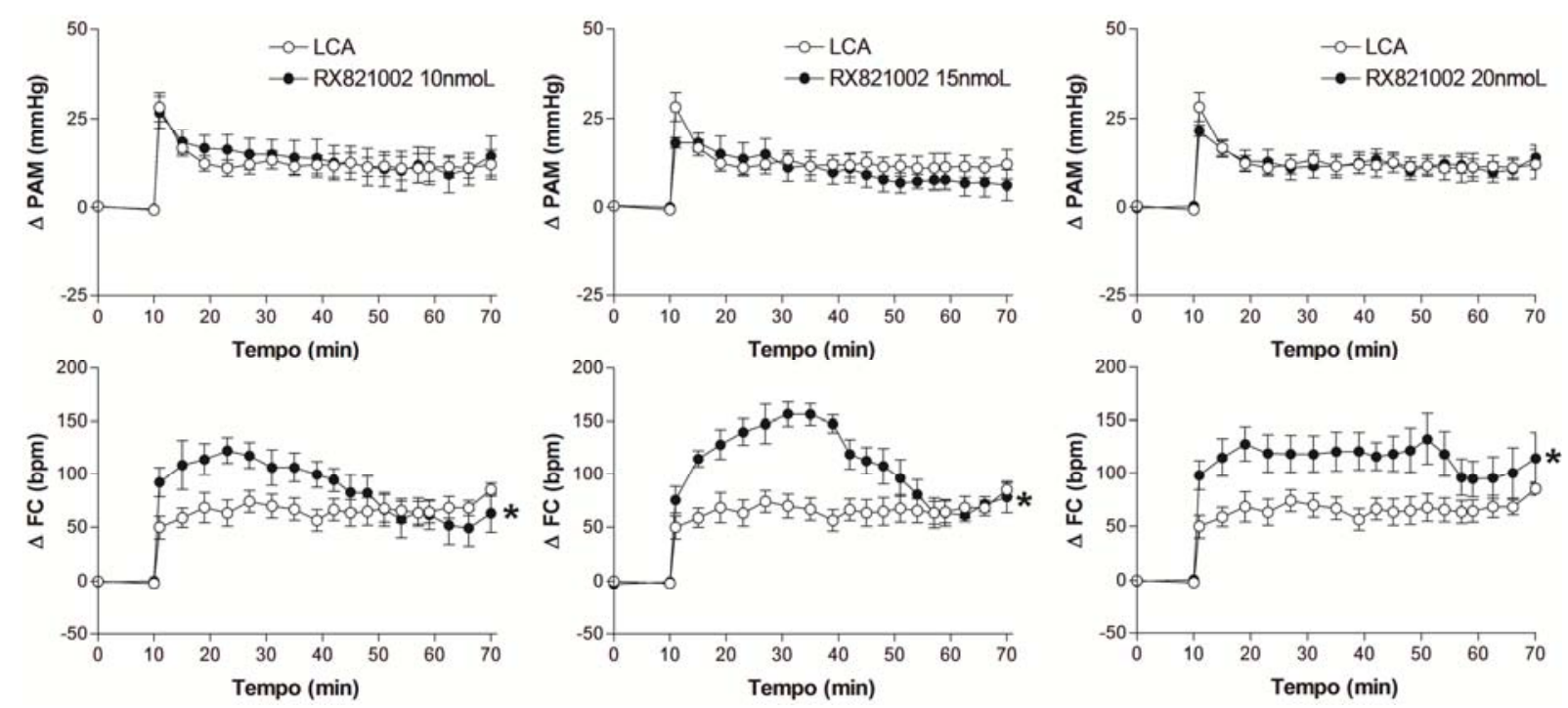

Figura 24. Curvas temporais mostrando as alterações na $\triangle P A M$ e $\triangle F C$ observadas durante o ER em animais tratados bilateralmente com $100 \mathrm{~nL}$ de veículo $(\mathrm{LCA}, \mathrm{n}=8)$ ou RX821002 em diferentes doses (10, 15 e 20nmol; $n=6,5$ e 6 respectivamente). Dados foram analisados utilizando o two-way ANOVA (variância de dois fatores) seguida pelo pós-teste de Bonferroni, ${ }^{*} p<0,05$. 

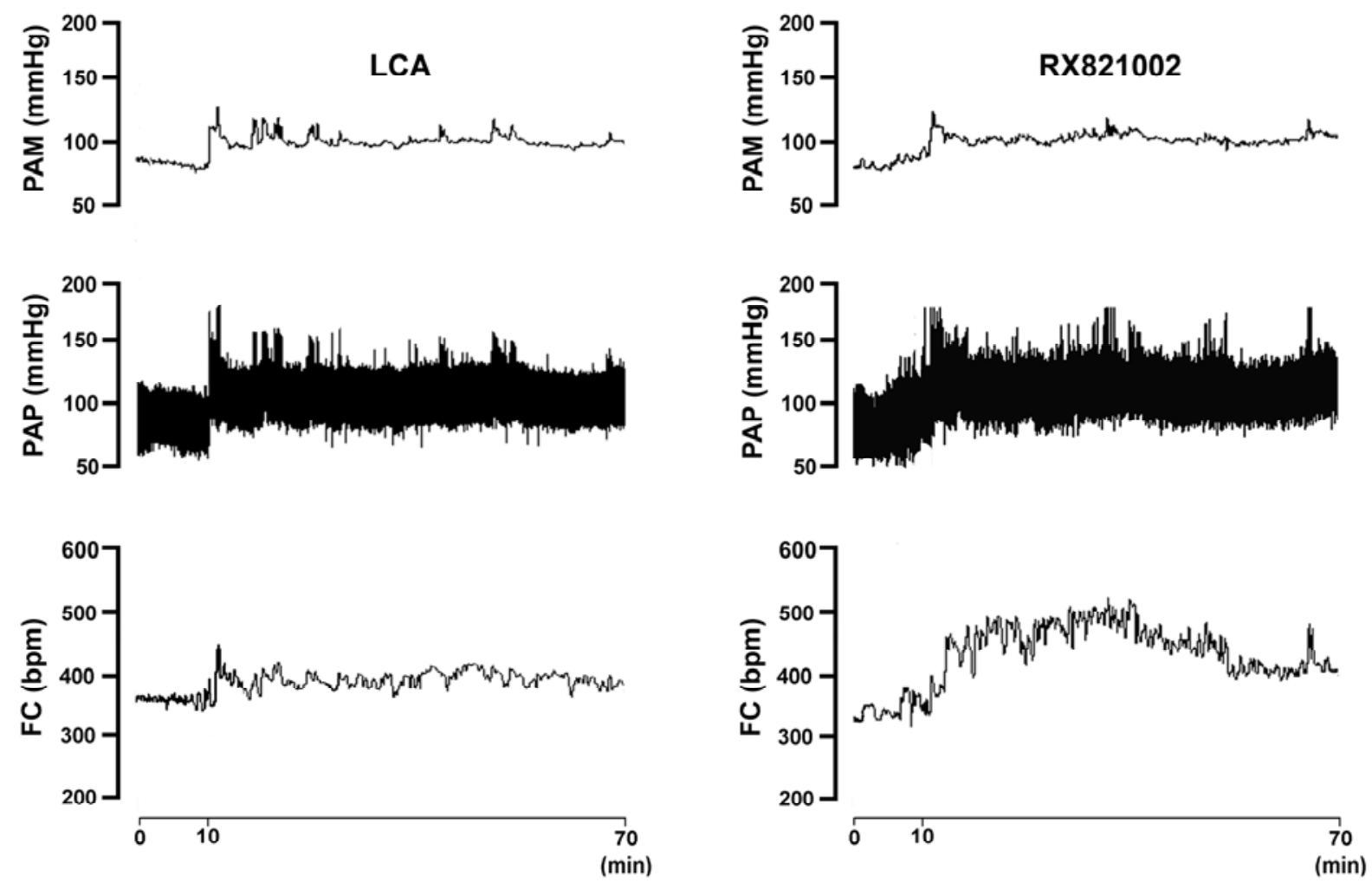

Figura 25. Registros representativos de um rato do grupo tratado com microinjeção bilateral de veículo (LCA) e de um rato tratado com RX821002 (15nmol/100nL) no NMA e submetidos ao ER, mostrando as alterações na pressão arterial média (PAM), pressão arterial pulsátil (PAP) e frequência cardíaca (FC) observadas durante o período de 60 min de restrição. $O$ inicio da restrição ocorreu em t=10 min. 
10) Efeito da microinjeção de diferentes doses de antagonista não seletivo dos receptores $\beta$-adrenérgico propranolol no MNA sobre as respostas cardiovasculares ao ER

A microinjeção $100 \mathrm{~nL}$ de veículo (LCA) bilateralmente no NMA não alterou os valores basais de PAM (100 \pm 4 vs. $96 \pm 3 \mathrm{mmHg}, \mathrm{t}=0.88, \mathrm{P}>0.05, \mathrm{n}=6)$ ou da FC (361 \pm 9 vs. $356 \pm 7$ bpm, $t=0.41, P>0.05, n=6)$.

Propranolol dose de $10 \mathrm{nmol}$ - A microinjeção de propranolol (10nmol/100nL) no NMA não causou alterações nos valores basais de PAM (88 \pm 3 vs $90 \pm 4 \mathrm{mmHg}$, $t=0.37, P>0.05, n=9)$ ou $F C(345 \pm 7$ vs $338 \pm 5 b p m, t=0.76, P>0.05, n=9)$.

O ER causou aumento da PA e da FC nos animais tratados com veículo (LCA, 100nL bilateral) ou tratados com propranolol (10nmol, bilateral) no NMA. Não houve diferença significativa no padrão das respostas cardiovasculares causadas pelo ER ( $\triangle$ PAM Interação: $F_{5,78}=0,19, P=0,96$; Tratamento: $F_{1,78}=0,58, P=0,44$; Tempo: $F_{5,78}=37,52, P<0,0001$, e $\Delta F C$, Interação: $F_{5,78}=0,59, P=0,70$; Tratamento: $F_{1,78}=$ 1,81, $P=0,17$; Tempo: $\left.F_{5,78}=20,41, P<0,0001\right)$, figura 26 .

Propranolol dose de $15 \mathrm{nmol}$ - A microinjeção de propranolol (15nmol/100nL) no NMA não causou alterações nos valores basais de PAM (95 \pm 3 vs $94 \pm 4$ mmHg, $\mathrm{t}=$ 0.16, $\mathrm{P}>0.05, \mathrm{n}=6)$ ou FC (365 \pm 11 vs $365 \pm 7 \mathrm{bpm}, \mathrm{t}=0.002, \mathrm{P}>0.05, \mathrm{n}=6)$.

O ER causou resposta taquicárdica significativamente maior nos ratos tratados com propranolol quando comparados aos animais tratados com LCA no NMA $(\triangle \mathrm{FC}$, Interação: $F_{5,60}=5,10, P=0,0006$; Tratamento: $F_{1,60}=11,45, P=0,0013$; Tempo: $F_{5,60}=33,84, P<0,0001 ;$ analise de variância de dois fatores), Não houve diferença significativa na resposta pressora ao ER entre os grupos propranolol e LCA ( $\triangle \mathrm{PAM}$, 
Interação: $F_{5,60}=0,05, P=0,99$; Tratamento: $F_{1,60}=0,06, P=0,79$; Tempo: $F_{5,60}=$ $32,13, \mathrm{P}<0,0001)$, figura 26.

Registros representativos de um animal tratado com LCA e de um rato tratado com microinjeção bilateral de propranolol (15nmol) no NMA e submetidos ao ER, mostrando os efeitos sobre as alterações cardiovasculares estão apresentados na figura 27.

Propranolol dose de 20nmol - A microinjeção de propranolol (20nmol/100nL) no NMA não causou alterações nos valores basais de PAM (83 \pm 3 vs $94 \pm 4$ mmHg, $\mathrm{t}=$ 2.08, $\mathrm{P}>0.05, \mathrm{n}=6)$ ou FC (341 \pm 3 vs $347 \pm 8$ bpm, $\mathrm{t}=0.70, \mathrm{P}>0.05, \mathrm{n}=6)$.

O ER causou aumento tanto da PA quanto da FC nos animais do grupo tratado com veículo (LCA, 100nL bilateral) ou tratados com propranolol no NMA. Não houve diferença significativa no padrão das respostas cardiovasculares causadas pelo ER ( $\triangle$ PAM, Interação: $F_{5,60}=1,08, P=0,37$; Tratamento: $F_{1,60}=1,04, P=0,31$; Tempo: $F_{5,60}=35,75, P<0,0001$, e $\Delta F C$, Interação: $F_{5,60}=0,61, P=0,69$; Tratamento: $F_{1,60}=$ 0,87, $P=0,35$; Tempo: $\left.F_{5,60}=9,81, P<0,0001\right)$, figura 26 .

Diagramas modificados do atlas do cérebro de rato (PAXINOS e WATSON, 1997), indicando a dispersão dos sítios de microinjeção das diferentes doses de propranolol (10, 15 e 20nmol) ou veículo (LCA) no NMA estão apresentados na figura 28. Uma fotomicrografia de uma secção coronal do cérebro de um rato mostrando sítios bilaterais de microinjeção no NMA está apresentada na figura 29. 

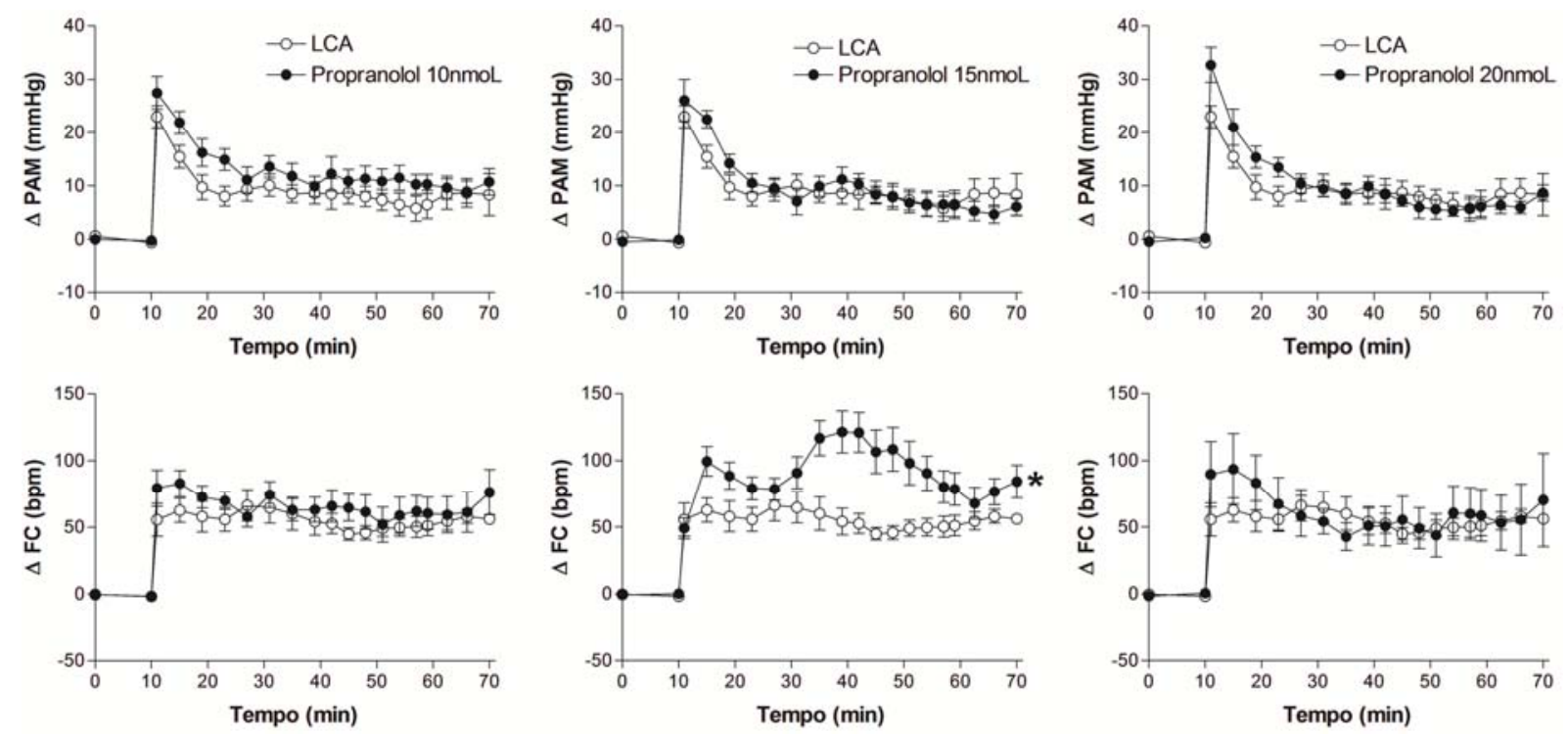

Figura 26. Curvas temporais mostrando as alterações na $\triangle \mathrm{PAM}$ e $\triangle \mathrm{FC}$ observadas durante o ER em animais tratados bilateralmente com $100 \mathrm{~nL}$ veículo ( $\mathrm{LCA}, \mathrm{n}=6$ ) ou propranolol em diferentes doses (10, 15 e 20nmol; $n=9,6$ e 6 respectivamente). Dados foram analisados utilizando o two-way ANOVA (variância de dois fatores) seguida pelo pós-teste de Bonferroni, ${ }^{*} p<0,05$. 

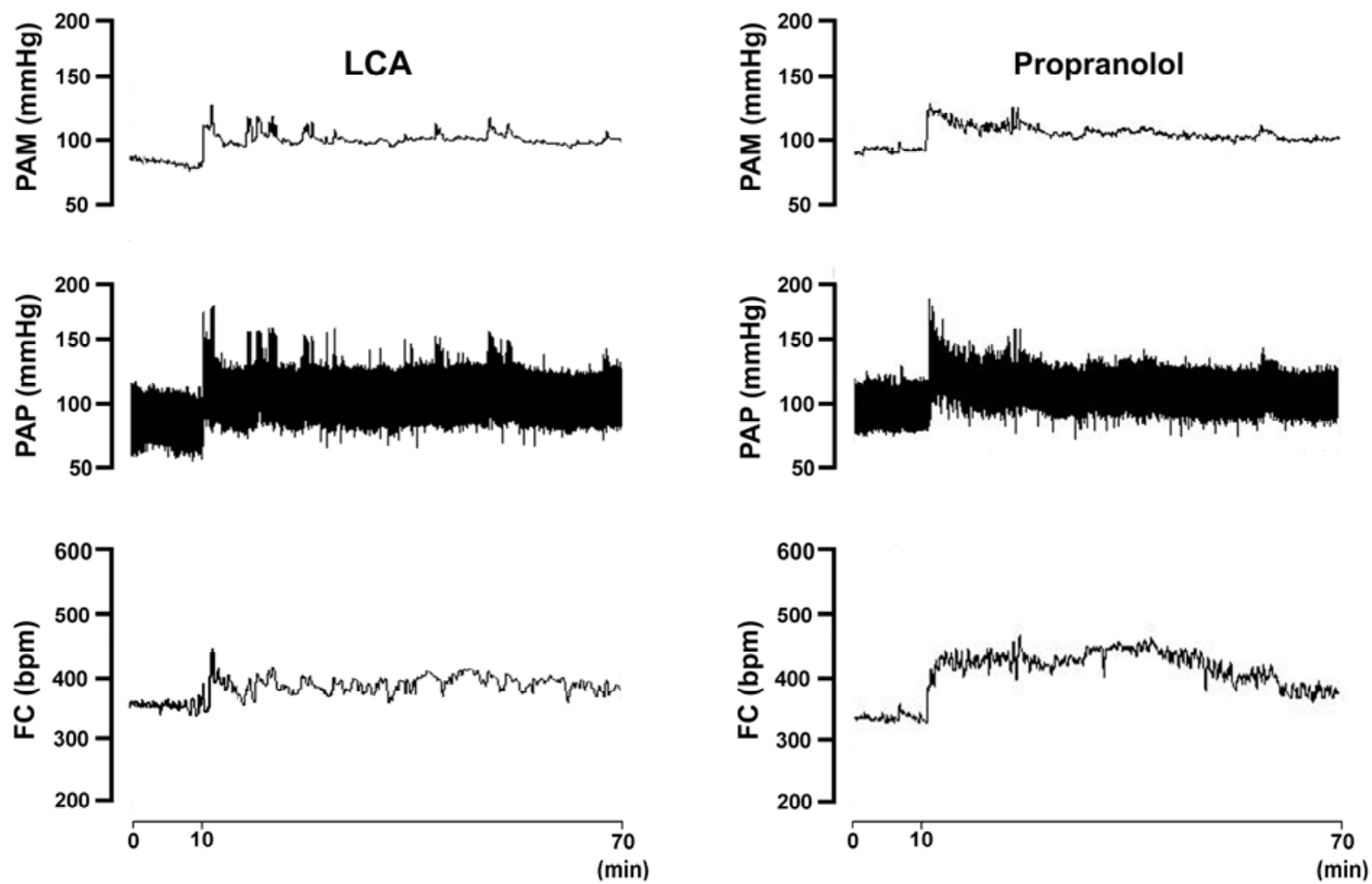

Figura 27. Registros representativos de um rato do grupo tratado com microinjeção bilateral de veículo (LCA) e de um rato tratado com propranolol (15nmol/100nL) no NMA e submetidos ao ER, mostrando as alterações na pressão arterial média (PAM), pressão arterial pulsátil (PAP) e frequência cardíaca (FC) observadas durante o período de 60 min de restrição. $O$ inicio da restrição ocorreu em t=10 min. 

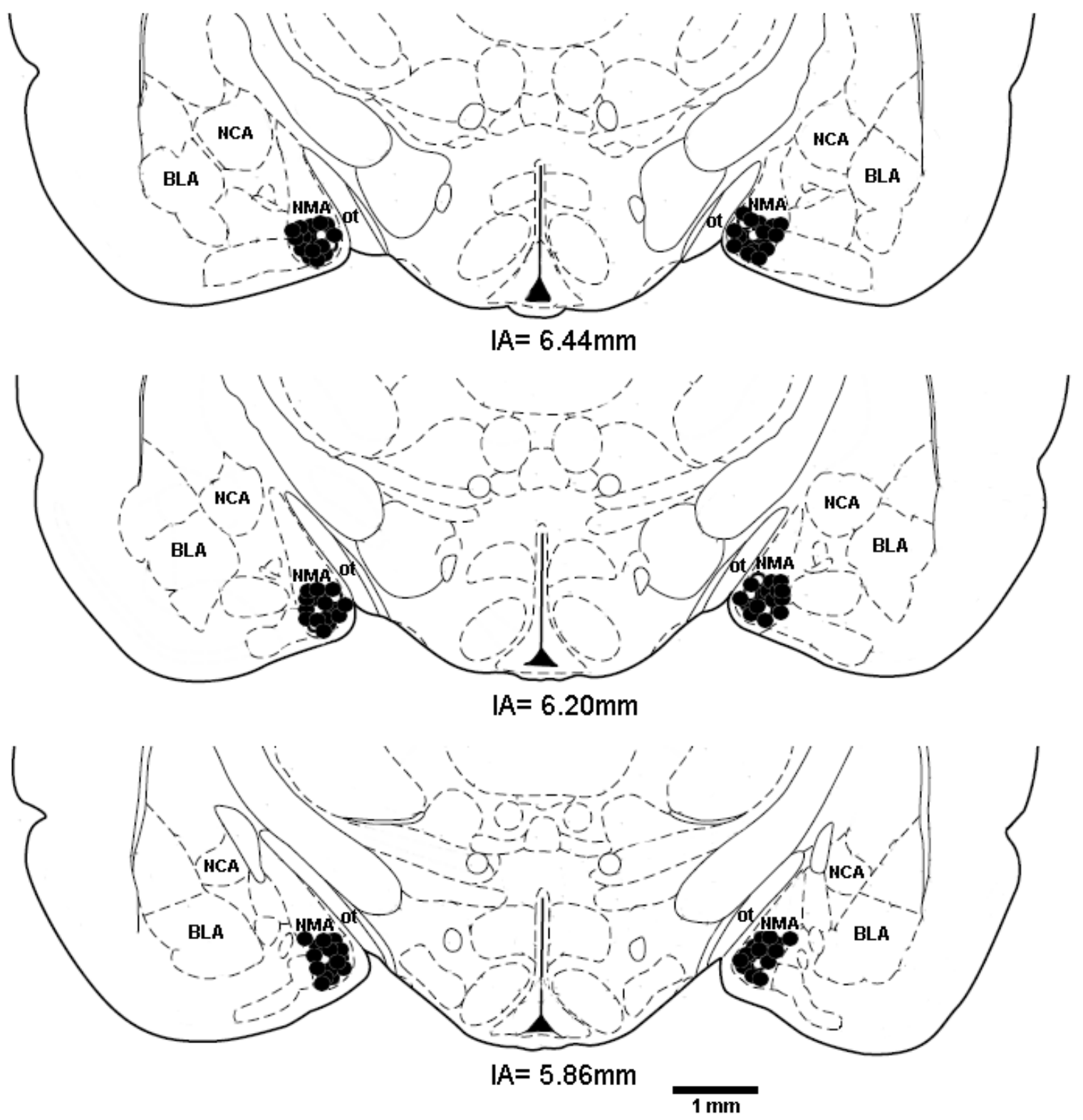

Figura 28. Diagramas modificados do atlas do cérebro de rato (PAXINOS e WATSON, 1997), indicando a dispersão dos sítios de microinjeção das diferentes doses de propranolol, CGP 20712 ou ICI 118,551 (círculos pretos) e LCA (círculos brancos) no núcleo medial da amígdala (NMA), IA - interaural; NCA - núcleo central da amígdala. BLA - núcleo basolateral da amígdala. ot - trato óptico. 


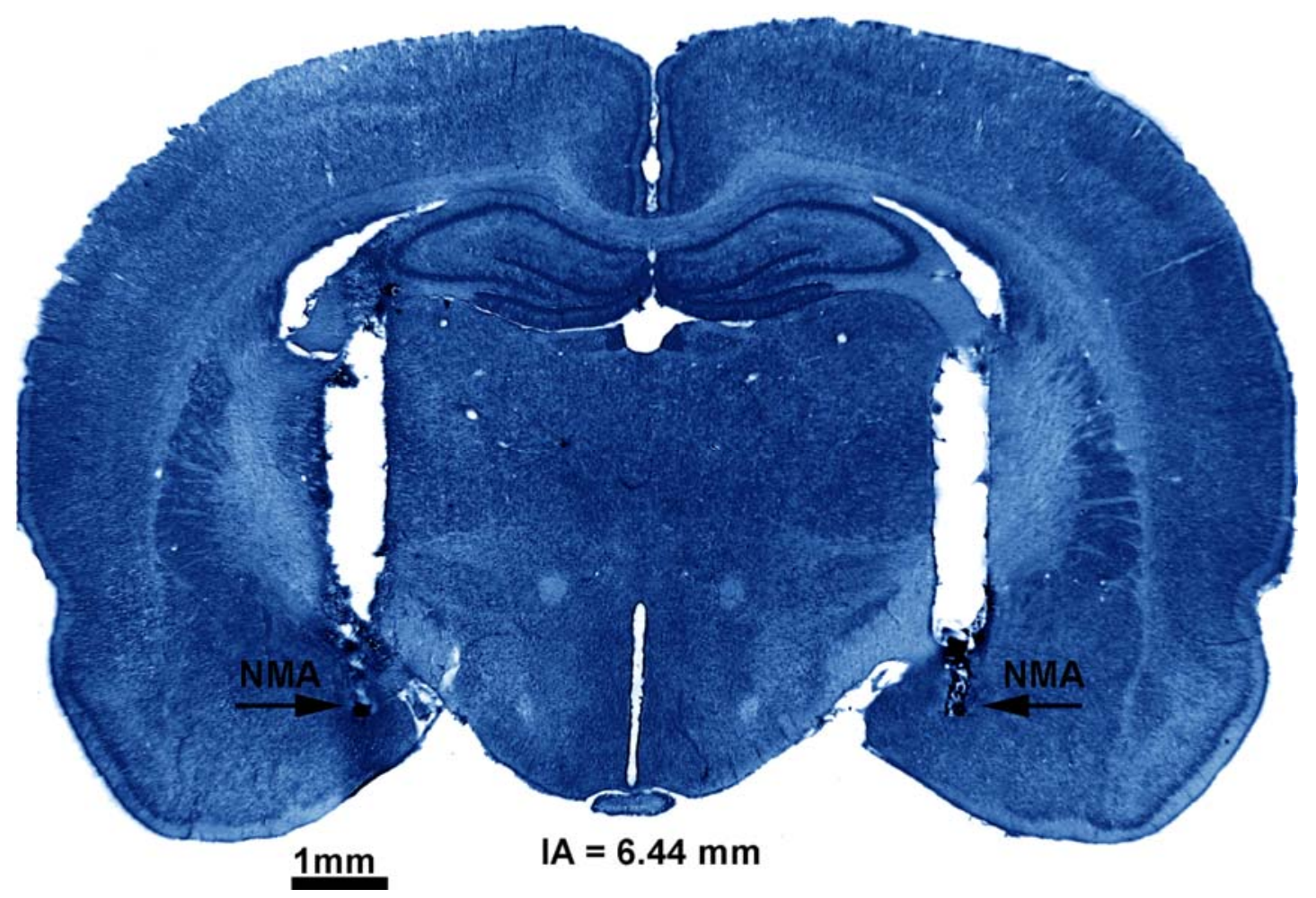

Figura 29. Fotomicrografia de corte histológico do cérebro de rato mostrando o sítio da microinjeção de droga no núcleo medial da amígdala (NMA), indicado pela seta. IA - interaural. 
11) Efeito da microinjeção de diferentes doses de antagonista dos receptores $\beta_{1}$-adrenérgico no MNA sobre as respostas cardiovasculares ao ER

CGP 20712 dose de 10nmol - A microinjeção de CGP 20712 (10nmol/100nL) no NMA não causou alterações nos valores basais de PAM $(95 \pm 2$ vs $94 \pm 2$ mmHg, t= $0.21, P>0.05, n=7)$ ou FC $(353 \pm 11$ vs $366 \pm 14$ bpm, $t=0.68, P>0.05, n=7)$.

O ER causou aumento da PA e da FC nos animais do grupo tratado com veículo (LCA, 100nL bilateral) ou tratados com CGP 20712 (10nmol, bilateral) no NMA. Não houve diferença significativa no padrão das respostas cardiovasculares causadas pelo ER ( $\triangle \mathrm{PAM}$ Interação: $F_{5,66}=0,20, P=0,96$; Tratamento: $F_{1,66}=0,09$, $P=0,76$; Tempo: $F_{5,66}=36,78, P<0,0001$; e $\Delta F C$, Interação: $F_{5,66}=0,47, P=0,79$; Tratamento: $F_{1,66}=3,34, P=0,07$; Tempo: $\left.F_{5,66}=15,16, P<0,0001\right)$, figura 30 .

CGP 20712 dose de 15nmol - A microinjeção de CGP 20712 (15nmol/100nL) no NMA não causou alterações nos valores basais de PAM $(100 \pm 2$ vs $98 \pm 3 \mathrm{mmHg}$, $t=0.48, P>0.05, n=6)$ ou FC $(365 \pm 10$ vs $381 \pm 12$ bpm, $t=1.01, P>0.05, n=6)$.

O ER causou aumento da PA e da FC nos animais do grupo tratado com veículo (LCA, 100nL bilateral) ou tratados com CGP 20712 (15nmol bilateral) no NMA. Não houve diferença significativa no padrão das respostas cardiovasculares causadas pelo ER ( $\triangle \mathrm{PAM}$, Interação: $F_{5,60}=0,20, P=0,95$; Tratamento: $F_{1,60}=0,73$, $P=0,39$; Tempo: $F_{5,60}=32,32, P<0,0001$, e $\Delta F C$, Interação: $F_{5,60}=1,01, P=0,41$; Tratamento: $F_{1,60}=0,37, P=0,54 ;$ Tempo: $F_{5,60}=15,73, P<0,0001$; analise de variância de dois 2 fatores), figura 30. 
CGP 20712 dose de 20nmol - A microinjeção de CGP 20712 (20nmol/100nL) no NMA não causou alterações nos valores basais de PAM (92 \pm 2 vs $96 \pm 3 \mathrm{mmHg}$, $\mathrm{t}=$ 1.20, $\mathrm{P}>0.05, \mathrm{n}=6)$ ou FC (347 \pm 19 vs $354 \pm 17$ bpm, $\mathrm{t}=0.29, \mathrm{P}>0.05, \mathrm{n}=6)$.

O ER causou aumento da PA e da FC tanto nos animais do grupo tratado com veículo (100nL, LCA bilateral) quanto nos tratados com CGP 20712 (20nmol, bilateral) no NMA. O ER causou resposta taquicárdica significativamente menor nos ratos tratados com CGP 20712 quando comparados a animais controles $(\Delta \mathrm{FC}$, Interação: $F_{5,60}=0,98, P=0,43$; Tratamento: $F_{1,60}=4,97, P=0,02$; Tempo: $F_{5,60}=$ 16,46, $\mathrm{P}<$ 0,0001; analise de variância de dois fatores), Não houve diferença significativa na resposta pressora ao ER entre os grupos CGP 20712 e controle ( $\triangle$ PAM, Interação: $F_{5,60}=0,37, P=0,86$; Tratamento: $F_{1,60}=3,11, P=0,08$; Tempo: $\left.F_{5,60}=29,53, P<0,0001\right)$, figura 30.

Registros representativos de um animal do grupo tratado com veículo (LCA) e de um rato tratado com microinjeção bilateral de CGP 20712, mostrando os efeitos do tratamento sobre as alterações cardiovasculares decorrentes ao ER estão apresentados na figura 31 .

Diagramas modificados do atlas do cérebro de rato (PAXINOS e WATSON, 1997), indicando a dispersão dos sítios de microinjeção das diferentes doses de CGP 20712 (10, 15 e 20nmol) e LCA no NMA estão apresentados na Figura 28. 

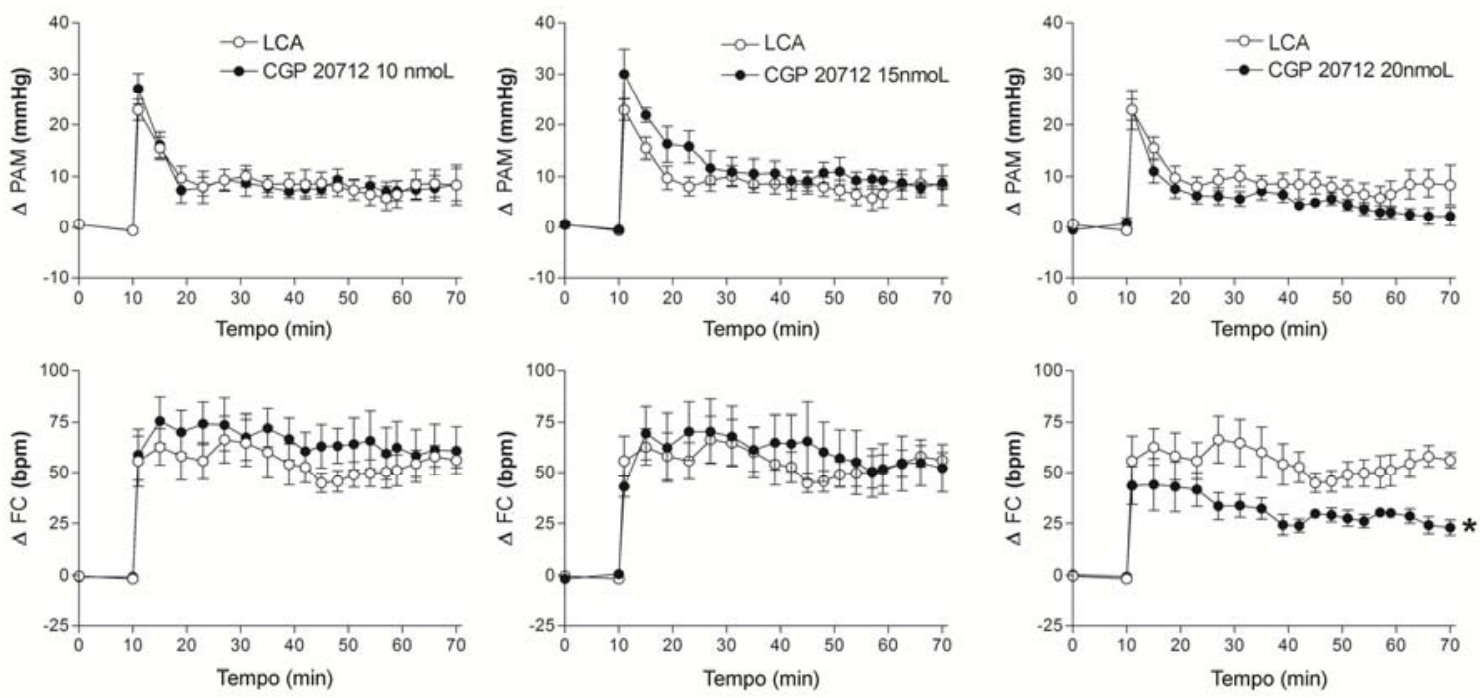

Figura 30. Curvas temporais mostrando as alterações na $\triangle \mathrm{PAM}$ e $\triangle \mathrm{FC}$ observadas durante o ER em animais tratados bilateralmente com $100 \mathrm{~nL}$ de veículo (LCA, $n=6)$ ou CGP 20712 em diferentes doses (10, 15 e 20nmol; n= 7, 6 e 6 respectivamente). Dados foram analisados utilizando o two-way ANOVA (variância de dois fatores) seguida pelo pós-teste de Bonferroni, ${ }^{*} p<0,05$. 

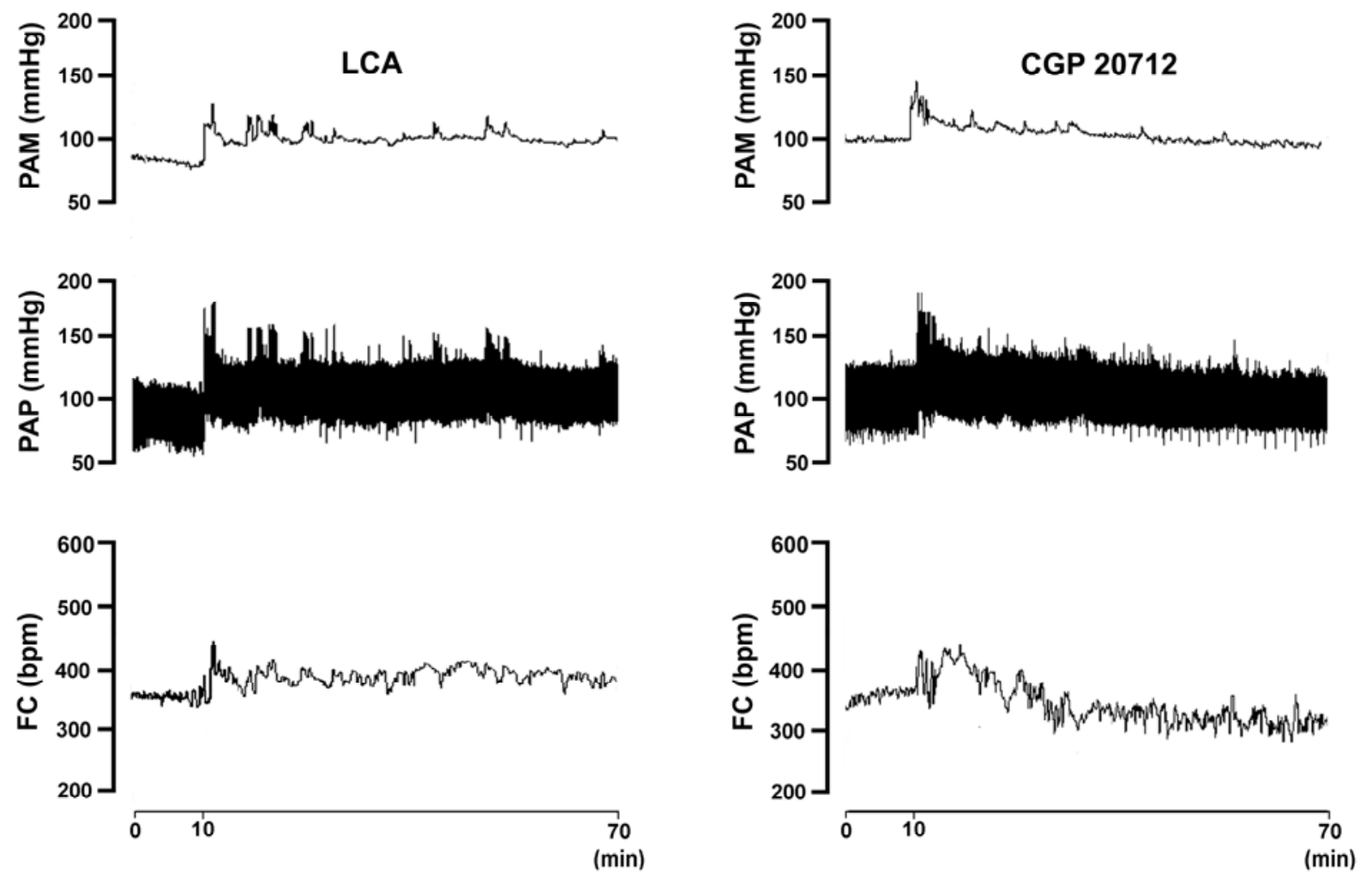

Figura 31. Registros representativos de um rato do grupo tratado com microinjeção bilateral de veículo (LCA) e de um rato tratado com CGP20712 (20nmol/100nL) no NMA e submetidos ao ER, mostrando as alterações na pressão arterial média (PAM), pressão arterial pulsátil (PAP) e frequência cardíaca (FC) observadas durante o período de 60 min de restrição. O inicio da restrição ocorreu em t=10 min. 
12) Efeito da microinjeção de diferentes doses de antagonista dos receptores $\beta_{2}$-adrenérgico no MNA sobre as respostas cardiovasculares ao ER

ICI 118,551 dose de $10 \mathrm{nmol}$ - A microinjeção de ICI 118,551 (10nmol/100nL) no NMA não causou alterações nos valores basais de PAM $(90 \pm 8$ vs $88 \pm 8 \mathrm{mmHg}$, $\mathrm{t}=$ $0.20, P>0.05, n=6)$ ou FC $(380 \pm 14$ vs $369 \pm 9$ bpm, $t=0.65, P>0.05, n=6)$.

O ER causou aumento tanto da PA quanto da FC nos animais do grupo tratado com veículo (LCA, 100nL bilateral) ou tratados com ICI 118,551 no NMA. Não houve diferença significativa no padrão das respostas cardiovasculares ( $\triangle \mathrm{PAM}$ Interação: $F_{5,60}=0,039, P=0,99 ;$ Tratamento: $F_{1,60}=0,07, P=0,78 ;$ Tempo: $F_{5,60}=30,27, P<$ 0,0001, e $\Delta F C$, Interação: $F_{5,60}=1,90, P=0,10$; Tratamento: $F_{1,60}=1,88, P=0,17$; Tempo: $\left.F_{5,60}=14,42, P<0,0001\right)$, figura 32 .

ICI 118,551 dose de 15nmol - A microinjeção de ICI 118,551 (15nmol/100nL) no NMA não causou alterações nos valores basais de PAM $(84 \pm 6$ vs $85 \pm 6$ mmHg, t= $0.19, P>0.05, n=6)$ ou FC (365 \pm 18 vs. $374 \pm 9$ bpm, $t=0.47, P>0.05, n=6)$.

O ER causou resposta taquicárdica significativamente maior nos ratos tratados com ICl 118,551 quando comparados a animais tratados com LCA ( $\Delta \mathrm{FC}$, Interação: $F_{5,60}=5,77, P=0,0002 ;$ Tratamento: $F_{1,60}=20,92, P<0,0001 ;$ Tempo: $F_{5,60}=29,48, P$ $<0,0001)$. Não houve diferença significativa na resposta pressora ao ER entre os grupos ICI 118,551 e LCA ( $\triangle \mathrm{PAM}$, Interação: $F_{5,60}=0,95, P=0,45$; Tratamento: $F_{1,60}=1,40, P=0,24 ;$ Tempo: $F_{5,60}=20,44, P<0,0001$ ), figura 32 .

Registros representativos de um animal tratado com LCA e de um tratado com microinjeção bilateral de ICI 118,551 (15nmol), mostrando os efeitos dos tratamentos 
sobre as alterações cardiovasculares decorrentes ao ER estão apresentados na figura 33.

ICI 118,551 dose de 20nmol - A microinjeção de ICI 118,551 (20nmol/100nL) no NMA não causou alterações nos valores basais de PAM (96 \pm 3 vs $96 \pm 3 \mathrm{mmHg}$, t= 0.07, $\mathrm{P}>0.05, \mathrm{n}=6)$ ou $\mathrm{FC}(370 \pm 6$ vs $357 \pm 5$ bpm, $\mathrm{t}=1.46, \mathrm{P}>0.05, \mathrm{n}=6)$.

O ER causou resposta taquicárdica significativamente maior nos ratos tratados com ICl 118,551 quando comparados a animais tratados com LCA no NMA ( $\Delta \mathrm{FC}$, Interação: $F_{5,60}=3,58, P=0,0066$; Tratamento: $F_{1,60}=24,33, P<0,0001$; Tempo: $\left.F_{5,60}=31,36, P<0,0001\right)$. Não houve diferença significativa na resposta pressora ao ER entre os grupos ICI 118,551 e LCA ( $\triangle \mathrm{PAM}$, Interação: $F_{5,60}=0,05, P=0,99$; Tratamento: $F_{1,60}=0,11, P=0,73$; Tempo: $\left.F_{5,60}=20,34, P<0,0001\right)$, figura 32 .

Diagramas modificados do atlas do cérebro de rato (PAXINOS e WATSON, 1997), indicando a dispersão dos sítios de microinjeção das diferentes doses de ICI 118,551 (10, 15 e 20nmol) e LCA no NMA estão apresentados na Figura 28. 

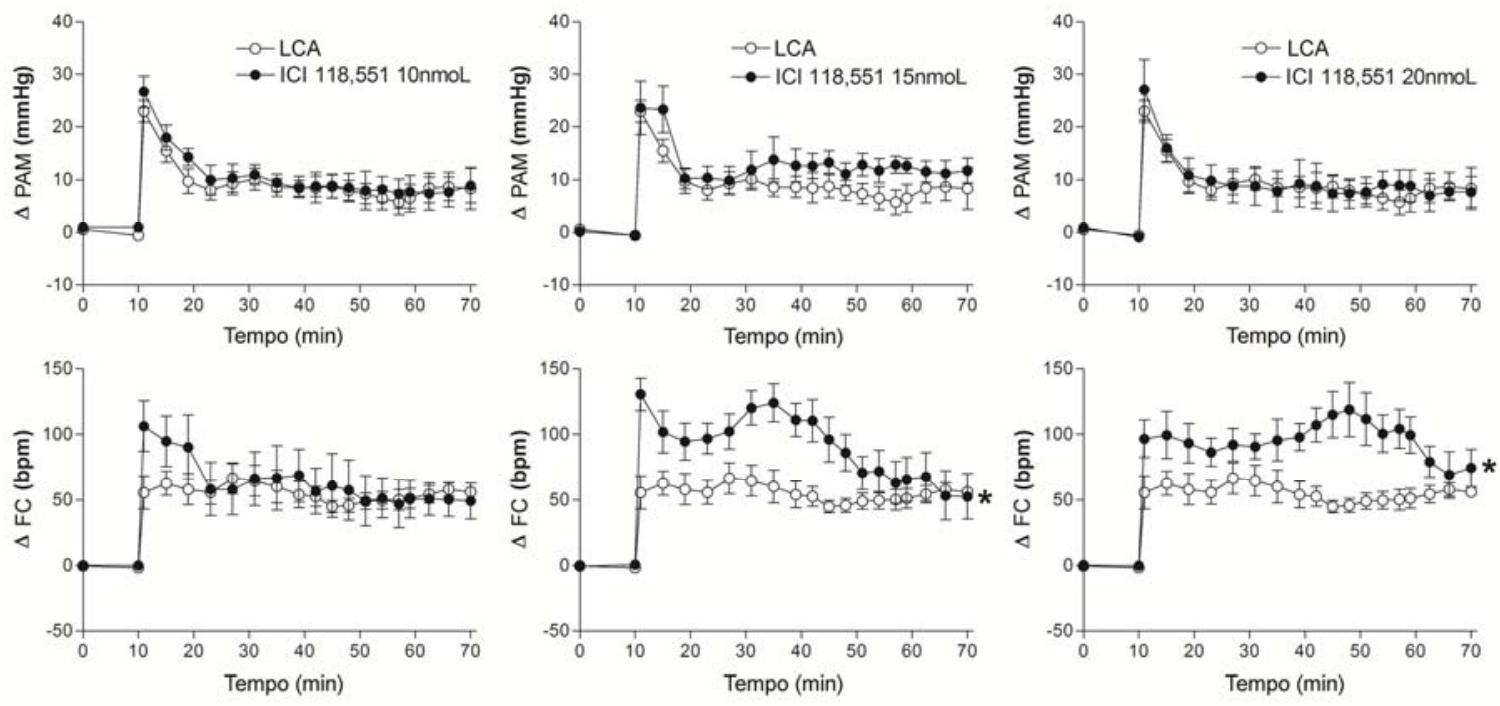

Figura 32. Curvas temporais mostrando as alterações na $\triangle P A M$ e $\triangle F C$ observadas durante o ER em animais tratados bilateralmente com $100 \mathrm{~nL}$ veículo $(\mathrm{LCA}, \mathrm{n}=6)$ ou ICI 118,551 em diferentes doses (10, 15 e 20nmol; $n=6,6$ e 6 respectivamente). Dados foram analisados utilizando o two-way ANOVA (variância de dois fatores) seguida pelo pós-teste de Bonferroni, ${ }^{*} p<0,05$. 

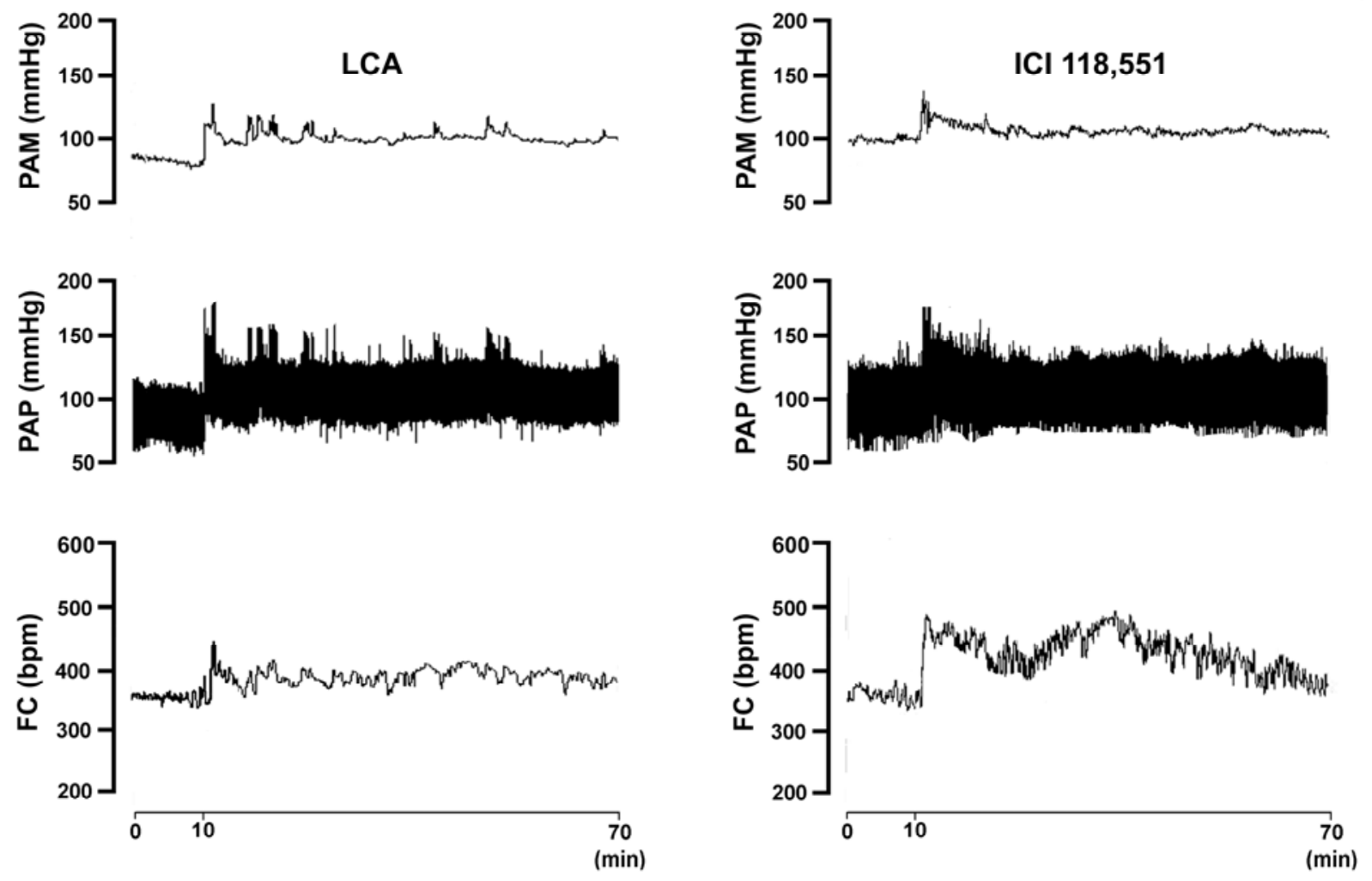

Figura 33. Registros representativos de um rato do grupo tratado com microinjeção bilateral de veículo (LCA) e de um rato tratado com ICl 118,551 (15nmol/100nL) no NMA e submetidos ao ER, mostrando as alterações na pressão arterial média (PAM), pressão arterial pulsátil (PAP) e frequência cardíaca (FC) observadas durante o período de 60 min de restrição. O inicio da restrição ocorreu em $\mathrm{t}=10 \mathrm{~min}$. 


\section{DISCUSSÃO}

Os resultados referentes à primeira parte dos nossos objetivos mostraram que a microinjeção de noradrenalina (NA) no núcleo medial da amígdala (NMA) de ratos não anestesiados causou resposta pressora e bradicárdica de maneira dosedependente, decorrentes da ativação dos receptores $\alpha_{2}$-adrenérgicos locais e dependentes da liberação de vasopressina periférica. Além do mais, em nosso estudo nós observamos que sinapses no núcleo paraventricular (NPV) e no núcleo supra-óptico (NSO) do hipotálamo estão envolvidas na mediação dessas respostas cardiovasculares desencadeadas pela microinjeção de NA no NMA.

A amígdala está envolvida no controle de varias funções autonômicas incluindo o controle do sistema cardiovascular. Em experimentos em que se realizou ablação da amígdala foi observado um retardo no desenvolvimento de hipertensão espontânea (GALENO et al., 1982). Além disso, MOGENSON e CALARESU (1973) relataram que a estimulação elétrica do NMA causa respostas pressoras em ratos anestesiados com uretana, enquanto causa respostas depressoras em ratos anestesiados com alfa cloralose.

Existem evidências do envolvimento da neurotransmissão noradrenérgica do complexo amigdalóide modulando repostas cardiovasculares. A microinjeção de NA neste complexo causou resposta pressora e bradicárdica (OHTA et al., 1991). Todavia, esses autores observaram apenas alterações cardiovasculares significativas após microinjeção bilateral de NA no complexo amigdalóide. Diferentemente, em nosso estudo observamos efeitos cardiovasculares causados pela administração local unilateral de NA apenas no NMA, sugerindo o envolvimento específico deste núcleo na modulação de respostas cardiovasculares 
desencadeadas pela microinjeção local de NA. Também, durante nosso estudo foi microinjetada a NA nas áreas ao redor ao NMA, tais como o trato óptico e a cápsula interna e não houve alterações cardiovasculares significativas, reforçando a ideia de uma ação restrita da NA no NMA.

A observação de que a magnitude da resposta bradicárdica causada pela microinjeção de NA no NMA se correlaciona significativamente com a magnitude da resposta pressora, favorece a ideia de uma resposta bradicárdica de origem reflexa. Além disso, a magnitude da resposta bradicárdica observada após a microinjeção de NA no NMA foi similar às observadas após a ativação do barorreflexo pela infusão intravenosa de fenilefrina (RESSTEL et al., 2004), sugerindo que a bradicardia causada pela microinjeção de NA no NMA seria um reflexo natural da resposta pressora.

Para determinar qual subtipo de receptor adrenérgico no NMA estaria envolvido na mediação da resposta cardiovascular à microinjeção de NA, os animais foram pré-tratados localmente com antagonista dos receptores $\alpha_{2}$-adrenérgico (RX821002) ou antagonista seletivo $\alpha_{1}$-adrenérgico (WB4101). O bloqueio do receptor $\alpha_{2}$ adrenérgico pelo $\mathrm{R} \times 821002$ reduziu significativamente as respostas cardiovasculares após a microinjeção de NA, porém o pré-tratamento com o antagonista dos receptores $\alpha_{1}$-adrenérgico WB4101, não alterou as respostas cardiovasculares, sugerindo que o subtipo $\alpha_{2}$ dos receptores adrenérgicos está envolvido na mediação da resposta cardiovascular à microinjeção de NA no NMA. Estudos de ligação detectaram a presença de receptores adrenérgicos do subtipo $\alpha_{2}$ no NMA (UNNERSTALL et al., 1984; FLUGGE et al., 1994). Doses similares desses antagonistas foram previamente utilizadas para identificar qual o subtipo de receptores adrenérgico estaria envolvido na mediação da resposta pressora e 
bradicárdica causada pela microinjeção de NA no córtex pré-frontal medial (FERNANDES et al., 2003) ou na área septal lateral (SCOPINHO et al., 2006). Nestas áreas, a resposta cardiovascular desencadeada pela microinjeção de NA foi bloqueada pelo pré-tratamento com WB4101 e não pelo pré-tratamento com RX821002, sugerindo uma mediação preferencial via ativação dos receptores adrenérgicos do subtipo $\alpha_{1}$. Entretanto, no núcleo supra-óptico do hipotálamo, a resposta pressora e bradicárdica foi bloqueada pelo pré-tratamento com RX821002, sugerindo que nesse núcleo as respostas são mediadas por receptores adrenérgicos do subtipo $\alpha_{2}$ (BUSNARDO et al., 2009a).

Os receptores $\alpha_{2}$-adrenérgico podem ser classificados como pré ou póssináptico nos neurônios (ARIMA et al., 1998). O presente estudo não pode distinguir entre esses dois mecanismos, mas devido a esses receptores serem inibitórios, nós podemos sugerir que eles podem interagir com outros neurotransmissores. Animais tratados com reboxetina, um inibidor da recaptação de NA, apresentaram down regulation na expressão de mRNA de ácido glutamínico descarboxilase no giro dentado do hipocampo e no NMA (HERMAN et al., 2003). A diminuição de GABA sugere o aumento da ativação dessas áreas. Portanto, a microinjeção de NA no NMA poderia ativar uma inibição da liberação de GABA via receptores $\alpha_{2-}$ adrenérgicos. Mais estudos serão necessários para avaliar está hipótese.

Neste trabalho também estudamos o mecanismo periférico envolvido na resposta cardiovascular à microinjeção de NA no NMA. Um mecanismo que poderia estar sendo ativado seria o aumento da atividade do sistema nervoso autônomo, o que levaria a um aumento da atividade simpática e parassimpática. O pentolínio é um potente bloqueador ganglionar de efeito prolongado (MATSUMURA et al., 2000) 
e foi escolhido como ferramenta farmacológica para inibir a eferência do sistema nervoso autônomo.

O pré-tratamento sistêmico com o bloqueador ganglionar reduziu significativamente os valores basais de pressão arterial, confirmando dessa forma o bloqueio do sistema nervoso simpático. Todavia, a resposta pressora causada pela microinjeção de NA foi potencializada e a bradicardia bloqueada após o bloqueio ganglionar. Esse resultado sugere que o sistema nervoso simpático não está envolvido na mediação da resposta pressora à microinjeção de NA no NMA.

Como a ação cardíaca causada pela microinjeção de NA no NMA foi bloqueada pelo tratamento com pentolínio, mas não o efeito vascular, a redução da resposta bradicárdica nos sugere que foi devido ao bloqueio da atividade do sistema nervoso autônomo. Portanto, é possível que a bradicardia causada pela microinjeção de NA no NMA, pode ser causada pela estimulação vagal decorrente da ativação dos barorreceptores, como resposta reflexa decorrente ao aumento da pressão arterial. Estes resultados sugerem que o sistema nervoso simpático não está envolvido na mediação da resposta pressora e também sugere a participação de um fator humoral na resposta pressora. O pentolínio causou potencialização semelhante em respostas pressoras causadas pela microinjeção de NA em outras regiões do cérebro, sugerindo o envolvimento de uma mediação humoral. Outros estudos do nosso grupo mostraram que o aumento da pressão arterial e queda na frequência cardíaca causado pela microinjeção de NA em diversas regiões do cérebro foi mediado por liberação de vasopressina (CORREA et al., 1985; FERNANDES et al., 2003; PELOSI e CORREA, 2005; SCOPINHO et al., 2006; CRESTANI et al., 2007; PELOSI et al., 2008; BUSNARDO et al., 2009a). 
A vasopressina é sintetizada nos neurônios magnocelulares do NSO e do NPV do hipotálamo e transportada para a neurohipófise, onde é armazenada em vesículas para depois ser liberada na circulação periférica (SILVERMAN e ZIMMERMAN, 1983). A liberação de vasopressina na circulação sistêmica participa da manutenção do fluido homeostático e no controle cardiovascular (COWLEY e BARBER, 1983; COWLEY e LIARD, 1988; PERSSON, 1996). Para investigar se a resposta pressora à microinjeção de NA no NMA foi mediada pela liberação de vasopressina, nós administramos um antagonista vasopressinérgico (i.v.), o dTyr(CH2)5(Me)AVP. A resposta pressora e bradicárdica à NA no NMA foi significativamente reduzida após o pré-tratamento com dTyr(CH2)5(Me)AVP, sugerindo que a ativação dos receptores V1 pela vasopressina é o mecanismo que medeia a resposta pressora desencadeada pela microinjeção de NA no NMA.

A estimulação elétrica ou química tanto no NPV quanto no NSO foi relatada causar respostas pressoras e bradicárdicas que são mediadas pelo aumento da atividade simpática e a liberação de vasopressina, portanto, indicando o envolvimento desses núcleos na modulação cardiovascular (CIRIELLO e CALARESU, 1980; BUSNARDO et al., 2007; BUSNARDO et al., 2009a; b).

Para verificar qual dos núcleos hipotalâmicos responsáveis pela síntese de vasopressina (NPV ou NSO) estariam envolvidos na mediação das respostas cardiovasculares desencadeadas pela microinjeção de NA no NMA, nos prétratamos esses núcleos com o inibidor inespecífico de sinapses, o cloreto de cobalto $\left(\mathrm{CoCl}_{2}\right)$. A microinjeção de $\mathrm{CoCl}_{2}$ em núcleos cerebrais é uma ferramenta amplamente utilizada para causar o bloqueio farmacológico da transmissão sináptica, agindo sobre a condutância dos canais de cálcio (KRETZ, 1984). Previamente, a microinjeção do $\mathrm{CoCl}_{2}$ foi utilizada em varias áreas límbicas como 
ferramenta farmacológica para causar uma inativação funcional reversiva (SCOPINHO et al., 2008; CRESTANI, ALVES et al., 2009; CRESTANI, BUSNARDO et al., 2009; FORTALEZA et al., 2009; ALVES et al., 2011).

As respostas cardiovasculares evocadas pela microinjeção de NA no NMA foram parcialmente inibidas pelo pré-tratamento com $\mathrm{CoCl}_{2}$ tanto no NPV quanto no NSO. Esses resultados sugerem que ambos os núcleos hipotalâmicos estão envolvidos na mediação das respostas cardiovasculares causadas pela NA no NMA. Todavia, a redução das respostas cardiovasculares foi mais evidente após o bloqueio farmacológico do NPV quando comparado ao efeito do pré-tratamento do NSO com o $\mathrm{CoCl}_{2}$, indicando portanto, uma resposta residual significante, persistente após a ablação farmacológica do NSO, que seria mediada pela ativação do NPV. Estudos neuroanatômicos revelaram que existem projeções diretas do NMA para o NPV (SILVERMAN et al., 1981; SAWCHENKO e SWANSON, 1983). Existem evidências na literatura indicando que a microinjeção de $\mathrm{CoCl}_{2}$ no NPV foi eficaz na inibição da liberação de vasopressina que medeia a resposta pressora e bradicárdica observada após a microinjeção de NA em várias áreas do sistema límbico, tais como o córtex pré-limbico, o núcleo leito da estria terminal, a área septal lateral e a substância cinzenta periaqueductal dorsal (FERNANDES et al., 2007; SCOPINHO et al., 2008; CRESTANI, BUSNARDO et al., 2009; PELOSI et al., 2009). Portanto, esses dados indicam o NPV como a estrutura final nessas vias cardiovasculares ativadas pela microinjeção de NA.

O NSO não apenas recebe aferências do tronco cerebral, mas também de outras regiões conhecidas por estarem envolvidas com o controle cardiovascular, tais como a área medial pré-óptica, núcleo leito da estria terminal, órgão vasculoso da lamina terminal e especialmente do NMA (HAMAMURA et al., 1982; YANG et al., 
1994; MEDDLE et al., 2000). Além do mais, estudos eletrofisiológicos tem mostrado que os neurônios vasopressinérgicos do NSO recebem predominantemente aferências sinápticas exitatórias do NMA (HAMAMURA et al., 1982).

Nossos dados sugerem que ambos os núcleos hipotalâmicos NPV e NSO são responsáveis pela liberação de vasopressina na circulação sistêmica, sendo as estruturas finais da via cardiovascular ativadas pela NA no NMA.

Alguns autores têm mostrado que a estimulação elétrica em estruturas do sistema límbico tais como amígdala e a área septal, causa liberação de vasopressina na circulação sanguínea (DINGMAN e GAITAN, 1959; HAYWARD e SMITH, 1963; PAPEZ, 1995). O complexo amigdalóide possui uma densa conexão neuronal com o hipotálamo e estruturas do tronco cerebral que são conhecidas por terem um papel importante na regulação cardiovascular (OHTA et al., 1991; DAMPNEY, 1994). Além disso, existe uma via indireta da amígdala para o núcleo leito da estria terminal (NLET) e da área pré-óptica que conecta-se com a amígdala para o núcleo paraventricular (SAWCHENKO e SWANSON, 1983; MCDONALD, 1988). O NLET é um componente heterogêneo funcional da amígdala estendida que tem sido implicado na modulação das respostas cardiovasculares (CRESTANI et al., 2007). Administração de NA no NLET causa resposta pressora e bradicardia que dependem da liberação de vasopressina pelo NPV (CRESTANI, BUSNARDO et al., 2009). Além disso, o NMA tem conexões com a área septal lateral (CANTERAS et al., 1995). A estimulação dessa área pela microinjeção local de NA causa respostas pressora e bradicárdica (SCOPINHO et al., 2006) que também são mediadas pela liberação de vasopressina para a circulação sanguinea após ativação do NPV (SCOPINHO et al., 2008). A resposta pressora e bradicárdica causada pela NA na área septal lateral foi significativamente reduzida pela administração do inbidor 
sináptico $\mathrm{CoCl}_{2}$ no NMA (SCOPINHO et al., 2012). Considerando que a área septal lateral não envia projeções diretamente ao NPV (TAVARES et al., 2005) e que foram descritas conexões entre NMA e essa estrutura (CANTERAS et al., 1995), esses resultados sugerem que NMA é um relé na via envolvida na liberação vasopressina após a ativação da área septal lateral após estimulação local com NA.

Dados da literatura relatam que a vasopressina é liberada em maior quantidade após hemorragia ou hipovolemia (KASTING, 1988). Situações de estresse ativam a liberação de NA em áreas límbicas, como o córtex pré-frontal medial, aréa septal lateral, NLET e NMA (CECCHI, KHOSHBOUEI, JAVORS et al., 2002; PARDON et al., 2002; MA e MORILAK, 2005). Além disso, o NMA tem um papel importante na modulação das respostas cardiovasculares observadas durante o ER (KUBO et al., 2004; FORTALEZA et al., 2009). Portanto, as sinapses noradrenérgicas dentro do NMA podem estar envolvidas na mediação da liberação de vasopressina, observadas durante a integração cardiovascular e a resposta neuroendócrina para os estímulos estressantes.

Sabe-se que existe um circuito no sistema nervoso central responsável pela liberação de vasopressina, nossos resultados sugerem que o NMA faz parte deste circuito, juntamente com outras estruturas. Este circuito poderia regular o equilíbrio homeostático em situações de estresse físico. A resposta cardiovascular relatada à microinjeção de NA no NMA em ratos não anestesiados é a primeira evidência de um efeito funcional da ativação do sistema noradrenérgico neste núcleo, e indica que a ativação de receptores adrenérgicos na NMA está associado à liberação de vasopressina.

Estudos utilizando a técnica de microdiálise mostraram aumento nas concentrações de NA em várias regiões do sistema límbico, principalmente no NMA 
de animais submetidos ao estresse de imobilização (CECCHI, KHOSHBOUEI, JAVORS et al., 2002; CECCHI, KHOSHBOUEl e MORILAK, 2002; PARDON et al., 2002; MORILAK et al., 2005; VAN GINKEL et al., 2005; BONDI et al., 2007), sugerindo o envolvimento do sistema noradrenérgico deste núcleo na modulação de respostas causadas por situações aversivas.

O estresse de restrição (ER) é uma situação aversiva inescapável que provoca intensas alterações cardiovasculares que são caracterizadas por aumento na pressão arterial (PA) e frequência cardíaca (FC) (BARRON e VAN LOON, 1989; CHEN e HERBERT, 1995; KUBO et al., 2004; MCDOUGALL et al., 2005; TAVARES e CORREA, 2006; SALOME et al., 2007; FORTALEZA et al., 2009). Além disso, diferentes mecanismos podem ser evocados durante o ER, tais como o aumento dos níveis sanguineos do hormônio liberador de corticotropina $(\mathrm{CRH})$, que desempenha um papel importante na secreção adrenocorticotropina (ACTH) e de corticosteróides (HARBUZ et al., 1992).

Dados anteriores do nosso laborátorio mostraram que a inibição de sinapses do NMA pela microinjeção bilateral de $\mathrm{CoCl}_{2}$ não afetou o aumento causado sobre a PA, mas aumentou significativamente a resposta taquicárdica desencadeada pelo ER (FORTALEZA et al., 2009). Este resultado indica um papel inibitório do NMA sobre a taquicardica causada pelo ER. No entanto, devido ao bloqueio não seletivo da neurotransmissão local causado pelo $\mathrm{CoCl}_{2}$, seria possível que algum tipo de neurotransmissão poderia modular essas respostas cardiovasculares durante o ER, em particular, a neurotransmissão noradrenérgica.

Dados da literatura mostraram maior ativação do NMA, entre outros núcleos amígdala, durante situações de estresse, como indicado ter uma maior expressão de proteína c-fos nessa área após a exposição a situações aversivas (CANTERAS et 
al., 1995; CHEN e HERBERT, 1995; CULLINAN et al., 1995; DAYAS et al., 1999; DAYAS, BULLER, CRANE et al., 2001; DAYAS, BULLER e DAY, 2001; KUBO et al., 2004; TRNECKOVA et al., 2006). No entanto, o aumento da ativação da proteína cfos na NMA é observada após a exposição a diferentes estimulos de estresse, tais como, estresse de novidade, nado forçado, ER e interação social (THRIVIKRAMAN et al., 1997; CARTER et al., 2004). Estudos utilizando a técnica de microdiálise mostraram aumento dos níveis de NA em diversas regiões prosencefálicas do sistema límbico, principalmente no NMA dos animais submetidos ao estresse de imobilização. Este resultado indica que existe um sistema noradrenérgico funcionante nestas estruturas durante situações aversivas (CECCHI, KHOSHBOUEI, JAVORS et al., 2002; PARDON et al., 2002; MA e MORILAK, 2005; MORILAK et al., 2005; BONDI et al., 2007). Além disso, estudos de expressão de mRNA e de ligação detectaram a presença de receptores adrenérgicos do subtipo a e $\beta$ no NMA (JONES et al., 1986; DOMYANCIC e MORILAK, 1997), sugerindo a existência de sistema noradrenérgico nesta área.

Uma vez que nós observamos que a neurotransmissão noradrenérgica do NMA modula respostas cardiovasculares, que o NMA está envolvido na modulação cardiovascular de animais submetidos ao ER (KUBO et al., 2004; FORTALEZA et al., 2009) e que animais submetidos a uma situação aversiva apresenta aumento da liberação de NA no NMA, tornou-se relevante avaliar o papel da neurotransmissão noradrenérgica na modulação das respostas cardiovasculares causadas pelo ER.

Para estudar um possível envolvimento dessa neurotransmissão do NMA na modulação das respostas cardiovasculares ao ER, nós pré-tratamos os animais nesta área, com diferentes doses com os antagonistas seletivos dos receptores $\alpha-$ 
adrenérgicos, e com diferentes doses de antagonistas dos receptores $\beta$ adrenérgico.

Portanto, a segunda parte dos nossos resultados mostrou que a microinjeção de diferentes doses de antagonista dos receptores $\alpha_{1}$-adrenérgicos (WB4101) no NMA, foi capaz de causar redução de maneira dose-dependente na resposta taquicárdica causada pelo ER, sem alterações significativas na resposta pressora. Este resultado sugere que os receptores $\alpha_{1}$-adrenérgicos presentes no NMA tem uma influência facilitatória na modulação da resposta taquicárdica ao ER em ratos. Estes dados são diferentes dos resultados gerados pela administração de $\mathrm{CoCl}_{2}$ no NMA, que causou a potencialização da resposta taquicárdica durante o ER (FORTALEZA et al., 2009). No entanto, a diferença desses resultados pode ser explicada pelo fato que o $\mathrm{CoCl}_{2}$ inibi todos os tipos de neurotransmissão sináptica na área.

Nossos resultados também mostraram que a microinjeção bilateral de diferentes doses de antagonista dos receptores $\alpha_{2}$-adrenérgico (RX821002) aumentou de forma dose-dependente a resposta taquicárdica sem alteração significativa sobre a resposta pressora causada pelo ER, sugerindo que os receptores $\alpha_{2}$-adrenérgicos no MNA tem uma influência inibitória sobre a resposta taquicárdica ao ER em ratos. Ativação de receptores $\alpha_{2}$-adrenérgicos resulta na inibição de disparos neuronais e na diminuição da liberação de NA. Concomitantemente, é bem conhecido que antagonistas seletivos de receptores $\alpha_{2}$ adrenérgicos, tal como RX821002, podem facilitar ou potenciar a liberação de noradrenalina em ratos em condições basais ou durante a exposição ao estresse, por meio do bloqueio central de receptores $\alpha_{2}$-adrenérgicos (ABERCROMBIE e JACOBS, 1987; DENNIS et al., 1987; THOMAS e HOLMAN, 1991; TJURMINA et al., 
1999; WORTLEY, HEAL et al., 1999; WORTLEY, HUGHES et al., 1999; KAWAHARA et al., 2000). Isto pode levar ao aumento dos níveis de NA em áreas de cérebro de rato, como no NMA (ITOH et al., 1990; MERMET et al., 1990; LAITINEN et al., 1995; FINN et al., 2002).

Nossos resultados mostram que os receptores $\alpha_{1}$ e $\alpha_{2}$-adrenérgicos no NMA têm influências diferentes sobre a atividade cardíaca durante a restrição aguda. $O$ controle autonômico cardíaco é um equilíbrio entre atividade parassimpática e simpática (BERNTSON et al., 1991). A estimulação parassimpática deprime a força de contração cardíaca enquanto a ativação simpática aumenta. Embora o controle vagal e da atividade simpática do sistema nervoso possa ocorrer durante o barorreflexo, a co-ativação simultânea de ambos os sistemas autônomos é observada durante os reflexos fisiológicos associados aos quimiorreceptores e às respostas nocivas e defensivas (PATON et al., 2005). Respostas cardíacas e pressoras relacionados ao estresse são mediadas pelo sistema simpático, porque ambas são abolidas após o bloqueio gânglionar ou pelo bloqueio dos receptores $\beta$ ou $\alpha$-adrenérgicos, respectivamente (CARRIVE, 2002; 2006). Além disso, trabalhos anteriores indicaram que o tratamento com um bloqueador parassimpático aumenta a resposta taquicárdica evocada pelo estresse psicológico (IWATA e LEDOUX, 1988; BAUDRIE et al., 1997; TAVARES e CORREA, 2006; CRESTANI, ALVES et al., 2009), sugerindo a ativação simultânea da atividade cardíaca parassimpática e simpática durante o estresse psicológico.

Além da presença de receptores $\alpha$-adrenérgicos, estudos sobre a expressão de mRNA e de ligação detectaram a presença de receptores $\beta$-adrenérgicos do NMA (JONES et al., 1986; DOMYANCIC e MORILAK, 1997), sugerindo que receptores $\beta_{1}$ e $\beta_{2}$-adrenérgicos podem estar envolvidos durante uma situação de estresse. 
Estudos no complexo amígdalóide em ratos com as técnicas de hibridação 'in situ' e com PCR em tempo real revelaram significantes níveis de expressão da transcrição de ambos receptores $\beta$-adrenérgicos, e o mRNA dos receptores $\beta_{2}$-adrenérgico foi encontrado ser cerca de 2,9 vezes mais prevalente do que o mRNA para receptores $\beta_{1}$-adrenérgico área, sugerindo que $\beta_{2}$-adrenérgicos são mais abundantes nesta área (ABRAHAM et al. , 2008).

Todavia, no presente estudo nós fizemos o pré-tratamento com a microinjeção bilateral de antagonista não seletivo dos receptores $\beta$-adrenérgico propranolol na NMA. Foi observado aumento da taquicardia causada pelo ER apenas quando foi injetada a dose de $15 \mathrm{nmol}$, ao passo que não foram observados efeitos após o tratamento com uma dose mais baixa $(10 \mathrm{nmol})$ ou em uma dose mais elevada de propranolol (20nmol). O pré-tratamento com propranolol no NMA não alterou de forma significativa a resposta pressora evocado pela exposição ao ER, independentemente da dose injetada. Estes resultados sugerem que os receptores $\beta$-adrenérgicos no NMA desempenham papel inibitório na resposta taquicardica ao ER, e não estão envolvidos na mediação da resposta ao pressora. O bloqueio dos receptores $\beta$-adrenérgicos do NMA causou aumento da taquicardia, semelhante ao observado após a inibição farmacológica dessa área com $\mathrm{CoCl}_{2}$ (FORTALEZA et al., 2009).

Para verificar qual o subtipo de receptor $\beta$-adrenérgico estaria mediando o aumento da resposta taquicardica, os animais foram pré-tratados com os

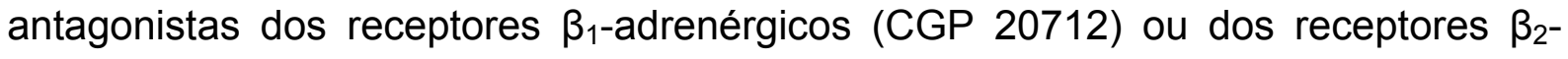
adrenérgicos (ICI 118,511). O pré-tratamento do NMA com ICI 118,511 nas doses de 15 e 20 nmol causou aumento significativo da resposta taquicardica causada pelo ER, de forma semelhante a resposta observada após o pré-tratamento com 
propranolol, sem causar alteração significativa na resposta pressora, portanto, indicando que os receptores $\beta_{2}$-adrenérgicos no NMA desempenham papel inibitório na resposta taquicardica ao ER. Esses efeitos observados após o pré-tratamento do NMA com os antagonistas $\beta$-adrenérgicos o propranolol e o ICl 116,511 foram semlhantes aqueles observados após a ablação farmacologica da área $\operatorname{com} \mathrm{CoCl}_{2}$ (FORTALEZA et al., 2009).

Por outro lado, o bloqueio dos receptores $\beta_{1}$-adrenérgicos do NMA pelo prétratamento com CGP 20712 diminuiu a resposta taquicárdica evocada pelo ER apenas após a administração bilateral da dose mais elevada (20nmol). O prétratamento com esse antagonista reduziu a magnitude da resposta taquicárdica ao ER, sem causar alteração significativa na resposta pressora. Esses resultados sugerem que os receptores $\beta_{1}$-adrenérgicos do NMA desempenham uma influência facilitatória na resposta taquicárdica durante o ER. O efeito do pré-tratamento com o CGP 20712 causa efeito oposto àqueles observados após o pré-tratamento com os antagonistas propranolol e ICI 118,511, resultados do presente estudo, e também efeito oposto ao resultados do estudo com o $\mathrm{CoCl}_{2}$ (FORTALEZA et al., 2009). Esses efeitos seriam devido ao propranolol ser um antagonista equipotente dos receptores $\beta_{1}$ e $\beta_{2}$-adrenérgicos, e por essa razão, não observamos alterações nas respostas cardiovasculares evocadas pelo ER quando fizemos o pré-tratamento com o propranolol na dose de $(20 \mathrm{nmol})$ no NMA. Porém, os efeitos opostos foram observados após o tratamento com doses altas dos antagonistas seletivos $\mathrm{ICl}$ 118,511 e CGP 20712. Assim, como ocorre uma janela estreita na seletividade do propranolol, isto poderia explicar o antagonismo funcional resultante da inibição simultânea dos receptores $\beta_{1}$ e $\beta_{2}$-adrenérgicos no NMA pelo propranolol, sobre as respostas cardiovasculares durante o ER. 
O aumento na PA e FC, induzido por esse estresse psicológico são predominantemente mediados por aumento na atividade do sistema nervoso simpático cardíaco (BARRON e VAN LOON, 1989). Além disso, o ER aumenta a atividade do eixo HPA (LANG et al., 1983; GIBBS, 1984; CARTER e LIGHTMAN, 1987; CALLAHAN et al., 1992; DAYAS et al., 1999). A ideia do envolvimento do NMA na mediação de respostas causadas por estresse é reforçada por dados na literatura que evidenciaram que a estimulação elétrica deste núcleo causa ativação do eixo HPA (DUNN e WHITENER, 1986).

Estruturas tais como a área septal lateral (KUBO et al., 2002; REIS et al., 2011); hipotálamo lateral (KROUT et al., 2005); córtex pré-frontal medial (TAVARES e CORREA, 2006); núcleo leito da estria terminales (CRESTANI et al., 2008) o NMA e o núcleo central da amígdala (NCA) (KUBO et al., 2004; SALOME et al., 2007; FORTALEZA et al., 2009) e o núcleo paraventricular do hipotálamo (PVN) (BUSNARDO et al., 2009b; TAVARES et al., 2009), fazem parte do circuito que modula as respostas cardiovasculares evocadas por ER.

Além dos diferentes papeis desempenhados pelos receptores adrenérgicos do NMA sobre a modulação das respostas cardiovasculares desencadeadas pelo ER, nossos resultados demonstraram claramente que a neurotransmissão noradrenérgica do NMA atua sobre o componente cardíaco da resposta cardiovascular ao estresse. A resposta taquicárdica evocada pelo ER em ratos está bem documentada por vários autores (BARRON e VAN LOON, 1989; CHEN e HERBERT, 1995; MCDOUGALL et al., 2005). Existem evidências que sugerem a amígdala como um drive responsável pelo aumento cardiáco simpático. A estimulação eléctrica ou química da amígdala causa aumento da frequência cardíaca (GALENO e BRODY, 1983; GELSEMA et al., 1987; AL MASKATI e 
ZBROZYNA, 1989; SOLTIS et al., 1998), sugerindo o envolvimento desta área na modulação de respostas cardíacas.

Em resumo, nossos resultados sugerem o envolvimento dos receptores $\alpha_{2}$ adrenérgicos na mediação das respostas cardiovasculares causadas pela microinjeção local de NA no NMA, dependente da liberação de vasopressina, pela ativação dos núcleos hipotalâmicos NPV e NSO em ratos. Além disso, os resultados indicam que receptores adrenérgicos do subtipo $\alpha_{1}$ e $\alpha_{2}$ presentes no NMA exercem, respectivamente papel facilitatório e inibitório, sobre o componente cardíaco das respostas cardiovasculares ao ER em ratos, e que os receptores $\beta_{1}$ e $\beta_{2^{-}}$ adrenérgicos também exercem papeis opostos no NMA no controle das resposta tarquicárdica evocada pelo ER. Os receptores $\beta_{2}$-adrenérgicos desempenham uma influência inibitória sobre a resposta taquicárdica ao $E R$, enquanto os receptores $\beta_{1^{-}}$ adrenérgicos desempenham uma influência facilitatória sobre a resposta taquicárdica ao ER.

Dessa forma, podemos concluir que a neurotransmissão noradrenérgica no NMA participa de um circuito neuronal envolvido na modulação de respostas cardiovasculares observadas durante exposição a situações aversivas. 


\section{CONCLUSÕES}

O trabalho apresentado nos permite concluir que;

- A microinjeção de NA no NMA causa respostas pressoras e bradicárdicas de forma dose-dependente e que essas repostas envolvem a ativação de receptores $\alpha_{2}$ adrenégicos presentes no NMA que causam a liberação de vasopressina para a circulação periférica.

- Os núcleos paraventricular (NPV) e supra-óptico (NSO) do hipotálamo, que sintetizam vasopressina são as estruturas finais envolvidas nas respostas cardiovasculares desencadeadas pela microinjeção de NA no NMA.

- Os receptores adrenérgicos do subtipo $\alpha_{1}$ e $\alpha_{2}$ presentes no NMA exercem, respectivamente papel facilitatório e inibitório, sobre o componente cardíaco das respostas cardiovasculares ao ER em ratos, e que os receptores $\beta_{1}$ e $\beta_{2^{-}}$ adrenérgicos também exercem papeis opostos no NMA no controle da resposta tarquicárdica evocada pelo ER. Os receptores $\beta_{2}$-adrenérgicos desempenham uma influência inibitória sobre a resposta taquicárdica ao ER, enquanto os receptores $\beta_{1}$ adrenérgicos desempenham uma influência facilitatória sobre a resposta taquicárdica ao ER. 


\section{REFERÊNCIAS BIBLIOGRÁFICAS}

ABERCROMBIE, E. D.; JACOBS, B. L. Single-unit response of noradrenergic neurons in the locus coeruleus of freely moving cats. I. Acutely presented stressful and nonstressful stimuli. J Neurosci, v. 7, n. 9, p. 2837-43, Sep 1987.

ABRAHAM, P. A. et al. beta1- and beta2-adrenoceptor induced synaptic facilitation in rat basolateral amygdala. Brain Res, v. 1209, p. 65-73, May 132008.

AGGLETON, J. P. The amygdala, a functional analysis. 2. Oxford: Oxford University Press, 2000.

AGGLETON, J. P.; KENTRIDGE, R. W.; SEMBI, S. Lesions of the fornix but not the amygdala impair the acquisition of concurrent discriminations by rats. Behav Brain Res, v. 48, n. 2, p. 103-12, Jun 81992.

AL MASKATI, H. A.; ZBROZYNA, A. W. Cardiovascular and motor components of the defence reaction elicited in rats by electrical and chemical stimulation in amygdala. J Auton Nerv Syst, v. 28, n. 2, p. 127-31, Nov 1989.

ALONSO, G. et al. Immunocytochemical evidence for stimulatory control by the ventral noradrenergic bundle of parvocellular neurons of the paraventricular nucleus secreting corticotropin releasing hormone and vasopressin in rats. Brain Res, v. 397, n. 2, p. 297-307, Nov 121986.

ALVES, F. H. et al. Hypothalamic supraoptic but not paraventricular nucleus is involved in cardiovascular responses to carbachol microinjected into the bed nucleus of stria terminalis of unanesthetized rats. Brain Res, v. 1393, p. 31-43, Jun 12011.

ARIMA, J. et al. alpha2-Adrenoceptor-mediated potassium currents in acutely dissociated rat locus coeruleus neurones. J Physiol, v. 508 ( Pt 1), p. 57-66, Apr 1 1998. ISSN 0022-3751 (Print).

ARNOLD, F. J. et al. Expression of $\mathrm{c}$-fos in regions of the basal limbic forebrain following intracerebroventricular corticotropin-releasing factor in unstressed or stressed male rats. Neuroscience, v. 51, n. 2, p. 377-90, Nov 1992.

ASTON-JONES, G.; RAJKOWSKI, J.; COHEN, J. Role of locus coeruleus in attention and behavioral flexibility. Biol Psychiatry, v. 46, n. 9, p. 1309-20, Nov 1 1999. 
BARRON, B. A.; VAN LOON, G. R. Role of sympathoadrenomedullary system in cardiovascular response to stress in rats. J Auton Nerv Syst, v. 28, n. 2, p. 179-87, Nov 1989.

BAUDRIE, V. et al. Autonomic components of the cardiovascular responses to an acoustic startle stimulus in rats. J Auton Pharmacol, v. 17, n. 5, p. 303-9, Oct 1997.

BERNTSON, G. G.; CACIOPPO, J. T.; QUIGLEY, K. S. Autonomic determinism: the modes of autonomic control, the doctrine of autonomic space, and the laws of autonomic constraint. Psychol Rev, v. 98, n. 4, p. 459-87, Oct 1991.

BHATNAGAR, S.; DALLMAN, M. Neuroanatomical basis for facilitation of hypothalamic-pituitary-adrenal responses to a novel stressor after chronic stress. Neuroscience, v. 84, n. 4, p. 1025-39, Jun 1998.

BONDI, C. O. et al. Noradrenergic facilitation of shock-probe defensive burying in lateral septum of rats, and modulation by chronic treatment with desipramine. Prog Neuropsychopharmacol Biol Psychiatry, v. 31, n. 2, p. 482-95, Mar 30 2007. ISSN 0278-5846 (Print).

BUSNARDO, C. et al. Cardiovascular effects of L-glutamate microinjection in the supraoptic nucleus of unanaesthetized rats. Neuropharmacology, v. 52, n. 6, p. 1378-84, May 2007.

BUSNARDO, C.; TAVARES, R. F.; CORREA, F. M. Mechanisms involved in the pressor response to noradrenaline microinjection into the supraoptic nucleus of unanesthetized rats. Auton Neurosci, v. 145, n. 1-2, p. 63-70, Jan 28 2009a. ISSN 1872-7484 (Electronic).

BUSNARDO, C.; TAVARES, R. F.; CORREA, F. M. Role of N-methyl-D-aspartate and non-N-methyl-D-aspartate receptors in the cardiovascular effects of L-glutamate microinjection into the hypothalamic paraventricular nucleus of unanesthetized rats. $\mathbf{J}$ Neurosci Res, v. 87, n. 9, p. 2066-77, Jul 2009b.

BUSNARDO, $C$. et al. Paraventricular nucleus modulates autonomic and neuroendocrine responses to acute restraint stress in rats. Auton Neurosci, v. 158, n. 1-2, p. 51-7, Dec 82010.

CAMPEAU, S. et al. Induction of the c-fos proto-oncogene in rat amygdala during unconditioned and conditioned fear. Brain Res, v. 565, n. 2, p. 349-52, Nov 291991. ISSN 0006-8993 (Print)0006-8993 (Linking). 
CAMPEAU, S.; WATSON, S. J. Neuroendocrine and behavioral responses and brain pattern of c-fos induction associated with audiogenic stress. J Neuroendocrinol, v. 9, n. 8, p. 577-88, Aug 1997.

CANTERAS, N. S.; SIMERLY, R. B.; SWANSON, L. W. Organization of projections from the medial nucleus of the amygdala: a PHAL study in the rat. J Comp Neurol, v. 360, n. 2, p. 213-45, Sep 181995.

CARRIVE, P. Cardiovascular and behavioural components of conditioned fear to context after ganglionic and alpha-adrenergic blockade. Auton Neurosci, v. 98, n. 12, p. 90-3, Jun 282002.

CARRIVE, P. Dual activation of cardiac sympathetic and parasympathetic components during conditioned fear to context in the rat. Clin Exp Pharmacol Physiol, v. 33, n. 12, p. 1251-4, Dec 2006.

CARTER, R. N.; PINNOCK, S. B.; HERBERT, J. Does the amygdala modulate adaptation to repeated stress? Neuroscience, v. 126, n. 1, p. 9-19, 2004. ISSN 0306-4522 (Print)0306-4522 (Linking).

$\mathrm{CECCHI}, \mathrm{M}$. et al. Modulatory effects of norepinephrine in the lateral bed nucleus of the stria terminalis on behavioral and neuroendocrine responses to acute stress. Neuroscience, v. 112, n. 1, p. 13-21, 2002. ISSN 0306-4522 (Print).

CECCHI, M.; KHOSHBOUEI, H.; MORILAK, D. A. Modulatory effects of norepinephrine, acting on alpha 1 receptors in the central nucleus of the amygdala, on behavioral and neuroendocrine responses to acute immobilization stress. Neuropharmacology, v. 43, n. 7, p. 1139-47, Dec 2002.

CHEN, X.; HERBERT, J. Regional changes in c-fos expression in the basal forebrain and brainstem during adaptation to repeated stress: correlations with cardiovascular, hypothermic and endocrine responses. Neuroscience, v. 64, n. 3, p. 675-85, Feb 1995.

CIRIELLO, J.; CALARESU, F. R. Role of paraventricular and supraoptic nuclei in central cardiovascular regulation in the cat. Am J Physiol, v. 239, n. 1, p. R137-42, Jul 1980.

CONTI, L. H. et al. Repeated restraint stress-induced increase in baroreceptor reflex sensitivity: role of corticotropin-releasing factor. Neuropeptides, v. 35, n. 2, p. 71-81, Apr 2001. ISSN 0143-4179 (Print)0143-4179 (Linking). 
CORREA, F. M. et al. Mechanism of the CNS-mediated pressor response to intracerebroventricular injection of noradrenaline in unanaesthetized rats. Neuropharmacology, v. 24, n. 9, p. 831-7, Sep 1985.

COWLEY, A. W., JR.; BARBER, B. J. Vasopressin vascular and reflex effects--a theoretical analysis. Prog Brain Res, v. 60, p. 415-24, 1983. ISSN 0079-6123 (Print).

COWLEY, A. W., JR.; LIARD, J. F. Vasopressin and arterial pressure regulation. Special lecture. Hypertension, v. 11, n. 2 Pt 2, p. 125-32, Feb 1988. ISSN 0194911X (Print).

CRANE, J. W.; FRENCH, K. R.; BULLER, K. M. Patterns of neuronal activation in the rat brain and spinal cord in response to increasing durations of restraint stress. Stress, v. 8, n. 3, p. 199-211, Sep 2005.

CRESTANI, C. C. et al. Cardiovascular effects of noradrenaline microinjection in the bed nucleus of the stria terminalis of the rat brain. $\mathbf{J}$ Neurosci Res, v. 85, n. 7, p. 1592-9, May 15 2007. ISSN 0360-4012 (Print).

CRESTANI, C. C. et al. Both alpha1 and alpha2-adrenoceptors mediate the cardiovascular responses to noradrenaline microinjected into the bed nucleus of the stria terminal of rats. Br J Pharmacol, v. 153, n. 3, p. 583-90, Feb 2008. ISSN 00071188 (Print).

CRESTANI, C. C. et al. Role of the bed nucleus of the stria terminalis in the cardiovascular responses to acute restraint stress in rats. Stress, v. 12, n. 3, p. 26878, 2009.

CRESTANI, C. C. et al. Involvement of hypothalamic paraventricular nucleus non-Nmethyl-D-aspartate receptors in the pressor response to noradrenaline microinjected into the bed nucleus of the stria terminalis of unanesthetized rats. Eur J Neurosci, v. 29, n. 11, p. 2166-76, Jun 2009.

CULLINAN, W. E. et al. Pattern and time course of immediate early gene expression in rat brain following acute stress. Neuroscience, v. 64, n. 2, p. 477-505, Jan 1995.

DAMPNEY, R. A. Functional organization of central pathways regulating the cardiovascular system. Physiol Rev, v. 74, n. 2, p. 323-64, Apr 1994.

DAVIS, M. The role of the amygdala in fear and anxiety. Annu Rev Neurosci, v. 15, p. 353-75, 1992. 
DAYAS, C. V. et al. Stressor categorization: acute physical and psychological stressors elicit distinctive recruitment patterns in the amygdala and in medullary noradrenergic cell groups. Eur J Neurosci, v. 14, n. 7, p. 1143-52, Oct 2001.

DAYAS, C. V.; BULLER, K. M.; DAY, T. A. Neuroendocrine responses to an emotional stressor: evidence for involvement of the medial but not the central amygdala. Eur J Neurosci, v. 11, n. 7, p. 2312-22, Jul 1999.

DAYAS, C. V.; BULLER, K. M.; DAY, T. A. Medullary neurones regulate hypothalamic corticotropin-releasing factor cell responses to an emotional stressor. Neuroscience, v. 105, n. 3, p. 707-19, 2001.

DAYAS, C. V.; DAY, T. A. Opposing roles for medial and central amygdala in the initiation of noradrenergic cell responses to a psychological stressor. Eur $\mathbf{J}$ Neurosci, v. 15, n. 10, p. 1712-8, May 2002.

DENNIS, T. et al. Presynaptic alpha-2 adrenoceptors play a major role in the effects of idazoxan on cortical noradrenaline release (as measured by in vivo dialysis) in the rat. J Pharmacol Exp Ther, v. 241, n. 2, p. 642-9, May 1987.

DINGMAN, J. F.; GAITAN, E. Subcortical stimulation of the brain and release of antidiuretic hormone in man. J Clin Endocrinol Metab, v. 19, p. 1346-9, Oct 1959. ISSN 0021-972X (Print).

DOMYANCIC, A. V.; MORILAK, D. A. Distribution of alpha1A adrenergic receptor mRNA in the rat brain visualized by in situ hybridization. J Comp Neurol, v. 386, n. 3, p. 358-78, Sep 291997.

DUNCAN, G. E.; KNAPP, D. J.; BREESE, G. R. Neuroanatomical characterization of Fos induction in rat behavioral models of anxiety. Brain Res, v. 713, n. 1-2, p. 79-91, Mar 25 1996. ISSN 0006-8993 (Print)0006-8993 (Linking).

FAIERS, A. A.; CALARESU, F. R.; MOGENSON, G. J. Pathway mediating hypotension elicited by stimulation of the amygdala in the rat. Am J Physiol, v. 228, n. 5, p. 1358-66, May 1975.

FERNANDES, K. B. et al. Mechanisms involved in the pressor response to noradrenaline injection into the cingulate cortex of unanesthetized rats. Neuropharmacology, v. 44, n. 6, p. 757-63, May 2003. ISSN 0028-3908 (Print).

FERNANDES, K. B. et al. The paraventricular nucleus of hypothalamus mediates the pressor response to noradrenergic stimulation of the medial prefrontal cortex in unanesthetized rats. Neurosci Lett, v. 426, n. 2, p. 101-5, Oct 162007. 
FINN, D. P. et al. Imidazoline(2) (I(2)) binding site- and alpha(2)-adrenoceptormediated modulation of central noradrenergic and HPA axis function in control rats and chronically stressed rats with adjuvant-induced arthritis. Neuropharmacology, v. 42, n. 7, p. 958-65, Jun 2002.

FLUGGE, G.; AHRENS, O.; FUCHS, E. Monoamine receptors in the amygdaloid complex of the tree shrew (Tupaia belangeri). J Comp Neurol, v. 343, n. 4, p. 597608, May 22 1994. ISSN 0021-9967 (Print).

FORTALEZA, E. A.; TAVARES, R. F.; CORREA, F. M. The medial amygdaloid nucleus modulates cardiovascular responses to acute restraint in rats. Neuroscience, v. 159, n. 2, p. 717-26, Mar 17 2009. ISSN 0306-4522 (Print).

FURUSE, J. et al. Adverse hepatic events caused by radiotherapy for advanced hepatocellular carcinoma. J Gastroenterol Hepatol, v. 20, n. 10, p. 1512-8, Oct 2005. ISSN 0815-9319 (Print)0815-9319 (Linking).

GALENO, T. M.; BRODY, M. J. Hemodynamic responses to amygdaloid stimulation in spontaneously hypertensive rats. Am J Physiol, v. 245, n. 2, p. R281-6, Aug 1983.

GALENO, T. M.; VAN HOESEN, G. W.; BRODY, M. J. Central amygdaloid nucleus lesion attenuates exaggerated hemodynamic responses to noise stress in the spontaneously hypertensive rat. Brain Res, v. 291, n. 2, p. 249-59, Jan 231984.

GALENO, T. M. et al. Contribution of the amygdala to the development of spontaneous hypertension. Brain Res, v. 246, n. 1, p. 1-6, Aug 191982.

GELSEMA, A. J.; MCKITRICK, D. J.; CALARESU, F. R. Cardiovascular responses to chemical and electrical stimulation of amygdala in rats. Am J Physiol, v. 253, n. $5 \mathrm{Pt}$ 2, p. R712-8, Nov 1987.

GOLD, P. W.; CHROUSOS, G. P. The endocrinology of melancholic and atypical depression: relation to neurocircuitry and somatic consequences. Proc Assoc Am Physicians, v. 111, n. 1, p. 22-34, Jan-Feb 1999.

GUERTZENSTEIN, P. G.; SILVER, A. Fall in blood pressure produced from discrete regions of the ventral surface of the medulla by glycine and lesions. J Physiol, $v$. 242, n. 2, p. 489-503, Oct 1974.

GUYENET, P. G.; DARNALL, R. A.; RILEY, T. A. Rostral ventrolateral medulla and sympathorespiratory integration in rats. Am J Physiol, v. 259, n. 5 Pt 2, p. R1063-74, Nov 1990. 
HAMAMURA, M.; SHIBUKI, K.; YAGI, K. Amygdalar inputs to ADH-secreting supraoptic neurones in rats. Exp Brain Res, v. 48, n. 3, p. 420-8, 1982.

HARBUZ, M. S. et al. Paradoxical responses of hypothalamic corticotropin-releasing factor (CRF) messenger ribonucleic acid (mRNA) and CRF-41 peptide and adenohypophysial proopiomelanocortin mRNA during chronic inflammatory stress. Endocrinology, v. 130, n. 3, p. 1394-400, Mar 1992.

HAYWARD, J. N.; SMITH, W. K. Influence of Limbic System on Neurohypophysis. Arch Neurol, v. 9, p. 171-7, Aug 1963. ISSN 0003-9942 (Print).

HERMAN, J. P.; RENDA, A.; BODIE, B. Norepinephrine-gamma-aminobutyric acid (GABA) interaction in limbic stress circuits: effects of reboxetine on GABAergic neurons. Biol Psychiatry, v. 53, n. 2, p. 166-74, Jan 15 2003. ISSN 0006-3223 (Print).

HILTON, S. M. Hypothalamic regulation of the cardiovascular system. Br Med Bull, v. 22, n. 3, p. 243-8, Sep 1966.

HILTON, S. M.; ZBROZYNA, A. W. Amygdaloid region for defence reactions and its efferent pathway to the brain stem. J Physiol, v. 165, p. 160-73, Jan 1963.

$\mathrm{ITOH}, \quad \mathrm{Y}$. et al. In vivo measurement of noradrenaline and 3,4dihydroxyphenylethyleneglycol in the rat hypothalamus by microdialysis: effects of various drugs affecting noradrenaline metabolism. J Pharmacol Exp Ther, v. 255, n. 3, p. 1090-7, Dec 1990.

IWATA, J.; LEDOUX, J. E. Dissociation of associative and nonassociative concomitants of classical fear conditioning in the freely behaving rat. Behav Neurosci, v. 102, n. 1, p. 66-76, Feb 1988.

JOHNSON, E. O. et al. Mechanisms of stress: a dynamic overview of hormonal and behavioral homeostasis. Neurosci Biobehav Rev, v. 16, n. 2, p. 115-30, Summer 1992.

JONES, L. S.; GAUGER, L. L.; DAVIS, J. N. Localization of alpha 1-adrenergic receptors in normal and weaver mouse brain with in vitro 125I-HEAT autoradiography. Neurosci Lett, v. 65, n. 3, p. 259-64, Apr 24 1986. ISSN 03043940 (Print).

KAEHLER, S. T.; SINNER, C.; PHILIPPU, A. Release of catecholamines in the locus coeruleus of freely moving and anaesthetized normotensive and spontaneously hypertensive rats: effects of cardiovascular changes and tail pinch. Naunyn Schmiedebergs Arch Pharmacol, v. 361, n. 4, p. 433-9, Apr 2000. 
KAPUSTA, D. R.; DAYAN, L. A.; KENIGS, V. A. Nociceptin/orphanin FQ modulates the cardiovascular, but not renal, responses to stress in spontaneously hypertensive rats. Clin Exp Pharmacol Physiol, v. 29, n. 3, p. 254-9, Mar 2002.

KASTING, N. W. Simultaneous and independent release of vasopressin and oxytocin in the rat. Can J Physiol Pharmacol, v. 66, n. 1, p. 22-6, Jan 1988.

KAWAHARA, H.; KAWAHARA, Y.; WESTERINK, B. H. The role of afferents to the locus coeruleus in the handling stress-induced increase in the release of noradrenaline in the medial prefrontal cortex: a dual-probe microdialysis study in the rat brain. Eur J Pharmacol, v. 387, n. 3, p. 279-86, Jan 172000.

KNUEPFER, M. M. et al. Hemodynamic response patterns to acute behavioral stressors resemble those to cocaine. Am J Physiol Regul Integr Comp Physiol, v. 281, n. 6, p. R1778-86, Dec 2001.

KRETZ, R. Local cobalt injection: a method to discriminate presynaptic axonal from postsynaptic neuronal activity. J Neurosci Methods, v. 11, n. 2, p. 129-35, Jun 1984.

KROUT, K. E. et al. CNS neurons with links to both mood-related cortex and sympathetic nervous system. Brain Res, v. 1050, n. 1-2, p. 199-202, Jul 192005. ISSN 0006-8993 (Print)0006-8993 (Linking).

KUBO, T. et al. The lateral septal area is involved in mediation of immobilization stress-induced blood pressure increase in rats. Neurosci Lett, v. 318, n. 1, p. 25-8, Jan 182002.

KUBO, T. et al. Involvement of the medial amygdaloid nucleus in restraint stressinduced pressor responses in rats. Neurosci Lett, v. 354, n. 1, p. 84-6, Jan 22004.

LAITINEN, K. S.; TUOMISTO, L.; MACDONALD, E. Effects of a selective alpha 2adrenoceptor antagonist, atipamezole, on hypothalamic histamine and noradrenaline release in vivo. Eur J Pharmacol, v. 285, n. 3, p. 255-60, Oct 241995.

LAM, W.; LOUIS, W. J.; VERBERNE, A. J. Effect of dorsal periaqueductal grey lesion on baroreflex and cardiovascular response to air-jet stress. J Auton Nerv Syst, v. 53, n. 1, p. 35-42, May 171995.

LEDOUX, J. Fear and the brain: where have we been, and where are we going? Biol Psychiatry, v. 44, n. 12, p. 1229-38, Dec 151998. 
LI, H. Y.; SAWCHENKO, P. E. Hypothalamic effector neurons and extended circuitries activated in "neurogenic" stress: a comparison of footshock effects exerted acutely, chronically, and in animals with controlled glucocorticoid levels. J Comp Neurol, v. 393, n. 2, p. 244-66, Apr 61998.

LOEWY, A. D. Forebrain nuclei involved in autonomic control. Prog Brain Res, v. 87, p. 253-68, 1991.

LOEWY, A. D.; MCKELLAR, S. The neuroanatomical basis of central cardiovascular control. Fed Proc, v. 39, n. 8, p. 2495-503, Jun 1980.

MA, S.; MORILAK, D. A. Induction of FOS expression by acute immobilization stress is reduced in locus coeruleus and medial amygdala of Wistar-Kyoto rats compared to Sprague-Dawley rats. Neuroscience, v. 124, n. 4, p. 963-72, 2004.

MA, S.; MORILAK, D. A. Norepinephrine release in medial amygdala facilitates activation of the hypothalamic-pituitary-adrenal axis in response to acute immobilisation stress. J Neuroendocrinol, v. 17, n. 1, p. 22-8, Jan 2005.

MATSUMURA, K. et al. Central effects of leptin on cardiovascular and neurohormonal responses in conscious rabbits. Am J Physiol Regul Integr Comp Physiol, v. 278, n. 5, p. R1314-20, May 2000.

MCDONALD, A. J. Projections of the intermediate subdivision of the central amygdaloid nucleus to the bed nucleus of the stria terminalis and medial diencephalon. Neurosci Lett, v. 85, n. 3, p. 285-90, Mar 101988.

MCDONALD, A. J. Cortical pathways to the mammalian amygdala. Prog Neurobiol, v. 55, n. 3, p. 257-332, Jun 1998.

MCDOUGALL, S. J.; WIDDOP, R. E.; LAWRENCE, A. J. Central autonomic integration of psychological stressors: focus on cardiovascular modulation. Auton Neurosci, v. 123, n. 1-2, p. 1-11, Dec 302005.

MEDDLE, S. L. et al. Direct pathways to the supraoptic nucleus from the brainstem and the main olfactory bulb are activated at parturition in the rat. Neuroscience, v. 101, n. 4, p. 1013-21, 2000.

MERMET, C.; SUAUD-CHAGNY, M. F.; GONON, F. Electrically evoked noradrenaline release in the rat hypothalamic paraventricular nucleus studied by in vivo electrochemistry: autoregulation by alpha-2 receptors. Neuroscience, v. 34, n. 2, p. 423-32, 1990. 
MORIGUCHI, S. et al. Central administration of a nitric oxide synthase inhibitor causes pressor responses via the sympathetic nervous system and the reninangiotensin system in Wistar rats. Neurosci Lett, v. 245, n. 2, p. 109-12, Apr 31998.

MORILAK, D. A. et al. Role of brain norepinephrine in the behavioral response to stress. Prog Neuropsychopharmacol Biol Psychiatry, v. 29, n. 8, p. 1214-24, Dec 2005. ISSN 0278-5846 (Print).

MORILAK, D. A.; FRAZER, A. Antidepressants and brain monoaminergic systems: a dimensional approach to understanding their behavioural effects in depression and anxiety disorders. Int J Neuropsychopharmacol, v. 7, n. 2, p. 193-218, Jun 2004.

MULLER, J. R. et al. Hemodynamic response pattern predicts susceptibility to stress-induced elevation in arterial pressure in the rat. Am J Physiol Regul Integr Comp Physiol, v. 281, n. 1, p. R31-7, Jul 2001.

OHTA, H.; WATANABE, S.; UEKI, S. Cardiovascular changes induced by chemical stimulation of the amygdala in rats. Brain Res Bull, v. 26, n. 4, p. 575-81, Apr 1991.

ORDWAY, G. A.; GAMBARANA, C.; FRAZER, A. Quantitative autoradiography of central beta adrenoceptor subtypes: comparison of the effects of chronic treatment with desipramine or centrally administered l-isoproterenol. J Pharmacol Exp Ther, v. 247, n. 1, p. 379-89, Oct 1988.

PADOVAN, C. M.; DEL BEL, E. A.; GUIMARAES, F. S. Behavioral effects in the elevated plus maze of an NMDA antagonist injected into the dorsal hippocampus: influence of restraint stress. Pharmacol Biochem Behav, v. 67, n. 2, p. 325-30, Oct 2000. ISSN 0091-3057 (Print)0091-3057 (Linking).

PAPEZ, J. W. A proposed mechanism of emotion. 1937. J Neuropsychiatry Clin Neurosci, v. 7, n. 1, p. 103-12, Winter 1995. ISSN 0895-0172 (Print).

PARDON, M. C. et al. Stress reactivity of the brain noradrenergic system in three rat strains differing in their neuroendocrine and behavioral responses to stress: implications for susceptibility to stress-related neuropsychiatric disorders. Neuroscience, v. 115, n. 1, p. 229-42, 2002. ISSN 0306-4522 (Print).

PATON, J. F. et al. The yin and yang of cardiac autonomic control: vago-sympathetic interactions revisited. Brain Res Brain Res Rev, v. 49, n. 3, p. 555-65, Nov 2005.

PAXINOS, G.; WATSON, C. The Rat Brain in Stereotaxic Coordinates. Academic Press, Sidney, Australia., 1997. 
PELOSI, G. G.; CORREA, F. M. Cardiovascular effects of noradrenaline microinjected into the dorsal periaqueductal gray area of unanaesthetized rats. Eur $\mathbf{J}$ Neurosci, v. 22, n. 12, p. 3188-94, Dec 2005. ISSN 0953-816X (Print).

PELOSI, G. G. et al. Cardiovascular responses to noradrenaline microinjection in the ventrolateral periaqueductal gray of unanesthetized rats. J Neurosci Res, v. 86, n. 3, p. 712-9, Feb 15 2008. ISSN 1097-4547 (Electronic).

PELOSI, G. G. et al. Paraventricular nucleus mediates pressor response to noradrenaline injection into the dorsal periaqueductal gray area. Auton Neurosci, v. 151, n. 2, p. 74-81, Dec 32009.

PERSSON, P. B. Modulation of cardiovascular control mechanisms and their interaction. Physiol Rev, v. 76, n. 1, p. 193-244, Jan 1996. ISSN 0031-9333 (Print).

PEZZONE, M. A. et al. Induction of c-Fos immunoreactivity in the rat forebrain by conditioned and unconditioned aversive stimuli. Brain Res, v. 597, n. 1, p. 41-50, Nov 271992.

PITKANEN, A.; AMARAL, D. G. Distribution of reduced nicotinamide adenine dinucleotide phosphate diaphorase (NADPH-d) cells and fibers in the monkey amygdaloid complex. J Comp Neurol, v. 313, n. 2, p. 326-48, Nov 81991.

PITKANEN, A.; SAVANDER, V.; LEDOUX, J. E. Organization of intra-amygdaloid circuitries in the rat: an emerging framework for understanding functions of the amygdala. Trends Neurosci, v. 20, n. 11, p. 517-23, Nov 1997.

PRICE, J. L.; RUSSCHEN, F. T.; AMARAL, D. G. The Limbic Region. II: The Amygdaloid Complex. New York: Elsevier Science, 1987.

QUAGLIOTTO, E. et al. Histamine in the posterodorsal medial amygdala modulates cardiovascular reflex responses in awake rats. Neuroscience, v. 157, n. 4, p. 70919, Dec 102008.

RAINBOW, T. C.; PARSONS, B.; WOLFE, B. B. Quantitative autoradiography of beta 1- and beta 2-adrenergic receptors in rat brain. Proc Natl Acad Sci U S A, v. 81, n. 5, p. 1585-9, Mar 1984.

REIS, D. G. et al. Behavioral and autonomic responses to acute restraint stress are segregated within the lateral septal area of rats. PLoS One, v. 6, n. 8, p. e23171, 2011.

REIS, D. J. The brain and hypertension: reflections on 35 years of inquiry into the neurobiology of the circulation. Circulation, v. 70, n. 5 Pt 2, p. III31-45, Nov 1984. 
RESSTEL, L. B.; FERNANDES, K. B.; CORREA, F. M. Medial prefrontal cortex modulation of the baroreflex parasympathetic component in the rat. Brain Res, $\mathrm{V}$. 1015, n. 1-2, p. 136-44, Jul 232004.

RODER, S.; CIRIELLO, J. Innervation of the amygdaloid complex by catecholaminergic cell groups of the ventrolateral medulla. J Comp Neurol, v. 332, n. 1, p. 105-22, Jun 11993.

SADIKOT, A. F.; PARENT, A. The monoaminergic innervation of the amygdala in the squirrel monkey: an immunohistochemical study. Neuroscience, v. 36, n. 2, p. 43147, 1990.

SAH, P. et al. The amygdaloid complex: anatomy and physiology. Physiol Rev, v. 83, n. 3, p. 803-34, Jul 2003.

SALOME, N.; NGAMPRAMUAN, S.; NALIVAIKO, E. Intra-amygdala injection of GABAA agonist, muscimol, reduces tachycardia and modifies cardiac sympathovagal balance during restraint stress in rats. Neuroscience, v. 148, n. 2, p. 335-41, Aug 24 2007. ISSN 0306-4522 (Print)0306-4522 (Linking).

SANDERS, B. J. et al. Central amygdaloid lesions attenuate cardiovascular responses to acute stress in rats with borderline hypertension. Physiol Behav, v. 56, n. 4, p. 709-13, Oct 1994.

SAWCHENKO, P. E.; SWANSON, L. W. The organization of forebrain afferents to the paraventricular and supraoptic nuclei of the rat. J Comp Neurol, v. 218, n. 2, p. 121-44, Aug 11983.

SCOPINHO, A. A.; FORTALEZA, E. A.; CORREA, F. M. The medial amygdaloid nucleus is involved in the cardiovascular pathway activated by noradrenaline into the lateral septal area of rats. Eur J Neurosci, Jul 15 2012. ISSN 1460-9568 (Electronic) 0953-816X (Linking).

SCOPINHO, A. A. et al. Pressor effects of noradrenaline injected into the lateral septal area of unanesthetized rats. Brain Res, v. 1122, n. 1, p. 126-34, Nov 292006. ISSN 0006-8993 (Print).

SCOPINHO, A. A. et al. Non-N-methyl-D-aspartate glutamate receptors in the paraventricular nucleus of hypothalamus mediate the pressor response evoked by noradrenaline microinjected into the lateral septal area in rats. J Neurosci Res, v. 86, n. 14, p. 3203-11, Nov 12008. 
SILVERMAN, A. J.; HOFFMAN, D. L.; ZIMMERMAN, E. A. The descending afferent connections of the paraventricular nucleus of the hypothalamus (PVN). Brain Res Bull, v. 6, n. 1, p. 47-61, Jan 1981.

SILVERMAN, A. J.; ZIMMERMAN, E. A. Magnocellular neurosecretory system. Annu Rev Neurosci, v. 6, p. 357-80, 1983.

SIMS, K. S.; WILLIAMS, R. S. The human amygdaloid complex: a cytologic and histochemical atlas using Nissl, myelin, acetylcholinesterase and nicotinamide adenine dinucleotide phosphate diaphorase staining. Neuroscience, v. 36, n. 2, p. 449-72, 1990.

SOLTIS, R. P. et al. EAA receptors in the dorsomedial hypothalamic area mediate the cardiovascular response to activation of the amygdala. Am J Physiol, v. 275, n. 2 Pt 2, p. R624-31, Aug 1998.

SOUTHWICK, S. M. et al. Abnormal noradrenergic function in posttraumatic stress disorder. Arch Gen Psychiatry, v. 50, n. 4, p. 266-74, Apr 1993.

STOCK, G. et al. Psychomotor behaviour and cardiovascular patterns during stimulation of the amygdala. Pflugers Arch, v. 376, n. 2, p. 177-84, Sep 61978.

SULLIVAN, G. M. et al. The noradrenergic system in pathological anxiety: a focus on panic with relevance to generalized anxiety and phobias. Biol Psychiatry, v. 46, n. 9, p. 1205-18, Nov 11999.

TAVARES, R. F.; CORREA, F. M. Role of the medial prefrontal cortex in cardiovascular responses to acute restraint in rats. Neuroscience, v. 143, n. 1, p. 231-40, Nov 172006.

TAVARES, R. F.; DE AGUIAR CORREA, F. M. Pressor effects of L-glutamate injected into the diagonal band of Broca of unanesthetized rats. Brain Res, v. 959, n. 2, p. 312-9, Jan 102003.

TAVARES, R. F. et al. Neural connections between prosencephalic structures involved in vasopressin release. Cell Mol Neurobiol, v. 25, n. 3-4, p. 663-72, Jun 2005.

TAVARES, R. F.; PELOSI, G. G.; CORREA, F. M. The paraventricular nucleus of the hypothalamus is involved in cardiovascular responses to acute restraint stress in rats. Stress, v. 12, n. 2, p. 178-85, 2009. 
THOMAS, D. N.; HOLMAN, R. B. A microdialysis study of the regulation of endogenous noradrenaline release in the rat hippocampus. J Neurochem, v. $56, \mathrm{n}$. 5, p. 1741-6, May 1991.

THRIVIKRAMAN, K. V.; SU, Y.; PLOTSKY, P. M. Patterns of Fos-Immunoreactivity in the CNS Induced by Repeated Hemorrhage in Conscious Rats: Correlations with Pituitary-Adrenal Axis Activity. Stress, v. 2, n. 2, p. 145-158, Dec 1997. ISSN 16078888 (Electronic)1025-3890 (Linking).

TJURMINA, O. A. et al. Alpha2-adrenoceptor-mediated restraint of norepinephrine synthesis, release, and turnover during immobilization in rats. Brain Res, v. 826, n. 2, p. 243-52, May 11999.

TRNECKOVA, L. et al. Differences in the brain expression of c-fos mRNA after restraint stress in Lewis compared to Sprague-Dawley rats. Brain Res, v. 1077, n. 1, p. 7-15, Mar 102006.

UNNERSTALL, J. R.; KOPAJTIC, T. A.; KUHAR, M. J. Distribution of alpha 2 agonist binding sites in the rat and human central nervous system: analysis of some functional, anatomic correlates of the pharmacologic effects of clonidine and related adrenergic agents. Brain Res, v. 319, n. 1, p. 69-101, Mar 1984. ISSN 0006-8993 (Print).

VAN DEN BUUSE, $M$. et al. Blood pressure, heart rate, and behavioral responses to psychological "novelty" stress in freely moving rats. Psychophysiology, v. 38, n. 3, p. 490-9, May 2001.

VAN GINKEL, F. W. et al. Enterotoxin-based mucosal adjuvants alter antigen trafficking and induce inflammatory responses in the nasal tract. Infect Immun, v. 73, n. 10, p. 6892-902, Oct 2005. ISSN 0019-9567 (Print)0019-9567 (Linking).

VLAHAKOS, D.; GAVRAS, I.; GAVRAS, H. alpha-Adrenoceptor agonists applied in the area of the nucleus tractus solitarii in the rat: effect of anesthesia on cardiovascular responses. Brain Res, v. 347, n. 2, p. 372-5, Nov 181985.

WORTLEY, K. E.; HEAL, D. J.; STANFORD, S. C. Modulation of sibutramineinduced increases in extracellular noradrenaline concentration in rat frontal cortex and hypothalamus by alpha2-adrenoceptors. Br J Pharmacol, v. 128, n. 3, p. 65966, Oct 1999.

WORTLEY, K. E. et al. Comparison of changes in the extracellular concentration of noradrenaline in rat frontal cortex induced by sibutramine or d-amphetamine: modulation by alpha2-adrenoceptors. Br J Pharmacol, v. 127, n. 8, p. 1860-6, Aug 1999. 
YANG, C. R.; SENATOROV, V. V.; RENAUD, L. P. Organum vasculosum lamina terminalis-evoked postsynaptic responses in rat supraoptic neurones in vitro. $\mathbf{J}$ Physiol, v. 477 ( Pt 1), p. 59-74, May 151994.

YOSHINO, K. et al. Closed-loop analysis of cardiovascular variability in rats under restraint stress. Auton Neurosci, v. 119, n. 1, p. 61-6, Apr 29 2005. ISSN 1566-0702 (Print)1566-0702 (Linking). 


\title{
ANEXOS
}

\section{Cardiovascular responses to microinjection of noradrenaline into the medial amygdaloid nucleus of conscious rats result from $\alpha_{2}$-receptor activation and vasopressin release}

Eduardo Albino Trindade Fortaleza, América Augusto Scopinho and Fernando Morgan de Aguiar Corrêa Department of Pharmacology, School of Medicine of Ribeirão Preto, University of São Paulo, Bandeirantes Avenue, 3900, Ribeirão Preto, SP 14049-900, Brazil

Keywords: $\alpha_{2}$-adrenoceptor, cardiovascular system, noradrenergic system, vasopressin

\begin{abstract}
The medial amygdaloid nucleus $(\mathrm{MeA})$ is involved in the modulation of physiological and behavioral processes, as well as regulation of the autonomic nervous system. Moreover, MeA electrical stimulation evokes cardiovascular responses. Thus, as noradrenergic receptors are present in this structure, the present study tested the effects of local noradrenaline (NA) microinjection into the MeA on cardiovascular responses in conscious rats. Moreover, we describe the types of adrenoceptor involved and the peripheral mechanisms involved in the cardiovascular responses. Increasing doses of NA (3, 9, 27 or $45 \mathrm{nmol} / 100 \mathrm{~nL})$ microinjected into the $\mathrm{MeA}$ of conscious rats caused dose-related pressor and bradycardic responses. The NA cardiovascular effects were abolished by local pretreatment of the MeA with $10 \mathrm{nmol} / 100 \mathrm{~nL}$ of the specific $\alpha_{2}$-receptor antagonist RX821002, but were not affected by local pretreatment with $10 \mathrm{nmol} / 100 \mathrm{~nL}$ of the specific $\alpha_{1}$-receptor antagonist WB4101. The magnitude of pressor response evoked by NA microinjected into the MeA was potentiated by intravenous pretreatment with the ganglion blocker pentolinium $(5 \mathrm{mg} / \mathrm{kg})$, and blocked by intravenous pretreatment with the selective $\mathrm{V}_{1}$-vasopressin antagonist dTyr $\left(\mathrm{CH}_{2}\right)_{5}(\mathrm{Me}) \mathrm{AVP}(50 \mu \mathrm{g} / \mathrm{kg})$. In conclusion, our results show that microinjection of $\mathrm{NA}$ into the $\mathrm{MeA}$ of conscious rats activates local $\alpha_{2}$-adrenoceptors, evoking pressor and bradycardic responses, which are mediated by vasopressin release.
\end{abstract}

Introduction

The amygdaloid complex is a limbic structure involved in the modulation of physiological and behavioral processes, as well as in regulation of the autonomic nervous system (Eleftheriou, 1973; Ben-Ari, 1981; Davis, 1992; Pitkanen et al., 1997; LeDoux, 1998; Aggleton, 2000; Sah et al., 2003). The amygdaloid complex is divided into three groups: (i) the deep or basolateral group, which includes the lateral, basal and accessory basal nuclei; (ii) the superficial or cortical-like group, which includes the cortical nuclei and the nucleus of the lateral olfactory tract; and (iii) the centromedial group, composed of the medial and central nuclei (Pitkanen et al. 1997; Sah et al., 2003).

The medial amygdaloid nucleus $(\mathrm{MeA})$ modulates stress responses and is involved in cardiovascular regulation (Gelsema et al., 1987; Ma \& Morilak, 2005). Previous results have shown that local electrical stimulation of the MeA in anesthetized rats is able to evoke increases of both mean arterial pressure (MAP) and heart rate (HR) (Faiers et al., 1975). However, the specific neurotransmitters involved with the cardiovascular responses are not clear.

Correspondence: Fernando Morgan de Aguiar Corrẻa, as above.

E-mail: fmdacorr $a$ fimm. usp.br

Received 29 Octoher 2010, revised 8 February 2011, accepted 10 February 2011
Noradrenaline (NA) is a neurotransmitter with an important role in central cardiovascular regulation and is a mediator in several structures of the central nervous system. Cardiovascular responses were observed after microinjection of $\mathrm{NA}$ into brain regions involved in modulation of the cardiovascular system, such as the nucleus of the solitary tract (Vlahakos et al., 1985), the medial prefrontal cortex (Fernandes et al., 2003), the periaqueductal gray area (Pelosi \& Correa, 2005), the lateral septal area (Scopinho et al., 2006), the bed nucleus of the stria terminalis (Crestani et al., 2007), the supraoptic nucleus (Busnardo et al., 2009), and the amygdala (Ohta et al., 1991). The $\mathrm{MeA}$ receives substantial noradrenergic innervations originating in the A6 neurons in the locus coeruleus and other groups of noradrenergic neurons located in the lateral tegmental area (Sadikot \& Parent, 1990; Roder \& Ciriello, 1993). Furthermore, studies of expression of mRNA and binding detected the presence of noradrenergic receptor subtypes $\alpha$ and $\beta$ in the MeA (Jones et al., 1986; Domyancic \& Morilak, 1997), suggesting the existence of the noradrenergic system in this area. Finally, it was shown that NA microinjected into the amygdaloid complex evoked pressor and bradycardic responses (Ohta et al., 1991). However, this study did not differentiate which nucleus of the amygdala the NA effects depended on and what peripheral and central mechanisms could be involved in these responses. Thus, as the MeA is connected with other brain 
1678 E. A. T. Fortaleza et al.

structures of the limbic system involved in cardiovascular control (Ohta et al., 1991; Dampney, 1994; Cecchi et al., 2002a,b; Pardon et al., 2002; Ma \& Morilak, 2005; Morilak et al., 2005) and there is evidence of the presence of a noradrenergic system in this area, it is important to investigate the role of the noradrenergic system of the $\mathrm{MeA}$ in regulation of the cardiovascular system.

Therefore, in the present study, we studied the cardiovascular effects of NA microinjection into the MeA of conscious rats, the receptor subtype activated, and the peripheral mechanisms involved in these responses.

\section{Materials and methods \\ Animal preparation}

Male Wistar rats weighing 250-280 g were used. Animals were kept in the Animal Care Unit of the Department of Pharmacology of the School of Medicine of Ribeirão Preto, University of São Paulo. Rats were housed individually in plastic cages in a $20-25{ }^{\circ} \mathrm{C}$ temperaturecontrolled room, with free access to water and commercial chow. The Institution's animal ethics committee approved the housing conditions and the experimental protocol (no. 057/2009).

Animals were anesthetized with intraperitoneal tribromoethanol $(250 \mathrm{mg} / \mathrm{kg})$, and their heads were fixed to a stereotaxic apparatus (Stoelting, Wood Dale, IL, USA). The skull was surgically exposed and trepanned with a dental drill at a point located $3.4 \mathrm{~mm}$ from the midline and $6.2 \mathrm{~mm}$ anterior to the interaural line, according to the rat brain atlas of Paxinos and Watson (1997). Ipsilateral stainless steel guide cannulae $(24 \mathrm{G}, 15 \mathrm{~mm}$ ) were lowered $8.0 \mathrm{~mm}$ from the skull. Guide cannulae were positioned $1 \mathrm{~mm}$ above the intended injection sites, and fixed to the skull with a metal screw and dental cement. Animals were allowed to recover for $48 \mathrm{~h}$. A polyethylene catheter was implanted into the femoral artery under anesthesia for chronic recording of MAP and HR. The catheter was exposed on the dorsum of the animals and attached to the skin, allowing arterial pressure recording of conscious rats $24 \mathrm{~h}$ after surgery.

\section{Measurement of cardiovascular responses}

After surgery, the animals were kept in individual cages in the Animal Care Unit, which were then transported to the experimental room. Animals were allowed a period of $15 \mathrm{~min}$ to adapt to the conditions of the experimental room, such as sound and illumination, prior to the start of blood pressure and HR recording. The experimental room was acoustically isolated and had constant background noise generated by an air exhauster. At least one other period of $15 \mathrm{~min}$ was allowed before the experiments were initiated, and care was taken to start injection whenever a stable blood pressure and, especially, HR were observed. The injection needle was slowly introduced into the guide cannulae without the animals being touching or restrained. The pulsatile arterial pressure (PAP) of freely moving animals was recorded with an HP-7754A preamplifier (Hewlett Packard, Palo Alto, CA, USA) and an acquisition board (MP100A; Biopac Systems Inc., Goleta, CA, USA) connected to a computer. MAP and HR values were derived from the PAP recordings and processed online. Care was taken to start injections only when blood pressure and HR were stable.

\section{Drug injections}

Drugs were dissolved in artificial cerebrospinal fluid (ACSF) $(100 \mathrm{mM}$ $\mathrm{NaCl} ; 2 \mathrm{~mm} \mathrm{Na} \mathrm{PO}_{4} ; 2.5 \mathrm{~mm} \mathrm{KCl} ; 1.0 \mathrm{mM} \mathrm{MgCl}_{2} ; 27 \mathrm{~mm} \mathrm{NaHCO}$; $\left.2.5 \mathrm{mM} \mathrm{CaCl}_{2} ; \mathrm{pH} 7.4\right)$ and injected in a final volume of $100 \mathrm{~nL}$. Drugs were injected over a period of $15 \mathrm{~s}$, with a $1-\mu \mathrm{L}$ syringe (model $705-\mathrm{N}$; Hamilton, Reno, NV, USA) and a stainless steel (33G) dental injection needle.

\section{Experimental procedures}

Different doses of NA were microinjected into the MeA of conscious rats. All animals received one injection of ACSF (vehicle) and up to two injections of $3,9,27$ or $45 \mathrm{nmol}$ of NA. The order of the injections was randomized to reduce experimental variability.

A dose of $27 \mathrm{nmol}$ of NA was used to study the local adrenergic receptors in the $\mathrm{MeA}$ that are involved with the cardiovascular response. To study the involvement of $\alpha$-adrenoceptors, NA was administered before and after $100 \mathrm{~nL}$ of ACSF, $10 \mathrm{nmol}$ of the selective $\alpha_{1}$-adrenoceptor antagonist WB4101, or $10 \mathrm{nmol}$ of the selective $\alpha_{2}$-adrenoceptor antagonist RX821002 (Scopinho et al., 2006).

To study the peripheral mechanisms involved in the pressor response, NA was injected into the MeA of rats before and $10 \mathrm{~min}$ after intravenous treatment with saline $(1 \mathrm{~mL} / \mathrm{kg}), 5 \mathrm{mg} / \mathrm{kg}$ of the ganglion blocker pentolinium (Moriguchi et al., 1998), or $50 \mu \mathrm{g} / \mathrm{kg}$ of the vasopressin antagonist $\operatorname{dTyr}\left(\mathrm{CH}_{2}\right)_{5}(\mathrm{Me}) \mathrm{AVP}$ (Fernandes et al., 2003).

\section{Drugs}

The following drugs were used: noradrenaline- $\mathrm{HCl}$ (Sigma, St Louis, MO, USA), WB4101 (RBI, USA), RX821002 (RBI), pentolinium (Sigma), and dTyr $\left(\mathrm{CH}_{2}\right)_{5}(\mathrm{Me})$ AVP (Peninsula, Belmont, CA, USA).

\section{Histological procedure}

At the end of the experiments, the rats were anesthetized with intraperitoneal urethane $(1.25 \mathrm{~g} / \mathrm{kg})$, and $100 \mathrm{~nL}$ of filtered $1 \%$ Evan's Blue dye was injected into the $\mathrm{MeA}$ as a marker of the injection site. The chest was surgically opened, the descending aorta occluded, the right atrium severed, and the brain perfused with $10 \%$ formalin through the left ventricle. The brains were postfixed for $24 \mathrm{~h}$ at $4{ }^{\circ} \mathrm{C}$, and $40-\mu \mathrm{m}$ sections were cut with a cryostat (CM 1900; Leica, Wetzlar, Germany). Brain sections were stained with $1 \%$ neutral red. The actual placement of the injection needles was verified in serial sections.

\section{Statistical analysis}

Statistical analysis was performed with nonlinear regression analysis to compare MAP and HR results after NA administration into the MeA. Two-way ANOVA (treatment vs. time) followed by Bonferroni's post hoc test was used to compare the effects of the treatments on the cardiovascular MAP and the HR changes observed after microinjection of NA into the MeA. The maximal MAP and HR responses were compared by paired Student's $t$-test (before treatment vs. after treatment), and $P<0.05$ was assumed to be statistically significant.

\section{Results}

Cardiovascular effect of NA microinjection into the MeA of conscious rats

The microinjection of different doses of NA (3, 9, 27 or 45 $\mathrm{nmol} / 100 \mathrm{~nL})$ into the MeA of conscious rats $(n=20)$ caused 

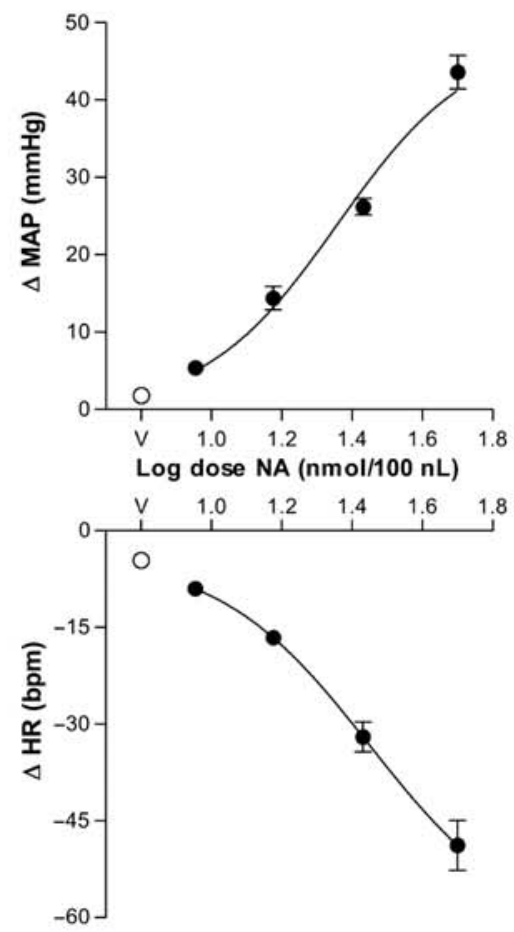

$t=0.6, P>0.05, n=6$ ). Pretreatment with WB4101 did not change cardiovascular responses to NA injection into the MeA ( $\triangle M A P$, $28.8 \pm 1.8$ vs. $27.4 \pm 1.9 \mathrm{mmHg} ; \Delta \mathrm{HR},-58.2 \pm 2.7$ vs. -55.8 \pm 3 beats $/ \mathrm{min}$ ).

\section{RX821002}

Microinjection of $10 \mathrm{nmol} / 100 \mathrm{~nL}$ of RX821002 into the MeA caused no changes in baseline MAP (100.6 \pm 0.5 vs. $100 \pm 0.4 \mathrm{mmHg}, t=0.0, P>0.05, n=5)$ or HR $(365.6 \pm 3.4 \mathrm{vs}$. $364.6 \pm 2.3$ beats $/ \mathrm{min}, t=0.8, P>0.05, n=5$ ). Pretreatment with RX821002 blocked cardiovascular responses to NA injection into the MeA ( $\triangle$ MAP, $23.2 \pm 1.33$ vs. $3.2 \pm 0.5 \mathrm{mmHg}$; $\Delta \mathrm{HR},-50.1 \pm 0.8$ vs. $-7.6 \pm 1.6$ beats $/ \mathrm{min}$; Fig. 2 ).

Cardiovascular recordings showing the effects of the microinjection of $27 \mathrm{nmol}$ of NA into the MeA of one conscious rat before and after RX821002 are presented in Fig. 2.

A representative photomicrograph indicating the microinjection sites of NA $(27 \mathrm{nmol} / 100 \mathrm{~nL})$ in the MeA and a diagrammatic representation of injection sites within the $\mathrm{MeA}$ of the rats used in the experiments is presented in Fig. 4.

Effect of intravenous treatment with ACSF, pentolinium or dTyr $\left(\mathrm{CH}_{2}\right)_{5}(\mathrm{Me})$ AVP on the cardiovascular effects of $\mathrm{NA}$ microinjected into the MeA

$A C S F$

The intravenous administration of $\operatorname{ACSF}(n=5)$ did not affect the cardiovascular responses to NA microinjected into the MeA ( $\triangle \mathrm{MAP}$, $22.8 \pm 1.1$ vs. $22.2 \pm 1.3 \mathrm{mmHg}: \Delta H R,-44.8 \pm 3.7$ vs. $-36 \pm 1.7$ beats $/ \mathrm{min}$ ).

FIG. 1. Changes in MAP and HR evoked by NA microinjection $(3,9,27$ or $45 \mathrm{nmol} / \mathrm{I} 00 \mathrm{~nL})$ into the MeA of conscious rats $(n=20)$. Points represent means and bars the standard error of the mean. Dose-response curves wer generated by nonlinear regression analysis and were statistically significant $\left(\Delta \mathrm{MAP}, r^{2}=0.96\right.$, d.f. $=16, P<0.05 ; \Delta \mathrm{HR}, r^{2}=0.91$, d.f. $\left.=16, P<0.05\right)$.

dose-related pressor and bradycardic responses, whereas injections of ACSF into the MeA had no cardiovascular effects on baseline values (MAP, $96 \pm 1$ vs. $100 \pm 1 \mathrm{mmHg}, t=1.7, P>0.05 ; \mathrm{HR}, 357 \pm 9$ vs. $351 \pm 11$ beats $/ \min , t=0.3, P>0.05 ; n=5$ ) (Fig. 1).

The approximate $\mathrm{ED}_{50}$ of cardiovascular responses was $27 \mathrm{nmol}$. The injection of $27 \mathrm{nmol}$ of $\mathrm{NA}$ into the MeA caused a pressor response ( $\triangle \mathrm{MAP}, 26 \pm 1 \mathrm{mmHg}, t=12.2, P<0.01, n=5$ ) and an $\mathrm{HR}$ decrease ( $\Delta \mathrm{HR},-32 \pm 2$ beats $/ \mathrm{min}, t=25.3, P<0.0001, n=5$ ) when compared with vehicle.

Effect of local pretreatment with ACSF, RX821002 or WB4101 on cardiovascular responses to NA injection into the MeA $A C S F$

Microinjection of $100 \mathrm{~nL}$ of ACSF into the MeA caused no changes in baseline MAP $(98.5 \pm 0.6$ vs. $100.3 \pm 0.2 \mathrm{mmHg}, t=2.6, P>0.05$, $n=5)$ or HR $(362.8 \pm 4.1$ vs. $365.3 \pm 3.6$ beats $/ \mathrm{min}, t=1.1$, $P>0.05, n=5$ ). Pretreatment with ACSF did not affect the cardiovascular responses to NA injection into the MeA ( $\triangle \mathrm{MAP}, 24 \pm 1.4 \mathrm{vs}$. $24 \pm 1.3 \mathrm{mmHg} ; \Delta \mathrm{HR},-50.2 \pm 3 \mathrm{vs} .-48 \pm 3.3$ beats $/ \mathrm{min})$.

\section{WB4I0I}

Microinjection of $10 \mathrm{nmol} / 100 \mathrm{~nL}$ of WB4101 into the MeA caused no changes in baseline MAP $(99.2 \pm 0.6$ vs. $99.8 \pm 0.5 \mathrm{mmHg}$, $t=1.1, P>0.05, n=5$ ) or HR ( $364 \pm 3$ vs. $363.6 \pm 2.5$ beats $/ \mathrm{min}$,

\section{$\operatorname{dTyr}\left(\mathrm{CH}_{2}\right)_{5}(\mathrm{Me}) \mathrm{AVP}$}

The intravenous administration of the $\mathrm{V}_{1}$-vasopressin antagonist dTyr $\left(\mathrm{CH}_{2}\right)_{5}(\mathrm{Me})$ AVP $(n=5)$ did not affect baseline MAP $(98.8 \pm 0.7$ vs. $98.6 \pm 1.0 \mathrm{mmHg}, t=0.3, P>0.05)$ or $\operatorname{HR}(362 \pm 2.4$ vs. $363.6 \pm 2.5$ beats $/ \mathrm{min}, t=2.3, P>0.05)$. However, pretreatment with d $\operatorname{Tyr}\left(\mathrm{CH}_{2}\right)_{5}(\mathrm{Me}) \mathrm{AVP}$ blocked cardiovascular responses to NA injection into the MeA ( $\triangle$ MAP, $28.6 \pm 1.3$ vs. $4.4 \pm 1.8 \mathrm{mmHg}$; $\Delta$ HR, $-44.6 \pm 4.4$ vs. $-6.6 \pm 1.7$ beats $/$ min; Fig. 3 ).

\section{Pentolinium}

The intravenous administration of the ganglion blocker pentolinium $(n=5)$ significantly reduced baseline MAP $(101.8 \pm 3.6$ vs. $72.8 \pm 1.8 \mathrm{mmHg}, t=7, P<0.05)$ but did not affect baseline HR $(366.3 \pm 2.4$ vs. $365.8 \pm 2.6$ beats $/ \mathrm{min}, t=1.3, P>0.05)$. Pretreatment with pentolinium significantly increased the pressor response to the injection of NA into the MeA ( $\triangle \mathrm{MAP}, 28.6 \pm 1.4$ vs. $77.2 \pm 1.1 \mathrm{mmHg})$ and blocked the HR decrease response $(\Delta H R$, $-64 \pm 2.8$ vs. $-7.2 \pm 1.9$ beats/min; Fig. 3 ).

\section{Effects of NA microinjection into structures surrounding the MeA}

Microinjections of $27 \mathrm{nmol}$ of NA into the optic tract ( $\triangle \mathrm{MAP}, 99.7 \mathrm{vs}$. $99.3 \pm 0.3 \mathrm{mmHg}, \quad t=0.93, \quad P>0.05 ; \Delta \mathrm{HR}, \quad 364.9 \pm 4.9 \quad$ vs. $364.6 \pm 4$ beats $/ \min , t=0.3, P>0.05 ; n=3$ ) and internal capsule ( $\triangle$ MAP, $98.7 \pm 0.3$ vs. $98.6 \pm 0.3 \mathrm{mmHg}, t=0.3, P>0.05 ; \Delta \mathrm{HR}$, $359.5 \pm 1.5$ vs. $358.8 \pm 2.1$ beats $/ \min , t=0.8, P>0.05 ; n=3$ ), areas surrounding the MeA, had no effects on MAP or HR. A diagrammatic representation of injection sites in the areas surrounding the MeA is presented in Fig. 5. 

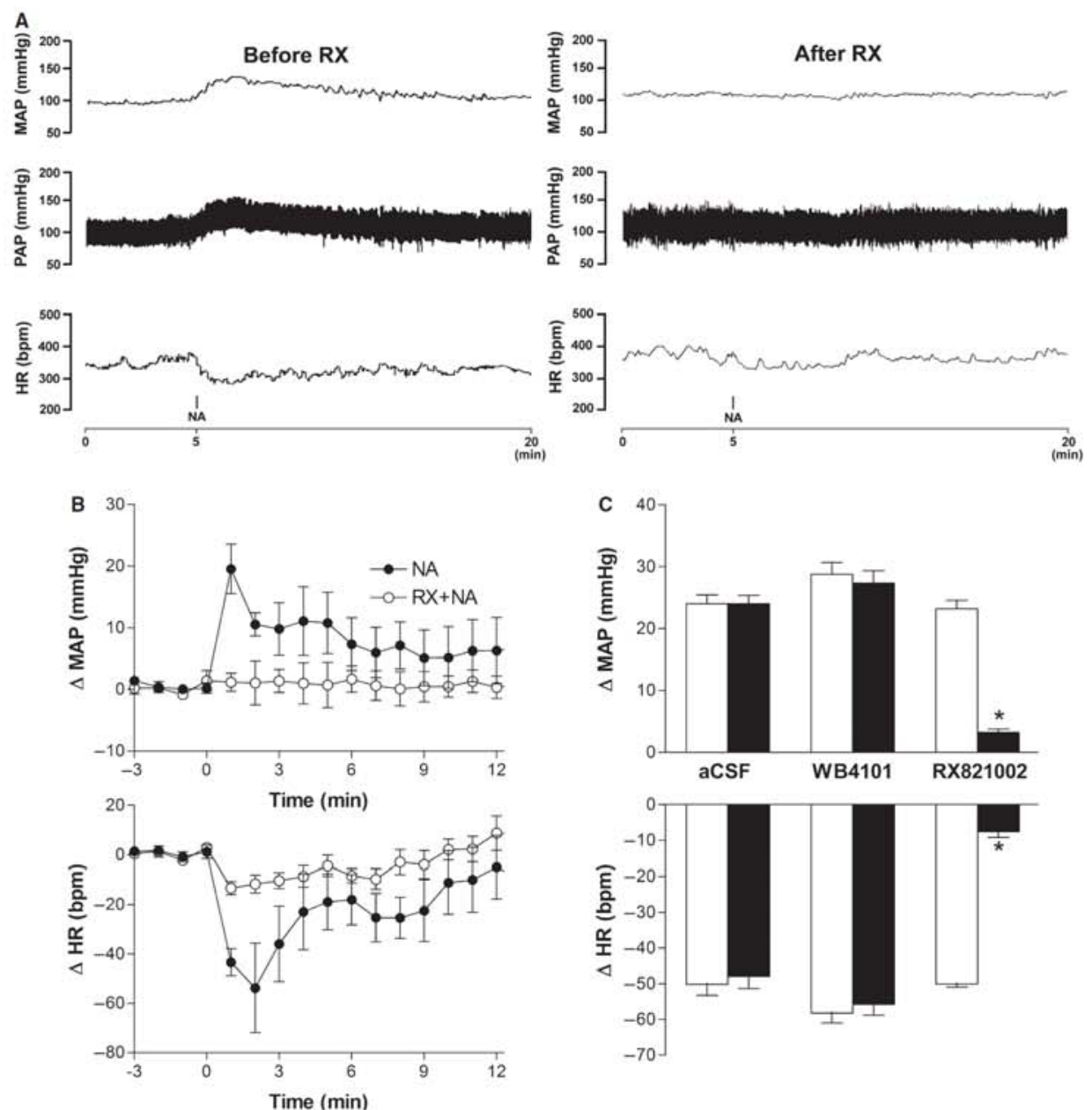

FIG. 2. (A) Recordings of MAP, PAP, and HR, showing the cardiovascular changes observed in response to NA ( $27 \mathrm{nmol} / 100 \mathrm{~nL})$ microinjection into the MeA of conscious rats before and after RX821002 administration. (B) Time course of the effect of $27 \mathrm{nmol} / 100 \mathrm{~nL}$ of NA microinjected into the MeA on $\triangle M A P$ and $\triangle H R$ before and after pretreatment with RX821002 (MAP, $F_{5,60}=17.8, P<0.0001 ; \mathrm{HR}, F_{5,60}=21.8, P<0.0001$; two-way ANOVA). NA injections were made at time 0 . Points represent the means, and bars the standard errors of the mean. (C) Effects of 27 nmol of NA injected in the MeA before (open columns) and after (filled columns) $100 \mathrm{~nL}$ of ACSF ( $\triangle \mathrm{MAP}, t=0.001, P>0.05 ; \Delta \mathrm{HR}, t=0.9, P>0.05 ; n=5), 10 \mathrm{nmol}$ of WB4I01 ( $\triangle \mathrm{MAP}, t=1.5, P>0.05 ; \Delta \mathrm{HR}, t=0.8, P>0.05 ;$ $n=5$ ) or $10 \mathrm{nmol}$ of RX821002 ( $\triangle \mathrm{MAP}, t=13.1, P<0.01 ; \Delta \mathrm{HR}, t=22.3, P<0.01 ; n=5$ ) on $\triangle \mathrm{MAP}$ and $\triangle \mathrm{HR}$ in response to NA in conscious rats. Columns represent means, and bars the standard errors of the mean; ${ }^{*} P<0.01$, paired Student's $t$-test.

\section{Discussion}

The present study showed that microinjection of NA into the MeA evoked dose-related pressor and bradycardic responses that were mediated by local $\alpha_{2}$-adrenoceptors and dependent on systemic vasopressin release. Moreover, microinjections of NA into surrounding areas such as the optic tract or the internal capsule had no cardiovascular effects, reinforcing the idea of an action restricted to the MeA.

The amygdala is involved in control of several autonomic functions, including control of the cardiovascular system. Experiments have shown that ablation of the amygdala delays the development of hypertension (Galeno et al., 1982, 1984). Electrical stimulation of the amygdaloid complex evoked increases in MAP, HR, vasodilatation in skeletal muscles and defense reactions that were characterized by an increase in the period of alertness and attention in rats (Hilton \& Zbrozyna, 1963; Stock et al., 1978; Galeno et al., 1982). Moreover, previous work showed that a pressor response was induced by electrical stimulation of the $\mathrm{MeA}$ in anesthetized rats with urethane, whereas a depressor response was elicited by stimulation of the same site in rats anesthetized with chloralose, suggesting that this complex could modulate the cardiovascular system (Mogenson \& Calaresu, 1973).

Studies using microdialysis have shown increased levels of NA in several forebrain regions of the limbic system, mainly in the MeA of animals subjected to immobilization stress. This result suggests that 

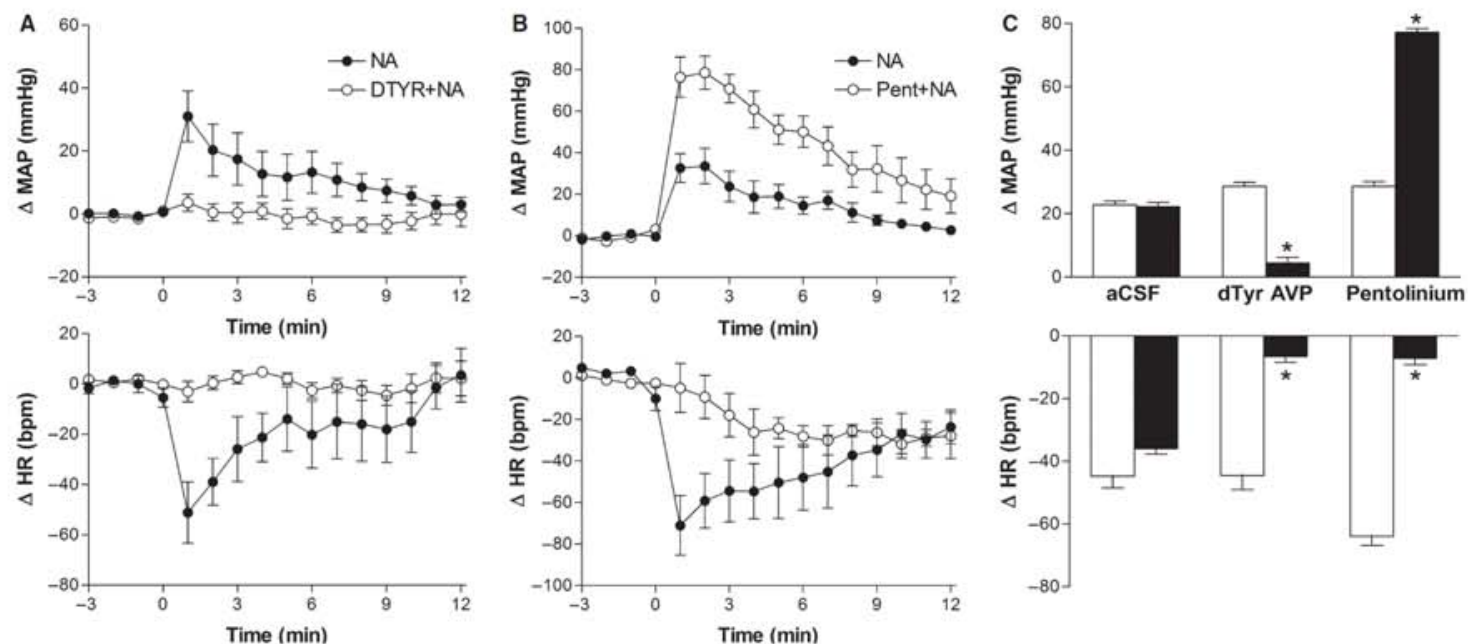

FIG. 3. (A) Time course of the effect of $27 \mathrm{nmol} / 100 \mathrm{~nL}$ of NA microinjected into the MeA on $\triangle \mathrm{MAP}$ and $\triangle H R$ before and after pretreatment with intravenous dTyr $\left(\mathrm{CH}_{2}\right)_{5}$ (Me)AVP (MAP, $F_{5,48}=35.4, P<0.0001 ; \mathrm{HR}, F_{5,48}=17.6, P=0.0001$; two-way ANOVA). (B) Time course of the effect of $27 \mathrm{nmol} / 100 \mathrm{~nL}$ of NA microinjected into the MeA on $\triangle \mathrm{MAP}$ and $\triangle \mathrm{HR}$ before and after pretreatment with intravenous pentolinium (MAP, $F_{5,48}=43.7, P<0.0001 ; \mathrm{HR}, F_{5,48}=35.4$. $P<0.0001$; two-way ANOVA). NA injections were made at time 0. (C) Effects of $27 \mathrm{nmol}$ of NA injected in the MeA before (open columns) and after (filled columns) administration of intravenous $\operatorname{ACSF}(\triangle \mathrm{MAP}, t=0.3, P>0.05 ; \Delta \mathrm{HR}, t=1.6, P>0.05 ; n=5), \mathrm{dTyr}\left(\mathrm{CH}_{2}\right) \mathrm{s}(\mathrm{Me}) \mathrm{AVP}(\Delta \mathrm{MAP}, t=9.6, P<0.01 ; \Delta \mathrm{HR}$, $t=6.6, P<0.01: n=5$ ) or pentolinium ( $\triangle \mathrm{MAP}, t=34.7, P<0.01: \Delta \mathrm{HR}, t=12.6, P<0.01: n=5$ ) on $\Delta \mathrm{MAP}$ and $\Delta$ HR in response to NA in conscious rats. Columns represent means, and bars the standard errors of the mean; $* P<0.01$, paired Student's $t$-test.

there is a noradrenergic system functioning in these structures (Cecchi et al., 2002a,b; Pardon et al., 2002; Ma \& Morilak, 2005; Morilak et al. 2005; Bondi et al., 2007). There is evidence of the involvement of noradrenergic neurotransmission in the amygdaloid complex modulating cardiovascular responses. NA microinjected into this complex caused pressor and bradycardic responses (Ohta et al., 1991). However, these authors observed significant cardiovascular changes only after bilateral microinjection of NA into the amygdaloid complex, unlike in our studies, where we observed cardiovascular effects evoked by NA unilaterally injected locally in the MeA.

The observation that the magnitude of the bradycardic response evoked by NA in the MeA significantly correlated with the magnitude of the pressor response favors the idea of a reflex origin. Additionally, the magnitude of the bradycardic responses observed after the microinjection of NA into the MeA was similar to that observed afte baroreflex activation by intravenous infusion of phenylephrine (Resstel et al., 2004), further favoring the idea of the reflex nature of bradycardic responses to NA in the MeA.

To determine which types of MeA local adrenoceptor are involved in mediation of the cardiovascular response to microinjection of NA, animals were pretreated with the selective $\alpha_{2}$-adrenoceptor antagonist RX821002 or the selective $\alpha_{1}$-adrenoceptor antagonist WB4101. Blockade of the $\alpha_{2}$-adrenoceptor by RX821002 decreased the cardiovascular response to microinjection of $\mathrm{NA}$, but treatment with the selective $\alpha_{1}$-adrenoceptor antagonist WB4101 did not affect this cardiovascular response, suggesting that $\alpha_{2}$-adrenoceptors are involved in mediating the cardiovascular response to NA microinjected into the MeA. $\alpha_{2}$-Adrenergic binding sites are distributed densely in the MeA (Unnerstall et al., 1984; Flugge et al., 1994). Similar doses of the selective antagonists WB4101 and RX821002 have been previously used to identify the type of $\alpha$-adrenoceptor involved in the mediation of pressor and bradycardic responses to NA microinjection into the medial prefrontal cortex (Fernandes et al.
2003) or the lateral septal area (Scopinho et al., 2006). In these areas, cardiovascular responses to NA were blocked by pretreatment with WB4101 but not blocked by pretreatment with RX821002, suggesting a preferential mediation via activation of $\alpha_{1}$-adrenoceptors. In the supraoptic nucleus, the pressor and bradycardic responses were blocked by pretreatment with RX821002, suggesting that these responses are mediated by $\alpha_{2}$-adrenoceptors (Busnardo et al., 2009). Also, the use of these antagonists showed a situation in which both $\alpha$ adrenoceptors were involved in the mediation of pressor and bradycardic responses to NA microinjected into the bed nucleus of the stria terminalis (Crestani et al., 2008), $\alpha_{2}$-Adrenoceptors may be presynaptic or postsynaptic for the NA system (Arima et al., 1998). The present studies cannot distinguish between these two locations. It is possible that these receptors can interact with other neurotransmitters to cause cardiovascular effects.

Animals treated with reboxetine, a selective NA reuptake inhibitor, showed preferential downregulation of glutamic acid decarboxylase mRNA expression in the hippocampal dentate gyrus and MeA (Herman et al., 2003). Decreased levels of GABA may cause increased activation of these areas. Then, NA microinjected into the $\mathrm{MeA}$ could be acting on $\alpha_{2}$-adrenoceptors, inhibiting the GABA release. Further studies would be needed to evaluate this hypothesis.

Systemic pretreatment with ganglion blockers has been traditionally used as a pharmacological tool to block autonomic nervous activity. Our results demonstrate that intravenous pretreatment with a ganglion blocker, pentolinium, significantly lowered basal blood pressure, as expected, thus confirming a sympathetic output blockade. However, the pressor response to the microinjection of NA was potentiated after ganglion blockade. This result rules out the possible involvement of the sympathetic nervous system in mediation of the cardiovascular responses to NA in the MeA.

Pentolinium evoked similar potentiation of the pressor response to NA in several areas, suggesting the involvement of humoral mediation 
1682 E. A. T. Fortaleza et al.

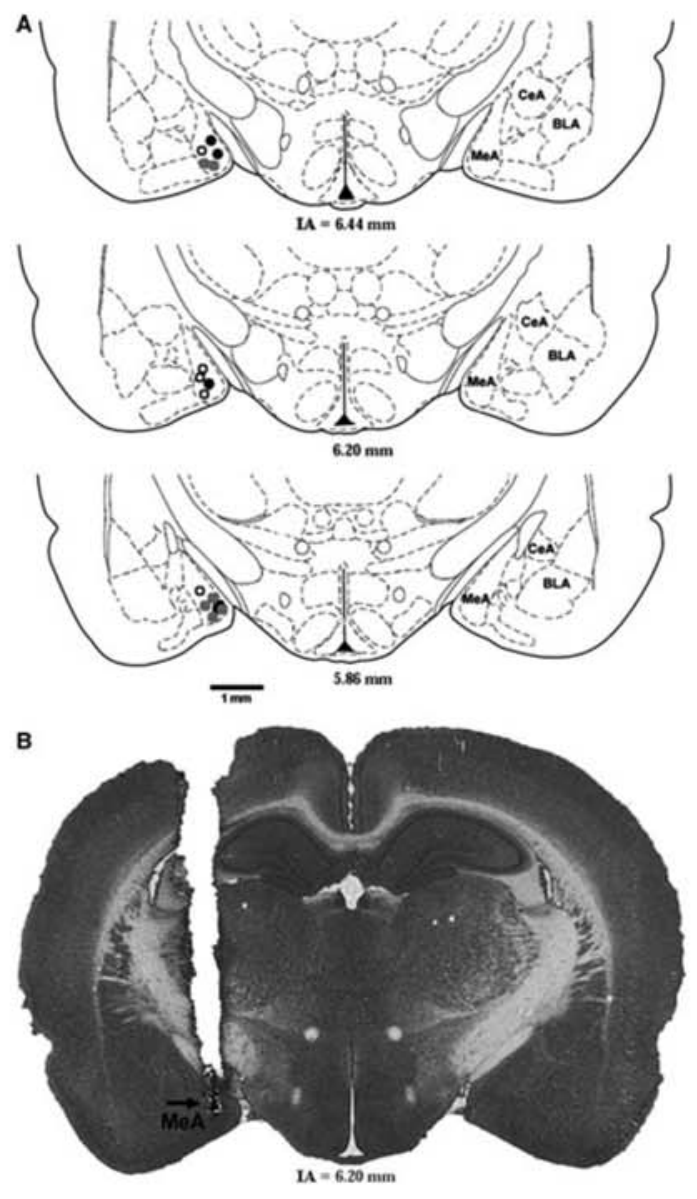

Fig. 4. (A) Diagrammatic representation based on the rat brain atlas of Paxinos and Watson (1997), indicating sites of injection of ACSF (white dots), WB4101 (gray dots) and RX821002 (black dots). IA, interaural coordinate; $\mathrm{CeA}$, central amygdaloid nucleus; BLA, basolateral amygdaloid nucleus. (B) $\mathrm{CeA}$, central amygdaloid nucleus: $\mathrm{BLA}$, basolateral amygdaloid nucleus. (B)
Photomicrograph of a coronal brain section from one representative rat. showing the microinjection site in the MeA.

(Fernandes et al., 2003; Pelosi \& Correa, 2005; Scopinho et al., 2006: Crestani et al., 2007; Pelosi et al., 2008; Busnardo et al., 2009). Under these conditions, the cardiovascular effects of NA are reported to be caused by vasopressin release into the peripheral circulation (Correa et al., 1985; Fernandes et al., 2003; Pelosi \& Correa, 2005; Scopinho et al., 2006; Crestani et al., 2007; Pelosi et al., 2008; Busnardo et al., 2009). As the cardiac action evoked by NA in the MeA is blocked by pentolinium, but not the vascular effect, the reduction of the bradycardic response is suggestive of cardiac autonomic activity. Thus, it is possible that bradycardia evoked by NA microinjected into the MeA could be a vagal baroreflex resulting from the increase in MAP. These results suggest that the sympathetic nervous system is not involved in mediation of the pressor response, but may be involved in the mediation (reflex response) of bradycardia, and also suggest the participation of humoral factors in the pressor response. Other studies from our group showed that the increase in blood pressure and HR decrease caused by microinjection of NA into other brain structures were dependent on the
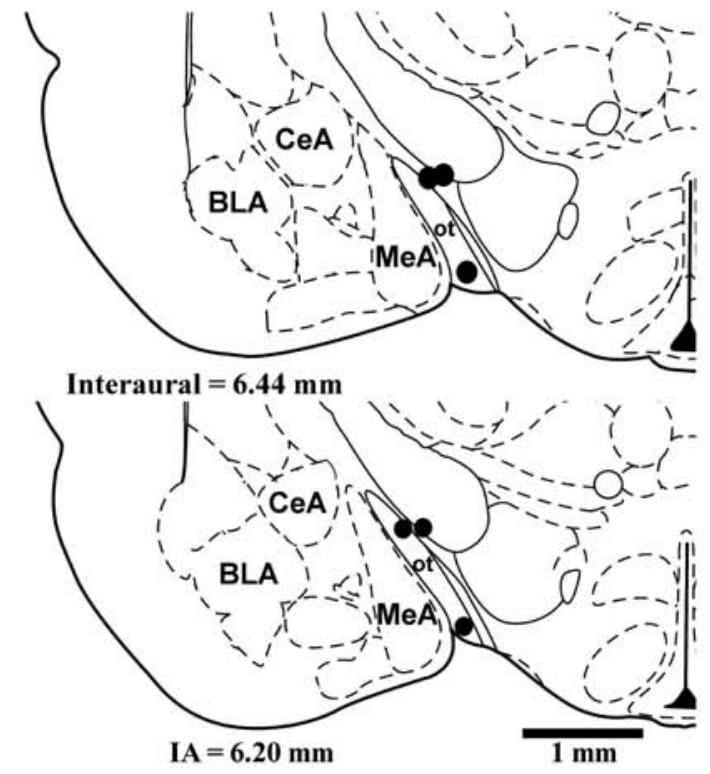

FIG. 5. Diagrammatic representation based on the rat brain atlas of Paxinos and Watson (1997), indicating sites of injection of NA (black dots), in the optical tract or internal capsula. IA, interaural coordinate; $\mathrm{CeA}$, central amygdaloid nucleus; BLA, basolateral amygdaloid nucleus; ot, optical tract.

peripheral release of vasopressin (Correa $e t$ al., 1985; Fernandes et al., 2003; Pelosi \& Correa, 2005; Scopinho et al., 2006; Crestani et al., 2007; Pelosi et al., 2008; Busnardo et al., 2009).

Vasopressin is synthesized in the supraoptic and paraventricular magnocellular neurons of the hypothalamus and transported to the neurohypophysis, where it is stored in vesicles for later release into the peripheral circulation. Vasopressin release into the systemic circulation has been shown to participate in fluid homeostasis and cardiovascular control (Cowley \& Barber, 1983; Cowley \& Liard, 1988; Persson, 1996). To investigate whether the pressor response to $\mathrm{NA}$ injection into the MeA was mediated by vasopressin release, we utilized $\operatorname{dTyr}\left(\mathrm{CH}_{2}\right)_{5}(\mathrm{Me}) \mathrm{AVP}$, an antagonist of vasopressin. The pressor response to NA was blocked by $\operatorname{dTyr}\left(\mathrm{CH}_{2}\right)_{5}(\mathrm{Me}) \mathrm{AVP}$, suggesting that vasopressin release is the mechanism that mediates the response to NA microinjected into the MeA. These findings, together with our results, suggest that it is likely that such structures, participating in noradrenergic mechanisms, play an important role in modulating the cardiovascular response upon release into the humoral peripheral circulation. In addition, some authors have shown that the electrical stimulation of structures of the limbic system, such as the amygdala and septal area, evoke vasopressin release into the blood circulation (Dingman \& Gaitan, 1959; Hayward \& Smith, 1963; Papez, 1995). The amygdaloid complex has dense neuronal connections with the hypothalamus and brainstem, which are areas known to play an important role in cardiovascular regulation (Ohta et al., 1991; Dampney, 1994). Moreover, an indirect pathway from the amygdala to the bed nucleus of the stria terminalis (BST) and the preoptic area connects the amygdala to the paraventricular nucleus (Sawchenko \& Swanson, 1983; McDonald, 1988). The BST is a functionally heterogenous component of the extended amygdala that has been implicated in the modulation of cardiovascular responses (Crestani et al., 2007). 
Administration of NA into the BST causes pressor and bradycardic responses that depend on vasopressin release by the paraventricular nucleus (Crestani et al., 2009). Furthermore, the MeA has connections with the lateral septal area (Canteras et al., 1995). Stimulation of the lateral septal area by local injection of NA evokes pressor and bradycardic responses (Scopinho et al., 2006) that are also caused by vasopressin release into blood circulation after paraventricular nucleus activation (Scopinho et al., 2008). Considering that the lateral septal area does not project directly to the paraventricular nucleus (Tavares et al., 2005) and that connections have been described between the MeA and that structure (Canteras et al., 1995), the MeA could be a relay in the pathway involved in vasopressin release after activation of the lateral septal area.

Vasopressin was reported to be released in greater amounts following restraint stress, hemorrhage, or isotonic hypovolemia (Kasting, 1988). Stress situation activates NA release in stress-related limbic areas, such as the medial prefrontal cortex, lateral septum, BST, and MeA (Cecchi et al., 2002a; Pardon et al., 2002; Ma \& Morilak, 2005). Also, the MeA has been implicated in mediation of the cardiovascular responses observed during stress restraint (Kubo et al. 2004; Fortaleza et al., 2009). Thus, adrenergic synapses within the MeA may be involved in mediation of the vasopressin release observed during the integrated cardiovascular and neuroendocrine response to stressful stimuli.

It is known that there is a circuit in the central nervous system responsible for the release of vasopressin. Our results suggest that the MeA is part of this circuit, along with other structures. This circuit could regulate the homeostatic balance under situations of physical stress. The presently reported cardiovascular response to the microinjection of NA into the MeA of conscious rats is the first evidence of a functional effect of the activation of $\mathrm{MeA}$ noradrenergic systems, and indicates that activation of adrenoceptors in the MeA is associated with vasopressin release.

Some limitations of our study must be considered, for example the differences between the responses caused by NA in the animals. Perhaps this difference is also attributable to the fact that these experiments were performed on different days and on different groups of animals. In general, NA microinjected into the MeA causes pressor and bradycardic responses, and the magnitude of these responses may change, depending on the conditions of animals on the day of experiment, too abrupt climate changes, or several other external factors. It is important to note here that the experiments were performed with different groups of animals and on different days. Another point concerns the blockade of the bradycardia caused by administration of pentolinium and $\operatorname{dyr}\left(\mathrm{CH}_{2}\right)_{5}(\mathrm{Me}) \mathrm{AVP}$. The intravenous admistration of both drugs abolished the bradycardic response to NA microinjected into the MeA. Together, these data suggest that the bradycardic response is a result of vagal baroreflex response activation, as a consequence of the MAP increase. Moreover, vasopressin has been reported to cause a positive chronotropic effect (Chiba, 1977), thus reinforcing the idea of a reflex bradycardia.

In summary, our results show that the cardiovascular response evoked by NA microinjection involves MeA local $\alpha_{2}$-adrenoceptors and is mediated by systemic vasopressin release.

\section{Acknowledgements}

The authors wish to thank Ivanilda A. C. Fortunato, Idália 1. B. Aguiar and Simone Guilhaume for technical help. E. A. T. Fortaleza is supported by a CNPq PhD fellowship (140118/2009-8), and A. A. Scopinho has a CAPES postdoctoral fellowship (PNPD0176087). The present research was supported by grants from the CNPq (501269/2005-3).

\section{Abbreviations}

ACSF, artificial cerebrospinal fluid; BST, bed nucleus of the stria terminalis; HR, heart rate: MAP, mean arterial pressure; MeA, medial amygdaloid nucleus; $\mathrm{NA}$, noradrenaline; PAP, pulsatile arterial pressure.

\section{References}

Aggleton, J.P. (2000) The Amygdala, a Functional Analysis. Oxford University Press, Oxford.

Arima, J., Kubo, C., Ishibashi, H. \& Akaike, N. (1998) alpha2-Adrenoceptormediated potassium currents in acutely dissociated rat locus coeruleus neurones. J. Physiol., 508, 57-66.

Ben-Ari, Y. (1981) The Amygdaloid Complex. Elsevier, Amsterdam.

Bondi, C.O., Barrera, G., Lapiz, M.D., Bedard, T., Mahan, A. \& Morilak, D.A. (2007) Noradrenergic facilitation of shock-probe defensive burying in lateral septum of rats, and modulation by chronic treatment with desipramine. Prog. Neuropsychopharmacol. Biol. Psychiatry, 31, 482-495.

Busnardo, C., Tavares, R.F. \& Correa, F.M. (2009) Mechanisms involved in the pressor response to noradrenaline microinjection into the supraoptic nucleus of unanesthetized rats. Auton. Neurosci., 145, 63-70.

Canteras, N.S., Simerly, R.B. \& Swanson, L.W. (1995) Organization of projections from the medial nucleus of the amygdala: a PHAL study in the rat. J. Comp. Neurol., 360, 213-245.

Cecchi, M., Khoshbouei, H., Javors, M. \& Morilak, D.A. (2002a) Modulatory effects of norepinephrine in the lateral bed nucleus of the stria terminalis on behavioral and neuroendocrine responses to acute stress. Neuroscience, 112 , 13-21.

Cecchi, M., Khoshbouei, H. \& Morilak, D.A. (2002b) Modulatory effects of norepinephrine, acting on alpha 1 receptors in the central nucleus of the amygdala, on behavioral and neuroendocrine responses to acute immobilization stress. Neuropharmacology, 43, 1139-1147.

Correa, F.M., Magro, I.A., Peres-Polon, V.L. \& Antunes-Rodrigues, J. (1985) Mechanism of the CNS-mediated pressor response to intracerebroventricular injection of noradrenaline in unanaesthetized rats. Neuropharmacology, 24, $831-837$.

Cowley, A.W. Jr \& Barber, B.J. (1983) Vasopressin vascular and reflex effects a theoretical analysis. Prog. Brain Res., 60, 415-424.

Cowley, A.W. Jr \& Liard, J.F. (1988) Vasopressin and arterial pressure regulation. Special lecture. Hypertension, 11, 125-32.

regulation. Special lecture. Hypertension, 11, 125-32.
Crestani, C.C., Alves, F.H., Resstel, L.B. \& Correa, F.M. (2007) Cardiovascular Crestani, C.C., Alves, F.H., Resstel, L.B. \& Correa, F.M. (2007) Cardiovascular
effects of noradrenaline microinjection in the bed nucleus of the stria terminalis of the rat brain. J. Neurosci. Res., 85, 1592-1599.

Crestani, C.C., Alves, F.H., Resstel, L.B. \& Correa, F.M. (2008) Both alphal and alpha2-adrenoceptors mediate the cardiovascular responses to noradrenaline microinjected into the bed nucleus of the stria terminal of rats. $\mathrm{Br} . J$. Pharmacol., 153, 583-590.

Crestani, C.C., Busnardo, C., Tavares, R.F., Alves, F.H. \& Correa, F.M. (2009) Involvement of hypothalamic paraventricular nucleus non-N-methyl-D-
(n) aspartate receptors in the pressor response to noradrenaline microinjected into the bed nucleus of the stria terminalis of unanesthetized rats. Eur: $J$. Neurosci., 29, 2166-2176.

Dampney, R.A. (1994) Functional organization of central pathways regulating the cardiovascular system. Physiol. Rev, 74, 323-364.

Davis, M. (1992) The role of the amygdala in fear and anxiety. Anmu. Rev: Neurosci., 15, 353-375.

Dingman, J.F. \& Gaitan, E. (1959) Subcortical stimulation of the brain and release of antidiuretic hormone in man. J. Clin. Endocrinol. Metab., 19,
, 1346-1349.

Domyancic, A.V. \& Morilak, D.A. (1997) Distribution of alphalA adrenergic receptor mRNA in the rat brain visualized by in situ hybridization. J. Comp. Neurol., 386, 358-378.

Eleftheriou, B.E. (1973) The Neumbiology of the Amygdala. Plenum Press,

New York.
Faiers, A.A., Calaresu, F.R. \& Mogenson, G.J. (1975) Pathway mediating Faiers, A.A., Calaresu, F.R. \& Mogenson, G.J. (1975) Pathway mediating
hypotension elicited by stimulation of the amygdala in the rat. $\mathrm{Am} . \mathrm{J}$. Physiol., 228, 1358-1366.

Femandes, K.B., Crippa, G.E., Tavares, R.F., Antunes-Rodrigues, J. \& Correa, F.M. (2003) Mechanisms involved in the pressor response to noradrenaline injection into the cingulate cortex of unanesthetized rats. Neuropharmacology, 44, 757-763.

Flugge, G., Ahrens, O. \& Fuchs, E. (1994) Monoamine receptors in the amygdaloid complex of the tree shrew (Tupaia belangeri). J. Comp. Neurol., 343, 597-608. 
1684 E. A. T. Fortaleza et al.

Fortaleza, E.A., Tavares, R.F. \& Correa, F.M. (2009) The medial amygdaloid nucleus modulates cardiovascular responses to acute restraint in rats. Neturoscience, 159, 717-726

Galeno, T.M., Van Hoesen, G.W., Maixner, W., Johnson, A.K. \& Brody, M.J. (1982) Contribution of the amygdala to the development of spontaneous hypertension. Brain Res,, 246, 1-6.

Galeno, T.M., Van Hoesen, G.W. \& Brody, M.J. (1984) Central amygdaloid nucleus lesion attenuates exaggerated hemodynamic responses to noise stress nucleus lesion attenuates exaggerated hemodynamic responses to
in the spontaneously hypertensive rat. Brain Res., 291, 249-259.

Gelsema, A.J.. McKitrick, D.J. \& Calaresu, F.R. (1987) Cardiovascular responses to chemical and electrical stimulation of amygdala in rats. $\mathrm{Am} . J$. Physiol., 253, R712-718.

Hayward, J.N. \& Smith, W.K. (1963) Influence of limbic system on neurohypophysis. Arch. Neurol., 9, 171-177.

Herman, J.P., Renda, A. \& Bodie, B. (2003) Norepinephrine-gammaaminobutyric acid $(\mathrm{GABA})$ interaction in limbic stress circuits: effects of aminobutync acid (GABA) interaction in limbic stress circuits:
reboxetine on GABAergic neurons. Biol. Psychiatry, 53, 166-174.

reboxetine on GABAergic neurons. Biol. Psychiatry, 53, 166-174.
Hilton, S.M. \& Zbrozyna, A.W. (1963) Amygdaloid region for defence reactions and its efferent pathway to the brain stem. J. Physiol., 165, 160-173.

Jones, L.S., Gauger, L.L. \& Davis, J.N. (1986) Localization of alpha 1adrenergic receptors in normal and weaver mouse brain with in vitro 1251HEAT autoradiography. Neurosci. Lett., 65, 259-264.

Kasting, N.W. (1988) Simultaneous and independent release of vasopressin and oxytocin in the rat. Can. J. Physiol. Pharmacol., 66, 22-26.

Kubo, T. Okatani, H., Nishigori, Y., Hagiwara, Y., Fukumori, R. \& Goshima, Y. (2004) Involvement of the medial amygdaloid nucleus in restraint stressinduced pressor responses in rats. Neurosci. Lett., 354, 8486.

LeDoux, J. (1998) Fear and the brain: where have we been, and where are we going? Biol. Psychiatry, 44, 1229-1238.

Ma, S. \& Morilak, D.A. (2005) Norepinephrine release in medial amygdala facilitates activation of the hypothalamic-pituitary-adrenal axis in response to acute immobilisation stress. J. Neuroendocrinol., 17, 22-28.

McDonald, A.J. (1988) Projections of the intermediate subdivision of the central amygdaloid nucleus to the bed nucleus of the stria terminalis and medial diencephalon. Neurvsci. Lett., 85, 285-290.

Mogenson, G.J. \& Calaresu, F.R. (1973) Cardiovascular responses to electrical stimulation of the amygdala in the rat. Exp. Neturol., 39, 166-180.

Morilak, D.A., Barrera, G., Echevarria, D.J., Garcia, A.S., Hemandez, A., Ma, S. \& Petre, C.O. (2005) Role of brain norepinephrine in the behavional response to stress. Prog. Neuropsychopharmacol. Biol. Psychiatry, 29. 1214-1224.

Ohta, H., Watanabe, S. \& Ueki, S. (1991) Cardiovascular changes induced by chemical stimulation of the amygdala in rats. Brain Res. Bull., 26, 575-581. Papez, J.W. (1995) A proposed mechanism of emotion. 1937. J. Neuropsychiatry Clin. Neurosci., 7, $103-112$.

Pardon, M.C., Gould, G.G., Garcia, A., Phillips, L., Cook, M.C., Miller, S.A., Mason, P.A. \& Morilak, D.A. (2002) Stress reactivity of the brain noradrenergic system in three rat strains differing in their neuroendocrine and behavioral responses to stress: implications for susceptibility to stressrelated neuropsychiatric disorders. Neuroscience, 115, 229-242.

Pelosi, G.G. \& Correa, F.M. (2005) Cardiovascular effects of noradrenaline microinjected into the dorsal periaqueductal gray area of unanaesthetized rats. Eur. J. Neurosci., 22, 3188-3194.

Pelosi, G.G., Tavares, R.F., Antunes-Rodrigues, J. \& Correa, F.M. (2008) Cardiovascular responses to noradrenaline microinjection in the ventrolateral periaqueductal gray of unanesthetized rats. J. Neurosci. Res, 86, 712-719. periaqueductal gray of unanesthetized rats. J. Neurosci. Res., 86, $712-719$.
Persson, P.B. (1996) Modulation of cardiovascular control mechanisms and their interaction. Physiol, Rev., 76, 193-244.

Pitkanen, A., Savander, V. \& LeDoux, J.E. (1997) Organization of intraamygdaloid circuitries in the rat: an emerging framework for understanding functions of the amygdala. Trends Neurosci., 20, 517-523.

Resstel, L.B., Fernandes, K.B. \& Correa, F.M. (2004) Medial prefrontal cortex modulation of the baroreflex parasympathetic component in the rat. Brain Res., 1015, 136-144.

Roder, S. \& Ciriello, J. (1993) Innervation of the amygdaloid complex by catecholaminergic cell groups of the ventrolateral medulla. J. Comp. Neurol., 332. 105-122.

332, 105-122.
Sadikot, A.F. \& Parent, A. (1990) The monoaminergic innervation of the amygdala in the squirrel monkey: an immunohistochemical study. Neuroscience, 36, 431-447.

Sah, P., Faber, E.S., Lopez De Armentia, M. \& Power, J. (2003) The amygdaloid complex: anatomy and physiology. Physiol. Rev, 83, 803-834. Sawchenko, P.E. \& Swanson, L.W, (1983) The organization of forebrain afferents to the paraventricular and supraoptic nuclei of the rat. J. Comp. afferents to the paravent
Neurol., 218, 121-144.

Scopinho, A.A., Resstel, L.B., Antunes-Rodrigues, J. \& Correa, F.M. (2006) Pressor effects of noradrenaline injected into the lateral septal area of unanesthetized rats. Brain Res., 1122, 126-134.

Scopinho, A.A., Tavares, R.F., Busnardo, C. \& Correa, F.M. (2008) Non-Nmethyl-D-aspartate glutamate receptors in the paraventricular nucleus of hypothalamus mediate the pressor response evoked by noradrenaline hypothalamus mediate the pressor response evoked by noradrenaline
microinjected into the lateral septal area in rats. J. Neurosci. Res., 86, microinjected

3203-3211.
Stock, G., Schlor, K.H., Heidt, H. \& Buss, J. (1978) Psychomotor behaviour and cardiovascular pattems during stimulation of the amygdala. Pflugers Arch., 376, 177-184.

Tavares, R.F., Fernandes, K.B., Pajolla, G.P., Nascimento, I.A. \& Correa, F.M. (2005) Neural connections between prosencephalic structures involved in vasopressin release. Cell. Mol Neurobiol, 25, 663-672.

Unnerstall, J.R., Kopajtic. T.A. \& Kuhar, M.J. (1984) Distribution of alpha 2 nnerstall, J.R., Kopajtic, T.A. \& Kuhar, M.J. (1984) Distribution of alpha 2
agonist binding sites in the rat and human central nervous system: analysis of some functional, anatomic correlates of the pharmacologic effects of clonidine and related adrenergic agents. Brain Res., 319, 69-101.

Vlahakos, D., Gavras, I. \& Gavras, H. (1985) alpha-Adrenoceptor agonists applied in the area of the nucleus tractus solitarii in the rat: effect of anesthesia on cardiovascular responses. Brain Res., 347, 372-375. 


\title{
$\alpha 1$ and $\alpha 2$-adrenoceptors in the medial amygdaloid nucleus modulate differently the cardiovascular responses to restraint stress in rats
}

\author{
Eduardo Albino Trindade Fortaleza, América Augusto Scopinho, Fernando Morgan de Aguiar Corrêa* \\ Department of Pharmacology. School of Medicine of Ribeirão Preto, University of São Paulo, Ribeirão Preto. São Paulo, Brazil
}

\section{A R T I C L E I N F O}

\section{Article history}

Received 27 February 2012

Received in revised form 28 March 2012

Accepted 9 April 2012

\section{Keywords:}

Central nervous system

Adrenoceptors

Cardiovascular system

Restraint stress

Autonomic nervous system

\begin{abstract}
A B S T R A C T
Medial amygdaloid nucleus (MeA) neurotransmission has an inhibitory influence on cardiovascular responses in rats submitted to restraint, which are characterized by both elevated blood pressure (BP) and intense heart rate (HR) increase, In the present study, we investigated the involvement of MeA adrenoceptors in the modulation of cardiovascular responses that are observed during an acute restraint. Male Wistar rats received bilateral microinjections of the selective $\alpha 1$-adrenoceptor antagonist WB4101 (10, 15 , and $20 \mathrm{nmol} / 100 \mathrm{~nL}$ ) or the selective $\alpha 2$-adrenoceptor antagonist RX821002 $(10,15$, and $20 \mathrm{nmol} / \mathrm{nL})$ into the MeA, before the exposure to acute restraint. The injection of WB4101 reduced the restraintevoked tachycardia. In contrast, the injection of RX821002 increased the tachycardia. Both drugs had no influence on BP increases observed during the acute restraint. Our findings indicate that $\alpha 1$ and $\alpha 2$ adrenoceptors in the MeA play different roles in the modulation of the HR increase evoked by restraint stress in rats. Results suggest that $\alpha 1$-adrenoceptors and $\alpha 2$-adrenoceptors mediate the MeA-related facilitatory and inhibitory influences on restraint-related HR responses, respectively.
\end{abstract}

() 2012 Elsevier Ltd. All rights reserved.

\section{Introduction}

Stress elicits both autonomic and behavioral responses, which involve an activation of the hypothalamo-pituitary-adrenal axis as well as the sympathetic nervous system [1]. Such responses are modulated by several limbic structures in the central nervous system [2-7]. Among these structures, the amygdaloid complex is known to modulate stress-related behavior and is connected with hypothalamic and brainstem areas that are involved with cardiovascular regulation [8-10]. In particular, the medial amygdaloid nucleus (MeA) of the amygdaloid complex is involved in the modulation of stress related responses and in cardiovascular control [1,11]. Electrical stimulation of the MeA was reported to evoke increased blood pressure and heart rate [12].

Stress is known to evoke cardiovascular changes that are characterized by moderate hypertension and intense tachycardia $[4,7,13-20]$. Pressor responses evoked by foot-shock in

Abbreviations: aCSF, artificial cerebrospinal fluid: ANOVA, analysis of variance; $B P$, blood pressure: $\mathrm{HR}$, heart rate: MAP, mean arterial pressure; MeA, medial amygdaloid nucleus: PAP, pulsatile arterial pressure; RS, restraint stress.

* Corresponding author at: Department of Pharmacology, School of Medicine of Ribeirào Preto, USP, Bandeirantes Avenue, 3900, 14049-900 Ribeirão Preto, São Paulo, Brazil. Tel.: +55 1636023206 ; fax: +55 1636332301.

E-mail address: fmdacorr@fmrp.usp.br (F.M. de Aguiar Corrêa). spontaneously hypertensive rats increased blood pressure and heart rate with contextual fear conditioning [6,21], while with exposure of borderline hypertensive rats to acute noise stress [22] they were reduced after electrolytic lesion of the amygdala, thus suggesting an involvement of the amygdala in the modulation of cardiovascular responses caused by stress. Moreover, increased cfos expression in the MeA was observed after exposure to a number of stressors, such as a novel environment, swimming, social interaction and acute restraint stress $[23,24]$.

MeA inhibition with muscimol was reported to attenuate the pressor response evoked during acute restraint [19]. Also, previous work from our laboratory showed that bilateral microinjection of the unspecific neurotransmitter blocker Cobalt chloride $(\mathrm{CoCl} 2)$ into the MeA caused enhanced restraint-related tachycardiac response [4]. These data suggest the involvement of this area in cardiovascular modulation during stress.

The MeA receives substantial noradrenergic innervations originating in the A6 neurons in the locus coeruleus (LC) and other groups of noradrenergic neurons located in the lateral tegmental area $[25,26]$. Furthermore, studies of expression of mRNA and binding detected the presence of noradrenergic receptor subtypes $\alpha$ and $\beta$ in the MeA [27,28], suggesting the existence of the noradrenergic system in this area.

Noradrenaline (NA) is a neurotransmitter with an important role in central cardiovascular regulation and is an important mediator in several structures of the central nervous system. Cardiovascular responses were observed after microinjection of NA into brain 
regions involved in the modulation of the cardiovascular system, such as the nucleus of the solitary tract (NTS); [29], the medial prefrontal cortex (CPFM); [30], the periaqueductal gray area (PAG); [31], the lateral septal area (ASL); [32], the bed nucleus of the stria terminal (BST): [33], the supraoptic nucleus (SON); [34] and the MeA [35].

Studies using microdialysis have shown increased levels of NA in several forebrain regions of the limbic system, mainly in the MeA of animals subjected to stress situations [1,36-40]. Although the noradrenergic system activation occurs in the MeA during stress, the role of this activation in the mediation of stress-induced cardiovascular responses has not yet been evaluated.

Several studies in the literature support the idea that acute restraint is an unavoidable aversive stimulus eliciting sustained $\mathrm{BP}$ and $\mathrm{HR}$ increase [41-46]. In this way, in the present study, we tested the hypothesis that noradrenergic neurotransmission within the MeA mediates the cardiovascular responses evoked by restraint stress. For that purpose, we pretreated the MeA with adrenoceptor antagonists and submitted the rats to acute restraint, after which we observed the cardiovascular responses evoked by this stressor.

\section{Materials and methods}

\subsection{Subjects}

Experimental procedures were carried out following protocols approved by the Ethical Review Committee of the School of Medicine of Ribeirão Preto (no. 057/2009). Male Wistar rats weighing $250-280 \mathrm{~g}$ were used in the present experiment. Animals were housed individually in plastic cages in a temperature-controlled room $\left(25^{\circ} \mathrm{C}\right)$ at the Animal Care Unit of the Department of Pharmacology. School of Medicine of Ribeirão Preto. Animals were kept under a 12:12 h light-dark cycle (lights on at 06:00). Animals had free access to water and standard laboratory food, except during the experimental period. Rats were transported to the experiment room and remained in their own cages until the experimental restraint procedure. Experiments were performed during the morning period to minimize possible circadian rhythm interferences.

\subsection{Surgical preparation}

Animals were anesthetized with tribromoethanol $(250 \mathrm{mg} / \mathrm{kg}$ i.p.) and their heads were fixed to a stereotaxic apparatus (Stoelting, USA). The skull was surgically exposed and trepanned with a dental drill at a point located $3.4 \mathrm{~mm}$ from midline and $6.2 \mathrm{~mm}$ anterior to the interaural line, according to the rat brain atlas of Paxinos and Watson [47]. Bilateral stainless steel guide cannulae (26G, 15 mmlong) were lowered $8.0 \mathrm{~mm}$ from the skull. Guide cannulae were positioned $1 \mathrm{~mm}$ above the intended injection sites and fixed to the skull by a metal screw and dental cement. Animals were allowed to recover for $48 \mathrm{~h}$ before a polyethylene catheter was implanted into the femoral artery under anesthesia, for chronic recording of arterial BP and HR. The catheter was exposed on the dorsum of the animals and attached to the skin, allowing arterial pressure recording of unanesthetized rats $24 \mathrm{~h}$ after surgery.

\subsection{Drug microinjection into the MeA}

Injections were performed in a volume of $100 \mathrm{~nL}$. For microinjections, we used a $1 \mu \mathrm{L}$ syringe (KH7001, Hamilton, USA) connected to a 33G injection needle (Small Parts Inc, FL, USA) by PE-10 polyethylene tubing. The injection needle was $1.0 \mathrm{~mm}$ longer than the guide cannula.

\subsection{Measurement of cardiovascular responses}

Pulsatile arterial pressure (PAP) was recorded using an amplifier (model 7754A. Hewlett Packard, USA) coupled to a computerized acquisition system (MP100, Biopac, USA). Mean arterial pressure (MAP) and HR were derived from PAP data using the AcqKnowledge III Software (Biopac, USA). The MAP was calculated according to the equation: diastolic pressure +(systolic-diastolic)/3. The HR (beats/min; bpm) was calculated from PAP peak intervals that were integrated each $6 \mathrm{~s}$.

\subsection{Drugs utilized in the experimental procedures}

The following drugs were used: Vehicle artificial cerebrospinal fluid (ACSF) had the following composition: $100 \mathrm{mM} \mathrm{NaCl} ; 2 \mathrm{mM}$ $\mathrm{Na} 3 \mathrm{PO} 4 ; 2.5 \mathrm{mM} \mathrm{KCl} ; 1 \mathrm{mM} \mathrm{MgCl} 2 ; 27 \mathrm{mM} \mathrm{NaHCO}$ 3; $2.5 \mathrm{mM}$ $\mathrm{CaCl} 2$ and $\mathrm{pH}=7.4), \mathrm{RX821002}(\alpha 2$-adrenoceptor antagonist), WB4101 ( $\alpha 1$-adrenoceptor antagonist) urethane (Sigma, USA), tribromoethanol (Aldrich, USA), streptomycins and penicillins (Pentabiotico, Fort Dodge, Brazil), flunixine meglumine (Banamine, Schering Plough, Brazil).

\subsection{Experimental procedure: acute restraint}

Animals were transported to the experimental room in their home cages. They were allowed a $1 \mathrm{~h}$ period to adapt to the conditions of the experimental room, such as sound and illumination, before starting blood pressure and heart rate recording. The experimental room was acoustically isolated and had a constant background noise generated by an air exhauster. At least another $20 \mathrm{~min}$ period was allowed for baseline recording before experiments were initiated. After recording baseline values, bilateral microinjections of drugs or vehicle were made into the MeA, each animal receiving only one microinjection per brain side. Care was taken to start injection whenever a stable blood pressure and especially a stable heart rate recording were observed. The injection needle was slowly introduced through the guide cannula without touching or restraining the animals. Ten min later, the animals were submitted to restraint, which was initiated by putting animals into a small plastic cylindrical restraining tube (diameter $=6.5 \mathrm{~cm}$ and length $=15 \mathrm{~cm}$ ). Restraint lasted for $60 \mathrm{~min}$ and immediately after. the animals were returned to their cages. Each animal was submitted to one session of restraint in order to prevent habituation.

Animals were divided into seven experimental groups: (1) aCSF group, vehicle microinjected into the MeA, (2) WB4101 dose $10 \mathrm{nmol}$ group, (3) WB4101 dose $15 \mathrm{nmol}$ group, (4) WB4101 dose $20 \mathrm{nmol}$ group, (5) RX821002 dose $10 \mathrm{nmol}$ group, (6) RX821002 dose $15 \mathrm{nmol}$ group and (7) RX821002 dose $20 \mathrm{nmol}$ group. The vehicle and all drugs were microinjected bilaterally into the MeA.

\subsection{Histological determination of the microinjection sites}

At the end of the experiments, animals were anesthetized with urethane $(1.25 \mathrm{~g} / \mathrm{kg}$ i.p.) and $100 \mathrm{~nL}$ of $1 \%$ Evan's blue was injected into the brain as a marker at the injection site. Animals were submitted to intracardiac perfusion with $0.9 \% \mathrm{NaCl}$ followed by $10 \%$ formalin. Brains were removed, and post-fixed for $48 \mathrm{~h}$ at $4^{\circ} \mathrm{C}$ and serial $40 \mu \mathrm{m}$-thick sections were cut with a cryostat (CM1900, Leica, Germany). Sections were stained with $1 \%$ violet cresyl for optical microscopy analysis. The actual placement of the microinjection needles was determined by analyzing serial sections, according to the rat brain atlas of Paxinos and Watson [47]. 


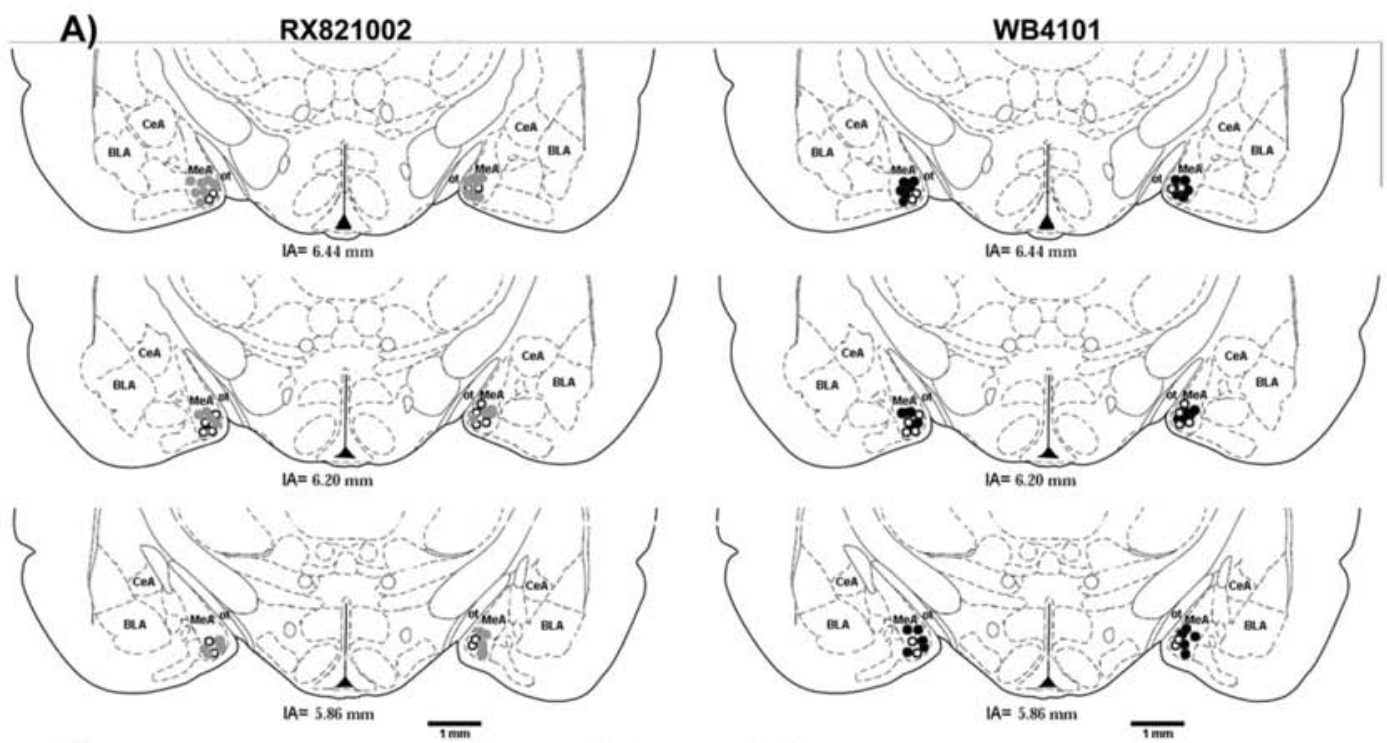

B)

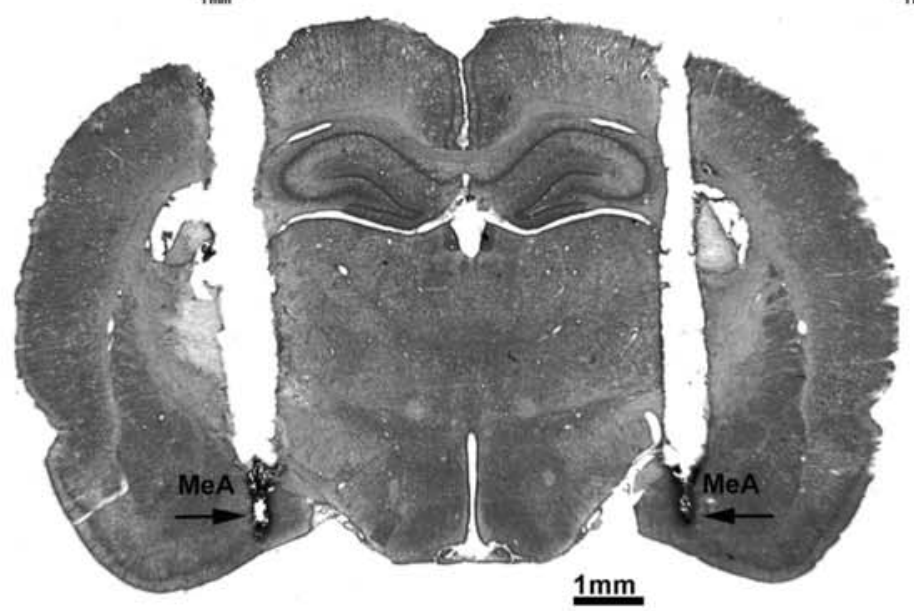

Fig. 1. (A) Diagrammatic representation modified from the rat brain atlas of Paxinos and Watson [47] indicating microinjection sites in the brain of rats used in the presen experiment, Dots in the figure indicate microinjection sites of RX821002 (gray dots, left side), WB4101 (black dots, right side) and vehicle (white dots). (B) Photomicrograph of a coronal section of a representative rat brain showing the sites of bilateral microinjections in the MeA, which are indicated by arrows. IA - interaural, CeA - central nucleus of the amygdala; BLA - basolateral nucleus of the amygdala; OT - optic tract.

\subsection{Statistical analysis}

Statistical analysis was performed using Prism software (GraphPad, USA). The paired Student's $t$-test was used to compare basal MAP and HR values before and after aCSF or drug treatment. To determine and compared $\triangle \mathrm{MAP}$ and $\triangle \mathrm{HR}$ changes, we used one-way ANOVA followed by Dunnett's test, to verify alterations between aCSF and drug treatments.

Although blood pressure was recorded throughout the experimental procedure, curves for statistical analysis or illustrative figures were generated with points obtained from different data sampling. Figs. 3 and 4 were generated from samplings of $0.64 / \mathrm{min}$ for more accurate representation. To verify possible correlations between drug doses and $\triangle \mathrm{MAP}$ or $\triangle \mathrm{HR}$ values, we used linear regression curves that were generated from selected points recorded during the $60 \mathrm{~min}$ restraint stress period. The significance was set at $p<0.05$. Data are presented as mean \pm SEM.

\section{Results}

\subsection{Determination of microinjection sites}

A diagrammatic representation showing microinjection sites in the MeA of the animals used in the study is presented in Fig. 1A A photomicrograph of a coronal brain section depicting bilateral microinjection sites in the MeA of one representative animal is presented in Fig. 1B.

\subsection{Effect of MeA pretreatment with the selective}

$\alpha_{1}$-adrenoceptor antagonist WB4101 on restraint-related cardiovascular changes

Bilateral microinjection of WB4101 (10,15 and $20 \mathrm{nmol} / 100 \mathrm{~nL})$ did not affect baseline BP and HR values when compared with aCSF-treated animals (Tables 1 and 2). The pretreatment with WB4101 significantly reduced the restraint-evoked $\triangle H R$ increase 
Table 1

Basal values of the mean arterial pressure (MAP), before and after the microinjection of different doses with WB4101 (selective $\alpha_{1}$-adrenoceptor antagonist) into the MeA of the rats.

\begin{tabular}{|c|c|c|c|c|}
\hline WB4101 (nmol/100 nL) & Before $(\mathrm{MAP}) \pm \mathrm{SEM}(\mathrm{mmHg})$ & After (MAP) \pm SEM $(\mathrm{mmHg})$ & $t=$ & $n=($ sample $)$ \\
\hline 0 & $96 \pm 4$ & $94 \pm 3$ & 0.2683 & 8 \\
\hline 10 & $101 \pm 4$ & $100 \pm 6$ & 0.01702 & 5 \\
\hline 15 & $86 \pm 1$ & $88 \pm 1$ & 0.7759 & 5 \\
\hline 20 & $91 \pm 1$ & $87 \pm 2$ & 1.262 & 7 \\
\hline
\end{tabular}

Table 2

Basal values of the heart rate (HR), before and after the microinjection of different doses with WB4101 (selective $\alpha_{1}$-adrenoceptor antagonist) into the MeA of the rats.

\begin{tabular}{|c|c|c|c|c|}
\hline WB4101 (nmol/100 nL) & Before $(\mathrm{HR}) \pm \mathrm{SEM}(\mathrm{bpm})$ & After $(\mathrm{HR}) \pm \operatorname{SEM}(\mathrm{bpm})$ & $t=$ & $n=($ sample $)$ \\
\hline 0 & $366 \pm 8$ & $358 \pm 5$ & 0.8270 & 8 \\
\hline 10 & $330 \pm 16$ & $334 \pm 8$ & 0.2197 & 5 \\
\hline 15 & $361 \pm 13$ & $370 \pm 10$ & 0.5522 & 5 \\
\hline 20 & $370 \pm 7$ & $375 \pm 5$ & 0.5746 & 7 \\
\hline
\end{tabular}
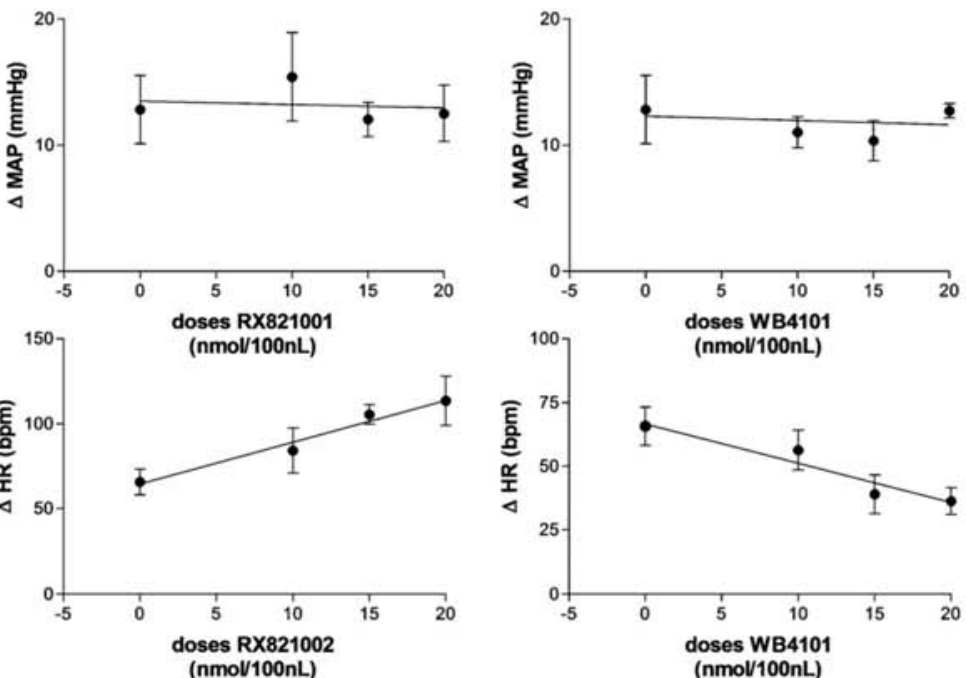

Fig. 2. Mean arterial pressure ( $\triangle M A P)$ and heart rate $(\triangle H R$ ) changes in response to the injection of increasing doses of RX821002 (left side) and WB4101 (right side) 10,15 and $20 \mathrm{nmol} / 100 \mathrm{~nL}$ in rats. Dose zero: vehicle (aCSF-treated,). Dose-effect curves were generated by linear regression analysis. Data shown represent the means \pm SEM of the variation of MAP and HR during the 60 min of acute restraint.
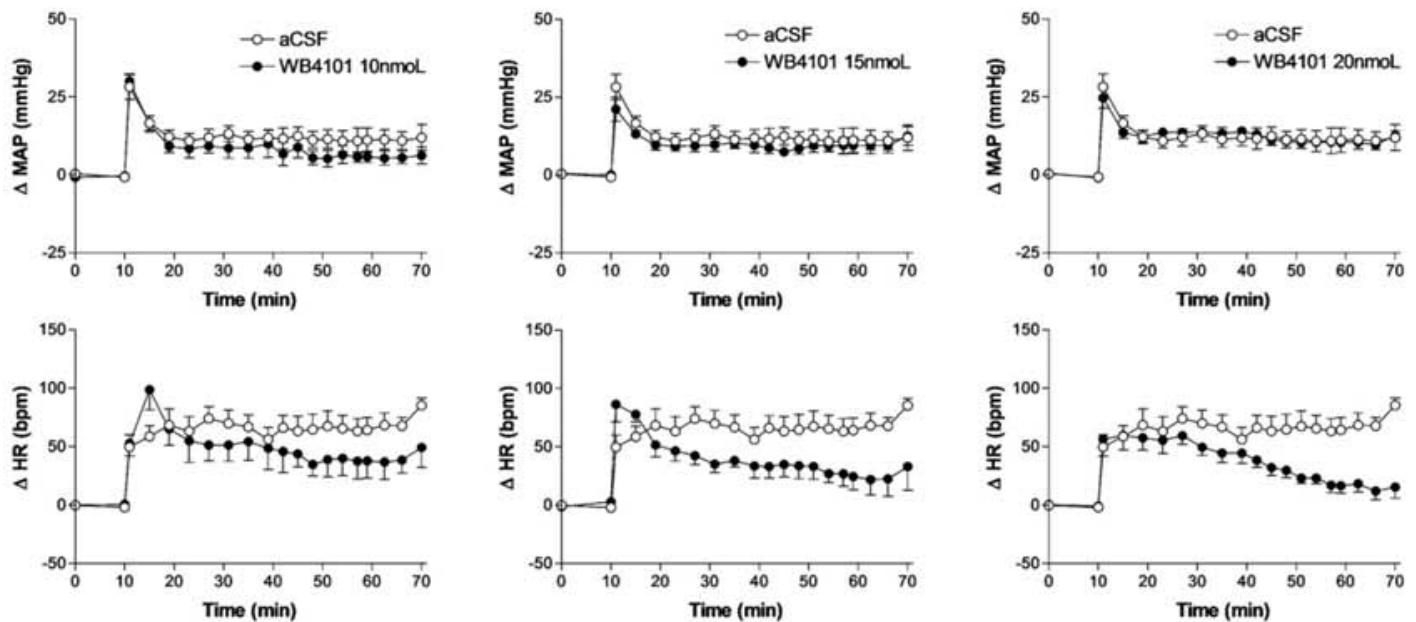

Fig. 3. Effects of different doses of (WB4101 - 10,15 and $20 \mathrm{nmol} n=5,5,7$ per group, respectively) or vehicle (aCSF-treated, $n=8$ ) on changes in mean arterial pressure $(\triangle \mathrm{MAP})$ and heart rate $(\triangle \mathrm{HR})$ of animals submitted to $60 \mathrm{~min}$ of restraint stress. The minute 10 indicates the beginning of the restraint period. Data shown represent the means \pm SEM. $P<0.05$, compared with vehicle group; ANOVA followed by Dunnett's post hoc test. 

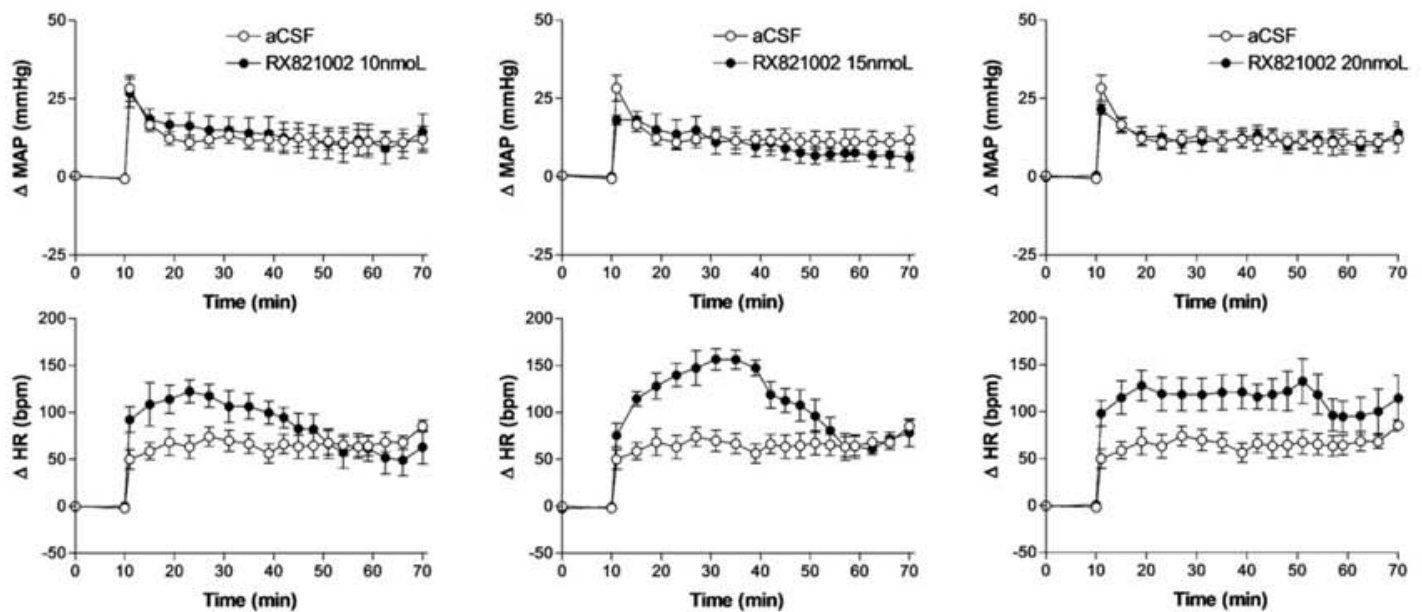

Fig. 4. Effects of different doses of ( $R X 821002-10,15$ and $20 \mathrm{nmol}, n=6,5,6$ per group, respectively) or vehicle (aCSF-treated, $n=8$ ) on changes in mean arterial pressure $(\triangle M A P)$ and heart rate $(\triangle H R)$ of animals submitted to 60 min of restraint stress. The minute 10 indicates the beginning of the restraint period. Data shown represent the means \pm SEM. $P<0.05$, compared with vehicle group; ANOVA followed by Dunnett's post hoc test.

at doses of 15 and $20 \mathrm{nmol}\left(\Delta \mathrm{HR}, F_{3.21}=4.267, P<0.05\right)$ without a significant effect on the $\triangle B P$ response, when compared with aCSFtreated animals $\left(\triangle M A P F_{3,21}=0.3792, P>0.05\right)$. The dose of $10 \mathrm{nmol}$ did not evoke a difference in restraint-related $\triangle \mathrm{MAP}$ or $\triangle \mathrm{HR}$ increases when compared with aCSF-treated animals $(P>0.05)$. A dose-dependent relation was evidenced by linear regression analysis with a significant correlation between doses and the attenuation in the $\triangle H R$ increase during restraint $\left(r^{2}=0.35, d f=23, P<0.05\right)$ without a significant effect on the $\triangle \mathrm{BP}$ response $\left(r^{2}=0.0003551\right.$, $\mathrm{df}=23, P>0.05$ ) (Fig. 2). Recordings showing the cardiovascular response of a rat pretreated with aCSF or WB4101 $(15 \mathrm{nmol} / 100 \mathrm{~nL})$ in the MeA and submitted to acute restraint are presented in Figs. 3-5.
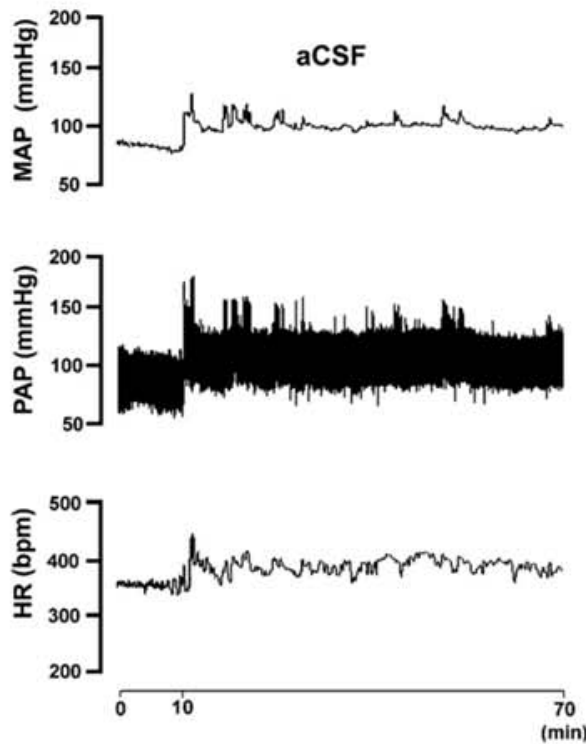

3.3. Effect of MeA pretreatment with the selective $\alpha_{2}$-adrenoceptor antagonist $R \times 821002$ on restraint-related cardiovascular changes

Bilateral microinjection of RX821002 (10, 15 and $20 \mathrm{nmol} / 100 \mathrm{~nL}$ ) did not affect baseline BP and HR values when compared with aCSF-treated animals (Tables 3 and 4). Pretreatment with RX821002 significantly enhanced the restraint-evoked $\triangle H R$ increase at doses of 15 and $20 \mathrm{nmol}\left(\Delta \mathrm{HR}, F_{3.21}=4.287, P<0.05\right)$ without a significant effect on the BP response, when compared with aCSF-treated animals ( $\triangle$ MAP $F_{3,21}=0.2910, P>0.05$ ) The dose of $10 \mathrm{nmol}$ did not evoke changes in restraint-related $\triangle \mathrm{MAP}$ or $\triangle \mathrm{HR}$ increases when compared with aCSF-treated
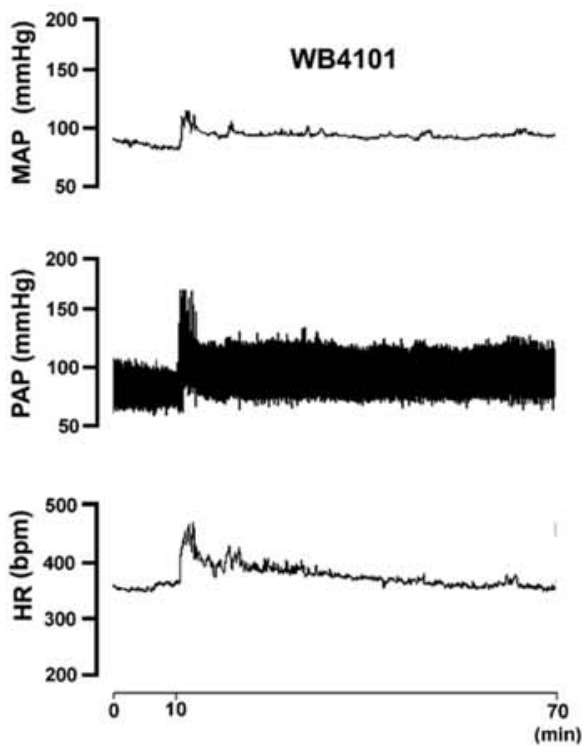

Fig. 5. Recordings of mean arterial pressure (MAP), pulsatile arterial pressure (PAP) and heart rate (HR) showing the cardiovascular changes observed before and during a restraint period of $60 \mathrm{~min}$ in a control rat and in a rat whose MeA was treated with WB4101 $-15 \mathrm{nmol} / 100 \mathrm{~nL}$. before restraint. The onset of restraint was at $t=10 \mathrm{~min}$. 
Table 3
Basal values of the mean arterial pressure (MAP), before and after the microinjection of different doses with RX821002 (selective $\alpha_{2}$-adrenoceptor antagonist) into the MeA Basal values

\begin{tabular}{|c|c|c|c|c|}
\hline RX821002 (nmol/100 nL) & Before $(\mathrm{MAP}) \pm \mathrm{SEM}(\mathrm{mmHg})$ & After $(\mathrm{MAP}) \pm$ SEM $(\mathrm{mmHg})$ & $t=$ & $n=($ sample $)$ \\
\hline 0 & $96 \pm 4$ & $94 \pm 3$ & 0.2683 & 8 \\
\hline 10 & $104 \pm 3$ & $101 \pm 4$ & 0.4893 & 6 \\
\hline 15 & $93 \pm 3$ & $92 \pm 5$ & 0.1785 & 5 \\
\hline 20 & $87 \pm 4$ & $90 \pm 5$ & 0.5337 & 6 \\
\hline
\end{tabular}

Table 4

Basal values of the heart rate (HR), before and after the microinjection of different doses with RX821002 (selective $\alpha_{2}$-adrenoceptor antagonist) into the MeA of the rats.

\begin{tabular}{|c|c|c|c|c|}
\hline RX821002 (nmol/100 nL) & Before $(\mathrm{HR}) \pm$ SEM $(\mathrm{bpm})$ & After (HR) \pm SEM (bpm) & $t=$ & $n=$ (sample) \\
\hline 0 & $366 \pm 8$ & $358 \pm 5$ & 0.8270 & 8 \\
\hline 10 & $356 \pm 7$ & $355 \pm 8$ & 0.1257 & 6 \\
\hline 15 & $351 \pm 8$ & $363 \pm 11$ & 0.8194 & 5 \\
\hline 20 & $355 \pm 9$ & $367 \pm 7$ & 0.9843 & 6 \\
\hline
\end{tabular}
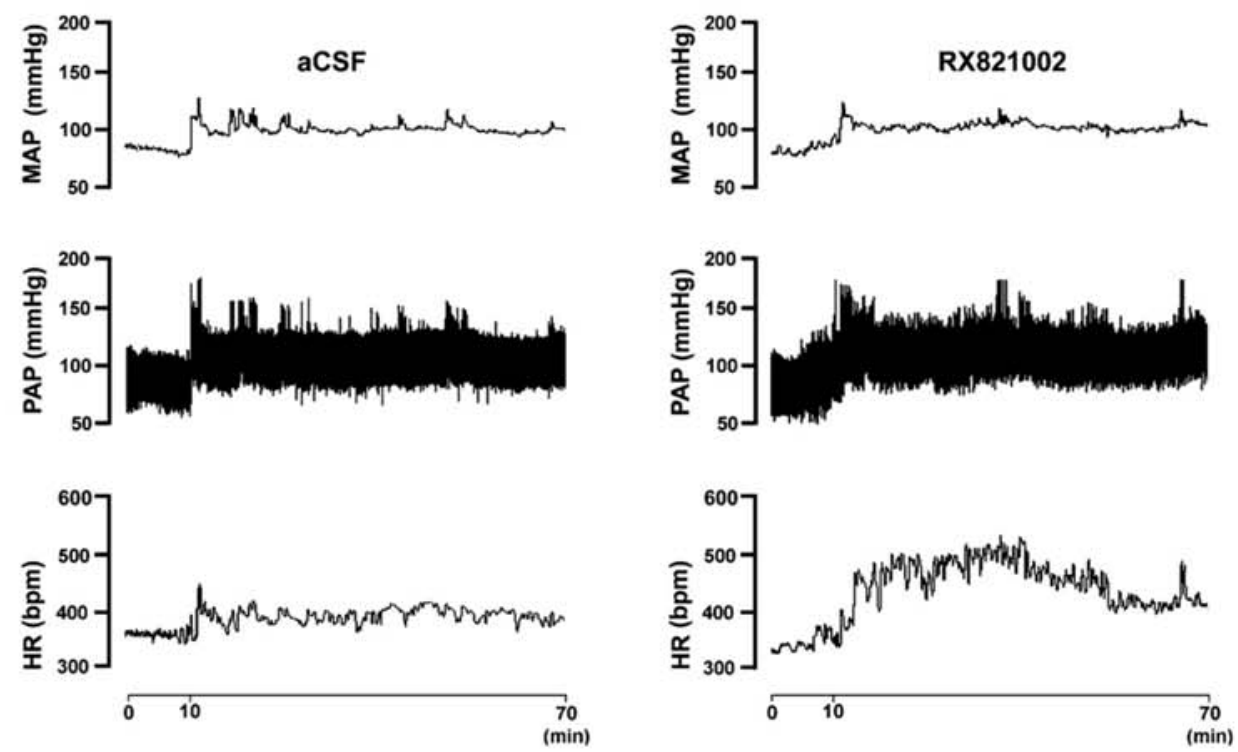

Fig. 6. Recordings of mean arterial pressure (MAP), pulsatile arterial pressure (PAP) and heart rate (HR) showing the cardiovascular changes observed before and during a restraint period of $60 \mathrm{~min}$ in a control rat and in a rat whose MeA was treated with RX821002 - $15 \mathrm{nmol} / 100 \mathrm{~nL}$ before restraint. The onset of restraint was at $t=10$ min.

animals $(P>0.05)$. A dose dependency was evidenced by linear regression analysis that showed a significant correlation between doses and enhancement in the $\Delta$ HR increase $\left(r^{2}=0.3703\right.$. $\mathrm{df}=23, P<0.05)$ without a significant effect on the $\Delta \mathrm{BP}$ response $\left(r^{2}=0.001064, \mathrm{df}=23, P>0.05\right)$ (Fig. 2). Recordings showing the cardiovascular response of a rat pretreated with aCSF or RX821002 $(15 \mathrm{nmol} / 100 \mathrm{~nL})$ in the $\mathrm{MeA}$ and submitted to acute restraint are presented in Fig. 6.

\section{Discussion}

To study the possible involvement of noradrenergic neurotransmission in the MeA in the modulation of restraint-evoked cardiovascular responses, we pretreated this area with different doses of selective $\alpha$-adrenoceptor antagonists. Bilateral microinjection of WB4101, a selective $\alpha_{1}$-adrenoceptor antagonist, into the MeA caused a significant reduction in tachycardia evoked by acute restraint. The effect of WB4101 on the restraint-evoked HR response was dose-dependent. Pretreatment with WB4101 had no significant effect on the restraint-evoked pressor response. In contrast, pretreatment with RX821002, a selective $\alpha_{2}$-adrenoceptor antagonist, significantly increased the restraint-evoked tachycardiac response, in a dose-related manner. Pretreatment with RX821002 did not affect the restraint-evoked pressor response.

The drugs used in our study did not affect baseline BP or HR, thus indicating that the MeA does not contribute to cardiovascular control at rest. These results corroborate previous data from the literature indicating no changes in cardiovascular responses after microinjection of these antagonists into the MeA or other brain structures $[4,19]$.

Restraint is an inescapable stressful stimulus that causes cardiovascular changes that are characterized by both BP and HR increases [7,19,41,48-50]. The idea of a MeA involvement in the mediation of stress-evoked responses is reinforced by data from the literature showing that its electrical stimulation activates the hypothalamic-pituitary-adrenal HPA axis in anesthetized rats [51]. Moreover, the MeA is connected with hypothalamic and brainstem areas that are involved in cardiovascular regulation [8-10].

Structures such as the lateral septal area [20,52], lateral hypothalamus [53,54], medial prefrontal cortex [7], bed nucleus of stria terminalis [3]. MeA and central amygdala (CeA) $[4,19,50]$ and the paraventricular nucleus of the hypothalamus (PVN) $[56,57]$ 
were proposed to be part of the circuitry that modulates restraintevoked cardiovascular responses. Data from the literature also indicate a larger activation of the MeA, among other amygaloid nuclei, during stressful situations, as is indicated by the large expression of $\mathrm{c}$-fos protein in this area after exposure to aversive situations [19,48,58-64].

Inhibition of the MeA with muscimol attenuated the restraintevoked pressor response [19]. In addition, in a previous study from our group, it was shown that bilateral microinjection of the nonselective synaptic blocker $\mathrm{CoCl}_{2}$ into the MeA increased the HR response to acute restraint, without a significant effect on the BP response [4]). Together, these data suggest that the MeA is involved in the modulation of cardiovascular responses evoked by acute restraint.

Besides activating the HPA axis and the sympathetic nervous system, exposure to stress also induces a noradrenaline (NA) release, which facilitates synaptic transmission in many of the brain regions involved in modulation of stress-related behavioral and physiological responses [65-67]. The NA may affect HPA reactivity not only by acting directly on the PVN [68-70], but also through actions in extrahypothalamic regions that exert a modulatory input on the HPA axis. For example, it has been shown that noradrenergic neurotransmission is activated in the MeA under acute immobilization stress, and that the NA released in MeA during stress facilitates the activation of the HPA axis [1]. The idea that the MeA participates in the extra hypothalamic circuitry facilitating the stress-induced HPA activation is consistent with previous reports showing that a direct stimulation of MeA increased corticosterone levels [51,71].

Studies on the expression of mRNA and receptor binding evidenced the presence of noradrenergic receptors in the MeA $[27,28]$, thus suggesting the existence of a noradrenergic system in this area. The selective blockade of $\alpha_{1}$-adrenoceptors by the microinjection of WB4101 (10, 15 and $20 \mathrm{nmol})$ into the MeA reduced, in a dose-dependent manner, the restraint-evoked $\mathrm{HR}$ response, without affecting the BP response. This result suggests that local $\alpha 1$-adrenoceptors play a facilitatory role on the restraint-evoked tachycardiac response in the rat. These data are different from those resulting from experiments performed with the administration of $\mathrm{CoCl}_{2}$ into the MeA, in which there was an increased tachycardiac restraint-evoked response [4]. However, it is important to point out that $\mathrm{CoCl}_{2}$ inhibits all synaptic neurotransmissions in the area. Selective antagonists such as WB4101 and RX821002 have been previously used to identify the subtype of $\alpha$-adrenoceptor that is involved in the mediation of restraint-evoked pressor and tachycardiac responses when microinjected into the BST [3]. The present results indicate that local $\alpha_{1}$-adrenoceptors in the MeA play an inhibitory role in the HR increase evoked by restraint stress.

The selective blockade of $\alpha_{2}$-adrenoceptors by the microinjection of RX821002 (10, 15 and $20 \mathrm{nmol})$ into the MeA caused dose-dependent increases in the restraint-evoked tachycardiac response, similarly to that observed after the pharmacological ablation of the area with $\mathrm{CoCl}_{2}$.

$\alpha 2$-Adrenoceptors are located both pre- and post-synaptically in the brain and are found in high density in the MeA $[72,73]$. The activation of $\alpha 2$-adrenoceptors results in the inhibition of neuronal firing and a decrease in NA release. Also, it is well known that selective $\alpha_{2}$-adrenoceptor antagonists such as the RX821002, can either facilitate or potentiate the noradrenaline release in rats under basal conditions or during exposure to stress [74-80]. This can lead to increased levels of noradrenaline in rat brain areas such as the MeA [81-84]. Our results suggest that $\alpha_{2}$-adrenoceptors in the MeA play an inhibitory influence on restraint-evoked tachycardiac responses in the rat.

$\alpha_{2}$-Adrenergic binding sites have been detected in the MeA $[72,73]$. Moreover, previous data indicate that the cardiovascular response evoked by NA microinjection into the MeA involves local $\alpha_{2}$-adrenoceptors [35], thus suggesting that in the MeA these receptors are involved with cardiovascular modulation.

The present results show that $\alpha 1$ - and $\alpha_{2}$-adrenoceptors in the MeA play different roles in the modulation of the cardiac response to acute restraint. Cardiac autonomic control is a result of a balance between parasympathetic and sympathetic activities [85] Parasympathetic stimulation depresses HR and cardiac contractile force, whereas sympathetic activation increases it. However, simultaneous activation of both autonomic systems is associated with chemoreceptor, startle, noxious and defensive responses [86]. Stress-related cardiac and pressor responses are sympathetically mediated, because both are abolished after ganglion blockade and are respectively blocked by pretreatment with either $\beta$ or $\alpha$ adrenergic antagonists [87,88]. Moreover, previous results from the literature indicated that treatment with a parasympathetic blocker increased the tachycardiac response evoked by a psychological stress $[3,7,89,90]$, thus suggesting a simultaneous activation of the cardiac parasympathetic and the sympathetic systems during psychological stress. An emotional-autonomic pathway has been localized in the extended amygdaloid complex of the rat. Microinjection of pseudorabies virus into the adrenal gland, stellate ganglion which regulates the heart, or celiac ganglion which innervates the gastrointestinal tract caused extensive transneuronal labeling in limbic system areas such as the extended amygdaloid complex, lateral septum, and infralimbic, insular, and ventromedial temporal cortical regions [91], suggesting that these areas are linked by multisynaptic connections to the sympathetic outflows.

Tachycardia evoked by restraint stress in rats is well documented $[41,48,92]$. There is evidence suggesting that the amygdaloid complex may be a part of the brain circuitry involved in this elevated cardiac sympathetic drive. Both electrical and chemical stimulation of the amygdala evoked heart rate increases [11,93-95], thus suggesting the involvement of this area in the modulation of cardiac responses.

\section{Conclusion}

In summary, we propose that in the rat, $\alpha_{1}$-adrenoceptors in the MeA play a facilitatory role in the cardiac component of the restraint-evoked cardiovascular response whereas $\alpha_{2}$ adrenoceptors have an inhibitory role in the modulation of the cardiac component of the response.

\section{Conflicts of interest}

None.

\section{Acknowledgements}

We acknowledge I.A.C. Fortunato, I.I.B. Aguiar and S.S. Guilhaume for Technical Assistance. Eduardo Albino Trindade Fortaleza is a PhD student enrolled in the Department of Pharmacology, School of Medicine of Ribeirão Preto-USP and recipient of a CNPq fellowship (140118/2009-8). América A. Scopinho is a postdoctoral fellow in the Department of Pharmacology. School of Medicine of Ribeirão Preto-USP and recipient of a CAPES fellowship (PNPD0176087). The present research was supported by grants from the CNPq (501269/2005-3).

\section{References}

[1] Ma S, Morilak DA. Norepinephrine release in medial amygdala facilitates activation of the hypothalamic-pituitary-adrenal axis in response to acute immobilisation stress. Journal of Neuroendocrinology 2005;17:22-8.

[2] Alves FH. Crestani CC, Correa FM. The insular cortex modulates cardiovascular responses to acute restraint stress in rats. Brain Research 2010;1333:57-63. 
[3] Crestani CC. Alves FH, Tavares RF, Correa FM. Role of the bed nucleus of the stria terminalis in the cardiovascular responses to acute restraint stress in rats. Stress 2009:12:268-78

[4] Fortaleza EA, Tavares RF, Correa FM. The medial amygdaloid nucleus modulates cardiovascular responses to acute restraint in rats. Neuroscience 2009:159:717-26.

[5] Pacak K, Palkovits M. Stressor specificity of central neuroendocrine responses: Implications for stress-related disorders. Endocrine Reviews 2001:22:502-48.

[6] Resstel LB, Joca SR, Guimaraes FG. Correa FM. Involvement of medial prefrontal cortex neurons in behavioral and cardiovascular responses to contextual fear conditioning. Neuroscience 2006:143:377-85.

[7] Tavares RF, Correa FM. Role of the medial prefrontal cortex in cardiovascular responses to acute restraint in rats. Neuroscience 2006:143:231-40.

[8] Swanson LW. The amygdala and its place in the cerebral hemisphere. Annals of the New York Academy of Sciences 2003:985:174-84.

[9] Price JL, Russchen FT. Amaral DG. The limbic region. Ii: The amygdaloid complex. New York: Elsevier Science: 1987.

[10] Dampney RA. Functional organization of central pathways regulating the cardiovascular system. Physiological Reviews 1994:74:323-64.

[11] Gelsema A]. McKitrick DJ. Calaresu FR. Cardiovascular responses to chemical and electrical stimulation of amygdala in rats. American Journal of Physiology 1987:253:R712-8.

[12] Faiers AA, Calaresu FR, Mogenson G]. Pathway mediating hypotension elicited by stimulation of the amygdala in the rat. American Journal of Physiology 1975:228:1358-66.

13] Lam W. Louis WJ. Verberne AJ. Effect of dorsal periaqueductal grey lesion on baroreflex and cardiovascular response to air-jet stress. Journal of the Autonomic Nervous System 1995:53:35-42.

[14] van den Buuse M, Van Acker SA, Fluttert M, De Kloet ER. Blood pressure, heart rate, and behavioral responses to psychological Novelty Stress in freely moving rats. Psychophysiology 2001:38:490-9,

[15] Kapusta DR, Dayan LA. Kenigs VA. Nociceptin/orphanin fq modulates the cardiovascular, but not renal, responses to stress in spontaneously hypertensive rats. Clinical and Experimental Pharmacology and Physiology 2002:29:254-9.

[16] Knuepfer MM. Purcell RM. Gan Q. Le KM. Hemodynamic response patterns to acute behavioral stressors resemble those to cocaine. American Journal of Physacute behavioral stressors resemble those to cocaine. American Journal of Phys-

17) Muller JR, Le KM, Haines WR, Gan Q, Knuepfer MM. Hemodynamic response pattern predicts susceptibility to stress-induced elevation in arterial pressure pattern predicts susceptibility to stress-induced elevation in arterial pressure
in the rat. American Journal of Physiology Regulatory. Integrative Comparative in the rat. American Journal o

[18] Kaehler ST, Sinner C. Philippu A. Release of catecholamines in the locus coeruleus of freely moving and anaesthetized normotensive and spontaneously hypertensive rats: Effects of cardiovascular changes and tail pinch. NaunynSchmiedebergs Archives of Pharmacology 2000:361:433-9.

[19] Kubo T, Okatani H, Nishigori Y, Hagiwara Y. Fukumori R, Goshima Y. Involvement of the medial amygdaloid nucleus in restraint stress-induced pressor responses in rats. Neuroscience Letters 2004:354:84-6.

[20] Kubo T, Kanaya T, Numakura H, Okajima H. Hagiwara Y, Fukumori R. The latera] septal area is involved in mediation of immobilization stress-induced blood pressure increase in rats. Neuroscience Letters 2002:318:25-8.

[21] Sanders BJ. Wirtz-Nole C, DeFord SM. Erling BF. Central amygdaloid lesions attenuate cardiovascular responses to acute stress in rats with borderline hypertension. Physiology and Behavior 1994:56:709-13.

[22] Galeno TM, Van Hoesen GW, Brody MJ. Central amygdaloid nucleus lesion attenuates exaggerated hemodynamic responses to noise stress in the spontaneously hypertensive rat, Brain Research 1984:291:249-59.

123] Carter RN, Pinnock SB. Herbert J. Does the amygdala modulate adaptation to repeated stress. Neuroscience 2004:126:9-19.

[24] Thrivikraman KV, Su Y, Plotsky PM. Patterns of fos-immunoreactivity in the cns induced by repeated hemorrhage in conscious rats: Correlations with pituitaryinduced by repeated hemorrhage in conscio

[25] Roder S, Ciriello]. Innervation of the amygdaloid complex by catecholaminergic cell groups of the ventrolateral medulla. Journal of Comparative Neurology 1993:332:105-22.

[26] Sadikot AF, Parent A. The monoaminergic innervation of the amygdala in the squirrel monkey: an immunohistochemical study. Neuroscience 1990:36:431-47.

[27] Domyancic AV, Morilak DA. Distribution of alpha1a adrenergic receptor mrna in the rat brain visualized by in situ hybridization. Journal of Comparative Neurology 1997; 386:358-78.

[28] Jones LS, Gauger LL. Davis JN. Localization of alpha 1-adrenergic receptors in normal and weaver mouse brain with in vitro 125i-heat autoradiography. Neuroscience Letters 1986:65:259-64.

[29] Vlahakos D. Gavras I, Gavras H. Alpha-adrenoceptor agonists applied in the area of the nucleus tractus solitarii in the rat: effect of anesthesia on cardiovascular responses. Brain Research 1985:347:372-5.

[30] Fernandes KB, Crippa GE. Tavares RF, Antunes-Rodrigues J. Correa FM. Mechanisms involved in the pressor response to noradrenaline injection into the cingulate cortex of unanesthetized rats. Neuropharmacology 2003:44:757-63.

31) Pelosi GG, Correa FM. Cardiovascular effects of noradrenaline microinjected into the dorsal periaqueductal gray area of unanaesthetized rats. European into the dorsal periaqueductal gray area

[32] Scopinho AA, Resstel LB. Antunes-Rodrigues J. Correa FM. Pressor effects of noradrenaline injected into the lateral septal area of unanesthetized rats. Brain Research 2006:1122:126-34.
133] Crestani CC, Alves FH Resstel LB, Correa FM. Cardiovascular effects of noradrenaline microinjection in the bed nucleus of the stria terminalis of the rat brain. Journal of Neuroscience Research 2007:85:1592-9.

[34] Busnardo C. Tavares RF, Correa FM. Mechanisms involved in the pressor response to noradrenaline microinjection into the supraoptic nucleus of unanesthetized rats. Autonomic Neuroscience 2009:145:63-70.

[35] Fortaleza EA, Scopinho AA, Correa FM. Cardiovascular responses to microinjection of noradrenaline into the medial amygdaloid nucleus of conscious rats result from alpha-receptor activation and vasopressin release. European Journal of Neuroscience 2011:33:1677-84.

[36] Bondi CO, Barrera G, Lapiz MD, Bedard T, Mahan A, Morilak DA. Noradrenergic facilitation of shock-probe defensive burying in lateral septum of rats, and modulation by chronic treatment with desipramine. Progress in NeuroPsychopharmacology and Biological Psychiatry 2007:31:482-95.

[37] Cecchi M, Khoshbouei H. Javors M. Morilak DA. Modulatory effects of norepinephrine in the lateral bed nucleus of the stria terminalis on behavioral and neuroendocrine responses to acute stress. Neuroscience 2002:112: 13-21.

[38] Morilak DA, Barrera G, Echevarria D], Garcia AS, Hernandez A, Ma S, et al. Role of brain norepinephrine in the behavioral response to stress. Progress in NeuroPsychopharmacology and Biological Psychiatry 2005:29:1214-24.

[39] Pardon MC, Gould GG, Garcia A, Phillips L, Cook MC, Miller SA, et al. Stress reactivity of the brain noradrenergic system in three rat strains differing in their neuroendocrine and behavioral responses to stress: Implications for susceptibility to stress-related neuropsychiatric disorders. Neuroscience 2002:115:229-42.

[40] Cecchi M. Khoshbouei H. Morilak DA. Modulatory effects of norepinephrine, acting on alpha 1 receptors in the central nucleus of the amygdala, on behavioral and neuroendocrine responses to acute immobilization stress. Neuropharmacology 2002:43:1139-47.

[41] Barron BA, Van Loon GR. Role of sympathoadrenomedullary system in cardiovascular response to stress in rats. Journal of the Autonomic Nervous System 1989:28:179-87

[42] Irvine RJ. White J. Chan R. The influence of restraint on blood pressure in the rat. Journal of Pharmacological and Toxicological Methods 1997:38:157-62.

[43] Krieman M]. Hershock DM, Greenberg IJ. Vogel WH. Effects of adinazolam on plasma catecholamine, heart rate and blood pressure responses in stressed and non-stressed rats. Neuropharmacology 1992:31:33-8.

[44] McDougall SJ, Paull JR, Widdop RE, Lawrence AJ. Restraint stress; differential cardiovascular responses in Wistar-kyoto and spontaneously hypertensive tial cardiovascular responses in Wist
rats. Hypertension 2000:35:126-9.

[45] Bhatnagar S, Dallman M. Neuroanatomical basis for facilitation of hypothalamic-pituitary-adrenal responses to a novel stressor after chronic stress. Neuroscience 1998:84:1025-39.

[46] Bhatnagar S, Dallman MF, Roderick RE, Basbaum AI, Taylor BK. The effects of prior chronic stress on cardiovascular responses to acute restraint and formalin injection. Brain Research 1998; 797:313-20.

[47] Paxinos G, Watson C. The rat brain in steretaxic coordinates, compact. 3rd ed. Academic Press: Sydney: 1997.

[48] Chen X. Herbert J. Regional changes in c-fos expression in the basal forebrain and brainstem during adaptation to repeated stress: correlations with cardiovascular, hypothermic and endocrine responses. Neuroscience 1995:64:675-85

[49] McDougall SJ, Lawrence AJ. Widdop RE. Differential cardiovascular responses to stressors in hypertensive and normotensive rats. Experimental Physiology 2005:90:141-50

[50] Salome N, Ngampramuan S, Nalivaiko E. Intra-amygdala injection of gabaa agonist, muscimol, reduces tachycardia and modifies cardiac sympatho-vagal balance during restraint stress in rats. Neuroscience 2007;148:335-41.

[51] Dunn JD, Whitener J. Plasma corticosterone responses to electrical stimulation of the amygdaloid complex: cytoarchitectural specificity. Neuroendocrinology 1986:42:211-7.

[52] Kanaya T, Okatani H. Hagiwara Y, Fukumori R, Goshima Y, Kubo T. Projections from the caudal part to the rostral part of the lateral septal area mediate blood pressure increase. Brain Research Bulletin 2003:61:505-10.

[53] Krout KE. Mettenleiter TC, Karpitskiy V. Nguyen XV, Loewy AD. Cns neurons with links to both mood-related cortex and sympathetic nervous system. Brain Research 2005:1050:199-202.

[54] Kubo T, Numakura H. Endo S, Hagiwara Y, Fukumori R. Angiotensin receptor blockade in the anterior hypothalamic area inhibits stress-induced pressor responses in rats. Brain Research Bulletin 2001:56:569-74.

[56] Busnardo C, Tavares RF, Resstel LB. Elias LL., Correa FM. Paraventricular nucleus modulates autonomic and neuroendocrine responses to acute restraint stress in rats. Autonomic Neuroscience 2010:158:51-7.

[57] Tavares RF, Pelosi GG, Correa FM. The paraventricular nucleus of the hypothalamus is involved in cardiovascular responses to acute restraint stress in rats. Stress 2009:12:178-85.

[58] Canteras NS. Simerly RB, Swanson LW. Organization of projections from the medial nucleus of the amygdala: a phal study in the rat.Journal of Comparative Neurology 1995:360:213-45.

[59] Crane JW, French KR, Buller KM. Patterns of neuronal activation in the rat brain and spinal cord in response to increasing durations of restraint stress. Stress 2005:8:199-211.

[60] Cullinan WE, Herman JP, Battaglia DF, Akil H. Watson SJ. Pattern and time course of immediate early gene expression in rat brain following acute stress. Neuroscience 1995;64:477-505. 
[61] Dayas CV, Buller KM, Crane JW, Xu Y. Day TA. Stressor categorization: Acute physical and psychological stressors elicit distinctive recruitment patterns in the amygdala and in medullary noradrenergic cell groups. European Journal of Neuroscience 2001:14:1143-52.

[62] Dayas CV. Buller KM, Day TA. Neuroendocrine responses to an emotional stressor: evidence for involvement of the medial but not the central amygdala. European Journal of Neuroscience 1999:11:2312-22.

[63] Dayas CV. Buller KM, Day TA. Medullary neurones regulate hypothalamic corticotropin-releasing factor cell responses to an emotional stressor. Neuroscience 2001:105:707-19.

[64] Trneckova L, Armario A, Hynie S, Sida P, Klenerova V. Differences in the brain expression of $\mathrm{c}$-fos mrna after restraint stress in lewis compared to SpragueDawley rats. Brain Research 2006:1077:7-15.

[65] Aston-Jones G. Rajkowski J. Cohen J. Role of locus coeruleus in attention and behavioral flexibility. Biological Psychiatry 1999:46:1309-20.

[66] Berridge CW, Waterhouse BD. The locus coeruleus-noradrenergic system: Modulation of behavioral state and state-dependent cognitive processes. Brain Research Brain Research Reviews 2003:42:33-84.

[67] Morilak DA. Frazer A. Antidepressants and brain monoaminergic systems: a dimensional approach to understanding their behavioural effects in depresdimensional approach to understanding their behavioural effects in depres-
sion and anxiety disorders. International Journal of Neuropsychopharmacology sion and anxiety disor.

[68] Feldman S, Conforti N. Melamed E. Norepinephrine depletion in the paraventricular nucleus inhibits the adrenocortical responses to neural stimuli. Neuroscience Letters 1986:64:191-5.

[69] Feldman S, Conforti N. Melamed E. Involvement of ventral noradrenergic bundle in corticosterone secretion following neural stimuli. Neuropharmacology 1988:27:129-33.

[70] Alonso G, Szafarczyk A, Balmefrezol M, Assenmacher I. Immunocytochemical evidence for stimulatory control by the ventral noradrenergic bundle of parvocellular neurons of the paraventricular nucleus secreting corticotropin releasing hormone and vasopressin in rats. Brain Research 1986:397: 297-307.

[71] Feldman S, Conforti N. Saphier D. The preoptic area and bed nucleus of the stria terminalis are involved in the effects of the amygdala on adrenocortical secretion. Neuroscience 1990;37:775-9.

[72) Flugge G, Ahrens O, Fuchs E. Monoamine receptors in the amygdaloid complex of the tree shrew (Tupaia belangeri). Journal of Comparative Neurology plex of the tree shrew

[73] Unnerstall JR, Kopajtic TA. Kuhar MJ. Distribution of alpha 2 agonist binding sites in the rat and human central nervous system: analysis of some functional, anatomic correlates of the pharmacologiceffects of clonidine and related tional, anatomic correlates of the pharmacologic effects
adrenergic agents. Brain Research 1984:319:69-101.

[74] Abercrombie ED. Jacobs BL. Single-unit response of noradrenergic neurons in the locus coeruleus of freely moving cats. I. Acutely presented stressful and nonstressful stimuli. Journal of Neuroscience 1987;7:2837-43.

[75] Dennis T, L'Heureux R. Carter C, Scatton B. Presynaptic alpha-2 adrenoceptors play a major role in the effects of idazoxan on cortical noradrenaline release (as measured by in vivo dialysis) in the rat. Journal of Pharmacology and Experimental Therapeutics 1987:241:642-9.

[76] Kawahara H. Kawahara Y, Westerink BH. The role of afferents to the locus coeruleus in the handling stress-induced increase in the release of noradrenaline in the medial prefrontal cortex: a dual-probe microdialysis study in the rat brain. European Journal of Pharmacology 2000:387: 279-86.

[77] Thomas DN. Holman RB. A microdialysis study of the regulation of endogenous noradrenaline release in the rat hippocampus. Journal of Neurochemistry 1991:56:1741-6.
[78] Tjurmina OA, Goldstein DS, Palkovits M, Kopin IJ. Alpha2-adrenoceptormediated restraint of norepinephrine synthesis, release, and turnover during immobilization in rats. Brain Research 1999:826:243-52.

[79] Wortley KE, Hughes ZA, Heal DJ. Stanford SC. Comparison of changes in the extracellular concentration of noradrenaline in rat frontal cortex induced by sibutramine or d-amphetamine: Modulation by alpha2-adrenoceptors. British Journal of Pharmacology 1999:127:1860-6.

[80] Wortley KE, Heal DJ. Stanford SC. Modulation of sibutramine-induced increases in extracellular noradrenaline concentration in rat frontal cortex and hypothalamus by alpha2-adrenoceptors. British Journal of Pharmacology 1999; 128:659-66.

[81] Laitinen KS. Tuomisto L. MacDonald E. Effects of a selective alpha 2-adrenoceptor antagonist, atipamezole, on hypothalamic histamine and noradrenaline release in vivo. European Journal of Pharmacology 1995:285:255-60,

[82] Mermet C. Suaud-Chagny MF, Gonon F. Electrically evoked noradrenaline release in the rat hypothalamic paraventricular nucleus studied by in vivo electrochemistry: autoregulation by alpha-2 receptors. Neuroscience 1990:34:423-32.

[83] Finn DP, Lalies MD, Harbuz MS, Jessop DS, Hudson AL, Imidazoline(2) Nutt D]. (i(2)) binding site-and alpha(2)-adrenoceptor-mediated modulation of central (i(2)) binding site-and alpha(2)-adrenoceptor-mediated modulation of central noradrenergic and hpa axis function in control rats and chronically stressed

[84] Itoh Y. Oishi R. Nishibori M. Saeki K. In vivo measurement of noradrenaline and 3.4-dihydroxyphenylethyleneglycol in the rat hypothalamus by microdialysis: effects of various drugs affecting noradrenaline metabolism. Journal of Pharmacology and Experimental Therapeutics 1990;255:1090-7.

[85] Berntson GG. Cacioppo JT, Quigley KS. Autonomic determinism: the modes of autonomic control, the doctrine of autonomic space, and the laws of autonomic constraint. Psychological Review 1991:98:459-87.

[86] Paton JF, Boscan P. Pickering AE, Nalivaiko E. The yin and yang of cardiac autonomic control: vago-sympathetic interactions revisited. Brain Research Brain Research Reviews 2005:49:555-65.

[87] Carrive P. Cardiovascular and behavioural components of conditioned fear to context after ganglionic and alpha-adrenergic blockade. Autonomic Neuroscience 2002:98:90-3.

[88] Carrive P. Dual activation of cardiac sympathetic and parasympathetic components during conditioned fear to context in the rat. Clinical and Experimental Pharmacology and Physiology 2006:33:1251-4.

[89] Baudrie V, Tulen JH, Blanc J. Elghozi JL. Autonomic components of the cardiovascular responses to an acoustic startle stimulus in rats. Journal of Autonomic Pharmacology 1997:17:303-9.

[90] Iwata], LeDoux JE. Dissociation of associative and nonassociative concomitants of classical fear conditioning in the freely behaving rat. Behavioral Neuroscience 1988:102:66-76.

[91] Westerhaus MJ. Loewy AD. Central representation of the sympathetic nervous system in the cerebral cortex. Brain Research 2001:903:117-27.

[92] McDougall SJ. Widdop RE, Lawrence AJ. Central autonomic integration of psychological stressors: Focus on cardiovascular modulation. Autonomic Neuroscience 2005;123:1-11.

[93] al Maskati HA. Zbrozyna AW. Cardiovascular and motor components of the defence reaction elicited in rats by electrical and chemical stimulation in amygdala. Journal of the Autonomic Nervous System 1989:28:127-31.

[94] Galeno TM, Brody M]. Hemodynamic responses to amygdaloid stimulation in spontaneously hypertensive rats. American Journal of Physiology 1983:245:R281-6.

[95] Soltis RP, Cook JC, Gregg AE, Stratton JM, Flickinger KA. Eaa receptors in the dorsomedial hypothalamic area mediate the cardiovascular response to activation of the amygdala. American Journal of Physiology 1998:275:R624-31. 


\section{PARAVENTRICULAR AND SUPRAOPTIC NUCLEI OF THE HYPOTHALAMUS MEDIATE CARDIOVASCULAR RESPONSES EVOKED BY THE MICROINJECTION OF NORADRENALINE INTO THE MEDIAL AMYGDALOID NUCLEUS OF THE RAT BRAIN}

\section{E. A. T. FORTALEZA, A. A. SCOPINHO AND F. M. A. CORRÊA}

Department of Pharmacology, School of Medicine of Ribeirão Preto, University of São Paulo, Brazil

\begin{abstract}
The medial amygdaloid nucleus (MeA) is a part of the limbic system and is involved in cardiovascular modulation. We previously reported that microinjection of noradrenaline (NA) into the MeA of unanesthetized rats caused pressor and bradycardiac responses, which were mediated by acute vasopressin release into the systemic circulation. In the present study, we tested the possible involvement of magnocellular neurons of the paraventricular (PVN) and/or supraoptic (SON) of the hypothalamus that synthesize vasopressin in the cardiovascular pathway activated by the microinjection of NA into the MeA. Pressor and bradycardiac responses to the microinjection of NA $(27 \mathrm{nmol} / 100 \mathrm{~nL})$ into the MeA were blocked by pretreatment of either the PVN or the SON with cobalt chloride $\left(\mathrm{CoCl}_{2}\right.$, $1 \mathrm{mM} / 100 \mathrm{~nL}$ ), thus indicating that both hypothalamic nuclei mediate the cardiovascular responses evoked by microinjection of NA into the MeA. Our results suggest that the pressor and bradycardiac response caused by the microinjection of NA into the MeA is mediated by magnocellular neurons in both the PVN and SON. (c) 2012 IBRO. Published by Elsevier Ltd. All rights reserved.
\end{abstract}

Key words: paraventricular nucleus of hypothalamus, supraoptic nucleus of hypothalamus, vasopressin release, noradrenaline, medial amygdaloid nucleus.

\section{INTRODUCTION}

The medial amygdaloid nucleus (MeA) is a limbic structure that is involved in modulation of physiological and behavioral processes, as well as in the regulation of the autonomic nervous system (Eleftheriou, 1973; Ben-Ari, 1981; Davis, 1992; Pitkanen et al., 1997; LeDoux, 1998;

"Corresponding author. Address: Department of Pharmacology School of Medicine of Ribeirão Preto, University of São Paulo. Avenida Bandeirantes, 3900, CEP: 14049-900 - Ribeirão Preto, SP, Brazil. Tel: + 55-16-36023206

E-mail address: fmdacorr@fmrp. usp. br (F. M. A. Corrèa)

Abbreviations: BST, bed nucleus of the stria terminalis; $\mathrm{CoCl}_{2}$, cobalt Abbreviations: BST, bed nucleus of the stra terminalis, $\mathrm{CoCl}_{2}$, cobalt chlonde; HPA, hypothalamic-piltitany-adrenal axis; $H R$, heart rate; LSA, lateral septal area; MAP, mean arterial pressure; MeA, medial amygdaloid nucleus; NA, noradrenaline; PAP, pulsatile arterial pressure; PVN, paraventricular; SON, supraoptic.

0306-4522/12 \$36.00 2012 IBRO Published by Elsevier Ltd. All rights reserved. http://dx.doi.org/10.1016/..neuroscience.2012.05.051
Aggleton, 2000; Sah et al., 2003; Fortaleza et al., 2009, 2011).

Furthermore, it has been proposed that the MeA modulates stress responses, being involved in cardiovascular regulation (Gelsema et al., 1987; Kubo et al., 2004; Ma and Morilak, 2005; Fortaleza et al., 2009, 2011). Electrical stimulation of the MeA was reported to evoke mean arterial pressure (MAP) and heart rate (HR) increases in anesthetized rats (Faiers et al., 1975). Moreover, there is evidence that it modulates baroreflex activity in rats (Quagliotto et al., 2008), suggesting that the MeA is involved in the central cardiovascular control. Cardiovascular changes have also been reported after chemical stimulation of the MeA. Microinjection of noradrenaline (NA) into the MeA of unanesthetized rats caused doserelated pressor and bradycardiac responses that were mediated by the activation of local $\alpha_{2}$-adrenoceptors. These responses were blocked by systemic pretreatment with a vasopressin antagonist, thus suggesting their mediation by an acute vasopressin release into the systemic circulation (Fortaleza et al., 2011). However, the neural pathway involved in cardiovascular responses to the microinjection of NA into the MeA is yet unknown. The $M e A$ receives substantial noradrenergic innervation originating from the $A 6$ neurons in the locus coeruleus as well as from other groups of noradrenergic neurons that are located in the lateral tegmental area (Sadikot and Parent, 1990; Roder and Ciriello, 1993), which provides a neuroanatomic substrate for the MeA noradrenergic pathway.

Vasopressin is also a potent vasoconstrictor hormone (Barer, 1961; Altura and Altura, 1984), which is synthesized by magnocellular neurons in the hypothalamic paraventricular (PVN) and supraoptic (SON) nuclei. The MeA is connected to hypothalamic and brainstem areas that are involved with cardiovascular regulation (Ohta et al., 1991; Dampney, 1994; Ma and Morilak, 2005). Moreover, the MeA presents connections with the PVN and SON (Hamamura et al., 1982; Yang et al., 1994; Canteras et al., 1995: Meddle et al., 2000). Because the cardiovascular responses to the microinjection of NA into the MeA were shown to be mediated by an acute vasopressin release (Fortaleza et al., 2011), the magnocellular neurons of the SON and/or PVN could be involved in the mediation of these responses.

In the present study, we examined the effect of a reversible synaptic blockade caused by the microinjection of cobalt chloride $\left(\mathrm{CoCl}_{2}\right)$ into the SON or PVN on pressor 
and bradycardiac responses to the microinjection of NA into the MeA of unanesthetized rats, to verify the involvement of these nuclei in their mediation.

\section{EXPERIMENTAL PROCEDURES}

\section{Animal preparation}

Male Wistar rats weighing $250-280 \mathrm{~g}$ were used. Animals were kept in the Animal Care Unit of the Department of Pharmacology of the School of Medicine of Ribeirão Preto, University of São Paulo. Rats were housed individually in plastic cages in a $20-25^{\circ} \mathrm{C}$ temperature-controlled room; with free access to water and commercial chow. The Institution's Animal Ethics Committee approved housing conditions and the experimental protocols (protocol 057/2009).

Animals were anesthetized with tribromoethanol $(250 \mathrm{mg} / \mathrm{kg}$ i.p.) and their heads were fixed to a stereotaxic apparatus (Stoelting. Wood Dale, IL, USA). For implants of guide cannulae in the MeA, the skull was surgically exposed and trepanned with a dental drill at a point located $3.4 \mathrm{~mm}$ from the midline and $6.2 \mathrm{~mm}$ anterior to the interaural line, according to the rat brain atlas of Paxinos and Watson (1997). Ipsilateral stainless steel guide cannulae (24 G, $15 \mathrm{~mm}$-long) were lowered $8.0 \mathrm{~mm}$ from the skull. Guide cannulae were positioned at $1 \mathrm{~mm}$ above the intended injection site and fixed to the skull by means of a metal screw and dental cement. Moreover, we used $A P=+7.2 \mathrm{~mm}$, $\mathrm{L}=+1.9 \mathrm{~mm}$ and $\mathrm{V}=-6.8 \mathrm{~mm}$ with a $12^{\circ}$ inclination for cannula implantation in the PVN. When cannulae were implanted in the SON and MeA, the following coordinates were used: $\mathrm{AP}=+6.2 \mathrm{~mm}, \mathrm{~L}=+1.9 \mathrm{~mm}$ and $\mathrm{V}=-9.5 \mathrm{~mm}$ with a $35^{\circ}$ inclination for the MeA and $A P=+6.9 \mathrm{~mm}, \mathrm{~L}=+1.9 \mathrm{~mm}$ and $\mathrm{V}=-8.0 \mathrm{~mm}$ for SON. Only two cannulae were implanted per rat. In one group, the first cannula was implanted in the MeA and the second one ipsilaterally in the PVN. In another group. the first cannula was implanted in the MeA and the second one ipsilaterally in the SON.

Animals were allowed to recover for $48 \mathrm{~h}$. A polyethylene catheter was implanted into the femoral artery, under anesthesia for chronic recording of MAP and HR. The catheter was exposed on the dorsum of the animal and was attached to the skin, allowing arterial pressure recording of unanesthetized rats, $24 \mathrm{~h}$ after surgery.

\section{Measurement of cardiovascular responses}

During experiments, the animals were kept in individual cages in the Animal Care Unit, which were used in their transport to the experimental room. Animals were allowed $1 \mathrm{~h}$ to adapt to the conditions of the experimental room, such as sound and illumination. before starting the blood pressure and heart rate recording. The experimental room was acoustically isolated and had a constant background noise that was caused by an air exhauster. Before the experiments were initiated, care was taken to initiate the injection whenever a stable blood pressure and especially a stable heart rate recording were observed. The injection needle was slowly introduced into the guide cannula, without touching or restraining the animals. The pulsatile arterial pressure (PAP) of freely moving animals was recorded using a HP-7754A preamplifier (Hewlett-Packard, USA) and an acquisition board (MP100A, Biopac Systems Inc., USA) connected to a computer. The mean arterial pressure (MAP $-\mathrm{mm} \mathrm{Hg}$ ) was calculated according to the equation: diastolic pressure + (systolic - diastolic)/3. The heart rate (HR - bpm) was calculated from PAP peak intervals integrated every $6 \mathrm{~s}$. Blood pressure baseline values were calculated as the average of the $1 \mathrm{~min}$ recording before the injection, whenever blood pressure recording was stable.

\section{Drugs}

The following drugs were used: noradrenaline- $\mathrm{HCl}$ (NA; Sigma, USA); cobalt chloride $\left(\mathrm{CoCl}_{2}\right.$; Sigma, USA).

Drugs were dissolved in artificial cerebrospinal fluid (aCSF: $\mathrm{NaCl} 100 \mathrm{mM} ; \mathrm{Na}_{3} \mathrm{PO}_{4} 2 \mathrm{mM} ; \mathrm{KCl} 2.5 \mathrm{mM} ; \mathrm{MgCl}_{2} 1.0 \mathrm{mM}$; NaH$\left.\mathrm{CO}_{3} 27 \mathrm{mM} ; \mathrm{CaCl}_{2} 2.5 \mathrm{mM} ; \mathrm{pH} 7.4\right)$. Drugs were injected by hand using a $1 \mu \mathrm{L}$ syringe (model $7002-\mathrm{KH}$, Hamilton Co., USA) and a stainless steel $(30 \mathrm{G})$ dental injection needle. One minute was allowed to elapse before the injection needle was removed from the guide cannula to avoid reflux.

\section{Experimental protocols}

Animals received $27 \mathrm{nmol} / 100 \mathrm{~nL}$ of NA (Fortaleza et al., 2011) that was microinjected into the $\mathrm{MeA} . \mathrm{CoCl}_{2}(1 \mathrm{mM} / 100 \mathrm{~nL})$ or aCSF (Resstel et al., 2004; Tavares and Correa, 2006; Scopinho et al., 2008; Crestani et al., 2009a; Fortaleza et al., 2009; Pelosi et al., 2009; Busnardo et al., 2010; Alves et al., 2011) were microinjected into the PVN or the SON $10 \mathrm{~min}$ prior to the microinjection of NA into the MeA.

\section{Histological procedure}

At the end of experiments, rats were anesthetized with urethane $(1.2 \mathrm{~g} / \mathrm{kg}$, i.p.) and $100 \mathrm{~nL}$ of filtered $1 \%$ Evan's blue dye was injected into the MeA, the PVN or the SON as a marker of the injection site. The chest was surgically opened and the descending aorta was occluded. The right atrium was severed and the brain was perfused with $10 \%$ formalin through the left ventricle. Brains were post-fixed for $24 \mathrm{~h}$ at $4{ }^{\circ} \mathrm{C}$, and $40 \mu \mathrm{m}$ sections were cut with a cryostat (CM 1900, Leica, Germany). Brain sections were stained with $0.5 \%$ violet cresyl for posterior analysis by light microscopy. The actual placement of the injection needles was verified in serial sections.

\section{Statistical analysis}

Statistical analysis was performed using two-way ANOVA (treatment vs. time) followed by Bonferroni's post hoc test, to compare the effects of treatments on MAP and HR changes that were observed after the microinjection of NA into the MeA. Maximal MAP and HR responses were compared using the paired Student's $t$-test (before treatment vs. after treatment), and $P<0.05$ was assumed to be statistically significant.

\section{RESULTS}

\section{Injection sites}

Photomicrographs of microinjection sites in the MeA and the PVN or in the MeA and the SON are shown respectively in Figs. 1 and 2. The dispersion of the injection sites of all animals used in the experiments is represented in Fig. 3.

Effect of pretreatment of the PVN with $\mathrm{CoCl}_{2}$ on cardiovascular responses to NA microinjection into the MeA of unanesthetized rats

The microinjection of NA into the MeA evoked pressor and bradycardiac responses $(\triangle \mathrm{MAP}=+41 \pm 4 \mathrm{~mm}$ $\mathrm{Hg}, \quad t=8.417, \quad P<0.0001 ; \Delta \mathrm{HR}=-49 \pm 7, \quad b p m$, $t=5.818, P=0.0002, n=6$ ).

The microinjection of $100 \mathrm{~nL}$ of aCSF into the PVN caused no changes in the baseline MAP $(93 \pm 6$ vs. $97 \pm 3 \mathrm{~mm} \mathrm{Hg}, t=0.8157, P>0.05, n=6$ ) or the HR 


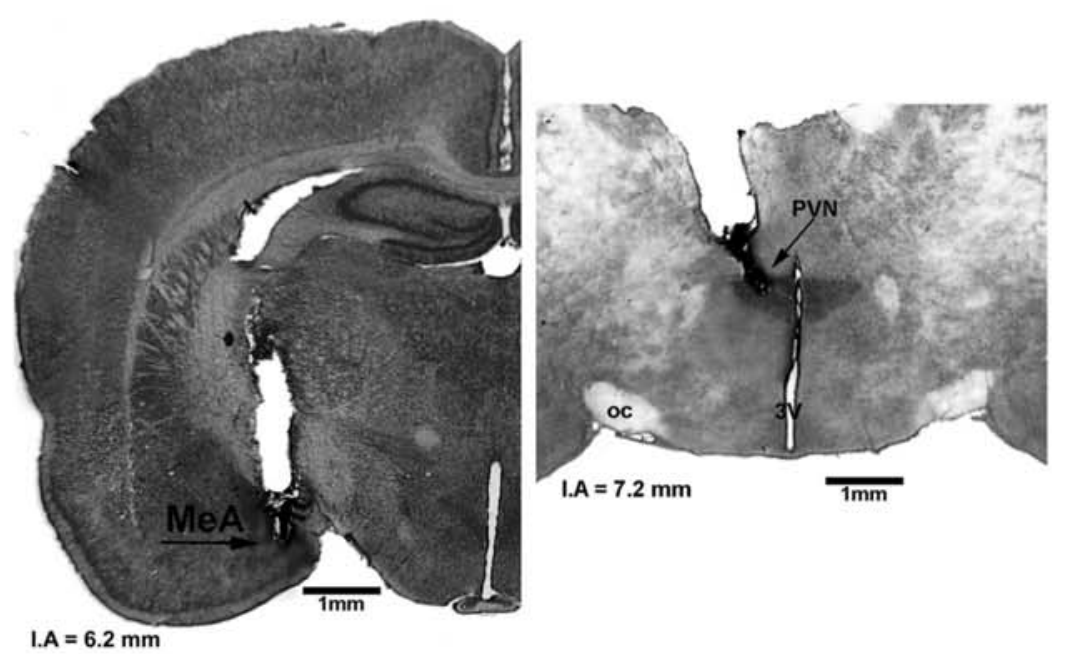

Fig. 1. Photomicrographs of coronal sections of rat brains showing typical sites of drug microinjection in the MeA and the PVN. Arrows indicate the tips of injection needles. IA: interaural coordinate; MeA: medial amygdaloid nucleus; LH: lateral hypothalamus; PVN: paraventricular nucleus; 3V, third ventricle; oc: optic chiasm and f: fornix.

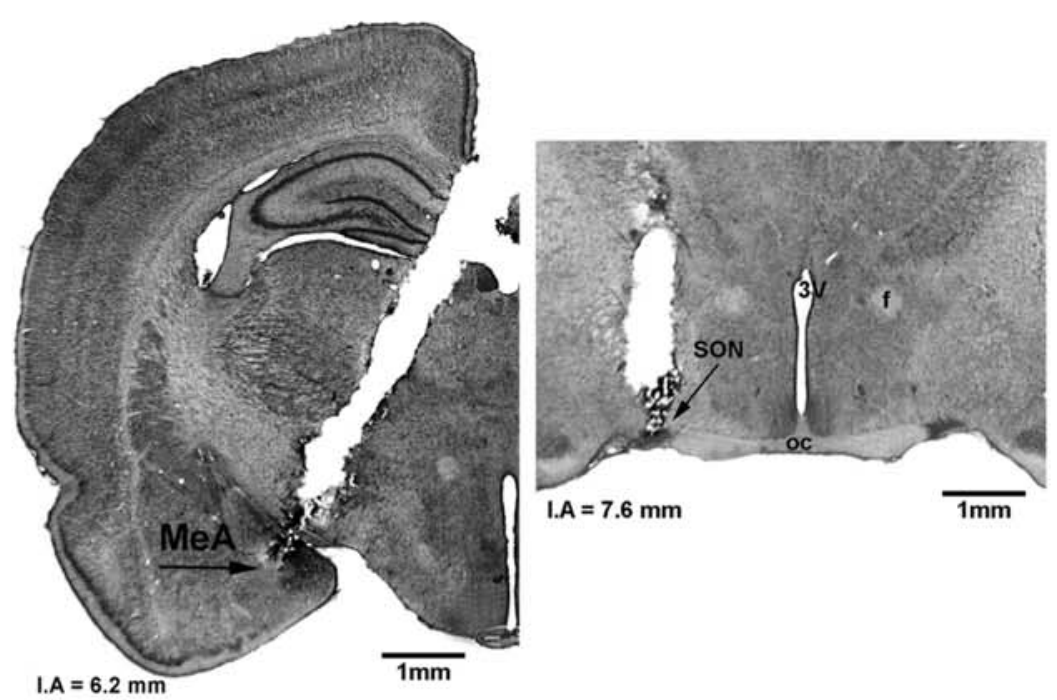

Fig. 2. Photomicrographs of coronal sections of rat brains showing typical sites of drug microinjection in the MeA and the SON. Arrows indicate the tips of injection needles. IA: interaural coordinate; MeA: medial amygdaloid nucleus; LH: lateral hypothalamus; SON: supraoptic nucleus; 3V, third ventricle; oc: optic chiasm and f: fornix.

$(331 \pm 18$ vs. $333 \pm 14 \mathrm{bpm}, t=0.07503, P>0.05$, $n=6)$. Also, the microinjection of aCSF into the PVN prior MeA microinjection of NA did not affect either the pressor $(137 \pm 5$ vs. $138 \pm 4 \mathrm{~mm} \mathrm{Hg}, t=0.1870$, $P>0.05)$ or the bradycardiac $(282 \pm 15$ vs. $277 \pm 15 \mathrm{bpm}, t=0.2489, P>0.05)$ response to the microinjection of NA into the MeA. Moreover, the microinjection of $\mathrm{CoCl}_{2}(1 \mathrm{nM} / 100 \mathrm{nl})$ into the PVN caused no changes in the baseline MAP $(98 \pm 3$ vs. $99 \pm 3 \mathrm{~mm}$ $\mathrm{Hg}, t=0.1468, P>0.05, n=6)$ or the HR $(370 \pm 12$ vs. $\quad 358 \pm 16 \mathrm{bpm}, \quad t=0.5734, \quad P>0.05, \quad n=6$ ). However, pretreatment of the PVN with $\mathrm{CoCl}_{2}$ blocked the pressor and bradycardiac responses evoked by the microinjection of NA into the MeA ( $\triangle \mathrm{MAP}$ Interaction: $F=7762, \quad P<0.0001 ; \quad$ Treatment: $F=216.6, \quad P<$ 0.0001 ; Time: $F=13.49, P<0.0001$, and $\Delta \mathrm{HR}$, Interaction: $F=2763, P=0.0004$; Treatment: $F=78.06$, $P<0.0001$; Time: $F=8019, \quad P<0.0001$; two-way ANOVA) (Fig. 4).

The recordings of the PAP, MAP and HR presented in Fig. 5 illustrate the marked reduction in the pressor response evoked by injection of $27 \mathrm{nmol}$ of NA into the $\mathrm{MeA}$ of unanesthetized rats after pretreatment of the PVN with $\mathrm{CoCl}_{2}$. 


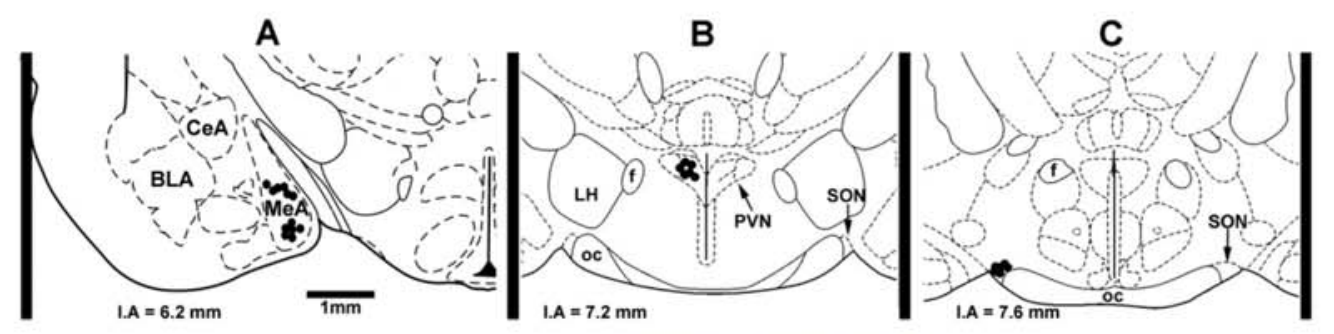

Fig. 3. Diagrammatic representation, based on the rat brain atlas of Paxinos and Watson (1997), showing the dispersion of injection sites among experiments. (A) Diagram: Twelve microinjection sites in the MeA; (B) diagram: six microinjection sites in the PVN and (C) diagram: six microinjection sites in the SON. Filled circles indicate microinjection sites of NA into the MeA and of $\mathrm{CoCl}_{2}$ in the PVN or SON. IA: interaural coordinate; MeA: medial amygdaloid nucleus; CeA: central amygdaloid nucleus; BLA: basolateral amygdaloid nucleus; LH: lateral hypothalamus; PVN: paraventricular nucleus; SON: supraoptic nucleus; oc: optic chiasm and f: fornix.

PVN
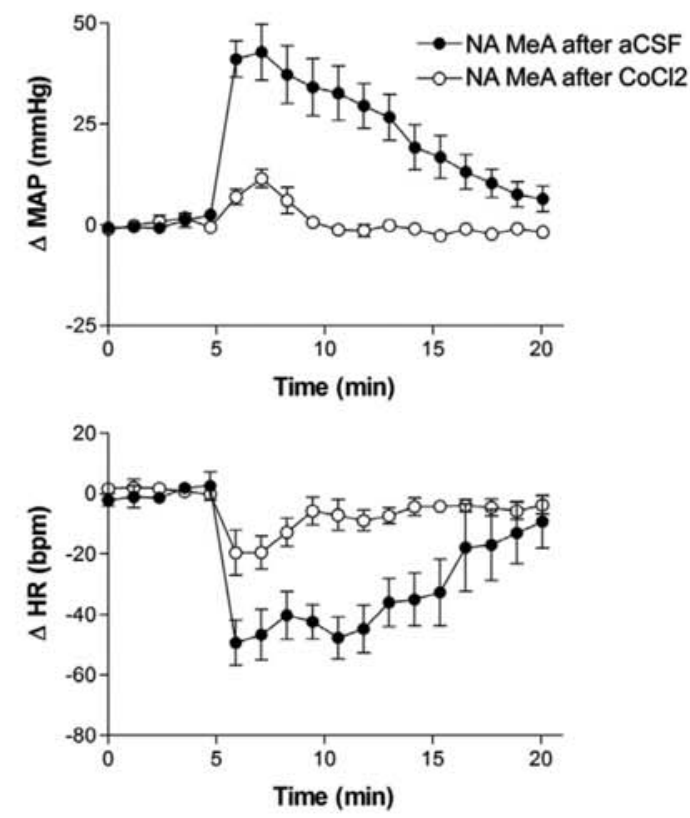

SON
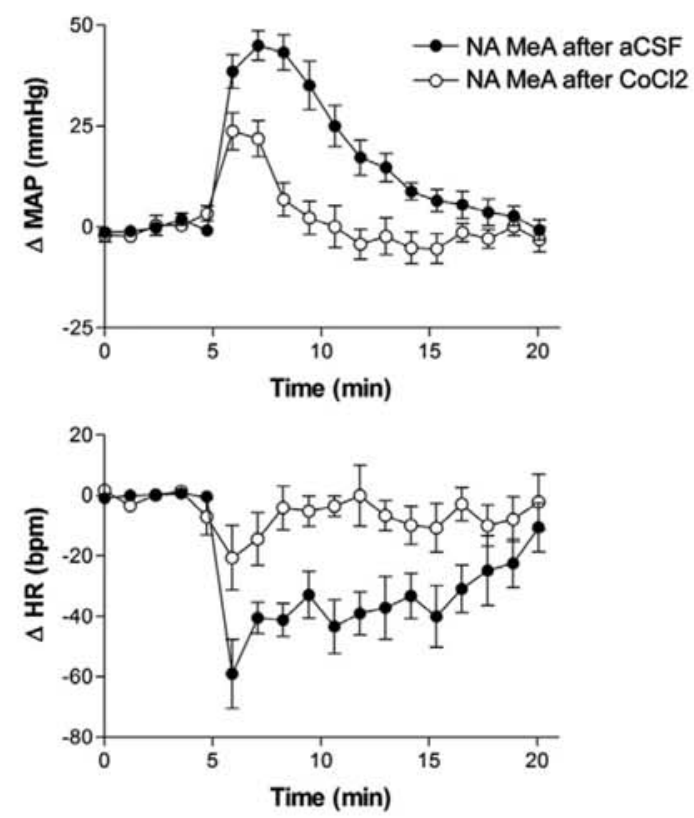

Fig. 4. Time curve for the effect of microinjection of noradrenaline (NA, $27 \mathrm{nmol} / 100 \mathrm{~nL}$ ) into the MeA either after aCSF (filled circles) or (open circles) pretreatment of either the PVN or the SON with $\mathrm{CoCl}_{2}(1 \mathrm{mM} / 100 \mathrm{~nL})$ on mean arterial pressure $(\Delta M A P)$ and heart rate $(\Delta \mathrm{HR})$ of unanesthetized rats ( $n=6 /$ group).

The effect of pretreatment of the SON with $\mathrm{CoCl}_{2}$ on the cardiovascular response to the microinjection of NA into the MeA of unanesthetized rats

The microinjection of NA into the MeA evoked pressor and bradycardiac responses $(\triangle \mathrm{MAP}=+34 \pm 3 \mathrm{~mm}$ $\mathrm{Hg}, \quad t=9.189, \quad P<0.0001 ; \quad \Delta \mathrm{HR}=-59 \pm 11 \mathrm{bpm}$, $t=5.099, P=0.0005, n=6$ ).

The microinjection of $100 \mathrm{~nL}$ of aCSF into the SON caused no changes in the baseline MAP $(96 \pm 2$ vs. $98 \pm 2 \mathrm{~mm} \mathrm{Hg}, t=0.5390, P=0.6017, n=6)$ or the $\mathrm{HR}(358 \pm 8$ vs. $366 \pm 6 \mathrm{bpm}, t=0.7637, P=0.4627$, $n=6$ ). Also, pretreatment of the SON with aCSF did not affect the pressor $(131 \pm 4$ vs. $132 \pm 4 \mathrm{~mm} \mathrm{Hg}$. $t=0.2622, P>0.05)$ or the bradycardiac $(307 \pm 10$ vs. $300 \pm 9 \mathrm{bpm}, t=0.5123, P>0.05$ ) responses to the microinjection of NA into the MeA. The microinjection of $\mathrm{CoCl}_{2}(1 \mathrm{nM} / 100 \mathrm{nl})$ into the SON did not affect the baseline MAP $(95 \pm 2$ vs. $100 \pm 1 \mathrm{~mm} \mathrm{Hg}, t=2.000$, $P=0.0734, \quad n=6)$ or the $\operatorname{HR}(361 \pm 19$ vs. $350 \pm 15 \mathrm{bpm}, \quad t=0.4849, \quad P=0.6382, \quad n=6)$. However, pretreatment of the SON with $\mathrm{CoCl}_{2}$ blocked the pressor and bradycardiac responses evoked by the microinjection of NA into the MeA ( $\triangle M A P$ Interaction: $F=2879, \quad P=0.0002 ; \quad$ Treatment: $\quad F=70.39$, $P<0.0001$; Time: $F=17.51, P<0.0001$, and $\Delta \mathrm{HR}$, Interaction: $\quad F=2603, \quad P=0.0009$; $\quad$ Treatment: $F=70.67, P<0.0001$; Time: $F=5471, P<0.0001$; two-way ANOVA) (Fig. 4). Fig. 5 shows recordings of PAP, MAP and HR, illustrating the partial reduction in 

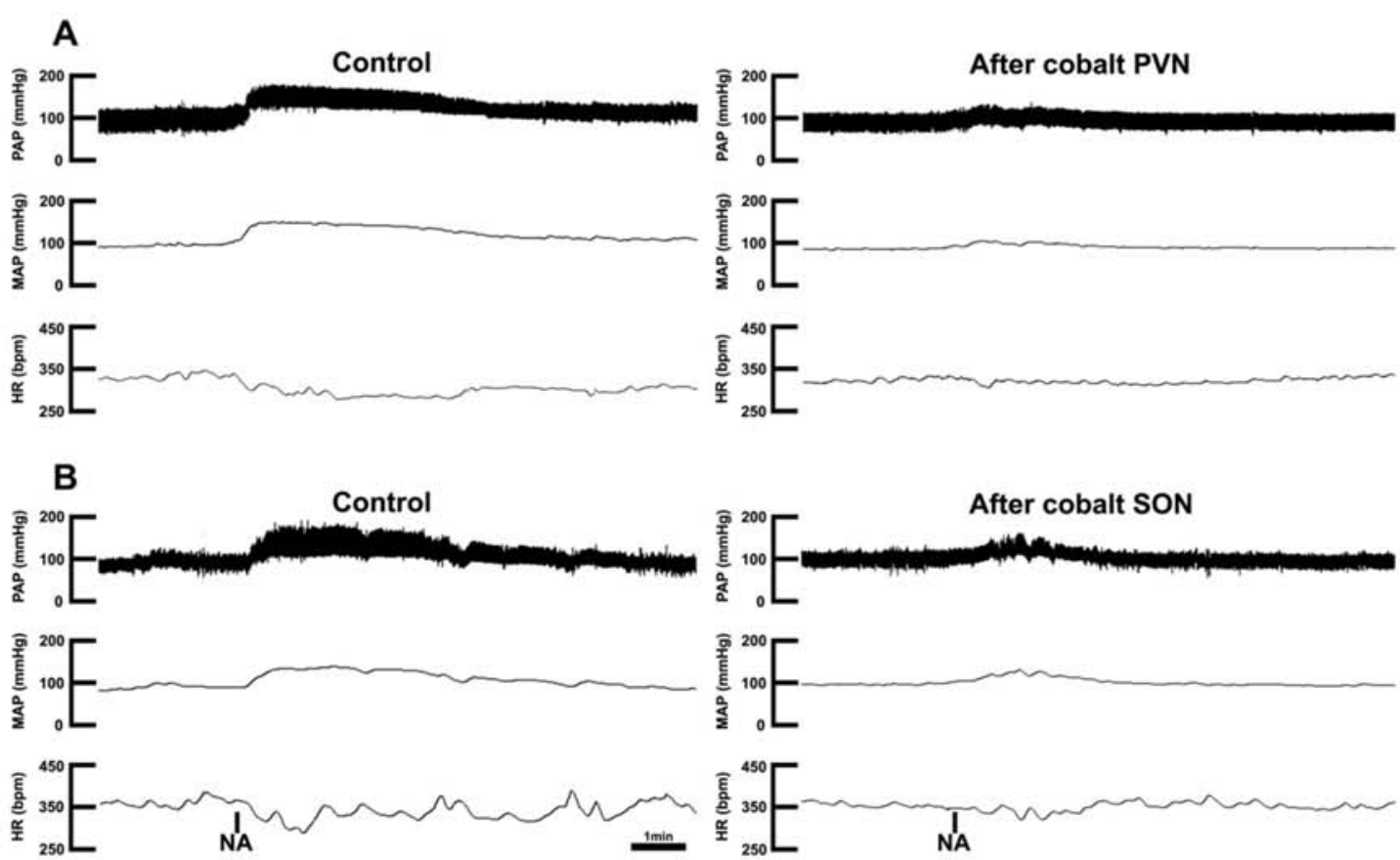

Fig. 5. (A) Representative recordings showing pulsatile arterial pressure (PAP), mean arterial pressure (MAP), and heart rate (HR) responses evoked by microinjection of NA $(27 \mathrm{nmol} / 100 \mathrm{~nL})$ into the MeA of unanesthetized rats either after aCSF (control) or pretreatment with CoCl $2(1 \mathrm{mM} /$ $100 \mathrm{~nL}$ ) in the PVN. (B) Representative recordings showing pulsatile arterial pressure (PAP), mean arterial pressure (MAP), and heart rate (HR) responses evoked by microinjection of $\mathrm{NA}(27 \mathrm{nmol} / 100 \mathrm{~nL})$ into the MeA of unanesthetized rats either after aCSF (control) or pretreatment with $\mathrm{CoCl}_{2}(1 \mathrm{mM} / 100 \mathrm{~nL})$ in the SON.

cardiovascular response to the microinjection of $27 \mathrm{nmol}$ of NA into the MeA of unanesthetized rats observed after pretreatment of the $\mathrm{SON}$ with $\mathrm{CoCl}_{2}$.

\section{DISCUSSION}

The present study showed that an acute pharmacological ablation of either the PVN or the SON by a local microinjection of $\mathrm{CoCl}_{2}$ reduced significantly the pressor and bradycardiac response to the microinjection of NA into the MeA of unanesthetized rats, thus suggesting that synapses in both the PVN and the SON are involved in the mediation of these responses.

The MeA is involved in the control of several autonomic functions, including the modulation of stress-related cardiovascular responses (Canteras et al., 1995; Chen and Herbert, 1995; Cullinan et al., 1995; Dayas et al., 1999; Dayas and Day, 2002; Kubo et al., 2004; Ma and Morilak, 2005; Fortaleza et al., 2009). Moreover, the $\mathrm{MeA}$ is an important target for the ascending noradrenergic innervation, as well as being involved in the descending activation of brainstem noradrenergic neurons observed in response to a psychogenic stress, because lesions of the MeA were reported to abolish restraint stress-induced Fos expression in noradrenergic neurons of the medullary $A 1$ and $A 2$ regions (Dayas and Day, 2002). Electrical stimulation of the amygdaloid complex evoked increases in MAP and HR; vasodilatation in skeletal muscles and defense reactions that were characterized by an increase in the period of alertness and attention, in rats (Hilton and Zbrozyna, 1963; Stock et al., 1978; Galeno et al., 1982). Lesions of the MeA attenuated the secretion of adrenocorticotropic hormone (ACTH) and glucocorticoid in response to an acoustic or a photic stress (Feldman et al., 1990), and reduced the stress-induced expression of c-Fos in corticotropin-releasing-hormone $(\mathrm{CRH})$ and oxytocin-synthesizing neurons in the PVN and SON (Dayas et al., 1999). This observation suggests that the MeA may also be involved in regulation of the hypothalamic-pituitary-adrenal axis (HPA) and that stress-induced NA release in the MeA would lead to activation of the HPA axis (Ma and Morilak, 2005).

We have previously reported that microinjection of NA into the MeA of unanesthetized rats evoked a pressor response that was associated with bradycardia, via the activation of local $\alpha 2$-adrenoceptors (Fortaleza et al., 2011). Intravenous pretreatment with the ganglion blocker pentolinium significantly lowered the basal blood pressure, thus confirming an effective blockade of the sympathetic output. The pressor response to microinjection of NA was potentiated after the ganglion blockade, thus ruling out the possible involvement of the sympathetic nervous system in the mediation of the cardiovascular responses to the microinjection of NA into the MeA. Because the bradycardiac response evoked by the microinjection of NA into the MeA was blocked by pretreatment with pentolinium, it is suggested that the cardiac response has a reflex origin. So it is possible that the bradycardia 
evoked by microinjection of NA into the MeA is a vagal baroreflex response resulting from the increase in MAP. The pressor response to NA was significantly reduced after systemic pretreatment with the $\mathrm{V}-1$ receptor antagonist $d \operatorname{Tyr}(\mathrm{CH} 2) 5(\mathrm{Me}) A V P$, thus suggesting that a vasopressin release mediates the response to NA. Besides, no bradycardia was observed after pretreatment with $\mathrm{dTyr}$ $(\mathrm{CH} 2) 5(\mathrm{Me}) A V P$, thus reinforcing the idea of its reflex nature (Fortaleza et al., 2011). Together, these data suggest a vagal baroreflex response consequent to the MAP increase, and that the pressor response is mediated by an acute release of vasopressin into the circulation. Because the response to the microinjection of NA into the MeA is mediated by vasopressin, the end structures in the pathway activated by the microinjection of NA should be the PVN, the SON or both hypothalamic nuclei.

Vasopressin is synthesized by magnocellular neurons located in the SON and PVN and is stored in the neurohypophysis for posterior release into the circulation (Silverman and Zimmerman, 1983). The hypothalamushypophyseal system plays an important role in water reabsorption by the kidneys, and it is also a potent vasoconstrictor agent (Cowley and Liard, 1988). Electrical or chemical stimulation of either the PVN or the SON was reported to cause pressor and bradycardiac responses that are mediated by an increase in sympathetic activity and vasopressin release, thus indicating the involvement of these nuclei in cardiovascular modulation (Ciriello and Calaresu, 1980; Busnardo et al., 2007, 2009a,b).

To verify whether synapses in the PVN and/or SON mediate cardiovascular responses to the microinjection of NA into the MeA, we pretreated these nuclei with the nonselective neurotransmission blocker $\mathrm{CoCl}_{2}$. The use of $\mathrm{CoCl}_{2}$ is a common approach to investigate the possible involvement of specific brain areas in a functional neural pathway. The technique is based on the administration of circumscribed microinjections of this compound, which is known to reversibly block neuronal activity over a given period of time by competing with endogenous $\mathrm{Ca}^{2+}$, acting on calcium channels' conductance (Kretz, 1984). The microinjection of $\mathrm{CoCl}_{2}$ into discrete brain areas was previously used to cause a reversible functional inactivation of different brain areas (Scopinho et al., 2008; Fortaleza et al., 2009; Crestani et al., 2009a; Alves et al., 2011).

Cardiovascular responses evoked by microinjection of NA into the MeA were partially inhibited by pretreatment with $\mathrm{CoCl}_{2}$ of either the PVN or the SON, thus suggesting that both hypothalamic nuclei are involved in mediation of cardiovascular responses to NA. However, the reduction in the cardiovascular response was more evident after the pharmacological ablation of the PVN when compared with the effect of pretreatment of the SON with $\mathrm{CoCl}_{2}$, thus indicating that a significant residual response persisted after the pharmacological ablation of the SON that would be mediated by an activation of the PVN. Neuroanatomical studies revealed the existence of direct projections from the MeA to the PVN (Silverman et al., 1981; Sawchenko and Swanson, 1983). Furthermore, a population of neurons in the MeA that was activated in response to an acute restraint stress was shown to send projections to the PVN (Dayas et al., 1999). Evidence points to the MeA as a relay in the neural circuitry connecting limbic structures that are known to modulate neuroendocrine and cardiovascular responses to the PVN, such as hippocampus and the medial prefrontal cortex (Feldman et al., 1995; Herman and Cullinan, 1997; Herman et al., 2005; Ulrich-Lai and Herman, 2009). In addition, there is evidence in the literature indicating that the microinjection of $\mathrm{CoCl}_{2}$ into the PVN is effective in inhibiting the release of vasopressin that mediates the pressor and bradycardiac responses observed after the microinjection of NA into several brain areas, such as the prelimbic cortex, the bed nucleus of stria terminallis (BST), the lateral septal area (LSA) and the dorsal periaqueductal gray area (Fernandes et al., 2007; Scopinho et al., 2008; Pelosi et al., 2009; Crestani et al., 2009b), thus suggesting the PVN as the end structure in these cardiovascular pathways.

The SON not only receives important inputs from the brainstem, but also from other regions known to be involved with cardiovascular control, such as the medial preoptic area, the BST, organum vasculosum of the lamina terminalis, and especially from the MeA (Hamamura et al., 1982; Yang et al., 1994; Meddle et al., 2000). Additionally, electrophysiological studies have shown that vasopressinergic neurons in the SON receive predominantly excitatory synaptic inputs from the MeA (Hamamura et al., 1982).

Although tracing studies have shown direct projections from the MeA to the PVN (Silverman et al., 1981; Tribollet and Dreifuss, 1981; Sawchenko and Swanson, 1983) and SON (Hamamura et al., 1982), other studies have suggested that these projections are scarce (Dayas et al., 1999; Choi et al., 2007). Thus, the cardiovascular pathway activated by noradrenaline in the MeA that causes release of vasopressin in the systemic circulation could be directly or indirectly linked to the hypothalamic nuclei (PVN and SON).

The MeA, which is involved in the modulation of autonomic responses associated with stress (Ma and Morilak, 2005; Fortaleza et al., 2009), innervates preferentially the posterior division (pBST) of the BST (Dong et al., 2001). BST (or extended amygdala) components are highly interconnected and their functions are related to the autonomic and neuroendocrine system (de Olmos and Heimer, 1999). Earlier anterograde and retrograde tracing experiments showed the existence of projections from the pBST to the region of the paraventricular, supraoptic, and periventricular nuclei (Sawchenko and Swanson, 1983; Risold et al., 1997; Spencer et al., 2005). In this way, these hypothalamic nuclei are also involved in the modulation of neuroendocrine and autonomic responses (Busnardo et al., 2007, 2010). The pBST preferentially innervates components that regulate the secretion of hormones controlling ovulation, lactation, growth, and stress responses (Simerly, 2002; Gu et al., 2003). These set of data suggest that the PBST could be a relay between the MeA and hypothalamic nuclei (PVN and SON), constituting a cardiovascular pathway responsible for releasing vasopressin in the systemic circulation. Moreover, microinjection of noradrenaline or acetylcholine into the BST evokes pressor and bradycardic responses dependent 
on vasopressin release by the PVN and SON, respectively (Crestani et al., 2009b; Alves et al., 2011), reinforcing that perhaps the BST could indeed be a relay between the MeA and the hypothalamic nuclei. However, further studies are needed to evaluate this hypothesis.

It has been reported that electrical stimulation of limbic structures, such as the amygdala and the LSA, evokes vasopressin release into the blood circulation (Dingman and Gaitan, 1959; Hayward and Smith, 1963). The MeA has connections with the LSA (Canteras et al., 1995), which is a limbic structure involved in the modulation of autonomic and behavioral responses (Reis et al., 2011; Scopinho et al., 2006). Stimulation of the LSA by local injection of NA evoked pressor and bradycardiac responses (Scopinho et al., 2006) that were also shown to be caused by a vasopressin release into the blood circulation after PVN activation (Scopinho et al., 2008). Considering that the LSA does not project directly to the PVN (Tavares et al., 2005) and that connections have been described between the MeA and the LSA (Canteras et al., 1995), the MeA could be a relay between the LSA and the PVN in the pathway involved in vasopressin release control. In this way, the present data suggest the PVN and the SON both as end structures in the cardiovascular pathway activated by the microinjection of NA into the MeA, and that both hypothalamic nuclei are involved in this modulation, releasing vasopressin into the systemic circulation.

Vasopressin was reported to be released following some kinds of stress, such as hemorrhage, or isotonic hypovolemia (Kasting, 1988). Moreover, stress situation activates NA release in stress-related limbic areas, including medial prefrontal cortex, lateral septum, BST, and MeA (Cecchi et al., 2002; Pardon et al., 2002; Ma and Morilak, 2005). In particular, the MeA has been implicated in mediation of the cardiovascular responses observed during stress restraint (Kubo et al., 2004; Fortaleza et al., 2009). Thus, adrenergic synapses within the MeA may be involved in mediation of the vasopressin release observed during the integrated cardiovascular and neuroendocrine response to stressful stimuli.

\section{CONCLUSION}

In summary, the present results indicate that activation of magnocellular neurons of both the PVN and the SON are involved in mediation of the pressor response to the microinjection of NA into the MeA that is caused by a vasopressin release into the blood circulation.

Acknowledgments-The authors wish to thank Ivanilda A.C. Fortunato, Idália I.B. Aguiar and Simone Guilhaume for technical help. E.A.T. Fortaleza is supported by a CNPq PhD fellowship (140118/2009-8), and A.A. Scopinho has a CAPES postdoctoral fellowship (PNPD0176087). The present research was supported by grants from the CNPq (501269/2005-3).

\section{REFERENCES}

Aggleton JP (2000) The amygdala, a functional analysis. Oxford: Oxford University Press.
Altura BM, Altura BT (1984) Actions of vasopressin, oxytocin, and synthetic analogs on vascular smooth muscle. Fed Proc 43:80-86.

Alves FH, Crestani CC, Busnardo C, Antunes-Rodrigues J, Gomes FV, Resstel LB, Correa FM (2011) Hypothalamic supraoptic but not paraventricular nucleus is involved in cardiovascular responses to carbachol microinjected into the bed nucleus of stria terminalis of unanesthetized rats. Brain Res 1393:31-43.

Barer GR (1961) A comparison of the circulatory effects of angiotensin, vasopressin and adrenaline in the anaesthetized cat. J Physiol 156:49-66

Ben-Ari Y (1981) The amygdaloid complex. Amsterdam: Elsevier.

Busnardo C, Tavares RF, Antunes-Rodrigues J, Correa FM (2007) Cardiovascular effects of L-glutamate microinjection in the supraoptic nucleus of unanaesthetized rats. Neuropharmacology 52:1378-1384.

Busnardo C, Tavares RF, Correa FM (2009a) Mechanisms involved in the pressor response to noradrenaline microinjection into the supraoptic nucleus of unanesthetized rats. Auton Neurosci 145:63-70.

Busnardo C, Tavares RF, Correa FM (2009b) Role of N-methyl-Daspartate and non- $N$-methyl-D-aspartate receptors in the cardiovascular effects of L-glutamate microinjection into the hypothalamic paraventricular nucleus of unanesthetized rats. J Neurosci Res 87:2066-2077.

Busnardo C, Tavares RF, Resstel LB, Elias LL, Correa FM (2010) Paraventricular nucleus modulates autonomic and neuroendocrine responses to acute restraint stress in rats. Auton Neurosci 158:51-57.

Canteras NS, Simerly RB, Swanson LW (1995) Organization of projections from the medial nucleus of the amygdala: a PHAL study in the rat. $\mathrm{J}$ Comp Neurol 360:213-245.

Cecchi M, Khoshbouei H. Morilak DA (2002) Modulatory effects of norepinephrine, acting on alpha 1 receptors in the central nucleus of the amygdala, on behavioral and neuroendocrine responses to acute immobilization stress. Neuropharmacology 43:1139-1147.

Chen X. Herbert J (1995) Regional changes in c-fos expression in the basal forebrain and brainstem during adaptation to repeated stress: correlations with cardiovascular, hypothermic and endocrine responses. Neuroscience 64:675-685.

Choi DC, Furay AR, Evanson NK, Ostrander MM, Ulrich-Lai YM, Herman JP (2007) Bed nucleus of the stria terminalis subregions differentially regulate hypothalamic-pituitary-adrenal axis activity: implications for the integration of limbic inputs. I Neurosci 27:2025-2034

Ciriello J, Calaresu FR (1980) Role of paraventricular and supraoptic nuclei in central cardiovascular regulation in the cat. Am J Physiol 239:R137-R142.

Cowley Jr AW. Liard JF (1988) Vasopressin and arterial pressure regulation. Special lecture. Hypertension 11:125-132.

Crestani CC, Alves FH, Tavares RF, Correa FM (2009a) Role of the bed nucleus of the stria terminalis in the cardiovascular responses to acute restraint stress in rats. Stress 12:268-278.

Crestani CC, Busnardo C, Tavares RF, Alves FH, Correa FM (2009b) Involvement of hypothalamic paraventricular nucleus non- $\mathrm{N}$ methyl-D-aspartate receptors in the pressor response to noradrenaline microinjected into the bed nucleus of the stria terminalis of unanesthetized rats. Eur $J$ Neurosci 29:2166-2176.

Cullinan WE, Herman JP, Battaglia DF, Akil H, Watson SJ (1995) Pattern and time course of immediate early gene expression in rat brain following acute stress. Neuroscience 64:477-505.

Dampney RA (1994) Functional organization of central pathways regulating the cardiovascular system. Physiol Rev 74:323-364.

Davis M (1992) The role of the amygdala in fear and anxiety. Annu Rev Neurosci 15:353-375.

Dayas CV, Buller KM, Day TA (1999) Neuroendocrine responses to an emotional stressor: evidence for involvement of the medial but not the central amygdala. Eur J Neurosci 11:2312-2322.

Dayas CV, Day TA (2002) Opposing roles for medial and central amygdala in the initiation of noradrenergic cell responses to a psychological stressor. Eur J Neurosci 15:1712-1718. 
de Olmos JS, Heimer L (1999) The concepts of the ventral striatopallidal system and extended amygdala. Ann N Y Acad Sci 877:1-32.

Dingman JF, Gaitan E (1959) Subcortical stimulation of the brain and release of antidiuretic hormone in man. J Clin Endocrinol Metab 19:1346-1349

Dong HW, Petrovich GD, Swanson LW (2001) Topography of projections from amygdala to bed nuclei of the stria terminalis. Brain Res Brain Res Rev 38:192-246.

Eleftheriou BE (1973) The neurobiology of the amygdala. New York: Plenum Press.

Faiers AA, Calaresu FR, Mogenson GJ (1975) Pathway mediating hypotension elicited by stimulation of the amygdala in the rat. Am J Physiol 228:1358-1366.

Feldman S, Conforti N, Saphier D (1990) The preoptic area and bed nucleus of the stria terminalis are involved in the effects of the amygdala on adrenocortical secretion. Neuroscience 37:775-779.

Feldman S, Conforti N, Weidenfeld J (1995) Limbic pathways and hypothalamic neurotransmitters mediating adrenocortical responses to neural stimuli. Neurosci Biobehav Rev 19:235-240.

Fernandes KB, Tavares RF, Pelosi GG, Correa FM (2007) The paraventricular nucleus of hypothalamus mediates the pressor response to noradrenergic stimulation of the medial prefrontal cortex in unanesthetized rats. Neurosci Lett 426:101-105.

Fortaleza EA, Scopinho AA, Correa FM (2011) Cardiovascular responses to microinjection of noradrenaline into the medial amygdaloid nucleus of conscious rats result from alpha-receptor activation and vasopressin release. Eur $\mathrm{J}$ Neurosci 33:1677-1684.

Fortaleza EA, Tavares RF, Correa FM (2009) The medial amygdaloid nucleus modulates cardiovascular responses to acute restraint in rats. Neuroscience 159:717-726.

Galeno TM, Van Hoesen GW, Maixner W, Johnson AK, Brody MJ (1982) Contribution of the amygdala to the development of spontaneous hypertension. Brain Res 246:1-6.

Gelsema AJ, McKitrick DJ, Calaresu FR (1987) Cardiovascular responses to chemical and electrical stimulation of amygdala in rats. Am J Physiol 253:R712-R718.

Gu F, Dube N, Kim JW, Cheng A, Ibarra-Sanchez Mde J, Tremblay ML, Boisclair YR (2003) Protein tyrosine phosphatase 1B attenuates growth hormone-mediated JAK2-STAT signaling. Mol Cell Biol 23:3753-3762.

Hamamura M, Shibuki K, Yagi K (1982) Amygdalar inputs to ADHsecreting supraoptic neurones in rats. Exp Brain Res 48:420-428.

Hayward JN, Smith WK (1963) Influence of limbic system on neurohypophysis. Arch Neurol 9:171-177.

Herman JP, Cullinan WE (1997) Neurocircuitry of stress: central control of the hypothalamo-pituitary-adrenocortical axis. Trends Neurosci 20:78-84.

Herman JP, Ostrander MM, Mueller NK, Figueiredo H (2005) Limbic system mechanisms of stress regulation: hypothalamo-pituitaryadrenocortical axis. Prog Neuropsychopharmacol Biol Psychiatry 29:1201-1213.

Hilton SM, Zbrozyna AW (1963) Amygdaloid region for defence reactions and its efferent pathway to the brain stem. J Physiol 165:160-173.

Kasting NW (1988) Simultaneous and independent release of vasopressin and oxytocin in the rat. Can J Physiol Pharmacol 66:22-26.

Kretz R (1984) Local cobalt injection: a method to discriminate presynaptic axonal from postsynaptic neuronal activity. J Neurosci Methods 11:129-135.

Kubo T, Okatani H, Nishigori Y, Hagiwara Y, Fukumori R, Goshima Y (2004) Involvement of the medial amygdaloid nucleus in restraint stress-induced pressor responses in rats. Neurosci Lett 354:84-86.

LeDoux J (1998) Fear and the brain: where have we been, and where are we going? Biol Psychiatry 44:1229-1238.

Ma S, Morilak DA (2005) Norepinephrine release in medial amygdala facilitates activation of the hypothalamic-pituitary-adrenal axis in response to acute immobilisation stress. J Neuroendocrinol $17: 22-28$.

Meddle SL, Leng G, Selvarajah JR, Bicknell RJ, Russell JA (2000) Direct pathways to the supraoptic nucleus from the brainstem and the main olfactory bulb are activated at parturition in the rat. Neuroscience 101:1013-1021.

Ohta H. Watanabe S, Ueki S (1991) Cardiovascular changes induced by chemical stimulation of the amygdala in rats. Brain Res Bull 26:575-581.

Pardon MC, Gould GG, Garcia A, Phillips L, Cook MC, Miller SA, Mason PA, Morilak DA (2002) Stress reactivity of the brain noradrenergic system in three rat strains differing in their neuroendocrine and behavioral responses to stress: implications for susceptibility to stress-related neuropsychiatric disorders. Neuroscience 115:229-242.

Paxinos G, Watson C (1997) The rat brain in stereotaxic coordinates. Sidney, Australia: Academic Press.

Pelosi GG, Tavares RF, Busnardo C, Correa FM (2009) Paraventricular nucleus mediates pressor response to noradrenaline injection into the dorsal periaqueductal gray area. Auton Neurosci 151:74-81.

Pitkanen A Savander V, LeDoux JE (1997) Organization of intraamygdaloid circuitries in the rat: an emerging framework for understanding functions of the amygdala. Trends Neurosci 20:517-523.

Quagliotto E, Neckel H, Riveiro DF, Casali KR, Mostarda C, Irigoyen MC, Dall'ago P. Rasia-Filho AA (2008) Histamine in the posterodorsal medial amygdala modulates cardiovascular reflex responses in awake rats. Neuroscience 157:709-719.

Reis DG, Scopinho AA, Guimaraes FS, Correa FM, Resstel LB (2011) Behavioral and autonomic responses to acute restraint stress are segregated within the lateral septal area of rats. PLoS One 6:e23171.

Resstel LB, Fernandes KB, Correa FM (2004) Medial prefrontal cortex modulation of the baroreflex parasympathetic component in the rat. Brain Res 1015:136-144.

Risold PY, Thompson RH, Swanson LW (1997) The structural organization of connections between hypothalamus and cerebral cortex. Brain Res Brain Res Rev 24:197-254.

Roder S, Ciriello J (1993) Innervation of the amygdaloid complex by catecholaminergic cell groups of the ventrolateral medulla. J Comp Neurol 332:105-122.

Sadikot AF, Parent A (1990) The monoaminergic innervation of the amygdala in the squirrel monkey: an immunohistochemical study. Neuroscience 36:431-447.

Sah P, Faber ES, Lopez De Armentia M, Power J (2003) The amygdaloid complex: anatomy and physiology. Physiol Rev 83:803-834.

Sawchenko PE, Swanson LW (1983) The organization of forebrain afferents to the paraventricular and supraoptic nuclei of the rat. $J$ Comp Neurol 218:121-144.

Scopinho AA, Resstel LB, Antunes-Rodrigues J, Correa FM (2006) Pressor effects of noradrenaline injected into the lateral septal area of unanesthetized rats. Brain Res 1122:126-134.

Scopinho AA, Tavares RF, Busnardo C, Correa FM (2008) Non-Nmethyl-D-aspartate glutamate receptors in the paraventricular nucleus of hypothalamus mediate the pressor response evoked by noradrenaline microinjected into the lateral septal area in rats. J Neurosci Res 86:3203-3211.

Silverman AJ, Hoffman DL, Zimmerman EA (1981) The descending afferent connections of the paraventricular nucleus of the hypothalamus (PVN). Brain Res Bull 6:47-61.

Silverman AJ, Zimmerman EA (1983) Magnocellular neurosecretory system. Annu Rev Neurosci 6:357-380.

Simerly RB (2002) Wired for reproduction: organization and development of sexually dimorphic circuits in the mammalian forebrain. Annu Rev Neurosci 25:507-536.

Spencer SJ, Buller KM, Day TA (2005) Medial prefrontal cortex control of the paraventricular hypothalamic nucleus response to psychological stress: possible role of the bed nucleus of the stria terminalis. J Comp Neurol 481:363-376. 
Stock G, Schlor KH, Heidt H, Buss J (1978) Psychomotor behaviour and cardiovascular patterns during stimulation of the amygdala. Pflugers Arch 376:177-184.

Tavares RF, Correa FM (2006) Role of the medial prefrontal cortex in cardiovascular responses to acute restraint in rats. Neuroscience 143:231-240.

Tavares RF, Fernandes KB, Pajolla GP, Nascimento IA, Correa FM (2005) Neural connections between prosencephalic structures involved in vasopressin release. Cell Mol Neurobiol 25:663-672.
Tribollet E, Dreifuss JJ (1981) Localization of neurones projecting to the hypothalamic paraventricular nucleus area of the rat: a horseradish peroxidase study. Neuroscience 6:1315-1328.

Ulrich-Lai YM, Herman JP (2009) Neural regulation of endocrine and autonomic stress responses. Nat Rev Neurosci 10:397-409.

Yang CR, Senatorov VV, Renaud LP (1994) Organum vasculosum lamina terminalis-evoked postsynaptic responses in rat supraoptic neurones in vitro. J Physiol 477(Pt. 1):59-74. 


\section{$\beta$-ADRENOCEPTORS IN THE MEDIAL AMYGDALOID NUCLEUS MODULATE THE TACHYCARDIAC RESPONSE TO RESTRAINT STRESS IN RATS}

\author{
E. A. T. FORTALEZA, A. A. SCOPINHO AND \\ F. M. A. CORRÊA* \\ Department of Pharmacology, School of Medicine of Ribeiräo \\ Preto, University of São Paulo, Ribeirão Preto, São Paulo, Brazil
}

Abstract-In the present study, we investigated the involvement of $\beta$-adrenoceptors in the medial amygdaloid nucleus $(\mathrm{MeA})$ in cardiovascular responses evoked in rats submitted to an acute restraint stress. We first pretreated Wistar rats with the nonselective $\beta$-adrenoceptor antagonist propranolol microinjected bilaterally into the MeA $(10,15$, and $20 \mathrm{nmol})$ $100 \mathrm{~nL}) 10 \mathrm{~min}$ before exposure to acute restraint. The pretreatment with propranolol did not affect the blood pressure (BP) increase evoked by restraint. However, it increased the tachycardiac response caused by acute restraint when animals were pretreated with a dose of $15 \mathrm{nmol}$, without a significant effect on the BP response. This result indicates that $\beta$-adrenoceptors in the MeA have an inhibitory influence on restraint-evoked heart rate $(\mathrm{HR})$ changes. Pretreatment with the selective $\beta_{2}$-adrenoceptor antagonist ICI 118,551 (10, 15, and $20 \mathrm{nmol} / 100 \mathrm{~nL}$ ) significantly increased the restraintevoked tachycardiac response after doses of 15 and $20 \mathrm{nmol}$, an effect that was similar to that observed after the pretreatment with propranolol at a dose of $15 \mathrm{nmol}$, without a significant effect on the BP response. Pretreatment of the MeA with the selective $\beta_{1}$-adrenoceptor antagonist CGP $20712(10,15$, and $20 \mathrm{nmol} / 100 \mathrm{~nL}$ ) caused an opposite effect on the HR response, and a significant decrease in the restraint-evoked tachycardia was observed only after the dose of $20 \mathrm{nmol}$, without a significant effect on the BP response. Because propranolol is an equipotent antagonist of both $\beta_{1}$ and $\beta_{2}$-adrenoceptors, and opposite effects were observed after the treatment with the higher doses of the selective antagonists ICI 118,551 and CGP 20712, the narrow window in the doseresponse to propranolol could be explained by a functional antagonism resulting from the simultaneous inhibition of $\beta_{1}$ and $\beta_{2}$-adrenoceptors by the treatment with propranolol. The present results suggest that $\beta_{2}$-adrenoceptors have

"Corresponding author. Address: Department of Pharmacology School of Medicine of Ribeirão Preto. University of São Paulo, Bandeirantes Avenue, 3900, 14049-900 Ribeirão Preto, São Paulo, Brazil. Tel: +55-16-3602-3206; fax: +55-16-3633-2301

E-mail address: fmdacorr@fmrp.usp.br (F.M. A. Corrêa).

Abbreviations: aCSF, artificial cerebrospinal fluid; ANOVA, analysis of variance; $\mathrm{BP}$, blood pressure; $\mathrm{CRH}$, corticotropin-releasing hormone; HPA, hypothalamic-pituitary-adrenal; HR, heart rate; MAP, mean arterial pressure; MeA, medial amygdaloid nucleus; NA, noradrenaline; PAP, pulsatile arterial pressure: RS, restraint stress; SON, supraoptic nucleus. an inhibitory influence on the restraint-evoked tachycardiac response, whereas $\beta_{1}$-adrenoceptors have a facilitatory influence on the restraint-evoked tachycardiac response. (c) 2012 IBRO. Published by Elsevier Ltd. All rights reserved.

Key words: medial amygdaloid nucleus, ß-adrenoceptors, cardiovascular system, restraint stress.

\section{INTRODUCTION}

Stress causes autonomic and behavioral responses associated with an increased activation of the hypothalamo-pituitary-adrenal axis and the sympathoadrenal system (Ma and Morilak, 2005). Several stressful stimuli can be used to evoke cardiovascular responses. Restraint has been standardized in the literature as an unavoidable aversive stimulus that elicits a sustained blood pressure and heart rate increase (Muller et al., 2001). Stress-related responses are modulated by several CNS limbic structures (Pacak and Palkovits, 2001; Resstel et al., 2006; Tavares and Correa, 2006; Crestani et al., 2009; Fortaleza et al. 2009; Alves et al., 2010), and among them by the amygdaloid complex. The amygdaloid complex is a subcortical limbic structure that is divided into subnuclei, which include the medial, central, lateral, and the basolateral amygdaloid nuclei. It is connected with hypothalamic and brainstem areas that are involved in cardiovascular regulation and is known to modulate stress-related behavioral responses (Price et al., 1987; Dampney, 1994; Swanson, 2003; Kubo et al., 2004). In particular, the medial amygdaloid nucleus (MeA) is involved in the modulation of stress-evoked cardiovascular responses (Gelsema et al., 1987; Kubo et al., 2004; Ma and Morilak, 2005; Fortaleza et al., 2009, 2011).

The inhibition of the MeA by a local microinjection of muscimol was reported to attenuate the pressor response evoked in rats by the exposure to an acute restraint stress (Kubo et al., 2004). In a previous study from our laboratory, it was reported that a bilateral microinjection of the unspecific neurotransmission inhibitor cobalt chloride $\left(\mathrm{CoCl}_{2}\right)$ into the MeA increased the restraint-related tachycardiac response (Fortaleza et al., 2009).

The MeA receives substantial noradrenergic innervation that originates in the $A 6$ neurons of the locus coeruleus (LC) and also from noradrenergic 


\section{Author's personal copy}

neurons located in the lateral tegmental area (Sadikot and Parent, 1990; Roder and Ciriello, 1993). Furthermore, studies on the expression of mRNA and binding to noradrenergic receptors have detected the presence of both subtypes $\alpha$ and $\beta$ receptors in the MeA (Jones et al., 1986; Domyancic and Morilak, 1997). Previous studies using quantitative autoradiography have shown that both $\beta_{1}$ - and $\beta_{2}$-adrenoceptors are distributed heterogeneously among brain regions, with large anatomical differences in the relative amount of each subtype. These subtypes are present in the amygdala, and their distribution varies within the different amygdala nuclei (Rainbow et al., 1984). In the MeA, the distribution of $\beta$-adrenoceptor subtypes has been reported to be $53 \% \quad \beta_{1}$ and $47 \% \quad \beta_{2}$ (Rainbow et al. 1984). Although the noradrenergic system in the MeA has been reported to be activated during stress, its role in the mediation of stress-induced cardiovascular responses has not yet been evaluated.

There is considerable evidence that $\beta$-adrenoceptors in the CNS play a role in the autonomic regulation. Data from the literature showed that an i.c.v. injection of either a nonselective $\beta$-adrenoceptor antagonist or a selective $\beta_{2}$-adrenoceptor antagonist abolished the increase in the renal sympathetic nerve activity that was observed during the exposure of spontaneous hypertensive rats to air jet stress (Koepke and DiBona, 1985, 1986), and also attenuated the increase in tachycardia that was induced by an exposure of rats to water immersion stress (Tan et al., 2000). Furthermore, the i.c.v. injection of a $\beta$-adrenoceptor antagonist reduced the incidence of ischemic ventricular fibrillation in pigs exposed to an environmental stress (Parker et al., 1990), suggesting that central $\beta$-adrenoceptors are involved in the modulation of myocardial vulnerability to environmental stress-related arrhythmogenesis. These results suggest that central $\beta$-adrenoceptors are involved in the modulation of physiological responses induced by stress. Although there is evidence that central $\beta$-adrenoceptors are involved in the mediation of the cardiovascular response to stress, this possibility has never been fully verified, concerning the amygdala.

Therefore, in the present study, we tested the possible role of $\mathrm{MeA} \beta$-adrenoceptors in modulation of the cardiovascular response to restraint stress. We pretreated the MeA with the nonselective $\beta$-adrenoceptor antagonist propranolol, and later with the selective $\beta_{1}$-adrenoceptor antagonist CGP 20712 or the selective $\beta_{2}$-adrenoceptor antagonist $\mathrm{ICI} 118,551$, and observed their effects on the cardiovascular responses when rats were submitted to acute restraint.

\section{EXPERIMENTAL PROCEDURES}

\section{Subjects}

Experimental procedures were carried out following protocols approved by the Ethics Review Committee of the School of Medicine of Ribeirão Preto ( $\mathrm{n}^{\circ}$. 057/2009). Male Wistar rats ( $n=64$ ) weighing $250-280 \mathrm{~g}$ were used in the present experiment. Animals were housed individually in plastic cages in a temperature-controlled room $\left(25^{\circ} \mathrm{C}\right)$ at the Animal Care Unit of the Department of Pharmacology, School of Medicine of Ribeirão Preto. Animals were kept under a 12:12-h light-dark cycle (lights on at 06:00). Animals had free access to water and standard laboratory food, except during the experimental period. Rats were transported to the experiment room and remained in their own cages until the restraint procedure. Experiments were performed during the morning period, to minimize possible circadian rhythm interferences.

\section{Surgical preparation}

Animals were anesthetized with tribromoethanol $(250 \mathrm{mg} / \mathrm{kg}$ i.p.) and their heads were fixed to a stereotaxic apparatus (Stoelting, USA). The skull was surgically exposed and trepanned with a dental drill at a point located $3.4 \mathrm{~mm}$ from midline and $6.2 \mathrm{~mm}$ anterior to the interaural line, according to the rat brain atlas (Paxinos and Watson, 1997). Bilateral stainless steel guide cannulae (26G, $15 \mathrm{~mm}$-long) were lowered $8.0 \mathrm{~mm}$ from the skull. Guide cannulae were positioned $1 \mathrm{~mm}$ above intended injection sites and fixed to the skull by a metal screw and dental cement. After surgery, animals were treated with 100,000 units benzyl penicillin. Forty-eight hours later, animals were anesthetized and a polyethylene catheter was implanted into the femoral artery under anesthesia, for chronic recording of the arterial blood pressure and heart rate. The catheter was exposed on the dorsum of the animals and attached to the skin, allowing arterial pressure recording of rats $24 \mathrm{~h}$ after surgery. Flunixin meglumine $(2.5 \mathrm{mg} / \mathrm{kg}$ s.c.) was used as postoperative analgesic and antiinflammatory agent after surgical procedures.

\section{Drug microinjection into the MeA}

The following drugs were used: propranolol, CGP 20712 and IC 118,551 were dissolved in artificial cerebrospinal fluid (aCSF composition: $100 \mathrm{mM} \mathrm{NaCl} ; 2 \mathrm{mM} \mathrm{Na} \mathrm{PO}_{4} ; 2.5 \mathrm{mM} \mathrm{KCl} ; 1 \mathrm{mM}$ $\mathrm{MgCl}_{2} ; 27 \mathrm{mM} \mathrm{NaHCO}_{3} ; 2.5 \mathrm{mM} \mathrm{CaCl}_{2}$ and $\left.\mathrm{pH}=7.4\right)$. Injections were performed bilaterally in a volume of $100 \mathrm{~nL}$. For microinjections, we used a $1-\mu \mathrm{L}$ syringe $(\mathrm{KH} 7001$, Hamilton, USA) connected to a 33-G injection needle (Small Parts Inc. $F L$, USA) with PE-10 polyethylene tubing. The injection needle was $1.0 \mathrm{~mm}$ longer than the guide cannula.

\section{Measurement of cardiovascular responses}

Pulsatile arterial pressure (PAP) was recorded using an amplifier (model 7754A Hewlett Packard, USA) coupled to a computerized acquisition system (MP100, Biopac, USA). The mean arterial pressure (MAP) and heart rate (HR) were derived from PAP data using the AcqKnowledge III software (Biopac, USA). MAP was calculated according to the equation: diastolic pressure + (systolic-diastolic)/3. HR (beats/min; bpm) was derived from PAP peak intervals that were integrated each 6-5 interval.

\section{Drugs}

The following drugs were used: aCSF, propranolol (Sigma, St. Louis, MO, USA), ICI 118,551 (( \pm$)$-1-[(2,3-dihydro-7-methyl$1 \mathrm{H}$-inden-4-yl)oxy]-3-[(1-methylethyl)amino -2 -butanol hydrochloride; Tocris), CGP 20712 (1-[2-((3-carbamoyl-4-hydroxy) phenoxy)ethylamino]-3-[4-(1-methyl-4-trifluoromethyl-2-imidazolyl) phenoxy]-2-propanol dihydrochloride: Tocris), urethane (Sigma), tribromoethanol (Aldrich, USA), streptomycins and penicillins (Pentabiotico, Fort Dodge, Brazil), flunixine meglumine (analgesic Banamine, Schering Plough, Brazil), 


\section{Author's personal copy}

\section{Experimental procedure: acute restraint}

Animals were transported to the experimental room in their home cages. They were allowed a 1 -h period to adapt to the conditions of the experimental room, such as sound and illumination, before starting blood pressure and heart rate recording. The experimental room was acoustically isolated and had a constant background noise generated by an air exhauster. At least another 20-min period was allowed for baseline recording before experiments were initiated. After recording baseline values, bilateral microinjections of drugs or vehicle were made into the MeA. Each animal received only one microinjection per brain side. Care was taken to start the injection whenever a stable blood pressure and especially heart rate recording was observed. The injection needle was slowly introduced into the guide cannula without touching or restraining the animals. Ten minutes later, the animals were submitted to restraint, which was initiated by putting animals in a small plastic cylindrical restraining tube (diameter $=6.5 \mathrm{~cm}$ and length $=15 \mathrm{~cm}$ ) Restraint lasted $60 \mathrm{~min}$, after which the animals were returned to their cages. Each animal was submitted to one session of restraint in order to prevent habituation.

Animals were divided into ten experimental groups of drug injection into the MeA: (1) aCSF group $n=6$; (2) propranolol 10-nmol dose group $n=9$; (3) propranolol 15 -nmol dose group $n=6$; (4) propranolol $20-\mathrm{nmol}$ dose group $n=6$; (5) CGP 20712 10-nmol dose group $n=7$; (6) CGP 20712 15-nmol dose group $n=6$; (7) CGP 2071220 -nmol dose group $n=6$; (8) ICl 118,551 10-nmol dose group $n=6$; (9) ICl 118,551 15-nmol dose group $n=6$; (10) ICl 118,551 20-nmol dose group $n=6$.

\section{Histological determination of the microinjection sites}

At the end of experiments, animals were anesthetized with urethane $(1.25 \mathrm{~g} / \mathrm{kg}$ i.p.) and $100 \mathrm{~nL}$ of $1 \%$ Evan's Blue dye was injected into the brain as a marker of the injection site. Animals were submitted to an intracardiac perfusion with $0.9 \%$ $\mathrm{NaCl}$ followed by $10 \%$ formalin. Brains were removed and post fixed for $48 \mathrm{~h}$ at $4{ }^{\circ} \mathrm{C}$ and serial 40 - $\mu$ m-thick sections were cut with a cryostat (CM1900, Leica, Germany). Sections were stained with $1 \%$ Cresyl Violet for optical microscopy analysis. The actual placement of the microinjection needles was determined by analyzing serial sections according to the rat brain atlas of (Paxinos and Watson, 1997).

\section{Statistical analysis}

Statistical analysis was performed using Prism software (GraphPad, USA). Student's $t$ test was used to compare basal MAP and HR values, before and after aCSF or drug treatment. Two-way analysis of variance (ANOVA) for repeated measures was used to compare time curves of MAP ( $\triangle M A P)$ and HR $(\triangle H R)$ after aCSF and drug treatments. Although PAP was recorded throughout the experimental procedure, curves for statistical analysis or illustrative figures were generated with points obtained with different data sampling. For statistical purposes, curves were generated with a sampling of $0.07 / \mathrm{min}$ to generate 5 points (experiments with 5 subjects), or $0.08 / \mathrm{min}$ to generate 6 points (experiments with 6 subjects). Illustrative curves were generated using a sampling of $0.64 / \mathrm{min}$, for more accurate representation. The significance was set at $P<0.05$. Data are presented as mean \pm SEM.

\section{RESULTS}

Determination of microinjection sites

A diagrammatic representation showing microinjection sites in the MeA of all animals used in the study is presented in Fig. 1. A representative photomicrograph of a coronal brain section depicting the bilateral microinjection sites in the MeA of one representative animal is presented in Fig. 2 .

Effect of pretreatment of the MeA with the injection vehicle aCSF on restraint-related cardiovascular changes

The injection of aCSF into the MeA was used as a control for experiments with a pharmacological manipulation of the MeA. The microinjection of $100 \mathrm{~nL}$ of aCSF into the MeA did not affect baseline MAP $(100 \pm 4$ vs. $96 \pm$ $3 \mathrm{mmHg}, t=0.88, P>0.05, n=6)$ or HR (361 $\pm 9 \mathrm{vs}$. $356 \pm 7 \mathrm{bpm}, t=0.41, P>0.05, n=6$ ).

Effect of pretreatment of the MeA with the nonselective $\beta$-adrenoceptor antagonist on restraintrelated cardiovascular changes

Propranolol at a dose of $10 \mathrm{nmol}$. Microinjection of propranolol $(10 \mathrm{nmol} / 100 \mathrm{~nL})$ into the MeA caused no changes in baseline MAP $(88 \pm 3$ vs. $90 \pm 4 \mathrm{mmHg}$, $t=0.37, P>0.05, n=9)$ or $\mathrm{HR}(345 \pm 7$ vs. $338 \pm$ $5 \mathrm{bpm}, t=0.76, P>0.05, n=9)$. The injection of propranolol into the MeA did not change $\mathrm{BP}$ and $\mathrm{HR}$ increases evoked by acute restraint when compared with aCSF-treated animals ( $\triangle \mathrm{MAP}$ Interaction: $F_{5,78}=$ $0.19, \quad P=0.96$; Treatment: $\quad F_{1,78}=0.58, \quad P=0.44$; Time: $F_{5.78}=37.52, P<0.0001$, and $\Delta \mathrm{HR}$, Interaction: $F_{5,78}=0.59, P=0.70$; Treatment: $F_{1,78}=1.81, P=$ 0.17 ; Time: $\quad F_{5,66}=20.41, \quad P<0.0001$; $\quad$ two-way ANOVA), Fig. 3.

Propranolol at a dose of $15 \mathrm{nmol}$. Microinjection of propranolol $(15 \mathrm{nmol} / 100 \mathrm{~nL})$ into the MeA caused no changes in baseline MAP (95 \pm 3 vs. $94 \pm 4 \mathrm{mmHg}$, $t=0.16, P>0.05, n=6)$ or $\operatorname{HR}(365 \pm 11$ vs. $365 \pm$ $7 \mathrm{bpm}, t=0.002, P>0.05, n=6)$. Pretreatment with propranolol significantly increased the restraint-evoked tachycardiac response, without any significant effect on the BP response, when compared with aCSF-treated animals ( $\triangle \mathrm{MAP}$, Interaction: $F_{5,60}=0.05, \quad P=0.99$; Treatment: $F_{1,60}=0.06, P=0.79$; Time: $F_{5,60}=32.13$, $P<0.0001$, and $\Delta \mathrm{HR}$, Interaction: $F_{5,60}=5.10, P=$ 0.0006; Treatment: $F_{1,60}=11.45, P=0.0013$; Time: $F_{5,60}=33.84, P<0.0001$; two-way ANOVA), Fig. 3 . Recordings of the cardiovascular response of one rat submitted to acute restraint $10 \mathrm{~min}$ after the bilateral microinjection of $15 \mathrm{nmol}$ of propranolol into the MeA are presented in Fig. 4.

Propranolol at a dose of $20 \mathrm{nmol}$. Microinjection of propranolol $(20 \mathrm{nmol} / 100 \mathrm{~nL})$ into the MeA caused no changes in baseline MAP ( $83 \pm 3$ vs. $94 \pm 4 \mathrm{mmHg}$, $t=2.0, P>0.05, n=6)$ or HR $(341 \pm 3$ vs. $347 \pm$ $8 \mathrm{bpm}, t=0.70, P>0.05, n=6)$. The injection of propranolol $(20 \mathrm{nmol} / 100 \mathrm{~nL})$ into the MeA did not change $\mathrm{BP}$ and $\mathrm{HR}$ increases evoked by acute restraint, when compared with aCSF-treated animals ( $\triangle M A P$, Interaction: $F_{5,60}=1.08, P=0.37$; Treatment: $F_{1,60}=$ 


\section{Author's personal copy}
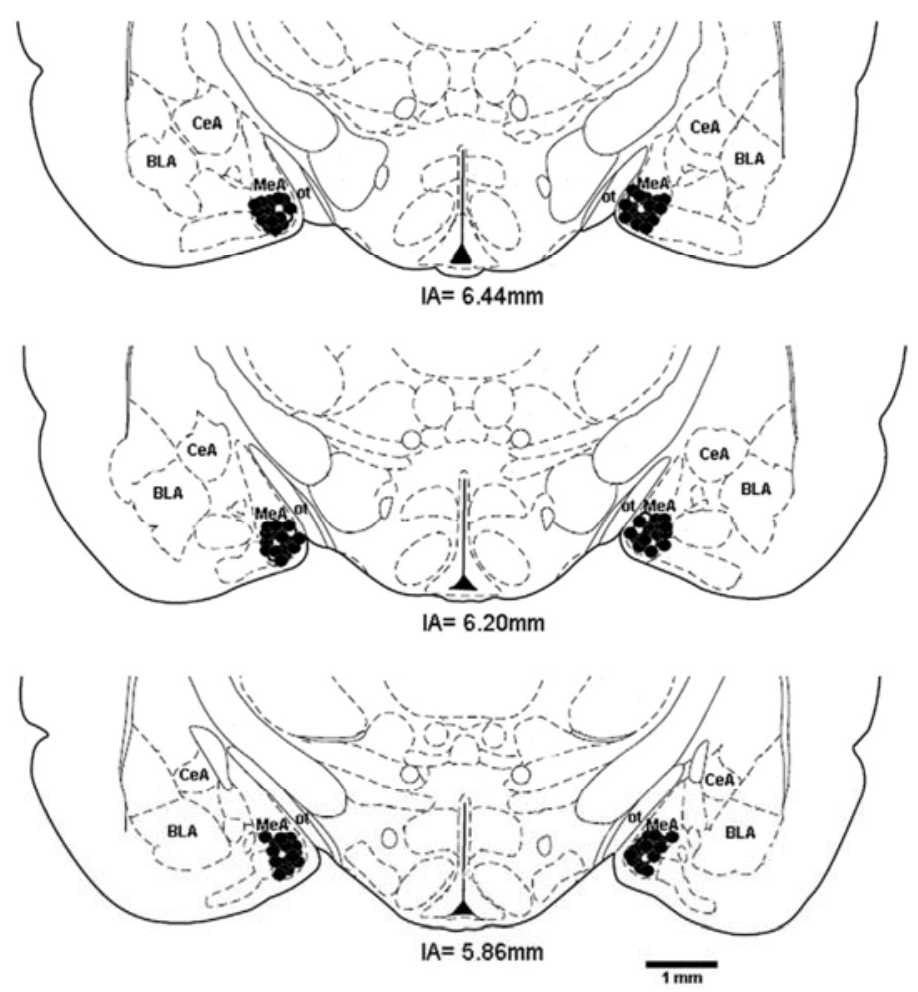

Fig. 1. A diagrammatic representation modified from the rat brain atlas of (Paxinos and Watson, 1997) indicating microinjection sites in the MeA of rats used in the present experiment. Filled dots indicate the microinjection sites of drugs and open dots indicate the microinjection sites of aCSF (vehicle for drugs). IA - interaural, CeA - central nucleus of the amygdala; BLA - basolateral nucleus of the amygdala; MeA - medial amygdaloid nucleus; OT - optic tract.

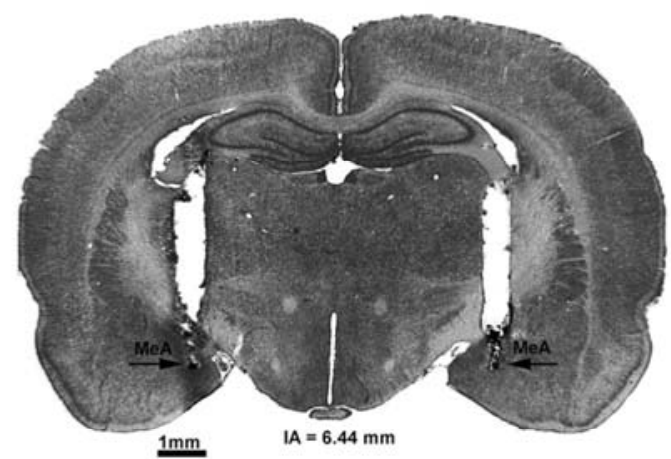

Fig. 2. A photomicrograph of a coronal section of a rat brain depicting the site of bilateral microinjection in the MeA. The microinjection sites are indicated by arrows. MeA - medial amygdaloid nucleus.

1.04, $P=0.31 ;$ Time: $F_{5.60}=35.75, P<0.0001$, and $\Delta \mathrm{HR}$, Interaction: $F_{5,60}=0.61, P=0.69$; Treatment: $F_{1,60}=0.87, P=0.35 ;$ Time: $F_{5,60}=9.81, P<0.0001$; two-way ANOVA), Fig. 3.
Effect of pretreatment of the MeA with the selective $\beta_{1}$-adrenoceptor antagonist CGP 20712 on restraintrelated cardiovascular changes

CGP 20712 at a dose of $10 \mathrm{nmol}$. Microinjection of CGP $20712(10 \mathrm{nmol} / 100 \mathrm{~nL})$ into the MeA caused no changes in baseline MAP (95 \pm 2 vs. $94 \pm 2 \mathrm{mmHg}$, $t=0.21, \quad P>0.05, \quad n=7)$ or $\operatorname{HR}(353 \pm 11$ vs. $366 \pm 14 \mathrm{bpm}, \quad t=0.68, \quad P>0.05, \quad n=7)$. The injection of CGP $20712(10 \mathrm{nmol} / 100 \mathrm{~nL})$ into the MeA did not change BP and HR increases evoked by acute restraint, when compared with aCSF-treated animals ( $\triangle$ MAP: Interaction: $F_{5,66}=0.20, P=0.96$; Treatment: $F_{1,66}=0.09, \quad P=0.76 ; \quad$ Time: $\quad F_{5,66}=36.78$, $P<0.0001 ; \Delta \mathrm{HR}$, Interaction: $F_{5.66}=0.47, P=0.79$; Treatment: $F_{1,66}=3.34, P=0.07$; Time: $F_{5,66}=15.16$, $P<0.0001$; two-way ANOVA), Fig. 5.

CGP 20712 at a dose of $15 \mathrm{nmol}$. Microinjection of CGP $20712(15 \mathrm{nmol} / 100 \mathrm{~nL})$ into the MeA caused no changes in baseline MAP $(100 \pm 2$ vs. $98 \pm 3 \mathrm{mmHg}$, $t=0.48, \quad P>0.05, n=6)$ or $\mathrm{HR} \quad(365 \pm 10$ vs. $381 \pm 12 \mathrm{bpm}, \quad t=1.01, \quad P>0.05, \quad n=6)$. The injection of CGP $20712(15 \mathrm{nmol} / 100 \mathrm{~nL})$ into the MeA did not change BP and HR increases evoked by acute 


\section{Author's personal copy}
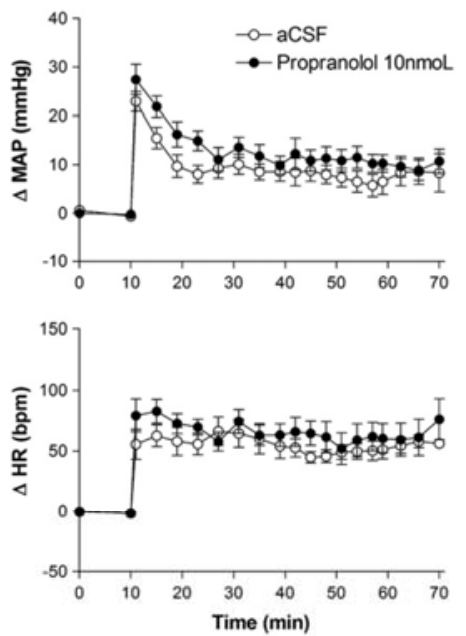

E. A. T. Fortaleza et al./Neuroscience 227 (2012) 170-179
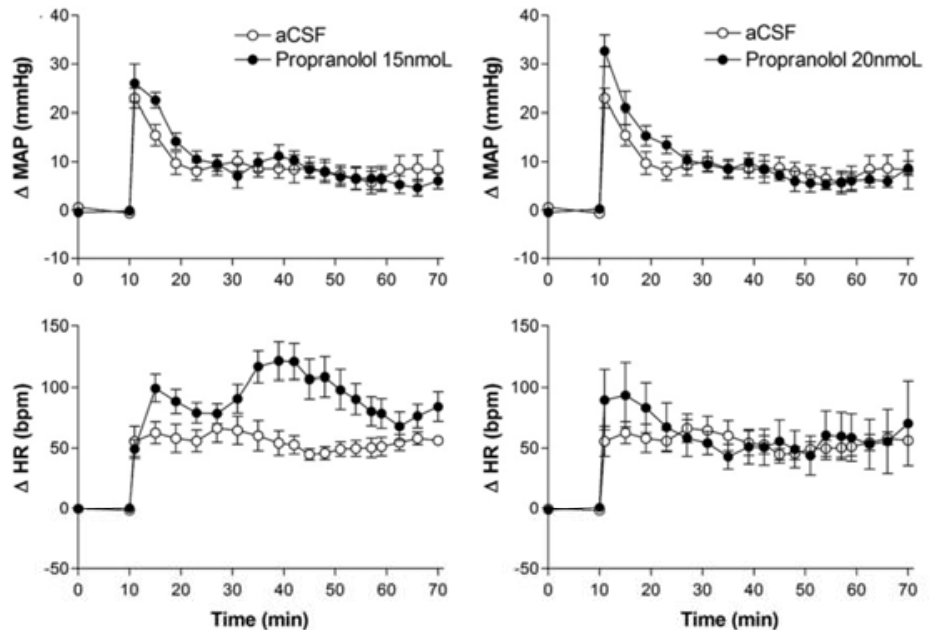

Fig. 3. Time course of changes in mean arterial pressure $(\triangle M A P)$ and heart rate $(\triangle H R)$ of animals treated in the MeA with either artificial cerebrospinal fluid (aCSF-treated, $100 \mathrm{~nL}, n=6$ ) or propranolol $(10,15$, and $20 \mathrm{nmol} / 100 \mathrm{~nL}$, respectively $n=9, n=6$ and $n=6$ ), which were observed during the restraint period. No significant difference was observed between propranolol and control animals (aCSF-treated), concerning the $\triangle \mathrm{MAP}$ response. A significant difference was only observed, between these two groups, in $\triangle \mathrm{HR}$ response caused by restraint after treatment with a dose of $15 \mathrm{nmol}$ of propranolol.
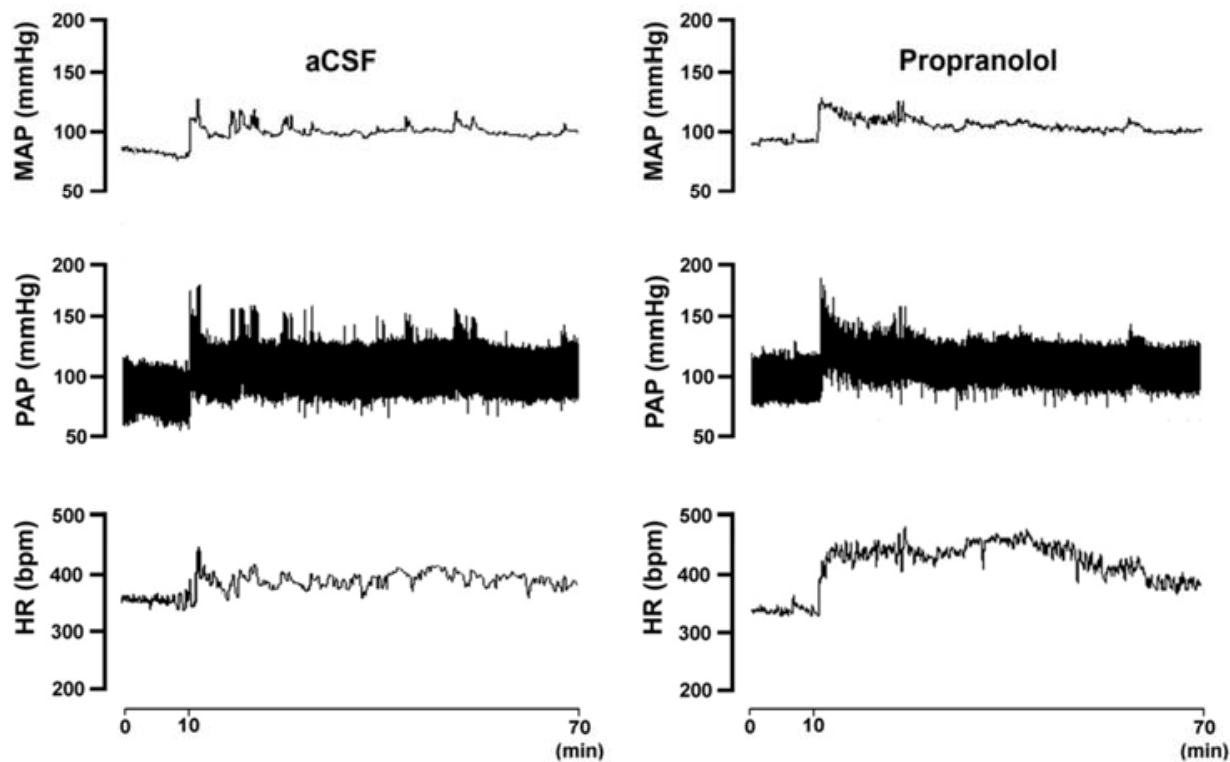

Fig. 4. Recordings of the mean arterial pressure (MAP), pulsatile arterial pressure (PAP) and heart rate (HR) showing cardiovascular changes observed before and during a restraint period of $60 \mathrm{~min}$ in a control rat and in a rat whose MeA was treated with $15 \mathrm{nmol}$ propranolol before restraint. The onset of restraint was at $t=10 \mathrm{~min}$.

restraint, when compared with aCSF-treated animals ( $\triangle \mathrm{MAP}$ : Interaction: $F_{5,60}=0.20, P=0.95$; Treatment: $F_{1,60}=0.73, \quad P=0.39 ; \quad$ Time: $\quad F_{5.60}=32.32$ $P<0.0001 ; \Delta \mathrm{HR}$, Interaction: $F_{5,60}=1.01, P=0.41$; Treatment: $F_{1,60}=0.37, P=0.54$; Time: $F_{5.60}=15.73$, $P<0.0001$; two-way ANOVA), Fig. 5.
CGP 20712 at a dose of $20 \mathrm{nmol}$. Microinjection of CGP $20712(20 \mathrm{nmol} / 100 \mathrm{~nL})$ into the MeA caused no changes in baseline MAP (92 \pm 2 vs. $96 \pm 3 \mathrm{mmHg}$ $t=1.20, P>0.05, n=6)$ or $\mathrm{HR}(347 \pm 19$ vs. $354 \pm$ $17 \mathrm{bpm}, t=0.29, P>0.05, n=6)$. The injection of CGP $20712(20 \mathrm{nmol} / 100 \mathrm{~nL})$ into the MeA significantly 


\section{Author's personal copy}

E. A. T. Fortaleza et al./Neuroscience 227 (2012) 170-179
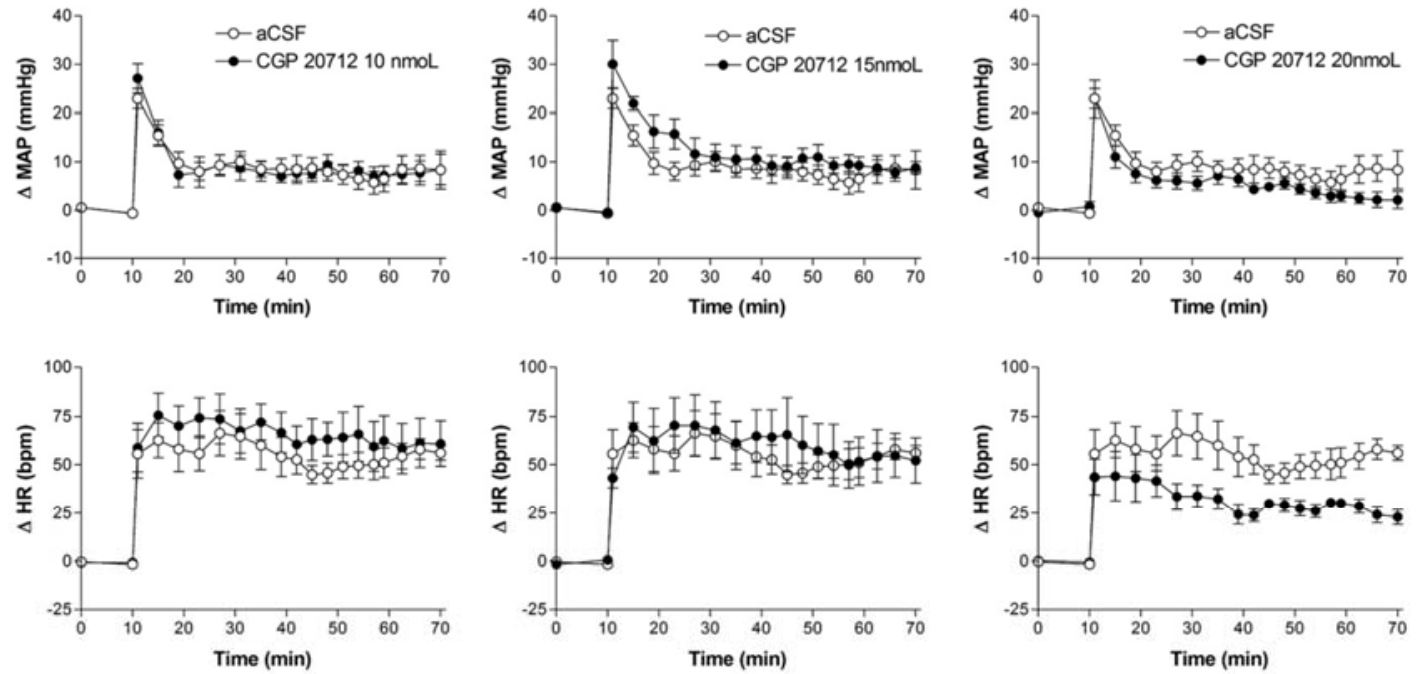

Fig. 5. Time course of changes in mean arterial pressure ( $\triangle M A P)$ and heart rate $(\triangle H R)$ of animals treated in the MeA with either artificial cerebrospinal fluid (aCSF-treated, $100 \mathrm{~nL}, n=6)$ or CGP $20712(10,15$, and $20 \mathrm{nmol} / 100 \mathrm{~nL}$, respectively $n=7, n=6$ and $n=6)$, which were observed during the restraint period. No significant difference was observed between CGP 20712 and control animals (aCSF-treated), concerning the $\triangle$ MAP response. Between these two groups, a significant difference was only observed in the $\triangle H R$ response caused by restraint after treatment with a dose of $20 \mathrm{nmol}$ of CGP 20712.
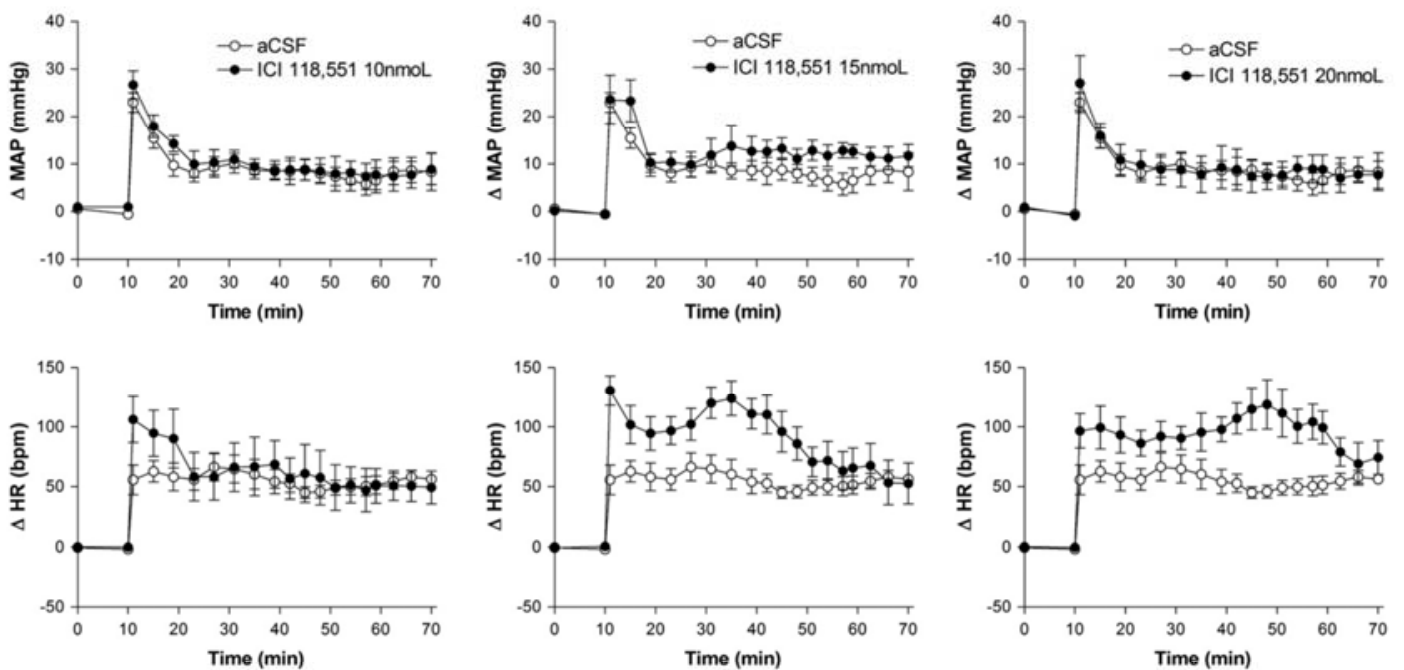

Fig. 6. Time course of changes in mean arterial pressure ( $\triangle M A P)$ and heart rate $(\triangle H R)$ of animals treated in the MeA with either artificial cerebrospinal fluid (aCSF-treated, $100 \mathrm{~nL}, n=6)$ or $\mathrm{ICl} 118,551(10,15$, and $20 \mathrm{nmol} / 100 \mathrm{~nL}$, respectively $n=6, n=6$ and $n=6$ ), which were observed during the restraint period. No significant difference was observed between ICI 118,551 and control animals (aCSF-treated) in the $\triangle M A P$ response. Between these two groups, significant differences were observed in the $\Delta H R$ response caused by restraint after treatment with doses of 15 and $20 \mathrm{nmol}$ of $\mathrm{ICl} 118,551$.

reduced restraint-evoked $H R$ increase without a significant effect on the BP response, when compared with aCSF-treated animals ( $\mathrm{MAP}$ : Interaction: $F_{5,60}=$ $0.37, \quad P=0.86$; Treatment: $F_{1.60}=3.11, \quad P=0.08$;
Time: $F_{5,60}=29.53, \quad P<0.0001 ; \Delta \mathrm{HR}$, Interaction: $F_{5,60}=0.98, \quad P=0.43 ; \quad$ Treatment: $\quad F_{1,60}=4.97$ $P=0.02$; Time: $F_{5,60}=16.46, \quad P<0.0001$; two-way ANOVA), Fig. 5 


\section{Author's personal copy}

Effect of pretreatment of the MeA with the selective $\beta_{2}$-adrenoceptor antagonist ICI 118,551 on restraintrelated cardiovascular changes

ICl 118,551 at a dose of $10 \mathrm{nmol}$. Microinjection of ICl $118,551(10 \mathrm{nmol} / 100 \mathrm{~nL})$ into the MeA caused no changes in baseline MAP $(90 \pm 8$ vs. $88 \pm 8 \mathrm{mmHg}$, $t=0.20, \quad P>0.05, \quad n=6)$ or $\mathrm{HR} \quad(380 \pm 14$ vs. $369 \pm 9 \mathrm{bpm}, t=0.65, P>0.05, n=6)$. The injection of $\mathrm{ICl} 118,551(10 \mathrm{nmol} / 100 \mathrm{~nL})$ into the MeA did not change $\mathrm{BP}$ and $\mathrm{HR}$ increases evoked by acute restraint, when compared with aCSF-treated animals, ( $\triangle M A P$ : Interaction: $F_{5,60}=0.039, P=0.99$; Treatment: $F_{1,60}$ $=0.07, P=0.78$; Time: $F_{5,60}=30.27, P<0.0001$; $\Delta \mathrm{HR}$, Interaction: $F_{5,60}=1.90, P=0.10$; Treatment: $F_{1,60}=1.88, \quad P=0.17 ; \quad$ Time: $\quad F_{5,60}=14.42, \quad P<$ 0.0001 ; two-way ANOVA), Fig. 6.

ICI 118,551 at a dose of $15 \mathrm{nmol}$. Microinjection of IC $118,551(15 \mathrm{nmol} / 100 \mathrm{~nL})$ into the MeA caused no changes in baseline MAP ( $84 \pm 6$ vs. $85 \pm 6 \mathrm{mmHg}$, $t=0.19, \quad P>0.05, n=6)$ or $\mathrm{HR} \quad(365 \pm 18$ vs. $374 \pm 9 \mathrm{bpm}, t=0.47, P>0.05, n=6)$. The injection of $\mathrm{ICl} 118,551(15 \mathrm{nmol} / 100 \mathrm{~nL})$ into the MeA significantly enhanced the restraint-evoked HR increase without a significant effect on the BP response, when compared with aCSF-treated animals ( $\mathrm{MAP}$ : Interaction: $F_{5,60}=0.95, P=0.45$; Treatment: $F_{1,60}=$ 1.40, $P=0.24$; Time: $F_{5,60}=20.44, P<0.0001 ; \Delta \mathrm{HR}$, Interaction: $\quad F_{5,60}=5.77, \quad P=0.0002$; Treatment $F_{1,60}=20.92, \quad P<0.0001 ; \quad$ Time: $\quad F_{5,60}=29.48$, $P<0.0001$; two-way ANOVA), Fig. 6 .

ICl 118,551 at a dose of $20 \mathrm{nmol}$. Microinjection of $\mathrm{ICl}$ $118,551(20 \mathrm{nmol} / 100 \mathrm{~nL})$ into the MeA caused no changes in baseline MAP $(96 \pm 3$ vs. $96 \pm 3 \mathrm{mmHg}$, $t=0.07, P>0.05, n=6)$ or $\mathrm{HR} \quad(370 \pm 6$ vs. $357 \pm 5 \mathrm{bpm}, t=1.46, P>0.05, n=6)$. The injection of $\mathrm{ICl} 118,551(20 \mathrm{nmol} / 100 \mathrm{~nL})$ into the MeA significantly enhanced restraint-evoked $H R$ increase without a significant effect on the $\mathrm{BP}$ response, when compared with aCSF-treated animals ( $\triangle \mathrm{MAP}$ : Interaction: $F_{5,60}=0.05, P=0.99$; Treatment: $F_{1,60}=$ $0.11, P=0.73$; Time: $F_{5,60}=20.34, P<0.0001 ; \Delta \mathrm{HR}$, Interaction: $\quad F_{5,60}=3.58, \quad P=0.0066$; Treatment: $F_{1.60}=24.33, \quad P<0.0001 ; \quad$ Time: $\quad F_{5.60}=31.36$ $P<0.0001$; two-way ANOVA), Fig. 6 .

\section{DISCUSSION}

In the present study, we have shown the involvement of MeA $\beta$-adrenoceptors in the modulation of restraintevoked tachycardiac responses.

Restraint is an unavoidable stressful stimulus that causes cardiovascular changes, which are characterized by an increase of both BP and HR (Barron and Van Loon, 1989; Chen and Herbert, 1995; Kubo et al., 2004; McDougall et al., 2005a; Tavares and Correa, 2006 Salome et al., 2007; Fortaleza et al., 2009). In addition, the response to stress is characterized by an increased circulating content of the corticotropin-releasing hormone $(\mathrm{CRH})$, which plays an important role in the secretion of adrenocorticotropin (ACTH) and corticosteroid (Harbuz et al., 1992). The restraint stress has been reported to activate the hypothalamicpituitary-adrenal (HPA) axis and to cause oxytocin release, but not the release of vasopressin (Lang et al. 1983; Gibbs, 1984; Carter and Lightman, 1987; Callahan et al., 1992; Dayas et al., 1999). Data from the literature also indicate a larger activation of the MeA among other amygdaloid nuclei, during stressful situations, as indicated by the large expression of c-Fos protein in this area after the exposure to aversive situations (Canteras et al., 1995; Chen and Herbert, 1995; Cullinan et al., 1995; Dayas et al., 1999; Dayas et al., 2001a, 2001b; Kubo et al., 2004; Crane et al. 2005; Trneckova et al., 2006).

Previously, we reported that an inhibition of MeA synapses by a bilateral microinjection of the unspecific synapse inhibitor $\mathrm{CoCl}_{2}$, did not affect the restraintevoked $\mathrm{BP}$ increase, but significantly enhanced the restraint-related tachycardiac response. This result indicates an inhibitory role of the MeA on the HR response to stress (Fortaleza et al., 2009). Data in the literature also indicate that cholinergic and GABA-ergic neurotransmissions in the $\mathrm{MeA}$ are involved in the regulation of cardiovascular responses in rats submitted to restraint stress (Kubo et al., 2004; Fortaleza et al., 2009). Another neurotransmitter that could be involved, in this area, in the modulation of stress-evoked cardiovascular responses is noradrenaline (NA). Data from our laboratory indicate that a noradrenergic system in the MeA is involved in the cardiovascular control (Fortaleza et al., 2011), and that MeA $\alpha$-adrenoceptors are involved in the modulation of the restraint-evoked cardiovascular response (Fortaleza et al., 2012).

Noradrenaline is an important neurotransmitter in central cardiovascular regulation. Cardiovascular responses were observed after the microinjection of NA into brain areas involved in modulation of the cardiovascular system, such as the nucleus of the solitary tract (NTS; Vlahakos et al., 1985), the medial prefrontal cortex (CPFM; Fernandes et al., 2003), the periaqueductal gray area (PAG; Pelosi and Correa, 2005), the lateral septal area (ASL; Scopinho et al. 2006), the bed nucleus of the stria terminal (BST; Crestani et al., 2007), the supraoptic nucleus (SON; Busnardo et al., 2009) and the MeA (Fortaleza et al., 2011).

Studies using microdialysis have detected increased levels of NA in several forebrain regions of the limbic system, mainly in the MeA of animals subjected to stressful situations (Cecchi et al., 2002a,b; Pardon et al., 2002; Ma and Morilak, 2005; Bondi et al., 2007). Furthermore, studies on the expression of mRNA and binding have detected the presence of noradrenergic receptors in the MeA (Jones et al., 1986; Domyancic and Morilak, 1997). Although the expression of adrenoceptor proteins are necessarily in proportion to their mRNA levels, the characteristics of differential expression profiles of $\beta_{1}$ - and $\beta_{2}$-adrenoceptors in the amygdala 


\section{Author's personal copy}

circuitry suggest that $\beta_{1}$-and $\beta_{2}$-adrenoceptors may play differential roles during a stress situation. Studies of rat amygdala with 'in situ' hybridization and real-time PCR analysis revealed significant levels of transcriptional expression of both $\beta$-adrenoceptors, and the $\beta_{2}$-adrenoceptor mRNA was found to be about 2.9 times more prevalent than the $\beta_{1}$-adrenoceptor mRNA in that area, thus suggesting that $\beta_{2}$-adrenoceptors are more abundant and may be more active than $\beta_{1}$-adrenoceptors in the amygdala (Abraham et al., 2008).

Besides the activation of the HPA axis and the sympathetic nervous system, stress also induces the release of NA, which has a modulatory role facilitating synaptic transmission in many brain regions involved in the mediation of behavioral or physiological stressevoked responses (Aston-Jones et al., 1999; Berridge and Waterhouse, 2003; Morilak and Frazer, 2004). NA may affect the HPA reactivity not only by acting directly on the paraventricular nucleus (PVN) (Alonso et al., 1986; Feldman et al., 1986, 1988) but also through actions in extra-hypothalamic regions that themselves exert a modulatory or regulatory influence on the HPA axis. For example, it has been demonstrated that noradrenergic neurotransmission is enhanced in the MeA under the exposure to an acute immobilization stress, and that NA released in the MeA during stress facilitates an activation of the HPA axis (Ma and Morilak, 2005). These observations indicate that the MeA is involved in the extra-hypothalamic facilitation of stress-induced HPA activation, which is consistent with previous reports showing that a direct stimulation of the $\mathrm{MeA}$ increased corticosterone levels (Dunn and Whitener, 1986; Feldman et al., 1990), whereas excitotoxic lesions of the MeA reduced the restrain stress-induced Fos activation in CRH cells of the medial parvocellular PVN, as well as in oxytocin cells of both the SON and the PVN (Dayas et al., 1999).

In the present study, a pretreatment of the MeA with the nonselective $\beta$-adrenoceptor antagonist propranolol microinjected bilaterally into the MeA only affected the stress-evoked HR response when it was injected at the dose of $15 \mathrm{nmol}$, whereas no effects were observed after the treatment with either a lower dose $(10 \mathrm{nmol})$ or a higher dose of propranolol $(20 \mathrm{nmol})$. The pretreatment with propranolol did not affect the BP response evoked by the exposure to restraint, regardless of the dose injected. These results suggest that $\beta$-adrenoceptors in the MeA play an inhibitory role on the HR response to restraint stress, and are not involved in the mediation of the stress-evoked BP response. To verify which subtype of $\beta$-adrenoceptors was mediating the increase in the tachycardiac response, animals were bilaterally treated with either the selective $\beta_{1}$-adrenoceptor antagonist CGP 20712 or the selective $\beta_{2}$-adrenoceptor antagonist $\mathrm{ICl} 118,551$. The pretreatment of the MeA with $\mathrm{ICI} 118,551$ in the doses of 15 and $20 \mathrm{nmol}$ significantly increased the tachycardiac response evoked by restraint in a similar manner to that observed after the pretreatment with propranolol, thus indicating that the inhibitory influence of MeA $\beta$-adrenoceptors on the HR increase evoked by restraint stress is mediated by the $\beta_{2}$-adrenoceptor subtype. The effect of pretreatment of the MeA with the $\beta$-adrenoceptor antagonists propranolol and $\mathrm{ICI} 118,551$ was similar to that observed after the pharmacological ablation of the area by its pretreatment with $\mathrm{CoCl}_{2}$ (Fortaleza et al., 2009). These results would indicate that the MeA plays a preferentially inhibitory role in the modulation of the HR response to restraint stress.

The blockade of $\beta_{1}$-adrenoceptors in the MeA by the microinjection of CGP 20712 only affected the restraintevoked HR response after the injection of the higher dose used $(20 \mathrm{nmol})$. The pretreatment with this selective $\beta_{1}$-adrenoceptor reduced the magnitude of the restraint-evoked HR response, without affecting the $\mathrm{BP}$ response. This result suggests that MeA $\beta_{1}$-adrenoceptors have a facilitatory influence on the restraint-evoked tachycardiac response. The effect of pretreatment with CGP 20712 is opposite to that observed after pretreatment of the MeA with either propranolol or $\mathrm{ICl} 118,551$ (present results) or $\mathrm{CoCl}_{2}$ (Fortaleza et al., 2009), in which case there was an increase in the restraint-evoked tachycardiac response. Because propranolol is an equipotent antagonist of both $\beta_{1}$ and $\beta_{2}$-adrenoceptors, and opposite effects were observed after treatment with higher doses of the selective antagonists ICI 118,551 and CGP 20712, the narrow window in the dose-response to propranolol could be explained by a functional antagonism resulting from the simultaneous inhibition of $\beta_{1}$ and $\beta_{2}$-adrenoceptors. Therefore the present results suggest that $\beta_{1}$ - and $\beta_{2}$-adrenoceptors play opposite roles in the $\mathrm{MeA}$ in the control of the restraint-evoked HR response. $\beta_{2}$-adrenoceptors have an inhibitory influence on the restraint-evoked tachycardiac response, whereas $\beta_{1}$-adrenoceptors have a facilitatory influence on the restraint-evoked tachycardiac response. The idea that the MeA plays a dual role in the control of the welldocumented restraint-evoked tachycardiac response (Barron and Van Loon, 1989; Chen and Herbert, 1995; McDougall et al., 2005b) is favored by evidence indicating that an electrical or chemical stimulation of the amygdala-evoked heart rate increases (Galeno and Brody, 1983; Gelsema et al., 1987; al Maskati and Zbrozyna, 1989; Soltis et al., 1998).

In summary, the present results indicate that the MeA is part of the brain circuitry that controls stress-evoked cardiovascular responses, and that $\beta$-adrenoceptors in the MeA are involved in modulation of the tachycardiac component of these responses but not in the modulation of the blood pressure response. The results also indicate that $\beta_{1}$ - and $\beta_{2}$-adrenoceptors in the MeA play respectively a facilitatory and an inhibitory role in modulation of the cardiac component of the restraintevoked cardiovascular response in rats.

Acknowledgements-We acknowledge I.A.C. Fortunato, I.I.B Aguiar and S.S. Guilhaume for technical assistance. Eduardo Albino Trindade Fortaleza is a Ph.D. student enrolled in the Department of Pharmacology, School of Medicine of Ribeirão Preto-USP and recipient of a CNPq fellowship (140118/2009-8) and América A. Scopinho is a postdoctoral fellow in the 


\section{Author's personal copy}

Department of Pharmacology, School of Medicine of Ribeirâo Preto-USP and recipient of a CAPES fellowship (PNPD0176087). The present research was supported by grants from the CNPq (501269/2005-3).

\section{REFERENCES}

Abraham PA, Xing G, Zhang L, Yu EZ, Post R, Gamble EH, Li H (2008) beta1- and beta2-adrenoceptor induced synaptic facilitation in rat basolateral amygdala. Brain Res 1209:65-73.

al Maskati HA, Zbrozyna AW (1989) Cardiovascular and motor components of the defence reaction elicited in rats by electrical and chemical stimulation in amygdala. J Auton Nerv Syst 28:127-131.

Alonso G, Szafarczyk A, Balmefrezol M, Assenmacher I (1986) Immunocytochemical evidence for stimulatory control by the ventral noradrenergic bundle of parvocellular neurons of the paraventricular nucleus secreting corticotropin releasing hormone and vasopressin in rats. Brain Res 397:297-307.

Alves FH, Crestani CC, Correa FM (2010) The insular cortex modulates cardiovascular responses to acute restraint stress in rats. Brain Res 1333:57-63.

Aston-Jones G, Rajkowski J, Cohen J (1999) Role of locus coeruleus in attention and behavioral flexibility. Biol Psychiatry 46:1309-1320.

Barron BA, Van Loon GR (1989) Role of sympathoadrenomedullary system in cardiovascular response to stress in rats. J Auton Nerv Syst 28:179-187.

Berridge CW. Waterhouse BD (2003) The locus coeruleusnoradrenergic system: modulation of behavioral state and statedependent cognitive processes. Brain Res Brain Res Rev 42:33-84.

Bondi CO, Barrera G, Lapiz MD, Bedard T, Mahan A, Morilak DA (2007) Noradrenergic facilitation of shock-probe defensive burying in lateral septum of rats, and modulation by chronic treatment with desipramine. Prog Neuropsychopharmacol Biol Psychiatry 31:482-495.

Busnardo C, Tavares RF, Correa FM (2009) Mechanisms involved in the pressor response to noradrenaline microinjection into the supraoptic nucleus of unanesthetized rats. Auton Neurosci 145:63-70.

Callahan MF, da Rocha MJ, Morris M (1992) Sinoaortic denervation does not increase cardiovascular/endocrine responses to stress. Neuroendocrinology 56:735-744.

Canteras NS, Simerly RB, Swanson LW (1995) Organization of projections from the medial nucleus of the amygdala: a PHAL study in the rat. J Comp Neurol 360:213-245.

Carter DA, Lightman SL (1987) Oxytocin stress responses are dependent upon emotionality. Psychoneuroendocrinology 12:219-223.

Cecchi M, Khoshbouei H, Javors M, Morilak DA (2002a) Modulatory effects of norepinephrine in the lateral bed nucleus of the stria terminal is on behavioral and neuroendocrine responses to acute stress. Neuroscience 112:13-21.

Cecchi M, Khoshbouei H, Morilak DA (2002b) Modulatory effects of norepinephrine, acting on alpha 1 receptors in the central nucleus of the amygdala, on behavioral and neuroendocrine responses to acute immobilization stress. Neuropharmacology 43:1139-1147.

Chen X. Herbert J (1995) Regional changes in c-fos expression in the basal forebrain and brainstem during adaptation to repeated stress: correlations with cardiovascular, hypothermic and endocrine responses. Neuroscience 64:675-685.

Crane JW, French KR, Buller KM (2005) Patterns of neuronal activation in the rat brain and spinal cord in response to increasing durations of restraint stress. Stress 8:199-211.

Crestani CC, Alves FH, Resstel LB, Correa FM (2007) Cardiovascular effects of noradrenaline microinjection in the bed nucleus of the stria terminalis of the rat brain. J Neurosci Res 85:1592-1599.
Crestani CC, Alves FH, Tavares RF, Correa FM (2009) Role of the bed nucleus of the stria terminalis in the cardiovascular responses to acute restraint stress in rats. Stress 12:268-278.

Cullinan WE, Herman JP, Battaglia DF, Akil H, Watson SJ (1995 Pattern and time course of immediate early gene expression in rat brain following acute stress. Neuroscience 64:477-505.

Dampney RA (1994) Functional organization of central pathways regulating the cardiovascular system. Physiol Rev 74:323-364.

Dayas CV, Buller KM, Crane JW, Xu Y, Day TA (2001a) Stressor categorization: acute physical and psychological stressors elicit distinctive recruitment patterns in the amygdala and in medullary noradrenergic cell groups. Eur J Neurosci 14:1143-1152.

Dayas CV, Buller KM, Day TA (1999) Neuroendocrine responses to an emotional stressor: evidence for involvement of the medial but not the central amygdala. Eur J Neurosci 11:2312-2322.

Dayas CV, Buller KM, Day TA (2001b) Medullary neurones regulate hypothalamic corticotropin-releasing factor cell responses to an emotional stressor. Neuroscience 105:707-719.

Domyancic AV, Morilak DA (1997) Distribution of alpha1A adrenergic receptor mRNA in the rat brain visualized by in situ hybridization. $J$ Comp Neurol 386:358-378.

Dunn JD, Whitener J (1986) Plasma corticosterone responses to electrical stimulation of the amygdaloid complex: cytoarchitectural specificity. Neuroendocrinology 42:211-217.

Feldman S, Conforti N, Melamed E (1986) Norepinephrine depletion in the paraventricular nucleus inhibits the adrenocortical responses to neural stimuli. Neurosci Lett 64:191-195.

Feldman S, Conforti N, Melamed E (1988) Involvement of ventral noradrenergic bundle in corticosterone secretion following neural stimuli. Neuropharmacology 27:129-133.

Feldman S, Conforti N, Saphier D (1990) The preoptic area and bed nucleus of the stria terminalis are involved in the effects of the amygdala on adrenocortical secretion. Neuroscience 37:775-779.

Fernandes KB, Crippa GE, Tavares RF, Antunes-Rodrigues J, Correa FM (2003) Mechanisms involved in the pressor response to noradrenaline injection into the cingulate cortex of unanesthetized rats. Neuropharmacology 44:757-763.

Fortaleza EA, Scopinho AA, Correa FM (2011) Cardiovascular responses to microinjection of noradrenaline into the medial amygdaloid nucleus of conscious rats result from $\alpha$-receptor activation and vasopressin release. Eur $J$ Neurosci 33:1677-1684.

Fortaleza EA, Scopinho AA, de Aguiar Correa FM (2012) $\alpha 1$ and $\alpha 2$. adrenoceptors in the medial amygdaloid nucleus modulate differently the cardiovascular responses to restraint stress in rats. Pharmacol Res 66:154-162.

Fortaleza EA, Tavares RF, Correa FM (2009) The medial amygdaloid nucleus modulates cardiovascular responses to acute restraint in rats. Neuroscience 159:717-726.

Galeno TM, Brody MJ (1983) Hemodynamic responses to amygdaloid stimulation in spontaneously hypertensive rats. Am J Physiol 245:R281-R286.

Gelsema AJ, McKitrick DJ, Calaresu FR (1987) Cardiovascular responses to chemical and electrical stimulation of amygdala in rats. Am J Physiol 253:R712-R718.

Gibbs DM (1984) Dissociation of oxytocin, vasopressin and corticotropin secretion during different types of stress. Life Sci 35:487-491.

Harbuz MS, Rees RG, Eckland D, Jessop DS, Brewerton D, Lightman SL (1992) Paradoxical responses of hypothalamic corticotropin-releasing factor (CRF) messenger ribonucleic acid (mRNA) and CRF-41 peptide and adenohypophysial proopiomelanocortin mRNA during chronic inflammatory stress. Endocrinology 130:1394-1400.

Jones LS, Gauger LL, Davis JN (1986) Localization of alpha 1. adrenergic receptors in normal and weaver mouse brain with in vitro 125I-HEAT autoradiography. Neurosci Lett 65:259-264.

Koepke JP, DiBona GF (1985) Central beta-adrenergic receptors mediate renal nerve activity during stress in conscious spontaneously hypertensive rats. Hypertension 7:350-356. 


\section{Author's personal copy}

Koepke JP, DiBona GF (1986) Central adrenergic receptor control of renal function in conscious hypertensive rats. Hypertension 8:133-141.

Kubo T, Okatani H, Nishigori Y, Hagiwara Y, Fukumori R, Goshima $Y$ (2004) Involvement of the medial amygdaloid nucleus in restraint stress-induced pressor responses in rats. Neurosci Lett 354:84-86.

Lang RE, Heil JW, Ganten D, Hermann K, Unger T, Rascher W (1983) Oxytocin unlike vasopressin is a stress hormone in the rat. Neuroendocrinology 37:314-316.

Ma S, Morilak DA (2005) Norepinephrine release in medial amygdala facilitates activation of the hypothalamic-pituitary-adrenal axis in response to acute immobilisation stress. J Neuroendocrinol 17:22-28.

McDougall SJ, Lawrence AJ, Widdop RE (2005a) Differential cardiovascular responses to stressors in hypertensive and normotensive rats. Exp Physiol 90:141-150.

McDougall SJ, Widdop RE, Lawrence AJ (2005b) Central autonomic integration of psychological stressors: focus on cardiovascular modulation. Auton Neurosci 123:1-11.

Morilak DA, Frazer A (2004) Antidepressants and brain monoaminergic systems: a dimensional approach to understanding their behavioural effects in depression and anxiety disorders. Int J Neuropsychopharmacol 7:193-218.

Muller JR, Le KM, Haines WR, Gan Q, Knuepfer MM (2001) Hemodynamic response pattern predicts susceptibility to stressinduced elevation in arterial pressure in the rat. Am J Physiol Regul Integr Comp Physiol 281:R31-R37.

Pacak K. Palkovits M (2001) Stressor specificity of central neuroendocrine responses: implications for stress-related disorders. Endocr Rev 22:502-548.

Pardon MC, Gould GG, Garcia A, Phillips L, Cook MC, Miller SA Mason PA, Morilak DA (2002) Stress reactivity of the brain noradrenergic system in three rat strains differing in their neuroendocrine and behavioral responses to stress: implications for susceptibility to stress-related neuropsychiatric disorders. Neuroscience 115:229-242.

Parker GW, Michael LH, Hartley CJ, Skinner JE, Entman ML (1990) Central beta-adrenergic mechanisms may modulate ischemic ventricular fibrillation in pigs. Circ Res 66:259-270.

Paxinos G, Watson C (1997) The rat brain in steretaxic coordinates. Sydney: Academic Press.

Pelosi GG, Correa FM (2005) Cardiovascular effects of noradrenaline microinjected into the dorsal periaqueductal gray area of unanaesthetized rats. Eur J Neurosci 22:3188-3194.
Price JL, Russchen FT, Amaral DG (1987) The limbic region. II: The amygdaloid complex. New York: Elsevier Science.

Rainbow TC, Parsons B, Wolfe BB (1984) Quantitative autoradiography of beta 1 - and beta 2-adrenergic receptors in rat brain. Proc Natl Acad Sci U S A 81:1585-1589.

Resstel LB, Joca SR, Guimaraes FG, Correa FM (2006) Involvement of medial prefrontal cortex neurons in behavioral and cardiovascular responses to contextual fear conditioning. Neuroscience 143:377-385.

Roder S, Ciriello J (1993) Innervation of the amygdaloid complex by catecholaminergic cell groups of the ventrolateral medulla. J Comp Neurol 332:105-122.

Sadikot AF, Parent A (1990) The monoaminergic innervation of the amygdala in the squirrel monkey: an immunohistochemical study. Neuroscience 36:431-447.

Salome N, Ngampramuan S, Nalivaiko E (2007) Intra-amygdala injection of GABAA agonist, muscimol, reduces tachycardia and modifies cardiac sympatho-vagal balance during restraint stress in rats. Neuroscience 148:335-341.

Scopinho AA, Resstel LB, Antunes-Rodrigues J, Correa FM (2006) Pressor effects of noradrenaline injected into the lateral septal area of unanesthetized rats. Brain Res 1122:126-134.

Soltis RP, Cook JC, Gregg AE, Stratton JM, Flickinger KA (1998) EAA receptors in the dorsomedial hypothalamic area mediate the cardiovascular response to activation of the amygdala. Am J Physiol 275:R624-R631.

Swanson LW (2003) The amygdala and its place in the cerebral hemisphere. Ann N Y Acad Sci 985:174-184.

Tan N, Morimoto A, Morimoto K, Sone R, Nishiyasu T, Watanabe T, Nakamura S, Murakami N (2000) Involvement of central betaadrenoceptors in the tachycardia induced by water immersion stress in rats. Physiol Behav 68:291-297.

Tavares RF, Correa FM (2006) Role of the medial prefrontal cortex in cardiovascular responses to acute restraint in rats. Neuroscience 143:231-240.

Tmeckova L, Armario A, Hynie S, Sida P, Klenerova V (2006) Differences in the brain expression of c-fos mRNA after restraint stress in Lewis compared to Sprague-Dawley rats. Brain Res 1077:7-15.

Vlahakos D, Gavras I, Gavras H (1985) alpha-Adrenoceptor agonists applied in the area of the nucleus tractus solitarii in the rat: effect of anesthesia on cardiovascular responses. Brain Res $347: 372-375$.

(Accepted 20 September 2012)
(Available online 28 September 2012) 